\title{
Intracellular pH in Cnidarian-Dinoflagellate Symbiosis
}

\author{
Emma M. Gibbin
}

\author{
A thesis submitted to \\ Victoria University of Wellington \\ in fulfilment of the requirements for the degree of \\ Doctor of Philosophy in Science
}


This thesis is dedicated to the loving memory of Ozzie

$(12 / 2000-02 / 2014)$

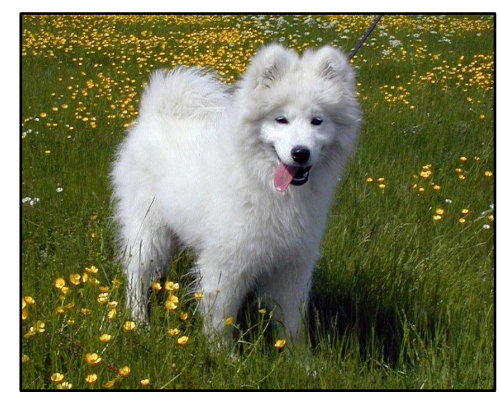




\section{Acknowledgements}

\section{"It is good to have an end to journey toward; but it is the journey that matters,}

in the end." - Ernest Hemingway

This thesis would not have been possible without the help of the many extraordinary scientists that I have been lucky enough to collaborate with and befriend over the past three years. First and foremost, I wish to thank my primary supervisor, A/Prof. Simon Davy. Simon, without your patience, compassion and brilliant mind I would have given up a long time ago, thank you for affording me this fantastic opportunity and for your continuous belief in me. I would also like to thank my secondary supervisor, Prof. Kevin Gould for the time and effort he invested in my project. Credit must also be extended to my fellow Davy Lab researchers: Paul Fisher, Anne Wietheger, Dorota Starzak, Scott Lawrence, Stefanie Pontasch, Ben Bradley, Jennifer Howe, Katie Hillyer, Ashley Sproles, and Jennifer Matthews, who have offered so much kindness and encouragement along the way. Special thanks though, are reserved for Shaun Wilkinson for his seemingly endless patience in explaining statistics to me, Thomas Krueger for forcing a smile every time I asked him to check my chemical calculations and Tom Hawkins for painstakingly editing (and improving) many manuscript drafts.

I am extremely grateful to Prof. Ruth Gates for her generosity in hosting me at the Hawai'i Institute of Marine Biology, and to Dr. Hollie Putnam for her friendship and relentless flow of brilliant ideas. I would also like to thank Matthew Nitschke for assisting in the data collection for Chapter 4, and all the members of the Gates Lab, for being so supportive of my research. I thank Scott Santos (Auburn University, Auburn, AL, USA), Gisele Muller-Parker (former Western Washington University, WA, USA) and Mary Alice Coffroth (University of Buffalo, Buffalo, NY, USA) for the supply of Symbiodinium cultures. Of course, this research would not have been possible without substantial financial backing the majority of which was provided by a Commonwealth PhD Scholarship. The Kathleen Stewart Scholarship and a Journal of Experimental Biology Travel Grant funded my travels to Hawaii, while an Australian Coral Reef Society travel grant, and a grant from the Wellington Botanical Society, enabled me to present my research at conferences overseas. 
As with every journey, there have been ups and downs along the way, but in hindsight I would not change a thing over the last three years. Despite being 12,000 miles away from home, I never felt homesick, and this is credit to the amazing support network I had along the way. To the SBS crew (you know who you are) thank you for all the good times, the dinners, the dancing, but not so much the hangovers. To the Wellington United girls, in particular Lou, Penny, Nat, Mel, Char and Soph, I am proud to have played for such a great club. You welcomed me with open arms and functioned as my extended family. Go the Oranje!

Finally, I wish to heartily thank Lindsey Alexander, my parents Jean and Mark, and indeed the rest of my growing family; Grandad Ray, Granny Lorna, Chloe, Sophie, Isobel, and Summer for your unwavering support, you are the best family anyone could wish for. 


\begin{abstract}
Accumulation of anthropogenic $\mathrm{CO}_{2}$ is fuelling the decline of coral reef ecosystems. Increasing sea surface temperatures disrupt the endosymbiotic relationship between cnidarians and their single-celled dinoflagellate partners (genus Symbiodinium), while ocean acidification is known to impede calcification. At the cellular level, however, ocean acidification also has the potential to cause acidosis, with negative impacts on cell structure and function. Yet, despite the importance of intracellular $\mathrm{pH}\left(\mathrm{pH}_{\mathrm{i}}\right)$, the mechanisms involved in $\mathrm{pH}$ regulation and the buffering capacity within coral cells are not well understood. Combining $\mathrm{pH}$-sensitive fluorescent dyes with either confocal microscopy or flow cytometry enables the measurement of $\mathrm{pH}_{\mathrm{i}}$ within live cells. Here, I employed these techniques to determine the relationship between symbiont photosynthesis and host- and symbiont $\mathrm{pH}_{\mathrm{i}}$ under ocean acidification and thermal stress. The specific aims of the study were: (1) to design a protocol for measuring the $\mathrm{pH}_{\mathrm{i}}$ of the Symbiodinium cell and to quantify the effect of the diel light cycle on the $\mathrm{pH}_{\mathrm{i}}$ of both members of the endosymbiosis; (2) to determine the role of the symbiont in modifying host cellular responses to short-term $\mathrm{CO}_{2}$-induced acidification; (3) to quantify how exposure to elevated temperature changes the responses of the host and the symbiont $\mathrm{pH}_{\mathrm{i}}$ to short-term $\mathrm{CO}_{2}$-induced acidification; and (4) to establish the relationship between photo-physiology and $\mathrm{pH}_{\mathrm{i}}$ after longerterm exposure to $\mathrm{CO}_{2}$-induced acidification.
\end{abstract}

In Chapter 2, I used flow cytometry in conjunction with the ratiometric fluorescent dye BCECF to quantify $\mathrm{pH}_{\mathrm{i}}$ in Symbiodinium cells and to monitor the effect of the diel light/dark cycle on $\mathrm{pH}_{\mathrm{i}}$. The $\mathrm{pH}_{\mathrm{i}}$ of ITS2 type $\mathrm{B} 1$ cells (freshly isolated from the sea anemone Aiptasia pulchella) was $7.25 \pm 0.01$ (mean \pm S.E.M) in the light and 7.10 \pm 0.02 in the dark. A comparable effect of irradiance was seen across a variety of cultured Symbiodinium genotypes (types A1, B1, E1, E2, F1, and F5) which varied between $\mathrm{pH}_{\mathrm{i}} 7.21-7.39$ in the light and 7.06-7.14 in the dark. Of note, there was a significant genotypic difference in $\mathrm{pH}_{\mathrm{i}}$, irrespective of irradiance, with this parameter being lowest in types $\mathrm{E} 2$ and $\mathrm{F} 1$. The $\mathrm{pH}_{\mathrm{i}}$ of $A$. pulchella host cells was then measured using the SNARF-4F probe and confocal microscopy. Light-induced alkalinisation 
observed in the dinoflagellate cells was reflected in the $\mathrm{pH}_{\mathrm{i}}$ of the host cells, with $\mathrm{pH}_{\mathrm{i}}$ increasing from $6.86 \pm 0.04$ in the dark, to $7.02 \pm 0.06$ in the light.

The inter-dependence of host cell $\mathrm{pH}_{\mathrm{i}}$ on its symbiont is described in Chapter 3 using cells isolated from the coral Pocillopora damicornis. BCECF was used in conjunction with confocal microscopy to determine how host- and symbiont $\mathrm{pH}_{\mathrm{i}}$ responds to $p \mathrm{CO}_{2}$-driven seawater acidification under saturating irradiance, in symbiotic and nonsymbiotic states, with and without the photosynthetic inhibitor DCMU. Each treatment was run under control $\left(\mathrm{pH}\right.$ 7.8) and $\mathrm{CO}_{2}$-acidified seawater conditions (decreasing $\mathrm{pH}$ from 7.8 - 6.8). After $105 \mathrm{~min}$ of $\mathrm{CO}_{2}$ addition, by which time the external $\mathrm{pH}\left(\mathrm{pH}_{\mathrm{e}}\right)$ had declined to 6.8 , the dinoflagellate symbionts had increased their $\mathrm{pH}_{\mathrm{i}} 0.5 \mathrm{pH}$ units above control levels. In contrast, in both symbiotic and nonsymbiotic host cells, $15 \mathrm{~min}$ of $\mathrm{CO}_{2}$ addition $\left(0.2 \mathrm{pH}\right.$ unit drop in $\left.\mathrm{pH}_{\mathrm{e}}\right)$ in the presence and absence of DCMU led to cytoplasmic acidosis equivalent to $0.4 \mathrm{pH}$ units. Despite further seawater acidification over the duration of the experiment, the $\mathrm{pH}_{\mathrm{i}}$ of nonsymbiotic coral cells did not change, though in host cells containing a symbiont cell the $\mathrm{pH}_{\mathrm{i}}$ recovered to control levels. This recovery was negated when cells were incubated with DCMU, revealing that the photosynthetic activity of the endosymbiont is tightly coupled with the ability of the host cell to recover from cellular acidosis after exposure to high $\mathrm{CO}_{2} /$ low $\mathrm{pH}$.

This raised the interesting possibility that bleached corals may be more sensitive to cellular acidosis than are their non-bleached counterparts, a hypothesis that was tested in Chapter 4. I exposed P. damicornis (a thermally sensitive coral) and Montipora capitata (a thermally resilient coral) fragments to four temperature treatments: 23.8 (ambient), 25.5, 28 and $31^{\circ} \mathrm{C}$. Host coral cells containing their symbionts were then isolated and subjected to $\mathrm{CO}_{2}$-addition, designed to mimic predicted the $\mathrm{VI} \mathrm{CO}_{2}$ stabilisation scenario $\left(\mathrm{pH}_{\mathrm{e}}\right.$ 7.6) provided by the Intergovernmental Panel on Climate Change (IPCC, 2014). Host cells in P. damicornis were much more susceptible to cellular acidosis under the highest temperature treatment $\left(7.40 \pm 0.07\right.$ at $23^{\circ} \mathrm{C}$ to 6.56 \pm 0.03 at $\left.31^{\circ} \mathrm{C}\right)$ than their counterparts in M. capitata $\left(7.35 \pm 0.07\right.$ at $23^{\circ} \mathrm{C}$ to $6.95 \pm$ 0.05 at $31^{\circ} \mathrm{C}$ ). A similar decrease was observed in the Symbiodinium cell, with $\mathrm{pH}_{\mathrm{i}}$ dropping from $7.45 \pm 0.02$ to $6.86 \pm 0.01$ in P. damicornis, and from $7.43 \pm 0.04$ to 
$7.14 \pm 0.03$ in $M$. capitata after $\mathrm{CO}_{2}$-addition, suggesting that thermally sensitive corals may be at the highest risk of cellular acidosis.

Finally in Chapter 5, I describe the relationship between $\mathrm{CO}_{2}$-driven acidification, photo-physiological performance and $\mathrm{pH}_{\mathrm{i}}$ in $A$. pulchella. I exposed anemones to ambient $(289.94 \pm 12.54 \mu \mathrm{atm})$, intermediate $(687.40 \pm 25.10 \mu \mathrm{atm})$ or high $(1459.92$ $\pm 65.51 \mu \mathrm{atm}) \mathrm{CO}_{2}$ conditions for two months, conditions that represent the IPCC IV and VI stabilisation scenarios (IPCC, 2014). At regular intervals I measured the maximum dark-adapted fluorescent yield of PSII $\left(\mathrm{F}_{\mathrm{v}} / \mathrm{F}_{\mathrm{m}}\right)$, the gross photosynthetic rate, respiration rate, symbiont population density, and the light-adapted $\mathrm{pH}_{\mathrm{i}}$ of both the symbiont and the host cell. I observed increases in all but one photo-physiological parameter $\left(\mathrm{P}_{\text {gross }}: \mathrm{R}\right.$ ratio). Increases in light-adapted symbiont $\mathrm{pH}_{\mathrm{i}}$ were observed under both intermediate and high $\mathrm{CO}_{2}$ treatments, relative to control conditions $\left(\mathrm{pH}_{\mathrm{i}}\right.$ $7.35 \pm 0.03$ and $7.46 \pm 0.06$ versus $\mathrm{pH}_{\mathrm{i}} 7.25 \pm 0.05$, respectively). The response of light-adapted host $\mathrm{pH}_{\mathrm{i}}$ was more complex, with no change observed under the intermediate $\mathrm{CO}_{2}$ treatment, but a $0.3 \mathrm{pH}$-unit increase under the highest $\mathrm{CO}_{2}$ treatment $\left(\mathrm{pH}_{\mathrm{i}} 7.19 \pm 0.01\right.$ and $7.48 \pm 0.02$, respectively). This suggests that, rather than causing cellular acidosis, the addition of $\mathrm{CO}_{2}$ will enhance the organism's photosynthetic performance, enabling the host-symbiont association to withstand the predicted ocean acidification scenarios.

Overall, the results from this study provide new insight into the cellular interactions that underpin cnidarian-dinoflagellate symbiosis. Moreover, they highlight the dynamic and species-specific nature of the cellular responses, reinforcing the need to incorporate species-specific acidification/warming interactions into models that are designed to predict the response of marine organisms to global climate change. 


\title{
List of abbreviations
}

\author{
${ }^{1} \mathbf{O}_{2} \quad$ singlet oxygen \\ $\beta$ a cell's innate buffering capacity \\ $\boldsymbol{\mu} \quad$ cell-specific growth rate
}

ANOVA analysis of variance

ADP adenosine diphosphate

ATP adenosine triphosphate

ASH aragonite saturation horizon

BCECF-AM 2',7'-bis-(2-carboxyethyl)-5-(and-6)-carboxyfluorescein-acetoxymethyl ester

BLAST basic local alignment search tool

BSA bovine serum albumin

CA carbonic anhydrase

$\mathrm{CaCO}_{3}$ calcium carbonate

CaFSW calcium free seawater

CCM carbon-concentrating mechanism

CE calicoblastic epithelium

Chl- $\boldsymbol{a} \quad$ chlorophyll- $a$

CMC carboxymethyl cellulose

$\mathrm{CO}_{2} \quad$ carbon dioxide

$\mathrm{CO}_{3}^{-} \quad$ carbonate ion

CSD cell specific density

DCMU 3-(3,4-dichlorophenyl)-1,1-dimethylurea

DIC dissolved inorganic carbon

DIN dissolved inorganic nitrogen

DMSO dimethyl sulfoxide

DNA deoxyribonucleic acid

DOM dissolved organic matter

EDTA ethylenediaminetetraacetic acid

ENSO el niño southern oscillation

FCM flow cytometry

FDA fluorescein diacetate 


\begin{tabular}{|c|c|}
\hline FSC & forward scatter \\
\hline FSW & $0.22 \mu \mathrm{m}$ filtered seawater \\
\hline $\mathbf{F}_{\mathrm{v}} / \mathbf{F}_{\mathrm{m}}$ & maximum dark-adapted yield of photosystem II \\
\hline G0 & gap phase zero of interphase \\
\hline G1 & gap phase one of interphase \\
\hline G2 & gap phase two of interphase \\
\hline $\mathbf{H}^{+}$ & proton \\
\hline $\mathrm{H}_{2} \mathrm{CO}_{3}$ & carbonic acid \\
\hline $\mathbf{H}_{2} \mathbf{O}_{2}$ & hydrogen peroxide \\
\hline $\mathrm{H}_{2} \mathrm{PO}_{4}^{-}$ & monobasic inorganic phosphate \\
\hline $\mathrm{HCl}$ & hydrochloric acid \\
\hline $\mathrm{HCO}_{3}^{-}$ & bicarbonate \\
\hline $\mathbf{I}$ & interphase stage of the cell cycle \\
\hline IPCC & intergovernmental panel on climate change \\
\hline ITS & internal transcribed spacer \\
\hline LED & light emitting diode \\
\hline MAA & mycosporine-like amino acid \\
\hline МАМР & microbe-associated molecular pattern \\
\hline MES & 2-[N-morpholino] ethanesulfonic acid \\
\hline MI & mitotic index \\
\hline $\mathrm{NaOH}$ & sodium hydroxide \\
\hline NBS & national bureau of standards \\
\hline NHE & $\mathrm{Na}^{+} / \mathrm{H}^{+}$exchangers \\
\hline NO & nitric oxide \\
\hline $\mathbf{O}_{2}^{-}$ & superoxide \\
\hline $\mathrm{OH}^{-}$ & hydroxide ion \\
\hline PAM & pulse amplitude modulation \\
\hline PAR & photosynthetically-active radiation \\
\hline PCR & polymerase chain reaction \\
\hline $\mathbf{P}_{\text {gross }}$ & gross photosynthetic oxygen evolution \\
\hline $\mathrm{pH}_{\mathrm{e}}$ & external $\mathrm{pH}$ \\
\hline $\mathbf{p H}_{\mathbf{i}}$ & intracellular $\mathrm{pH}$ \\
\hline PI & propidium iodide \\
\hline $\mathbf{P}_{\text {net }}$ & net photosynthetic oxygen evolution \\
\hline
\end{tabular}


POM particulate organic matter

PRR pattern recognition receptors

PSII photosystem II

R respiration

R123 rhodamine-123

rmANOVA repeated measures analysis of variance

RNA ribonucleic acid

RNS reactive nitrogen species

ROI region of interest

ROS reactive oxygen species

SCM subcalicoblastic epithelium

S.E.M standard error mean

SNARF seminaphtharhodafluor

TA total alkalinity

TDI time-delayed integration

TRIS tris(hydroxymethyl)aminomethane 


\section{Table of Contents}

Acknowledgements..................................................5

Abstract............................................................... 7

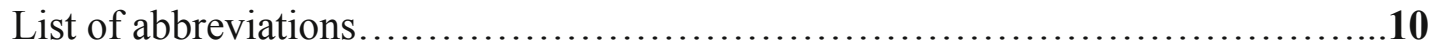

List of figures.........................................................

List of tables.................................................................

\section{Chapter 1: General Introduction}

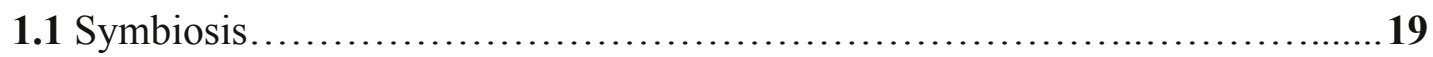

1.2 Cnidarian-dinoflagellate symbiosis................................. 20

1.2.1 Ecological significance of coral reefs............................21

1.2.2 Structure of cnidarian-dinoflagellate symbiosis......................21

1.2.3 Function of cnidarian-dinoflagellate symbiosis......................... 23

1.2.4 Host and symbiont diversity, and symbiosis specificity ..............27

1.3 Threats to the stability of cnidarian-dinoflagellate symbiosis................29

1.3.1 Global warming..............................................29

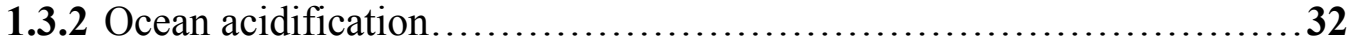

$1.4 \mathrm{pH}$ and cellular acidosis................................................... 36

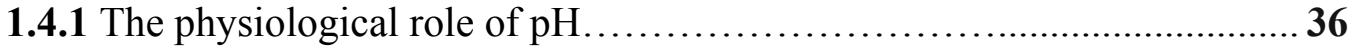

1.4.2 Regulation of $\mathrm{pH}$ and cellular acidosis............................................36

$\mathbf{1 . 4 . 3} \mathrm{pH}$ in the cnidarian-dinoflagellate symbiosis.......................38

1.5 Aims and specific objectives....................................... 41

Chapter 2: Quantifying the effect of light on the intracellular $\mathrm{pH}$ of cultured Symbiodinium cells, freshly isolated symbionts and Aiptasia pulchella host cells

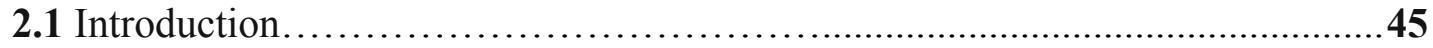

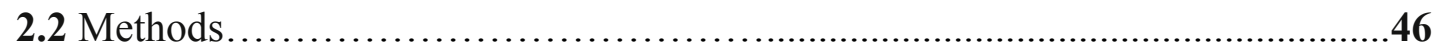

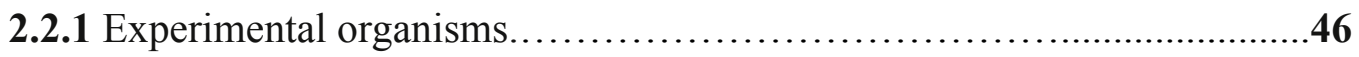

2.2.2 Developing a method for measuring the $\mathrm{pH}_{\mathrm{i}}$ of Symbiodinium cells......47

2.2.2.1 In vivo calibration of $\mathrm{pH}_{\mathrm{i}}$ with nigericin....................... 49

2.2.3 Obtaining viable $A$. pulchella cells...................................51

2.2.3.1 Measuring the $\mathrm{pH}_{\mathrm{i}}$ of $A$. pulchella cells.........................52 


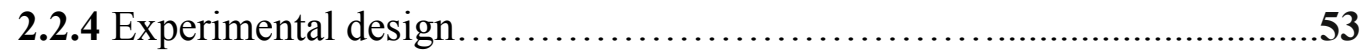

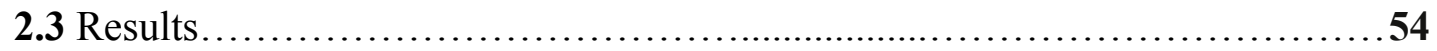

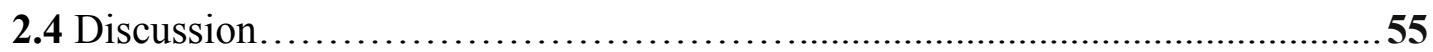

Chapter 3: Intracellular $\mathrm{pH}$ and its response to $\mathrm{CO}_{2}$-driven seawater acidification in symbiotic versus non-symbiotic coral cells

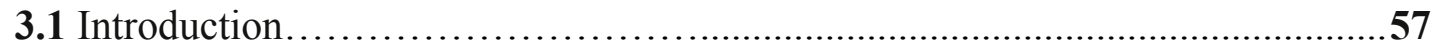

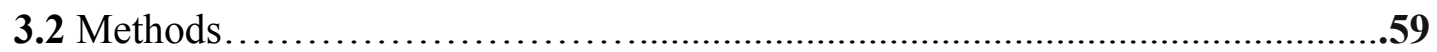

3.2.1 Coral collection and maintenance.................................59

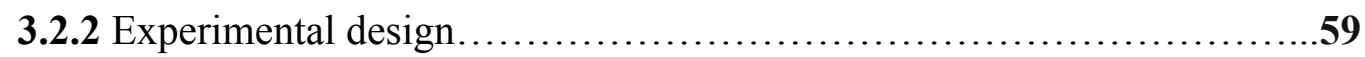

3.2.3 Isolation of cells and dye-loading procedure..........................61

3.2.4 Measurement of $\mathrm{pH}_{\mathrm{i}}$ by confocal microscopy ........................61

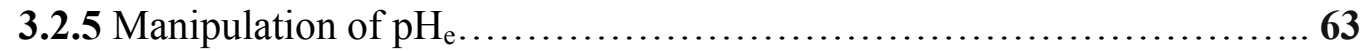

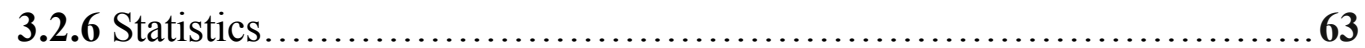

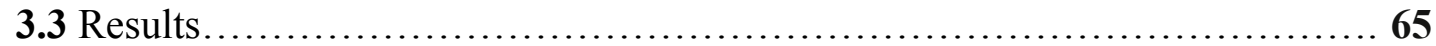

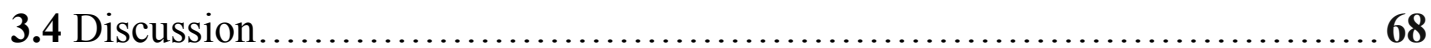

Chapter 4: Species-specific susceptibility to ocean acidification and cellular acidosis in reef corals is influenced by thermal sensitivity

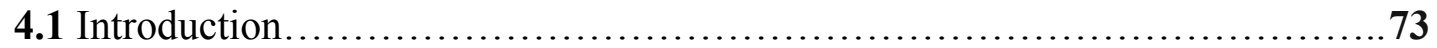

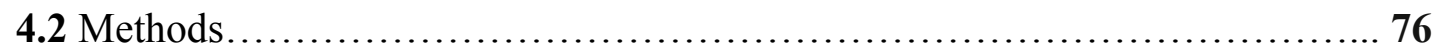

4.2.1 Collection and manipulation of coral fragments......................76

4.2.2 Quantifying the effects of temperature stress in coral fragments..........78

4.2.3 Isolation of cells and quantification of $\mathrm{pH}_{\mathrm{i}} \ldots \ldots \ldots \ldots \ldots \ldots \ldots \ldots \ldots \ldots . . . \ldots \ldots$

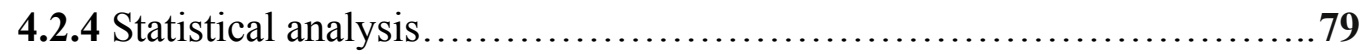

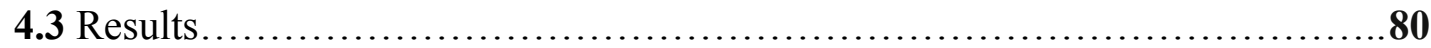

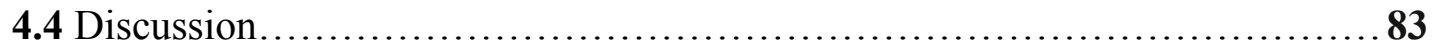

Chapter 5: The photo-physiological response of a model cnidarian-dinoflagellate symbiosis to $\mathrm{CO}_{2}$-induced acidification at the cellular level

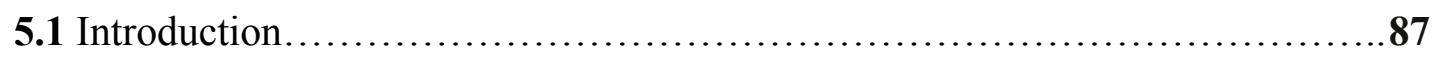

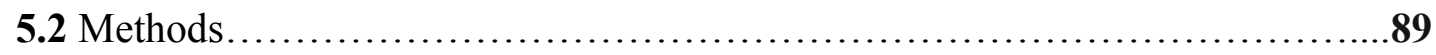

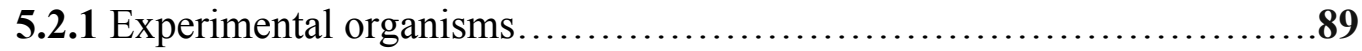

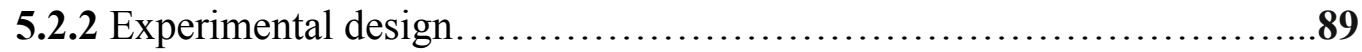


5.2.3 Photo-physiological responses

5.2.4 Statistical analysis.........................................92

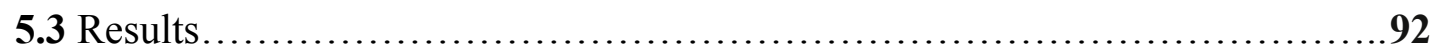

5.3.1 Photo-physiological responses to $\mathrm{CO}_{2}$ addition....................92

5.3.2 Cellular $\mathrm{pH}_{\mathrm{i}}$ response to $\mathrm{CO}_{2}$ addition..............................95

5.4 Discussion...................................................... 97

Chapter 6: General Discussion............................................101

6.1 Summary......................................................... 101

6.2 The cellular response to $\mathrm{CO}_{2}$ enrichment.............................. 101

6.2.1 What are the costs/benefits of $\mathrm{CO}_{2}$ supplementation?................101

6.2.2 The additional influence of temperature...............................................107

6.3 Implications for the future of coral reefs: a shift in dominance?.......................110

6.4 Limitations of the present study, and future work......................... 113

6.5 Conclusions .................................................................

References...........................................................117

A: Appendices......................................................149

B: Additional work................................................... 153

Publications............................................................. 157 


\section{List of figures}

Figure 1.1 Photosynthetic symbioses in the marine environment 20

Figure 1.2 Structure of cnidarian-dinoflagellate endosymbiosis 22

Figure 1.3 Inorganic carbon acquisition and nutrient translocation $\quad \mathbf{2 6}$

Figure 1.4 Sites of photosynthetic injury after thermal stress 31

Figure 1.5 Schematic depicting the processes involved in ocean acidification $\mathbf{3 3}$

Figure 1.6 Transmembrane protein pumps involved in the regulation of $\mathrm{pH}_{\mathrm{i}} \quad \mathbf{3 7}$

$\begin{array}{lll}\text { Figure 2.1 The spectral emission of BCECF-AM ester } & \mathbf{4 7}\end{array}$

Figure 2.2 Visualising BCECF in Symbiodinium cells $4 \mathbf{4 8}$

Figure 2.3 Flow cytometric calibration of Symbiodinium cells $\quad \mathbf{5 0}$

Figure 2.4 Calibration curve of $\mathrm{pH}_{\mathrm{i}}$ in cultured B1 Symbiodinium cells $\mathbf{5 1}$

Figure 2.5 Viable intact endodermal A. pulchella host cells $\mathbf{5 1}$

Figure 2.6 Calibration curve of SNARF-4F in A. pulchella host cells 52

Figure 3.1 Calibration curve of BCECF in symbiotic cells $\quad \mathbf{6 2}$

Figure 3.2 Stability of the live-cell $\mathrm{CO}_{2}$ incubator over time $\mathbf{6 3}$

Figure 3.3 Absolute change in the $\mathrm{pH}_{\mathrm{i}}$ of four cell types after $\mathrm{CO}_{2}$-addition $\mathbf{6 5}$

Figure 3.4 Confocal microscopy images of the $\mathrm{pH}_{\mathrm{i}}$ response to $\mathrm{CO}_{2}$-addition $\mathbf{6 6}$

Figure 3.5 Relative change in the $\mathrm{pH}_{\mathrm{i}}$ of four cell types after $\mathrm{CO}_{2}$-addition $\quad \mathbf{6 7}$

Figure 3.6 Model explaining the $\mathrm{pH}_{\mathrm{i}}$ fluctuations in P. damicornis cells $\quad 69$

Figure 4.1 Temperature and irradiance fluctuations in Kaneohe Bay, Hawaii $\mathbf{7 6}$

$\begin{array}{lll}\text { Figure 4.2 } 24 \mathrm{~h} \text { experimental irradiance curve } & 77\end{array}$

Figure 4.3 Temperature-sensitive BCECF calibration curve 79

$\begin{array}{lll}\text { Figure 4.4 Physiological response to } \mathrm{CO}_{2} \text {-addition after heat stress } & \mathbf{8 1}\end{array}$

Figure 5.1 Record of $\mathrm{pH}$ changes over the two-month experiment 90

Figure 5.2 Photo-physiological responses exposure to $\mathrm{CO}_{2}$-addition $\quad 94$

Figure 5.3 Cellular response of $\mathrm{pH}_{\mathrm{i}}$ to $\mathrm{CO}_{2}$-driven acidification. 96

Figure 5.4 Confocal microscope images of $\mathrm{pH}_{\mathrm{i}}$ in $A$. pulchella host cells $\quad 97$

$\begin{array}{lll}\text { Figure 6.1 Symbiodinium thermal resilience, productivity and host cell } \mathrm{pH}_{\mathrm{i}} & \mathbf{1 0 9}\end{array}$

$\begin{array}{lll}\text { Figure 6.2 Alternate stable state ecosystems } & \mathbf{1 1 1}\end{array}$

Figure A.2 P. damicornis and M. capitata photosynthesis-irradiance curves $\mathbf{1 5 0}$

$\begin{array}{lll}\text { Figure A.3 Visual bleaching in P. damicornis and M. capitata fragments } & 151\end{array}$

Figure B.1 Visualisation of propidium iodide stain in Symbiodinium cells $\mathbf{1 5 4}$

Figure B.2 Changes in Symbiodinium cell cycle dynamics upon $\mathrm{CO}_{2}$-addition 156 


\section{List of tables}

Table 2.1 Cultured Symbiodinium genotypes, the host they were first.........54 Isolated from, and the $\mathrm{pH}_{\mathrm{i}}$ after $12 \mathrm{~h}$ light and $12 \mathrm{~h}$ dark.

Table 3.1 Post hoc results of paired t-tests following rmANOVA on the......68 effect of 'symbiotic state $\times$ external $\mathrm{pH}^{\prime}$ ' on $\mathrm{pH}_{\mathrm{i}}$ at each time-point.

Table 4.1 Two-way ANOVA results summarising the effect of................82 temperature on symbiont density and chlorophyll- $\alpha$.

Table 5.1 Summary of the carbonate chemistry of the control and............90 experimental $\mathrm{pH}$ treatments used in Chapter 5.

Table 5.2 Statistical analyses of the response variables in A. pulchella........93 after exposure to different $\mathrm{pH}$ treatments. 


\section{Chapter 1: General Introduction}

\subsection{Symbiosis}

Symbioses are ubiquitous across terrestrial, aquatic and marine ecosystems, and have played a fundamental role in shaping biological life on Earth. Indeed, a transitory symbiosis between bacteria and eukaryotic cells is thought to have facilitated the development of both mitochondria and chloroplasts (Sagan, 1967), and so led to the oxygenation of our planet's atmosphere (Embley and Martin, 2006).

The term symbiosis was not formally coined until 1879 , when it was described by the German mycologist Heinrich Anton de Bary as "the living together of unlike organisms" (de Bary, 1879). Today, that definition has been refined and is broadly accepted as being the co-evolution of two genetically distinct organisms, which interact and form an ecologically significant association that is persistent over time (Trench, 1979). However, the definition does not specify what kind of association this has to be. As such, symbiosis spans a broad continuum from parasitism (where one partner benefits at the other's expense) through to mutualism (where both partners benefit). In the middle somewhere sits commensalism, where one partner gains from the association, while there is no benefit or loss to the other (Douglas, 2003).

Symbioses can be further classified according to the level of dependency that each organism exhibits towards the association. Obligate relationships describe those in which neither organism can survive outside the partnership (e.g. the tube worm Riftia pachyptila's reliance on sulphur-oxidising bacteria at hydrothermal vents (Minic and Herve, 2004). Facultative relationships describe those in which both partners can survive independently (e.g. the symbiosis between the bivalve Thyasira flexuosa and the chemolithotroph Thiobacillus thyasiris (Wood and Kelly, 1989). The association can be either intra- (endosymbiotic) or extracellular (ectosymbiotic). These terms describe the position of the symbiont (the smaller partner) relative to its host organism. For example, the gamma-proteobacterium Teredinibacter turnerae is found within host cells in the gills of its shipworm host rendering it endosymbiotic (Altamia et al., 2014), while the light organ harbouring the bioluminescent bacterium Vibrio 
fischeri in the bobtail squid Euprymna scolopes is ectosymbiotic (Overmann, 2006). Ascribing specificity to these partnerships is rather more complex. Monospecific symbiosis refers to associations where one host only interacts with one symbiont type and vice versa. This type of symbiosis is rare, and provides evidence of co-evolution between the host and symbiont (McFall-Ngai, 2001). Far more frequent is monospecificity exhibited by either the host or the symbiont (Baker, 2003; see section 1.2.4 for further discussion).

\subsection{Cnidarian-dinoflagellate symbiosis}

Photosynthetic symbioses are particularly widespread in the marine environment [Fig. 1.1] and are prevalent across the Chordata, Mollusca, Porifera, and Platyhelminthes phyla (Trench, 1979; Pawlowski et al., 2001; Venn et al., 2008). However, it is the relationship between members of the Cnidaria (hard and soft corals, sea anemones, jellyfish, and hydrocorals) and unicellular dinoflagellates belonging to the genus Symbiodinium (Freudenthal, 1962) that provides the best-known example. This wellstudied relationship is thought to have evolved some 200 million years ago in the Triassic, a period that coincides with the first paleolithic evidence of coral reef structures (Wood, 2001; Stanley, 2003; Muscatine et al., 2005).

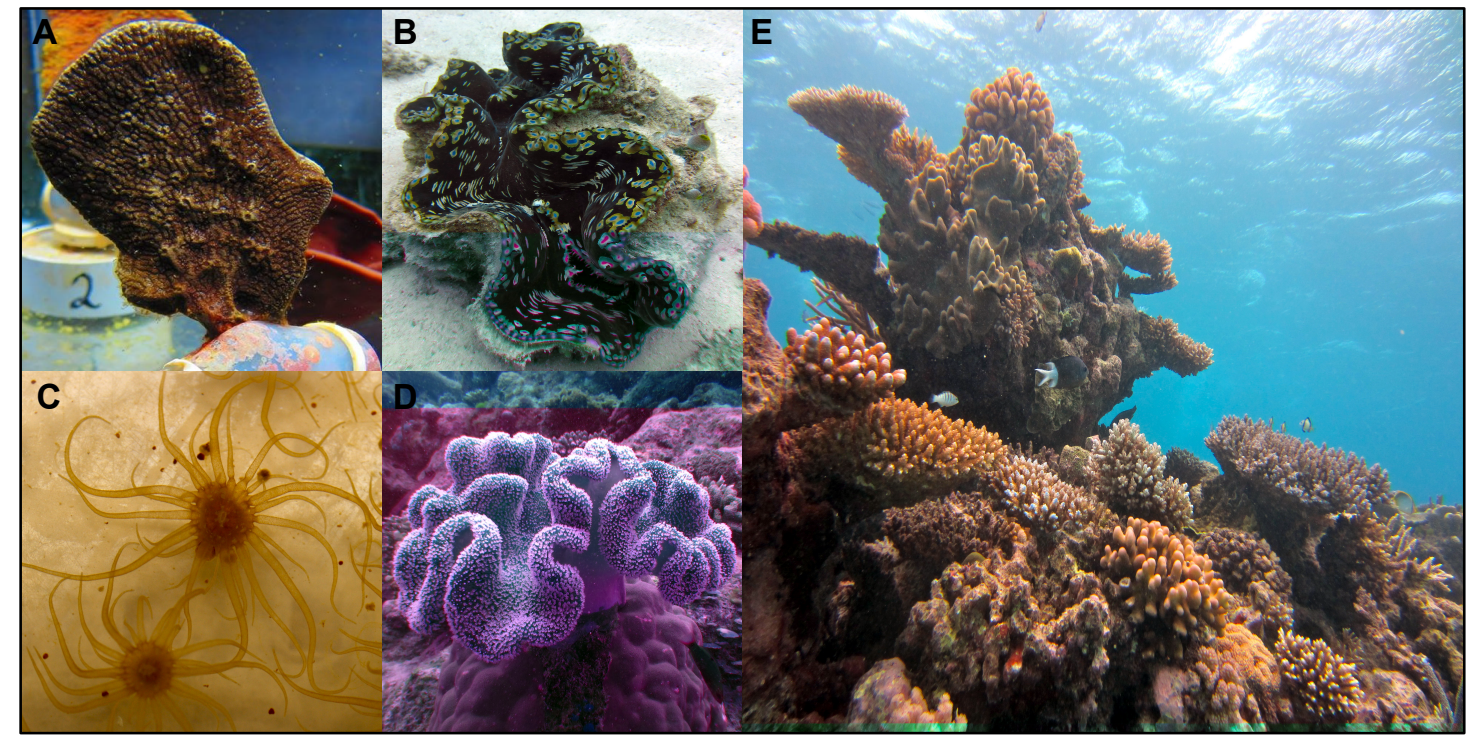

Fig. 1.1 Photosynthetic symbioses in the marine environment: [A] the tropical sponge Carteriospongia foliacens, photograph by M.C. Pineda; [B] the giant clam Tridacna gigas; [C] the tropical sea anemone Aiptasia pulchella [D] the leather coral Sarcophyton sp.; and [E] reef-building corals. 


\subsubsection{Ecological significance of coral reefs}

Coral reefs exist within a narrow band extending out from the Equator, to latitudes of approximately $30^{\circ}$ north to $30^{\circ}$ south (Muller-Parker and Davy, 2001), forming ecosystems of considerable environmental and socio-economic importance. The biogenic framework of a coral reef is formed from the calcium carbonate $\left(\mathrm{CaCO}_{3}\right)$ skeletons of scleractinian corals, which are fused together by coralline crustose algae. Despite covering less than $0.1 \%$ of the Earth's surface (Smith, 1978), reefs provide a habitat that is unparalleled in productivity, and support an extraordinarily high biodiversity of flora and fauna (Bellwood et al., 2001; Knowlton et al., 2010). These ecosystems are a vital food source for the burgeoning populations in the developing world (Hughes et al., 2013a; Teh et al., 2013) and also support a thriving tourism trade that is critical for the economic stability of many tropical countries (Barbier et al., 2012; Sarkis et al., 2013). Coupled with this anthropogenic dependence, reefs also play a critical role in protecting coastal shorelines (Villanoy et al., 2012), and in particular, defend ecologically significant mangrove and seagrass habitats that act as vital nursery grounds for many species (McMahon et al., 2012).

\subsubsection{Structure of cnidarian-dinoflagellate symbiosis}

Cnidarians are anatomically simple organisms. They are diploblastic, being composed of two epithelial layers - the outer epidermis and the inner endodermis, which are separated by a collagenous layer called the mesogloea. In Anthozoans, where the polyp life history phase dominates, the two layers are arranged to form a tubular shape called the body column. At the top of the column, the oral disc contains a mouth that acts as both the entrance and exit to the gastrovascular cavity - a digestive cavity spanning the length of the organism. The endodermal layer facing the gastrovascular cavity contains the phagocytic cells, which host the photosynthetic dinoflagellates. Here, the symbionts are bound within the symbiosome membrane complex (Roth et al., 1988) a series of phagocytically-derived algal membranes (Schwarz et al., 1999; 2002) encompassed by an outermost host-derived membrane (Wakefield and Kempf, 2001). The cells themselves are coccoid in shape, and between 5 and $15 \mu \mathrm{m}$ in size (Fig. 1.2B; Trench, 1979). Closer inspection reveals that 
the cells contain a 'lobulate' chloroplast(s) (LaJeunesse et al., 2010a), holding the photosynthetic pigments diadinoxanthin and peridinin (Hackett et al., 2004). The dinoflagellate life-history typically contains both a vegetative and a motile (dinomastigote) phase but, while free-living Symbiodinium cells are able to switch between the two, the flagella are lost in hospite and a vegetative cyst is dominant (Santos and Coffroth, 2003). In this phase, Symbiodinium cells propagate asexually through mitotic division (Fitt and Trench, 1983), though the remarkable diversity in this lineage, only now becoming apparent through the advancement of higher resolution molecular techniques (see section 1.2.4 for further details), provides growing evidence for sexual reproduction too (Porto et al., 2008; Chi et al., 2014).

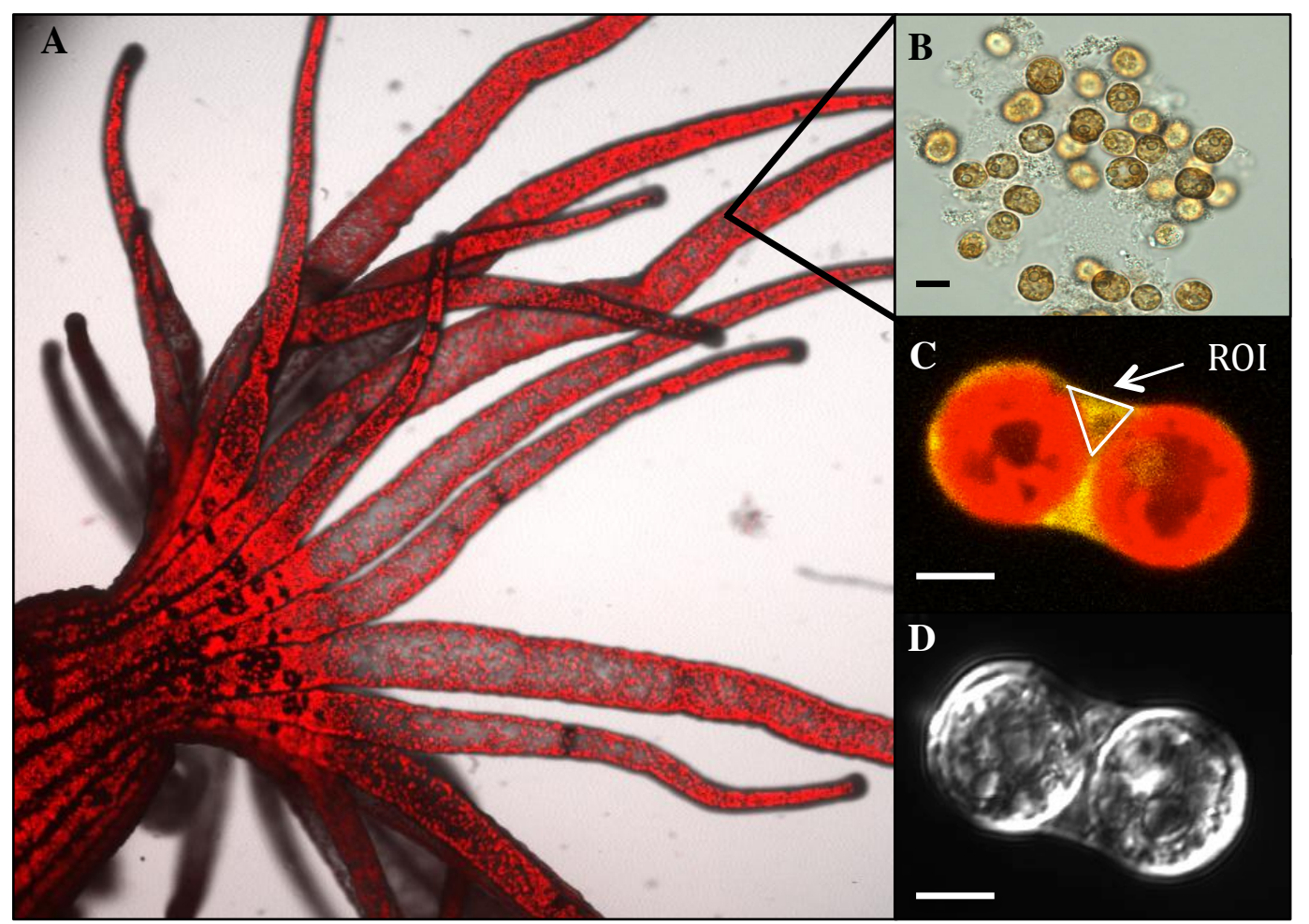

Fig. 1.2 Cnidarian-dinoflagellate endosymbiosis. [A] Confocal image of the tropical anemone Aiptasia pulchella; red fluorescence indicates the position of Symbiodinium cells (ex: 635, em: 655-755 nm). [B] Bright field micrograph of cultured Symbiodinium cells originally isolated from Acropora sp. in Okinawa, Japan; photograph by T.D. Hawkins). [C] Confocal image of an endodermal cell containing two algal cells. Host cell is stained yellow with SNARF-4F dye (ex: $559 \mathrm{~nm}$, em: $585 \pm 10 \mathrm{~nm}$ and $635 \mathrm{~nm} \pm 10 \mathrm{~nm}$ ). [D] Time-delayed integration (TDI) light micrograph of the same cell. Scale bar represents $10 \mu \mathrm{m}$.

Symbiodinium are closely related to parasitic apicomplexans and ciliates (Stat et al., 2006), so there has been a great deal of interest in determining what brings about the onset of symbiosis in this genus (Weis et al., 2001; Rodriguez-Lannetty et al., 2004; Wood-Charlson et al., 2006; Harii et al., 2009). We now know that more than $85 \%$ of 
corals acquire their symbionts from the environment, a process known as horizontal transmission (Babcock and Heyward, 1986), mainly through phagocytosis (Schwarz et al., 1999; Schwarz et al., 2002). In contrast, brooding corals such as Seriatopora hystrix generally employ a vertical transmission strategy, transferring their symbiont cohort directly to their young (Baird et al., 2009; Bongaerts et al., 2010). There are benefits and disadvantages to both approaches. Horizontal transmission affords the host access to environmental 'pools' of symbionts, which can be better acclimated to their local environment (Buddemeier and Fautin, 1993; van Oppen et al., 2004), but also presents the risk of not gaining any symbionts at all (Genkai-Kato and Yamamura, 1999). In comparison, vertical transmission is energetically costly to the host and may result in a less-than-optimal cohort of symbionts (Weis et al., 2001).

Horizontally transmitting species 'sort' the symbionts post-infection, in a complex process known as 'winnowing' (Nyholm and McFall-Ngai, 2004). Winnowing involves a cascade of molecular signaling between the symbiont and the host. Little is known about this process, but lectin/glycan interactions are likely to play an important role (Wood-Charlson et al., 2006; Logan et al., 2010), as are pattern recognition receptors (PRR's) and microbe-associated molecular patterns (MAMP's; see Davy et. al., 2012). Once inside the organism, live, functional cells are able to interfere with their host's immune defense response and present as "self" to avoid destruction (Fitt and Trench, 1983). In contrast, heat-stressed or DCMU-treated Symbiodinium cells are destroyed (Chen et al., 2005). In part, these interactions are thought to depend on the symbiont's ability to express the correct Rab protein. Healthy, intact symbionts are able to express the early endosomal marker Rab 5 (Chen et al., 2004). In contrast, the late endosomal Rab 7 marker is present around dead, and photosynthetically compromised symbionts (Chen et al., 2005; Fransolet et al., 2012).

\subsubsection{Function of cnidarian-dinoflagellate symbiosis}

The success of the symbiosis is largely founded on the recycling and conservation of nutrients, and the transfer of photosynthetic products between the two partners (Wang and Douglas, 1998). A truly mutualistic symbiosis, the coral affords its symbiont's protection from predators and access to the inorganic nutrients (primarily $\mathrm{CO}_{2}, \mathrm{NH}_{3}$, and $\mathrm{PO}_{4}$ ) present in the coral's waste (Muscatine and Porter, 1977; Muller-Parker and 
D'Elia, 1997). The Symbiodinium cells use these nutrients in photosynthesis, to synthesize a range of complex organic compounds, which are then returned to the host as sugars, alcohols, amino acids, fatty acids and lipids (Gordon and Leggat, 2010; Burriesci et al., 2012). In the nutrient-deplete waters of the tropics, this source of energy is invaluable to the coral, potentially meeting more than $100 \%$ of its energetic requirements (Falkowski et al., 1984; Muscatine, 1990).

Early studies were quick to recognise the nutritional value of photosynthetic products to the cnidarian host (Muscatine and Hand, 1958) and noted that the productivity of the symbiont appeared to be enhanced in hospite relative to free-living cultures (Muscatine et al., 1967). R.K. Trench published a seminal set of papers to this effect in the early 1970 's, identifying and tracking (with ${ }^{14} \mathrm{C}$ ) the compounds released by the symbiont (Trench 1971a-c). He analysed Symbiodinium cells freshly isolated from the temperate anemone Anthopleura elegantissima and concluded that $20-50 \%$ of all carbon was made available to the host. The majority of this is released in the form of glycerol and/or glucose (Lewis and Smith, 1971; Trench, 1974; Sutton and HoeghGuldberg, 1990; Whitehead and Douglas, 2003; Burriesci et al., 2012), although alanine, fumaric acid, succinic acid and glycolic acid derivatives are all present (Trench, 1971b). Despite decades of research, we still know little about the identity of the photosynthate released (Davy et al., 2012), although there is some evidence that lipids may also be translocated between the two (Kellog and Patton, 1983; Patton and Burris, 1983; Luo et al., 2009). We do however have a much greater appreciation for the role of these compounds in supporting growth, respiration, reproduction, and calcification (Falkowski et al., 1984; Muscatine et al., 1990; Gattuso et al., 1999; AlHorani et al., 2003; Allemand et al., 2004).

Photosynthetic activity is dependent on an adequate concentration of $\mathrm{CO}_{2}$ at the site of photosynthesis, and the provision of essential inorganic nutrients. Symbiodinium cells contain type II Rubisco, which has a much higher affinity for $\mathrm{O}_{2}$ than $\mathrm{CO}_{2}$ (Rowan et al., 1996). This, in addition to the intracellular location of the symbionts, and the low concentration of $\mathrm{CO}_{2}$ in seawater $(\sim 30 \mu \mathrm{M},<1 \%$ of all dissolved inorganic carbon (DIC)) requires considerable adaptations for the symbiosis. These adaptations come in the form of carbon-concentrating mechanisms (CCM's) and $\mathrm{H}^{+}$ATPases. CCM's facilitate the inter-conversion of $\mathrm{CO}_{2}$ and bicarbonate $\left(\mathrm{HCO}_{3}{ }^{-}\right)$, and 
are found widely across algae (Giordano et al., 2005). Carbonic anhydrases (CA's) are often a crucial component of CCM's (Badger, 2003). There is now considerable evidence for the importance of CA's in symbiont photosynthesis: (1) CA activity is light-dependent (Leggat et al., 1999) (2) there is a much higher concentration of CA in the tissues of symbiotic relative to aposymbiotic sea anemones (29-fold; Weis et al., 1989) and (3) the infection of previously symbiont-free organisms induced a 2.5fold increase in CA activity (Weis, 1991). Locating the CA activity, however, remains elusive (Davy et al., 2012).

Allemand and co-workers (1998) produced the first model to explain the mechanism of DIC uptake [Fig 1.3]. They hypothesised that a membrane-bound $\mathrm{H}^{+}$-ATPase pump exists on the ectodermal host cell, facilitating the dehydration of $\mathrm{HCO}_{3}{ }^{-}$into carbonic acid $\left(\mathrm{H}_{2} \mathrm{CO}_{3}\right)$, and subsequently into $\mathrm{CO}_{2}$, which is then able to enter the cell via passive diffusion (Furla et al., 2000). Once inside the cell a cytosolic CA hydrates the $\mathrm{CO}_{2}$ back into $\mathrm{HCO}_{3}^{-}$, essentially trapping the $\mathrm{HCO}_{3}^{-}$in the host's tissues (Bertucci et al., 2011). The exact mechanism by which carbon is transferred to the symbiont is presently unknown. However, it is clear that in order for the symbiont to be able to use the trapped $\mathrm{HCO}_{3}{ }^{-}$for photosynthesis, there must be a further dehydration step to produce $\mathrm{CO}_{2}$. An $\mathrm{H}^{+}$-ATPase pump that is localised to the symbiont's plasma membrane, and is only expressed in hospite (Bertucci et al., 2009), is likely to play a critical role in the delivery of $\mathrm{CO}_{2}$ to the site of photosynthesis. This model enables symbiotic organisms to exploit the $\mathrm{HCO}_{3}{ }^{-}$reservoir in seawater $(\sim 2.2$ $\mathrm{mM}$ ), and explains the disproportionately high $\mathrm{CO}_{2}$ concentration observed at the site of photosynthesis (up to $330 \mu \mathrm{M}$ ) compared to the surrounding seawater (Aizawa and Miyachi, 1986). Yet, despite these adaptations, photosynthesis in many marine algae remains DIC-limited (Reibesell et al., 1993; Nimer et al., 1999); a trait that also appears to be true for Symbiodinium in hospite (Weis, 1993; Goiran et al., 1996; Davy and Cook, 2001; Suggett et al., 2012).

Similarly, the conservation and exchange of nutrients such as nitrogen and phosphate is an important factor in determining coral reef productivity (Wang and Douglas, 1998). Dissolved inorganic nitrogen (DIN) in particular is essential for the synthesis of amino acids, proteins, nucleic acids, chlorophyll and Rubisco (Markell and Trench, 1993; Jiang et al., 2014). Yet, despite attaining higher concentrations of DIN (5-50 
$\mu \mathrm{M})$ than the surrounding seawater (Crossland and Barnes, 1977; Wilkerson and Muscatine, 1984), levels are still considered limiting in Symbiodinium cells in hospite (Cook and D'Elia, 1987; Jackson et al., 1989; Cook et al., 1992; Koop et al., 2001).

Nutrient limitation is thought to play a fundamental role in controlling the symbiont population density, and importantly, in stimulating the translocation of fixed carbon to the host (Cook et al., 1988; Falkowski, 1993; Smith and Muscatine, 1999), so it is in the host's interest to regulate the amount delivery of carbon, nitrogen, and phosphorus available to the symbiont [Fig. 1.3].

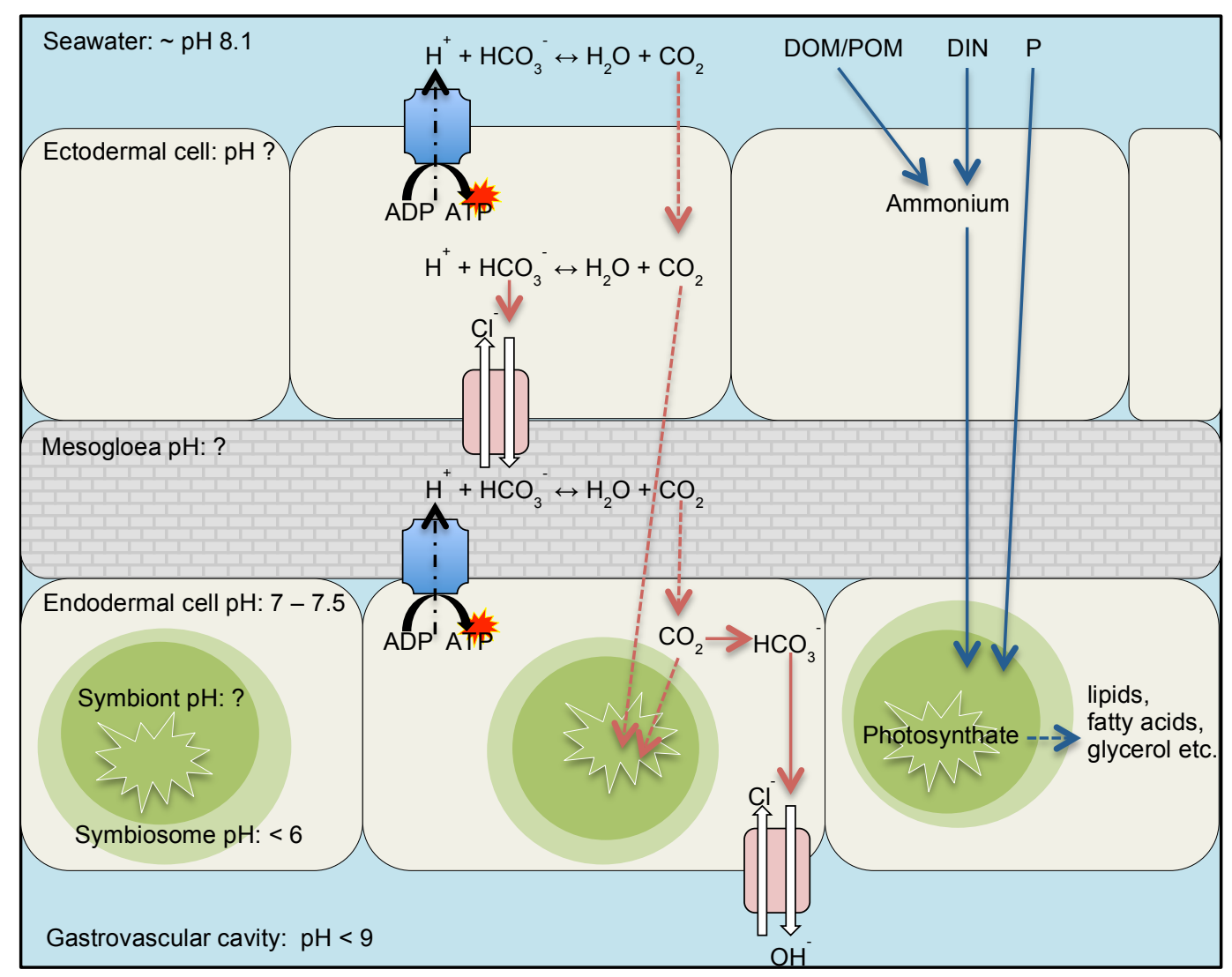

Fig. 1.3 Schematic depicting inorganic carbon acquisition and nutritional translocation between the three tissue layers (the ectodermis, mesogloea and the endodermis) of the cnidarian-dinoflagellate symbiosis. Red dashed arrows denote the passive diffusion of carbon dioxide $\left(\mathrm{CO}_{2}\right)$ and red solid arrows the transfer of bicarbonate $\left(\mathrm{HCO}_{3}{ }^{-}\right)$. Blue arrows show the transfer of dissolved organic matter/particulate organic matter (DOM/POM), dissolved inorganic nitrogen (DIN) and phosphate (P). The carbon and nutrient cycles have been offset for clarity. Membrane-bound $\mathrm{H}^{+}$-ATP-ases are in blue, transmembrane exchanger pumps are in red and the starburst sign represents photosynthesis. A full explanation of the mechanism is provided in the text above. Figure adapted from Allemand et al., 1998. 


\subsubsection{Host and symbiont diversity, and symbiosis specificity}

Originally, all symbiotic dinoflagellates were thought to belong to a single pandemic species, classified as Symbiodinium microadriaticum (Freudenthal, 1962). However advances in molecular genetics (Stat et al., 2006) have redefined the phylogeny of this lineage and revealed an astonishing diversity. Analysis of nuclear genes encoding for ribosomal DNA brought about a complete re-classification of the genus (Baker, 2003), with 9 clades of Symbiodinium (A-I) now formally recognised based on their internal transcribed tracer (ITS2) sequences (Pochon and Gates, 2010). Of these, just under half (A, B, C and D) frequently form associations with scleractinian corals (Baker, 2003), although there have been isolated reports of clades F and G in corals (Rodriguez-Lanetty et al., 2004; LaJeunesse et al., 2010b; Lien et al., 2012). Clade E has been isolated from the temperate anemone Anthopleura elegantissima (LaJeunesse and Trench, 2000) and from a water sample in Wellington Harbour, New Zealand (Baker, 2003), while, clades H and I are specific to Foraminifera (Pochon et al., 2006; Pochon and Gates, 2010). The evolution of cladal lineages is thought to have taken place some 50 million years ago in the Eocene (Pochon et al., 2006). Since then, numerous adaptive radiation events have transpired resulting in the high intrasubcladal diversification that exists today (LaJeunesse, 2005). Indeed, only now with the advances in genetic microsatellite markers (Pettay et al., 2009; LaJeunesse et al., 2012; Howells et al., 2013) are we beginning to comprehend the true diversity that exists within these sub-clades, with more than 100 ITS2 'types' assigned to clade C alone (LaJeunesse et al., 2004). The genetic composition, physiology, ecology, and biogeography vary substantially between types (Coffroth and Santos, 2005; Stat et al., 2006; Thornhill et al., 2007; Brading et al., 2011). Specifically, pigment composition, chlorophyll- $a$ content per cell, and the size and number of light-harvesting antennae differ between and within types (Chang and Trench, 1984; Iglesias-Prieto and Trench, 1994; Hennige et al., 2009), as does the ability to produce mycosporine-like amino acids (MAA's) that are crucial for UV protection (Banaszak and Trench, 1995; Banaszak et al., 2000). These factors cause substantial variation in the bio-optical properties of the symbiont, specifically affecting photosynthetic performance and thus the algal growth rate (Tchernov et al., 2004; Robison and Warner, 2006; Brading et al., 2011). The importance of these physiological differences becomes apparent upon exposure to thermal stress and/or high light (Chang and Trench, 1984; Robison and 
Warner, 2006; Suggett et al., 2008; Fisher et al., 2012; Howells et al., 2012). Some genotypes can modify their chlorophyll-protein complexes, reducing the impact of irradiance (Iglesias-Prieto and Trench, 1997), while others face decreases in their light-harvesting pigments, a reduction in the efficiency of photosystem II (PSII) and increased xanthophyll pool sizes (Krämer et al., 2012). As such, the type of symbiont that a host species associates with has generated considerable interest in the scientific community, because this effectively defines the environmental limits of the partnership in question (Buddemeier and Fautin, 1993; Iglesias-Prieto et al., 2004; Sampayo et al., 2008; Stat et al., 2009; Putnam et al., 2012).

Broadly speaking Symbiodinium genotypes can be classified into two distinct groups, 'generalists', which are able to form associations with many hosts (LaJeunesse et al., 2004) and 'specialists', which are endemic to specific locations and/or hosts (Fitt et al., 2009; Putnam et al., 2012). The former, comprised of the basal cladal members A1, C1, C3 and D1 (Putnam et al., 2012), are often fast growing and opportunistic (Stat et al., 2008; Stat and Gates, 2011). Conversely, the latter tend to be comprised of highly derived, hard-to-culture types such as C15 (Reimer and Todd, 2009; Krüeger and Gates, 2012). Symbiont specificity, however, is not synonymous with host specificity (Baker, 2003). A 'specialist' symbiont for example, may only be able to interact with one coral species, but the coral may be able to host more than one type of symbiont (Rowan and Knowlton, 1995, Goulet and Coffroth, 1997, Rowan et al., 1997, Santos et al., 2003; Silverstein et al., 2012). On the contrary (and perhaps more frequently), a coral may only be able to host one type of symbiont (Weis et al., 2001), whereas that type may be able to form associations across many host species (LaJeunesse et al., 2004). These patterns drive considerable temporal and biogeographical variation in the distribution of symbionts and their hosts (Rowan et al., 1996; Ulstrup and van Oppen, 2003; Schmidt et al., 2004; Stat et al., 2006). Broad inter-cladal patterns are now becoming apparent; corals in the tropics (e.g. the IndoPacific), predominantly harbour symbionts belonging to clade $\mathrm{C}$, whereas those at higher latitudes often host clades A, B and/or F (Rodriguez-Lanetty et al., 2001, Savage et al., 2002; Thornhill et al., 2009). There is also considerable variation within these regions, not only in the depth distribution of symbionts (Rowan et al., 1997; Toller et al., 2001; Frade et al., 2008), but also within individual coral colonies (Stat 
et al., 2011). The benefits of hosting more than one Symbiodinium type are still hotly debated (Putnam et al., 2012; Cunning et al., 2013). In theory, corals with a lowspecificity for Symbiodinium types should be more flexible to respond to stress (Berkelmans and van Oppen, 2006), but in practice corals that fall into this category, such as pocilloporids and acroporids are often the most susceptible to extended periods of stress (Stat et al., 2011; Putnam et al., 2012). Resolving these interactions is of the upmost importance given the threats posed to reefs over the coming century.

\subsection{Threats to the stability of cnidarian-dinoflagellate symbiosis}

Coral reefs currently face a catalogue of threats, ranging in scale and severity. Land run-off, pollution and over-fishing are all examples of localised threats, which can dramatically alter the structure and abundance of coral species on reefs (Chin et al., 2011; Hoegh-Guldberg et al., 2011; Hughes et al., 2013b). However, it should be possible to implement management strategies on a small scale and mitigate the effect of these stressors. The emergence of global climate change over the past century, though, is a very different proposition.

\subsubsection{Global warming}

Atmospheric $\mathrm{CO}_{2}$ levels have risen by $75 \%$ since 1970 and currently stand at $385 \mathrm{ppm}$ (IPCC, 2014). Although Earth's early climate may have witnessed atmospheric $\mathrm{CO}_{2}$ concentrations higher than this (Pearson and Palmer, 2000), the current rate of change is unprecedented in recent geological history, and shows no sign of slowing down (Hoegh-Guldberg et al., 2007). The most optimistic estimates place $\mathrm{CO}_{2}$ levels for 2100 at $450 \mathrm{ppm}$ (IPCC, 2014). Under this scenario there is a $66 \%$ chance of limiting warming (above temperatures from before the Industrial Revolution) to $2{ }^{\circ} \mathrm{C}$, although for this to eventuate, emissions must plateau and then decline. A more realistic 550 ppm trajectory reduces the chance to less than 50\% (IPCC, 2014), while some models caution that levels could reach up to 1000 ppm by 2100 (Meehl et al., 2007; Vuuren et al., 2011). Considered as a global average, a $2^{\circ} \mathrm{C}$ rise may not appear significant, however if water temperatures exceed the summer maxima by $1-2^{\circ} \mathrm{C}$ (Fitt et al., 2001), corals visibly pale, a process termed 'coral bleaching'. Bleaching refers to the 
characteristic whitening of tissues resulting from a decline in symbiont density and/or the degradation of photosynthetic pigments, resulting from the collapse of symbiosis (Douglas, 2003; Weis, 2008). The frequency, severity and duration of bleaching events have increased over the past 40 years and are expected to escalate further into the future (Hoegh-Guldberg et al., 2007; Pandolfi et al., 2011; Perry et al., 2013). Even under the most optimistic $\mathrm{CO}_{2}$ scenario, $23 \%$ of coral reefs are projected to experience annual bleaching events by 2050 (Van Hooidonk et al., 2013). Indeed, some mesophotic reefs in the Red Sea already experience such episodes (Nir et al., 2014). Mass bleaching events can have catastrophic consequences for reefs. The most severe event in recent history was witnessed in 1997/1998, when high temperatures coincided with the El Niño Southern Oscillation (ENSO), resulting in the loss of over $16 \%$ of the world's coral (Hughes et al., 2003), and up to $85 \%$ of hard coral cover was lost from reefs in the Western Indian Ocean alone (McClanahan, 2000).

Coral bleaching is induced by a number of stressors, including (but not limited to) extended periods of thermal stress (Bruno and Selig, 2007; Eakin et al., 2010) high irradiance (Lesser et al., 2011; Hill et al., 2012), low salinity (Kerswell and Jones, 2003), microbial infection (Kushmaro et al., 1996; Mills et al., 2013) and heavy metal contamination (Douglas, 2003). These factors can initiate bleaching independently, but they can also interact, lowering the thermal threshold required for bleaching (Lesser, 2006). The effects of bleaching however - namely decreased growth rates (Cantin et al., 2010), a reduction in reproductive success (Sudek et al., 2012; Airi et al., 2014) and, in some cases, mortality (Glynn et al., 2001; McClanahan et al., 2007) - persist irrespective of the cause. Yet despite decades of research, the mechanism involved in bleaching remains contentious (Weis, 2008). It is widely accepted that heat stress disrupts photosynthesis, most likely by damaging PSII (Takahashi et al., 2004; Lesser, 2011; Bhagooli, 2013; Hill et al., 2012). Three sites appear particularly vulnerable to injury [Fig 1.4]: the D1 protein (Warner et al., 1999; Takahashi et al., 2004); the thylakoid membrane (Tchernov et al., 2004; Díaz-Almeyda et al., 2011); and the Calvin Benson cycle (Jones et al., 1998; Hill et al., 2004). However, damage to these three sites is unlikely to always be mutually exclusive due to the high degree of inter-relatedness between the processes (Weis, 2008). More specifically: 
(1) The D1 protein is an integral part of the PSII water-splitting complex, but it is also sensitive to excessive irradiance and/or heat stress (Baroli and Melis, 1996; Warner et al., 1999). An active repair system ensures D1 continues to function, but under longer periods of elevated heat and/or light stress this mechanism becomes overwhelmed and can sustain direct damage itself (Takahashi and Murata, 2008; Takahashi et al., 2009). (2) Lipids present in the thylakoid membranes can become destabilised under the two stressors, disrupting the transfer of electrons from PSII to PSI (Tchernov et al., 2004). (3) The dark reaction of photosynthesis, particularly the fixation of $\mathrm{CO}_{2}$ by Rubisco, is susceptible to damage, which is likely to further impede the flow of electrons between the two-photosystem complexes (Jones et al., 1998).

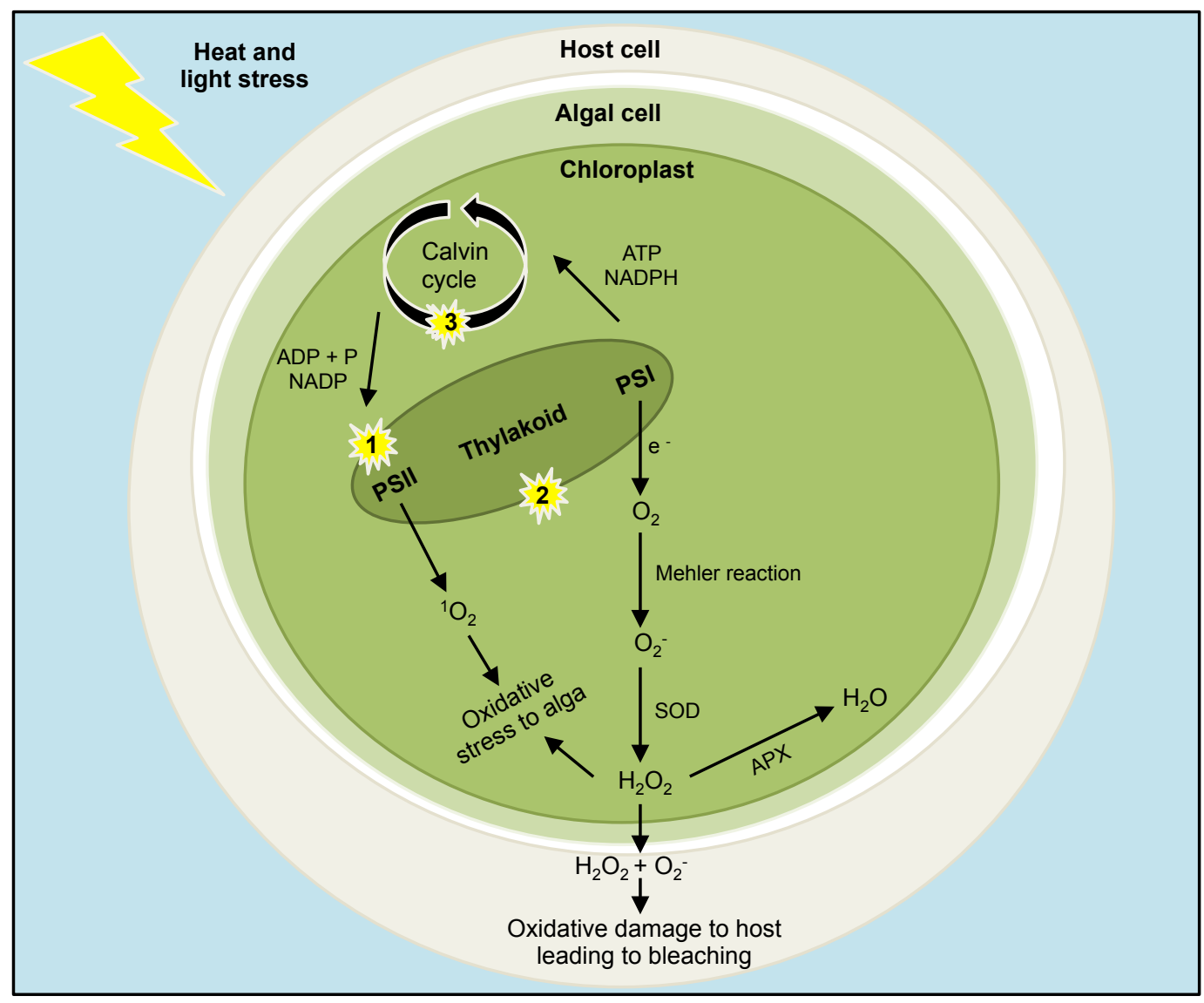

Fig. 1.4 Three sites of photosynthesis that are susceptible to damage upon exposure to elevated heat and/or light stress. [1] Photosystem II (PSII), more specifically the D1 protein; [2] destabilisation of the thylakoid membranes and [3] the Calvin cycle. All three lead to the formation of highly reactive molecules such as superoxide $\left(\mathrm{O}_{2}{ }^{-}\right)$, singlet oxygen $\left({ }^{1} \mathrm{O}_{2}\right)$ and/or hydrogen peroxide $\left(\mathrm{H}_{2} \mathrm{O}_{2}\right)$, collectively known as reactive oxygen species (ROS). The antioxidant activity of superoxide dismutase (SOD) and ascorbate peroxidase (APX) may reduce damage to the alga and/or the host, although the effectiveness of these measures depends on the rate of ROS production. Figure redrawn from Venn et al. (2008). 
Ultimately, all three mechanisms result in the production of highly reactive molecules such as superoxide $\left(\mathrm{O}_{2}{ }^{-}\right)$, singlet oxygen $\left({ }^{1} \mathrm{O}_{2}\right)$, hydrogen peroxide $\left(\mathrm{H}_{2} \mathrm{O}_{2}\right)$ and/or nitric oxide (NO), which are collectively termed reactive oxygen/nitrogen species (ROS/RNS; Lesser et al., 2006; Hawkins et al., 2012). Without adequate antioxidant mechanisms, ROS can denature proteins, mutate DNA, and oxidise lipids in cellular membranes (Richier et al., 2006). While failure to apprehend NO production can activate apoptotic and nectrotic cell death pathways (Perez and Weis, 2006; Bouchard and Yamasaki, 2009; Hawkins et al., 2013). Yet, production is not uniform across the Symbiodinium genus. At elevated temperature, types B1 and C1, for example, produce far more $\mathrm{H}_{2} \mathrm{O}_{2}$ than types A1 and F2 (Suggett et al., 2008; McGinty et al., 2012), whereas types A1 and B1 produce more RNS than C1 (Hawkins et al., 2012). Considered together, these findings may underpin some, but not all (see Baird et al., 2009 for a full discussion) of the variation observed in the bleaching susceptibility of corals hosting different symbiont populations (Sampayo et al., 2008; van Oppen et al., 2009).

\subsubsection{Ocean Acidification}

Global warming is not the only consequence of having high atmospheric $\mathrm{CO}_{2}$ levels. The world's oceans are estimated to have absorbed up to $30 \%$ of all of the carbon emitted during the Anthropocene (Sabine et al., 2004). While this process undeniably mitigates the effect on the atmosphere, it also causes the $\mathrm{pH}$ of the oceans to drop, a process termed ocean acidification. This process is a perfectly natural response to changes in $\mathrm{CO}_{2}$; in the atmosphere $\mathrm{CO}_{2}$ is a relatively un-reactive gas, however upon contact with the sea surface a series of dissolution reactions are initiated. $\mathrm{CO}_{2}$ reacts with water to form $\mathrm{H}_{2} \mathrm{CO}_{3}$. This weak acid quickly dissociates into $\mathrm{HCO}_{3}{ }^{-}$and $\mathrm{H}^{+}$, which are subsequently dehydrated to form carbonate $\left(\mathrm{CO}_{3}{ }^{2-}\right)$ and two protons, according to the equilibrium: $\mathrm{CO}_{2(\mathrm{~g})} \leftrightarrow \mathrm{CO}_{2(\mathrm{aq})}+\mathrm{H}_{2} \mathrm{O} \leftrightarrow \mathrm{H}_{2} \mathrm{CO}_{3}+\mathrm{H}^{+} \leftrightarrow 2 \mathrm{H}^{+}+\mathrm{CO}_{3}{ }^{2-}$. The relative proportions of these three forms of carbon $\left(\mathrm{CO}_{2}, \mathrm{HCO}_{3}{ }^{-}\right.$and $\left.\mathrm{CO}_{3}{ }^{2-}\right)$ reflect the $\mathrm{pH}$ of the seawater. The speciation of carbon has been stable for the past 20 million years, with seawater comprised of approximately $90 \% \mathrm{HCO}_{3}{ }^{-}\left(2000 \mu \mathrm{mol} \mathrm{kg}{ }^{-}\right.$ $\left.{ }^{1}\right), 9 \% \mathrm{CO}_{3}{ }^{2-}\left(240 \mu \mathrm{mol} \mathrm{kg}{ }^{-1}\right)$ and $1 \% \mathrm{CO}_{2}\left(15 \mu \mathrm{mol} \mathrm{kg}{ }^{-1}\right)$, so oceanic $\mathrm{pH}$ has also been constant ( $\sim 8.1$; Millero et al., 2002). Increasing the concentration of $\mathrm{CO}_{2}$ shifts the equilibrium to the left, resulting in a greater concentration of free $\mathrm{H}^{+}$. There are 
two main effects of this: (1) the seawater becomes more acidic; and (2) the additional $\mathrm{H}^{+}$reacts with $\mathrm{CO}_{3}{ }^{2-}$, generating $\mathrm{HCO}_{3}{ }^{-}$and reducing the amount of $\mathrm{CO}_{3}{ }^{2-}$ available. The $\mathrm{pH}$ of the world's oceans has already dropped $0.1 \mathrm{pH}$ units from pre-industrial levels, and it is expected to fall another $0.3-0.4 \mathrm{pH}$ units by 2100 leading to a bleak future for marine organisms (Silverman et al., 2009; Pandolfi et al., 2011). The future of calcifying organisms is strongly dependent on the $\mathrm{CO}_{3}{ }^{2-}$ concentration in the ocean. Currently this is stable at $\sim 210 \mu \mathrm{mol} \mathrm{kg}{ }^{-1}$, a level lower than at any point in the past 420,000 years (Hoegh-Guldberg et al., 2007). However, if this value falls below 200 $\mu \mathrm{mol} \mathrm{kg}{ }^{-1}$, aragonite (the structural polymorph of $\mathrm{CaCO}_{3}$ responsible for forming the skeletons in scleractinian corals) becomes undersaturated and it becomes far more difficult for corals to calcify (Kleypas and Langdon, 2006). Calcite on the other hand, (the polymorph predominantly used by soft corals) is more robust, and is expected to lag aragonite undersaturation by $50-100$ years (Orr et al., 2005).

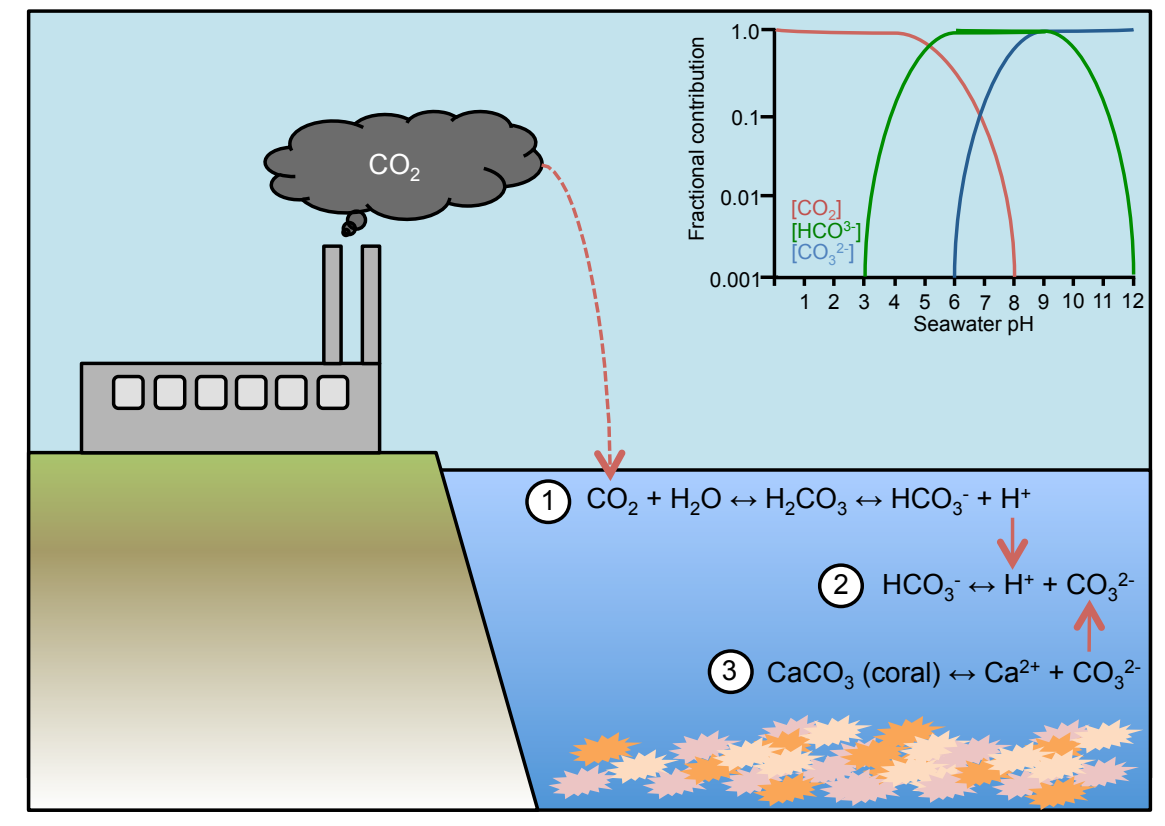

Fig. 1.5 Schematic depicting the processes involved in ocean acidification: dashed red arrows represent the fluxes of carbon dioxide $\left(\mathrm{CO}_{2}\right)$ and solid red arrows denote the flux of protons $\left[\mathrm{H}^{+}\right]$. [1] Upon contact with the sea surface, $\mathrm{CO}_{2}$ dissolves in water and dissociates to form carbonic acid $\left(\mathrm{H}_{2} \mathrm{CO}_{3}\right)$, which breaks down into bicarbonate $\left(\mathrm{HCO}_{3}{ }^{-}\right)$and an extra $\mathrm{H}^{+}$. [ 2 \& 3] The excess $\mathrm{H}^{+}$ions react with carbonate ions $\left(\mathrm{CO}_{3}{ }^{2-}\right)$, which are a principle component of the calcium carbonate skeletons $\left(\mathrm{CaCO}_{3}\right)$ of organisms such as corals. Changes in the concentration of these three carbon compounds influence the stability of seawater $\mathrm{pH}$ (Bering diagram, inset).

The effects of acidification are likely to be magnified in high latitude regions because colder waters have a higher capacity for $\mathrm{CO}_{2}$ absorption (Fabry et al., 2009). Indeed, 
areas of the Arctic Ocean are already experiencing seasonal aragonite-undersaturation events (Yamamoto-Kawai et al., 2009; Bates et al., 2013), a situation that is expected to become the norm in the Southern Ocean by 2050, and across the sub-Arctic Pacific Ocean by 2100 (Orr et al., 2005; McNeil and Matear, 2008). Likened to a 'bellwether for global acidification' by Fabry and co-workers (2009), these environments provide an opportunity to model the responses of calcifying organisms to ocean acidification. The effects observed so far have been stark and concerning; echinoderms, coralline red algae, gorgonians, and pteropods have all dissolved in undersaturated waters (Orr et al., 2005). The distribution of high latitude cold-water coral reefs, which occur in relatively deep waters, is limited by the aragonite saturation horizon (ASH; Roberts et al., 2006), the stratification between saturated and under-saturated waters. The depth of the ASH varies latitudinally, and between oceans; for example it is relatively deep in the South Pacific and the North Atlantic $(>800 \mathrm{~m})$, but is much shallower in the North Pacific $(<600 \mathrm{~m})$. Acidification is reducing the depth of the ASH (i.e. it is becoming shallower), a finding that has grave implications for deep-sea scleractinian corals (Turley et al., 2007) and commercial fishing grounds (Feely et al., 2004; Feely et al., 2008; Gruber et al., 2012). Indeed, by 2100 , up to $70 \%$ of all deep-sea corals are expected to be at risk of dissolution (Guinotte et al., 2006; Turley et al., 2007). Furthermore, marginal reef communities already living at the limits of their thermal tolerance, such as those on the Lord Howe Rise, may be particularly susceptible to acidification (Beger et al., 2013), as may the highly productive reef systems in areas of significant upwelling, such as Palmyra Atoll in the Central Pacific (Knowlton and Jackson, 2008).

Several hundred publications have been published on the causes and consequences of ocean acidification in reef corals in the past decade alone, providing a thorough database of inter- and intraspecific calcification responses under a variety of $\mathrm{CO}_{2}$ concentrations (Veron et al., 2011). It is beyond the scope of this introduction to describe the individual responses to $\mathrm{CO}_{2}$ alone, but excellent reviews exist on this topic (Doney et al., 2009; Hofmann et al., 2010; Veron et al., 2011). Meta-analyses of these results concluded that the responses are usually, but not always (Ries et al., 2009), negative in calcifying organisms (Silverman et al., 2009; Hendriks et al., 2010; Chan and Connolly, 2013; Kroeker et al., 2013) and are likely to be compounded by the increases in temperature (Anthony et al., 2011; Edmunds et al., 2012; Evenhuis et 
al., 2014). Exceptions to this rule are few and far between, but one such example found no change in the growth rate of the coral Stylophora pistillata after 5 weeks of exposure to $2 \times \mathrm{CO}_{2}$ (Reynaud et al., 2003). Reductions in adult growth rate may be the tip of the iceberg considering the number of life-history stages that could be affected by acidification prior to this. Early life history phases are particularly susceptible to high $\mathrm{CO}_{2}$ /low pH (Gibson et al., 2011); decreases in fertilisation and cleavage success (Kurihara et al., 2008), larval survival (Dupont et al., 2008) and larval settlement (Doropoulos et al., 2012) will all contribute to poor recruitment in an acidified ocean (Albright et al., 2010; Albright, 2011).

While laboratory experiments are undoubtedly important, many of the experiments are conducted under $\mathrm{CO}_{2}$ levels that are many times greater than those predicted for 2100. Furthermore they do not take into consideration the effects of factors such as community metabolism and predator/prey interactions (Edmunds et al., 2012; Poore et al., 2013). Natural volcanic $\mathrm{CO}_{2}$ seeps provide the perfect opportunity to examine these effects of ocean acidification in situ. Unsurprisingly, hard coral cover and species richness is negatively correlated with $\mathrm{pH}$ at sites across Papua New Guinea (Fabricius et al., 2011), Japan (Inoue et al., 2013), Mexico (Crook et al., 2012) and the Mediterranean (Hall-Spencer et al., 2008; Cigliano et al., 2010; Johnson et al., 2012), and no corals were found at sites of less than $\mathrm{pH} 7.7$ in Papua New Guinea (Fabricius et al., 2011). However, these vents were by no means barren, and were instead dominated by resistant species such as poritids (Rodolfo-Metalpa et al., 2011; Crook et al., 2012), soft corals (Inoue et al., 2013) and non-calcifying organisms such as anemones (Suggett et al., 2012). These findings are supported by the results of several laboratory studies. Indeed, increases in primary productivity under $\mathrm{CO}_{2}$-addition were observed in both the Mediterranean coral Stylophora pistillata (Marubini et al., 2008) and the temperate anemone species Anemonia viridis (Suggett et al., 2012; Jarrold et al., 2013) and Anthopleura elegantissima (Towanda and Thuesen, 2012). The benefits could be a direct result of the increase in substrate (i.e. $\mathrm{CO}_{2}$ ) for photosynthesis (Rodolfo-Metalpa et al., 2010; Gao et al., 2012), or indirect through a reduction in the energetic demands of $\mathrm{HCO}_{3}{ }^{-}$acquisition (Raven et al., 2012). Either way, they suggest that some species may be "winners" under ocean acidification (Fabricius et al., 2011) and that a shift in species dominance across ecosystems is likely (Norström et al., 2009; Bell et al., 2013). 


\section{4 pH and cellular acidosis}

\subsubsection{The physiological role of $\mathrm{pH}$}

An individual organism's response to ocean acidification is likely to depend on its ability to regulate its intracellular $\mathrm{pH}\left(\mathrm{pH}_{\mathrm{i}}\right.$; Fabry, 2008; McCulloch et al., 2012). $\mathrm{pH}_{\mathrm{i}}$ by definition is simply the intracellular ratio of $\mathrm{H}^{+}$ions to $\mathrm{OH}^{-}$ions, yet its regulation is fundamental to all metabolic processes within a cell. Eukaryotic cells typically maintain their $\mathrm{pH}_{\mathrm{i}}$ between 7 and 7.4 (Madshus, 1988), but values vary considerably between organelles. Plant thylakoid membranes, for example, can be as low as $\mathrm{pH} 4$, while the stroma can reach $\mathrm{pH} 8$ (Kurkdjian and Guern, 1989). The $\mathrm{pH}_{\mathrm{i}}$ of microalgae normally falls within the typical range of values (Walker and Smith, 1975; Lane and Burris, 1981; Gehl and Colman, 1985) although variation does exist between species, with values reaching as low as $\mathrm{pH} 6.5$ in the giant-celled alga Chaetomorpha darwinii (Raven and Smith, 1980) and as high as pH 7.6 in the blue-green alga Coccochloris peniocystis (Coleman and Colman, 1981). These differences play an important role biochemically, affecting the structure and function of proteins, the activity of enzymes and the efficiency of contractile elements (especially important in DNA/RNA synthesis), all of which influence the conductivity of ion channels and therefore control what can enter a cell (Smith and Raven, 1979; Madshus, 1988; Taylor et al., 2011; Taylor et al., 2012).

\subsubsection{Regulation of $\mathrm{pH}$ and cellular acidosis}

Cellular acidosis occurs when a cell's buffering capacity is exceeded, leaving the cell unable to respond to an acid-base imbalance. Failure to mitigate a rise in $\mathrm{H}^{+}$can modify the structure and function of ion channels, lower the efficiency of CA's (Bozzo and Colman, 2000) and alter the permeability of plasma membranes (Sobrino et al., 2005), all of which can seriously compromise an organism's fitness (Pörtner et al., 2005; Langenbuch et al., 2006; Rosa and Seibel, 2008). Exposure to a short-term reduction in external $\mathrm{pH}\left(\mathrm{pH}_{\mathrm{e}}\right)$ typically initiates a sub-lethal response in organisms. During this time, the cell reduces the most energetically expensive processes (usually protein synthesis; Hand, 1991). Over a longer period of time, metabolic dormancy can have severe repercussions on an organism's reproductive and therefore competitive 
fitness (Pörtner et al., 2004; Havenhand et al., 2008; Wood et al., 2008). To combat these, eukaryotic cells have evolved multiple buffer mechanisms at different cellular levels to minimise changes in $\mathrm{pH}_{\mathrm{i}}$ (Casey et al., 2010). These mechanisms can be divided into two categories: 1 ) the cell's innate buffering capacity $(\beta)$, which regulates acute changes over a short period of time (e.g. hours); and 2) permanent structural adaptations, which regulate chronic changes over a longer period of time (e.g. weeks).

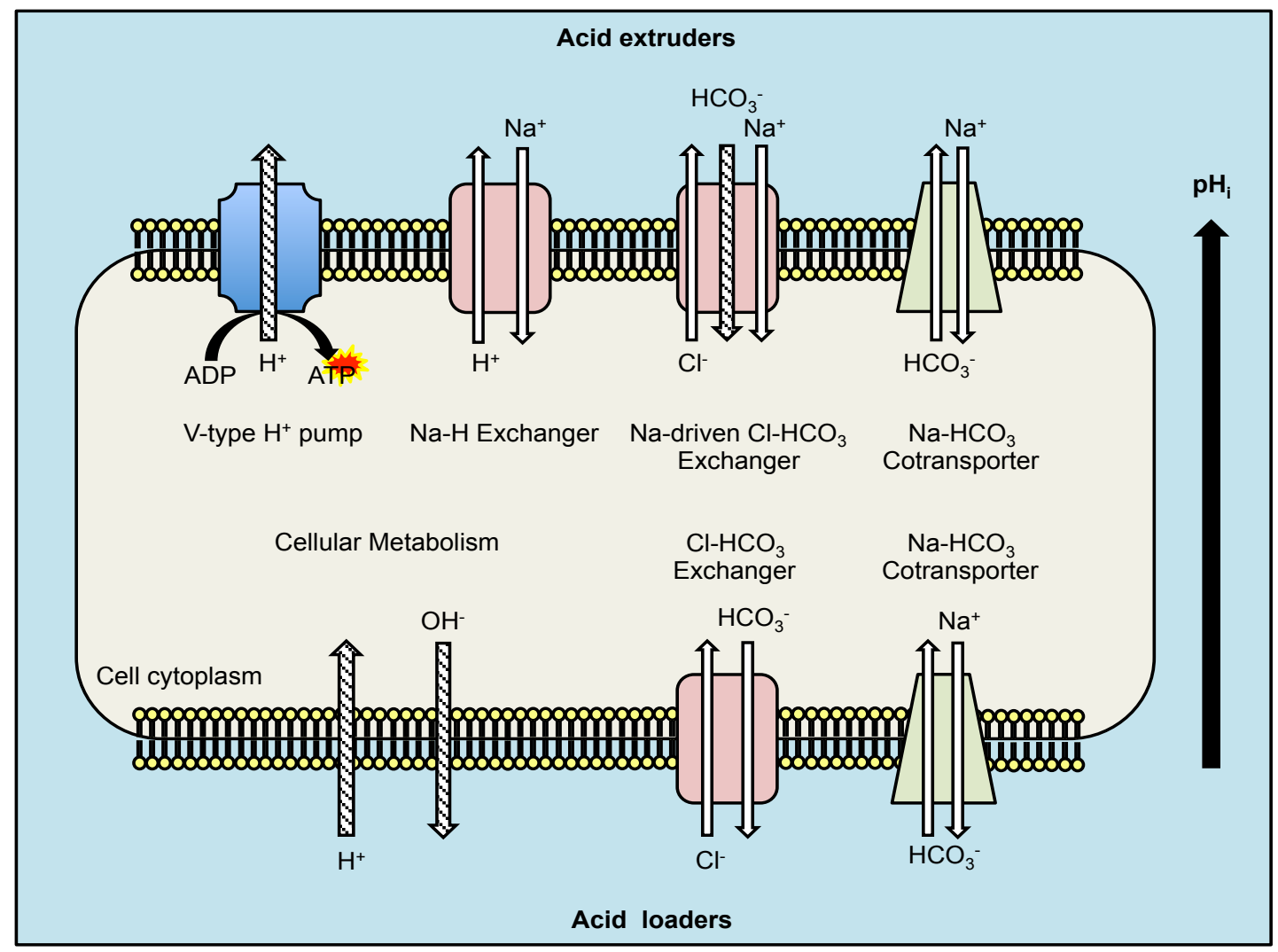

Fig. 1.6 Transmembrane protein pumps involved in the regulation of intracellular $\mathrm{pH}\left(\mathrm{pH}_{\mathrm{i}}\right)$. Acid extruders use energy to reduce the acidity of the $\mathrm{pH}_{\mathrm{i}}$, either by removing $\mathrm{H}^{+}$ions, or by increasing the concentration of $\mathrm{HCO}_{3}{ }^{-}$. Acid loaders reduce the $\mathrm{pH}_{\mathrm{i}}$ by increasing the concentration of $\mathrm{H}^{+}$in the cytoplasm. Colours represent the type of pump: $\mathrm{H}^{+}$-ATPases are blue; exchangers are red; and cotransporters are green. Figure adapted from Boron (2004).

$\beta$ is comprised of two mechanisms: a closed system $\left(\beta_{\text {intrinsic }}\right)$ and an open system $\left(\beta_{\mathrm{HCO} 3}\right)$. $\beta_{\text {intrinsic }}$ represents the buffering capacity of the intracellular weak acids and weak bases that are already present in the cytoplasm, such as (but not limited to) $\mathrm{NH}_{4}{ }^{+}, \mathrm{H}_{2} \mathrm{CO}_{3}$, and monobasic inorganic phosphate $\left(\mathrm{H}_{2} \mathrm{PO}_{4}{ }^{-}\right)$. The nature of weak acids is to dissociate into equilibrium between a proton and its conjugate base, which together form a buffer pair. In general terms this can be explained as: $\mathrm{HB}^{(n+1)} \leftrightarrow \mathrm{B}^{(n)}+$ $\mathrm{H}^{+}$, where $\mathrm{HB}$ is a weak acid, B its conjugate weak base and $n$ the valence. For each 
of these buffers, the equilibrium constant $(\mathrm{K})$ can be considered in general terms as: $\mathrm{K}$ $=\left[\mathrm{B}^{(n)}\right] \cdot\left[\mathrm{H}^{+}\right] /\left[\mathrm{HB}^{(n+1)}\right]$; or in its logarithmic form related to $\mathrm{pH}$ as: $\mathrm{pH}=\mathrm{pK}+\log _{10}$ $\left(\left[\mathrm{B}^{(n)}\right] /\left[\mathrm{HB}^{(n+1)}\right]\right)$. When an acute change in $\mathrm{pH}$ occurs, the free $\mathrm{H}^{+}$in the cytoplasm buffers the change by binding to $\mathrm{OH}^{-}$and forming water. Conversely, a weak base dissociates into its conjugate weak acid and releases $\mathrm{OH}^{-}$, to counteract any protons that are added into the system (Boron, 2004).

The $\beta_{\mathrm{HCO} 3}$ on the other hand, is an open system. This arises from the diffusive ability of the uncharged $\mathrm{CO}_{2}$ molecule, which is readily transported across all biological membranes. Once inside the cell, hydration and subsequent deprotonation of $\mathrm{H}_{2} \mathrm{CO}_{3}$ means that $\mathrm{CO}_{2}$ acts as a conjugate acid, splitting to form $\mathrm{HCO}_{3}{ }^{-}$and releasing a proton: $\mathrm{CO}_{2}+\mathrm{H}_{2} \mathrm{O} \leftrightarrow \mathrm{H}_{2} \mathrm{CO}_{3} \leftrightarrow \mathrm{HCO}_{3}^{-}+\mathrm{H}^{+}$. Considering this relationship, cells become increasingly resistant to changes in $\mathrm{pH}_{\mathrm{i}}$ as $\mathrm{pH}_{\mathrm{e}}$ increases (Boron, 2004). This is particularly important when cells are exposed to larger or longer lasting fluctuations in $\mathrm{pH}_{\mathrm{i}}$. Exposure to these chronic $\mathrm{pH}$ events requires structural adaptations in the form of a suite of acid-base membrane-bound transporters (Kaniewska et al., 2012). In general, these can be classified into two groups [Fig. 1.6]. First, acid extruders (e.g. V-type $\mathrm{H}^{+}$pumps, $\mathrm{Na}-\mathrm{H}^{+}$exchangers, Na-driven $\mathrm{Cl}-\mathrm{HCO}_{3}$ exchangers and $\mathrm{Na}-\mathrm{HCO}_{3}$ co-transporters) use energy to reduce the acidity of the $\mathrm{pH}_{\mathrm{i}}$, either by removing $\mathrm{H}^{+}$ ions, or by increasing the concentration of $\mathrm{HCO}_{3}{ }^{-}$. Second, under alkaline conditions, acid loaders (e.g. $\mathrm{Cl}-\mathrm{HCO}_{3}{ }^{-}$exchangers and $\mathrm{Na}-\mathrm{HCO}_{2}$ co-transporters) regulate the $\mathrm{pH}_{\mathrm{i}}$ by increasing the concentration of protons in the cytoplasm. Very little is known about the regulatory mechanisms involved in cnidarians; there is molecular evidence for the involvement of V-type $\mathrm{H}^{+}$pumps (Ganot et al., 2011; Kaniewska et al., 2012), but to date only one study has adopted a mechanistic approach to $\mathrm{pH}$ regulation. In this case Laurent et al. (2013b) used amiloride inhibitors, in combination with live cell $\mathrm{pH}_{\mathrm{i}}$ measurements, to demonstrate a role for $\mathrm{Na} / \mathrm{H}^{+}$exchangers (NHE) in the sea anemone Anemonia viridis.

\subsection{3 $p H$ in the cnidarian-dinoflagellate symbiosis}

In symbiotic cnidarians, $\mathrm{pH}_{\mathrm{i}}$ plays a particularly important role in coral calcification (Venn et al., 2011; 2013). Briefly, the coral skeleton is lined by a thin epithelium, called the calicoblastic epithelium (CE), which is comprised of calicoblastic cells and 
anchoring cells termed desmocytes (Muscatine et al., 1997). Above lies a fluid termed the subcalicoblastic medium ( $\mathrm{SCM})$. The $\mathrm{pH}_{\mathrm{i}}$ of the $\mathrm{SCM}$ is vital in the calcification process, directly influencing the concentration of $\mathrm{CO}_{3}{ }^{2-}$ in the $\mathrm{CE}$. Values of this layer measured in the corals Galaxea fascicularis $(\mathrm{pH} 8.13$ in the dark versus 9.29 in the light; Al-Horani et al., 2003) and S. pistillata ( $\mathrm{pH} 8.36$ versus 8.69, respectively; Venn et al., 2011) reveal the importance of irradiance (and therefore photosynthesis) in this process. The benefits of light-enhanced calcification rates have long been recognised (Kawaguti and Sakumoto, 1948), but the coupling between photosynthesis and calcification is less clear. The photosynthetic uptake of $\mathrm{CO}_{2}$ may increase the alkalinity of the coral tissue, aiding the deposition of the $\mathrm{CaCO}_{3}$ skeleton (Goreau, 1959). Alternatively, a $\mathrm{Ca}^{2+}$-ATPase pump may remove $\mathrm{H}^{+}$from the site of deposition (Zoccola et al., 2004), fueling the dehydration of $\mathrm{HCO}_{3}{ }^{-}$into $\mathrm{CO}_{2}$ in the gastrovascular cavity, and resulting in high calcification rates (Gattuso et al., 1999; Allemand et al., 2004; Holcomb et al., 2009). Either way, failure to regulate $\mathrm{pH}_{\mathrm{i}}$ in the SCM is likely to explain the decrease in calcification rates described earlier. It is becoming clear that disentangling the effects of ocean acidification will require intimate knowledge of the relationship between carbon speciation, $\mathrm{pH}_{\mathrm{i}}$ regulation, photosynthesis and calcification (Schneider and Erez, 2006; Brownlee, 2009; Venn et al., 2013).

The first measurements of $\mathrm{pH}_{\mathrm{i}}$ in coral cells were only reported in 2009 (Venn et al., 2009). Prior to this study, investigators were largely restricted by the methods available. The development of fluorescent $\mathrm{pH}$-sensitive intracellular dyes has been instrumental in furthering research in this field (Zhang et al., 2012). The use of fluorescent dyes in conjunction with confocal microscopy has significant advantages; in particular, membrane-permeable dyes facilitate real-time, high-resolution visualisation of $\mathrm{pH}$ changes in living cells. This is especially beneficial for the analysis of $\mathrm{pH}_{\mathrm{i}}$ in spatially confined areas such as coral cells, where the region of interest (ROI) is reduced by the presence of the dinoflagellate symbionts. Of the fluorochromes, two in particular are favoured. The cell-permeant acetoxymethyl ester form of 2',7'-bis(2-carboxyethyl)-5,6-carboxyfluorescein (BCECF) has been widely used to study $\mathrm{pH}_{\mathrm{i}}$ fluxes in marine organisms (Dixon et al., 1989; Davies et al., 1990; Hervé et al., 2012; Liu et al., 2012). While the recent development of the 
seminaphthorhodafluor-1 (SNARF) probe facilitated the first measurements of $\mathrm{pH}_{\mathrm{i}}$ in host cnidarian cells (from S. pistillata and A. viridis; Venn et al., 2009).

Venn and co-workers' initial study (Venn et al., 2009) had three aims: (1) to determine how symbiotic state influences the $\mathrm{pH}_{\mathrm{i}}$ of the host coral cell; (2) to measure the effect of light/dark on $\mathrm{pH}_{\mathrm{i}}$; and (3) to measure the $\mathrm{pH}_{\mathrm{i}}$ of the symbiosome (i.e. the vacuolar space surrounding the alga). Unfortunately, the latter aim could not be resolved any further than $<\mathrm{pH} 6$ (a value that is in agreement with other studies; Rands et al., 1993) because the SNARF probe only works reliably between $\mathrm{pH} 6$ and 8. Both cnidarians maintained a steep gradient between the $\mathrm{pH}_{\mathrm{i}}$ and the external seawater $(\sim \mathrm{pH} 8.1)$, however this gradient was greater in dark-adapted cells, where $S$. pistillata reached $7.13 \pm 0.24$ and $A$. viridis reached $7.01 \pm 0.27$. In contrast, the lightadapted $\mathrm{pH}_{\mathrm{i}}$ was measured as $7.41 \pm 0.22$ in the former and $7.29 \pm 0.15$ in the latter. Because light-induced alkalinisation was only witnessed in symbiont-bearing host cells, the authors concluded that the photosynthetic activity of the symbionts is able to directly influence the host cell $\mathrm{pH}_{\mathrm{i}}$. In a further experiment by this same research group (Laurent et al., 2013a), fluctuations in $\mathrm{pH}_{\mathrm{i}}$ were measured over a range of light levels, with and without a photosynthetic inhibitor, DCMU. Their results confirmed that the photosynthetic activity by the symbionts is responsible for the rise in alkalinity in their host cells' $\mathrm{pH}_{\mathrm{i}}$, and demonstrated that this change is proportional to the level of irradiance that the symbionts are exposed to. Starzak (2012) then investigated whether the $\mathrm{pH}_{\mathrm{i}}$ of the host cell is affected by the symbiont genotype, by re-infecting aposymbiotic $A$. pulchella with different symbiont types and exposing the organism to saturating light before measuring the $\mathrm{pH}_{\mathrm{i}}$ of the host cell. No statistical differences between genotypes were observed, although of note the $\mathrm{pH}_{\mathrm{i}}$ of host cells containing type E2 (a free-living strain) were more acidic than those containing homologous or heterologous B1 strains both in the dark $(6.6 \pm 0.10$ versus $6.9 \pm 0.04$ and $6.7 \pm 0.14)$ and light $(6.7 \pm 0.08$ versus $7.0 \pm 0.04$ and $6.9 \pm 0.08)$ respectively.

These results raised several interesting questions: What is the $\mathrm{pH}_{\mathrm{i}}$ of the symbiont? Does the $\mathrm{pH}_{\mathrm{i}}$ of the symbiont vary between different Symbiodinium genotypes? How will both partners of the symbiosis be impacted by external seawater acidification? And finally, if the photosynthetic activity of the symbiont is compromised (e.g. by heat), how will this affect the $\mathrm{pH}_{\mathrm{i}}$ of the host and its response to ocean acidification? 


\subsection{Aim and specific objectives}

No study has yet determined the $\mathrm{pH}_{\mathrm{i}}$ of the Symbiodinium cell. This will form a vital component of this thesis. I will then aim to determine the inter-relationship between symbiont photosynthesis, symbiont $\mathrm{pH}$ and host cell $\mathrm{pH}$, and how this is impacted by ocean acidification and thermal stress. The specific objectives of the study were to:

1. Measure the $\mathrm{pH}_{\mathrm{i}}$ of the dinoflagellate symbiont cell and establish (a) the effects of the diel light cycle on $\mathrm{pH}_{\mathrm{i}}$, (b) how this compares to the $\mathrm{pH}_{\mathrm{i}}$ of the host cell and (c) whether $\mathrm{pH}_{\mathrm{i}}$ differs between symbiont genotypes in culture.

Hypotheses: (a) Light will cause an alkalinisation of the Symbiodinium cell as $\mathrm{CO}_{2}$ is removed during photosynthesis (b) this will cause a similar lightinduced increase in $\mathrm{pH}_{\mathrm{i}}$ to occur in the host cell and (c) the magnitude of light-adapted alkalinisation will differ between symbiont types according to the efficiency of their $\mathrm{CO}_{2}$ removal (i.e. the culture with the highest lightadapted $\mathrm{pH}_{\mathrm{i}}$ will have the greatest photosynthetic productivity).

2. Determine how the presence/absence of symbionts and photosynthetic activity affect the response of host cell $\mathrm{pH}_{\mathrm{i}}$ to short-term $\mathrm{CO}_{2}$-driven seawater acidification in reef corals.

Hypotheses: (a) Endodermal coral cell's hosting Symbiodinium will be able to buffer short-term external $\mathrm{CO}_{2}$-addition by increasing their photosynthetic activity, (b) when photosynthesis (and hence $\mathrm{CO}_{2}$-removal) is inhibited, this additional buffering capacity will be lost, leading to acidosis of the host cell.

3. Measure and compare how elevated temperature impacts upon the cellular response to short-term $\mathrm{CO}_{2}$-driven seawater acidification in thermally sensitive versus thermally resilient reef corals.

Hypotheses: thermally sensitive corals will be more likely to suffer acidosis under high-temperature because the photosynthetic activity of the symbiont is compromised and $\mathrm{CO}_{2}$ will not be removed as efficiently. 
4. Establish the longer-term impacts of $\mathrm{CO}_{2}$-driven seawater acidification on the photo-physiology, stability and $\mathrm{pH}_{\mathrm{i}}$ of the intact cnidarian-dinoflagellate symbiosis.

Hypotheses: the addition of $\mathrm{CO}_{2}$ will enhance photosynthetic performance in A. pulchella enabling both the symbiont and host cell to withstand cellular acidosis under predicted ocean acidification scenarios.

The thesis has been written as a series of individual manuscripts, which are either published or in preparation, so there may be a degree of overlap in the content of each chapter, and particularly in their introductions. The author completed all laboratory work, fieldwork, analyses and writing, with further assistance as described below:

Chapter 2: This chapter is formatted as a stand-alone manuscript based on a published study. Gibbin, E. M. and Davy, S. K. (2013) Intracellular pH of symbiotic dinoflagellates, Coral Reefs 32 (3): 859-863. doi: 10.1007/s00338-013-1048-7. S. K. Davy assisted with experimental design, data analysis and writing.

Chapter 3: This chapter is formatted as a stand-alone manuscript based on a published study. Gibbin, E. M., Putnam, H. M., Davy, S. K., and Gates, R. D. (2014) Intracellular $\mathrm{pH}$ and its response to $\mathrm{CO}_{2}$-driven seawater acidification in symbiotic versus non-symbiotic coral cells. Journal of Experimental Biology 217: 1963-1969. doi: 10.1242/jeb.099549. H. M. Putnam assisted with experimental design, data analysis and writing, S. K. Davy and R. D. Gates assisted with experimental design and writing.

Chapter 4: This chapter is formatted as a stand-alone manuscript and is currently 'under review'. Gibbin, E. M., Putnam, H. M., Gates, R. D., Nitschke, M. R. and Davy, S. K. Species-specific susceptibility to ocean acidification and cellular acidosis in reef corals is influenced by thermal sensitivity. H. M Putnam assisted with experimental design, data analysis and writing, S. K. Davy and R. D. Gates assisted with experimental design and writing, and M. R. Nitschke assisted with data collection. 
Chapter 5: This chapter is formatted as a stand-alone manuscript based on a published study. Gibbin, E. M. and Davy, S. K. (2014) The photo-physiological response of a model cnidarian-dinoflagellate symbiosis to $\mathrm{CO}_{2}$-induced acidification at the cellular level. Journal of Experimental Marine Biology and Ecology 457: 1-7. doi: 10.1016/j.jembe.2014.03.015. S. K. Davy assisted with experimental design, data analysis and writing.

All published papers are provided at the end of the thesis. 


\section{Chapter 2: Quantifying the effect of light on the intracellular pH of cultured Symbiodinium cells, freshly isolated symbionts and Aiptasia pulchella host cells}

\subsection{Introduction}

Coral reefs are both ecologically and socio-economically important, and their success is founded on the mutualistic endosymbiosis between corals and dinoflagellate algae of the genus Symbiodinium (Hoegh-Guldberg, 1999). However, despite the importance of the cnidarian-dinoflagellate symbiosis, we know very little about its underlying cell biology (Weis et al., 2008; Davy et al., 2012). This hampers our understanding of how coral reefs function, both under 'normal' conditions and projected scenarios of environmental stress. The genus Symbiodinium is exceptionally diverse, with nine genetically distinct clades (A-I), which are further differentiated into sub-clades termed 'types' (Pochon and Gates, 2010). There is substantial variation in physiology between genotypes, particularly with respect to their photosynthetic response to light (Hennige et al., 2009) and thermal tolerance (Fisher et al., 2012). These physiological differences have the potential to confer significant advantages/disadvantages to a coral and can influence a host's resistance to stress (Baker et al., 2004). Yet despite this, one of the most fundamental attributes of the symbiotic algal cell, its intracellular $\mathrm{pH}\left(\mathrm{pH}_{\mathrm{i}}\right)$ was, until now, unknown.

Virtually all metabolic activity is $\mathrm{pH}$-dependent. $\mathrm{pH}$ also plays a key role in controlling progression through the cell cycle, protein synthesis, and the synthesis of both DNA and RNA (Madshus, 1988). Furthermore, the establishment of a proton gradient across a cell membrane creates an electrochemical potential, which is important for maintaining the flux of ions between cells, and in inter-cell signalling (Casey et al., 2010). Little, however, is known of the role of $\mathrm{pH}$ in the function of the cnidarian-dinoflagellate symbiosis, despite its potential significance in the regulation of inorganic carbon and nitrogen fluxes between the host and symbiont (Fitt et al., 1995; Brownlee, 2009; Venn et al., 2009), and the coordination of host and symbiont cell proliferation (Davy et al., 2012). Moreover, $\mathrm{pH}_{\mathrm{i}}$ is also known to affect the formation of crystals during coral calcification (Venn et al., 2013). Indeed, only recently has the $\mathrm{pH}_{\mathrm{i}}$ of the host cell been measured, with the photosynthetic activity of 
the symbionts causing an alkalinisation of the host cell (Venn et al., 2009), proportional to the irradiance intensity experienced by the symbiont (Laurent et al., 2013a). The aim of this study was to develop a method for measuring the $\mathrm{pH}_{\mathrm{i}}$ of Symbiodinium cells, to measure $\mathrm{pH}_{\mathrm{i}}$ over a daily light cycle in a range of Symbiodinium types, and to compare the $\mathrm{pH}_{\mathrm{i}}$ of Symbiodinium with that of its host cell in the sea anemone Aiptasia pulchella, an important model for coral research.

\subsection{Methods}

\subsubsection{Experimental organisms}

Cultured A.pulchella anemones hosting Symbiodinium ITS2 type B1, were grown at $25 \pm 1^{\circ} \mathrm{C}$ and an irradiance of $80-100 \mu \mathrm{mol}$ photons $\mathrm{m}^{-2} \mathrm{~s}^{-1}$ on a $12 \mathrm{~h}$ light: $12 \mathrm{~h}$ dark cycle (Osram Dulux 36W/890 fluorescent bulbs). Anemones were kept in $0.22 \mu \mathrm{m}$ filtered seawater (FSW) under these conditions for six months prior to experimentation. During this time, anemones were fed with Artemia sp. nauplii every 3 days. Six Symbiodinium types (A1, B1, E1, E2, F1 and F5) were also examined. One of the types, E2, was cultured from a free-living dinoflagellate whilst the others were originally isolated from a range of invertebrate hosts including corals, anemones and jellyfish [Table 2.1, page 52]. The cultures were grown in FSW enriched with Guillard's f/2 media (AlgaBoost, AusAqua Pty Ltd., Wallaroo, SA, Australia) and maintained under the same light regime and temperature as the anemones. The cells were kept in logarithmic growth phase (approximately 100000 cells $\mathrm{mL}^{-1}$ ) by regular sub-culturing in new $\mathrm{f} / 2$ media. Prior to experimentation, the cultures were genetically identified according to the protocol described by Logan et al. (2010).

Briefly, a $1 \mathrm{~mL}$ sample of each culture was centrifuged for $6 \mathrm{~min}$ at $3000 \times g$, before being re-suspended in guanidinium solution $\left(100 \mathrm{~mL} \mathrm{H}_{2} \mathrm{O}, 100 \mathrm{~g}\right.$ guanidinium isothiocyanate, $10.6 \mathrm{~mL}$ tris(hydroxymethyl)aminomethane (Tris) $1 \mathrm{M} \mathrm{pH} \mathrm{7.6,} 4.25$ $\mathrm{mL}$ ethylenediaminetetraacetic acid (EDTA) $0.5 \mathrm{M} ; 4.24 \mathrm{~g}$ sarkosyl and $2.1 \mathrm{~mL}$ bmercaptoethanol) and left for five days at $4{ }^{\circ} \mathrm{C}$. The DNA that was extracted was then subjected to an optimised PCR protocol $\left(10 \mathrm{~min}\right.$ at $95^{\circ} \mathrm{C}$ followed by 39 cycles of 2 min at $94^{\circ} \mathrm{C}, 30 \mathrm{~s}$ at $55^{\circ} \mathrm{C}, 30 \mathrm{~s} 72^{\circ} \mathrm{C}$, and then $10 \mathrm{~min}$ at $72^{\circ} \mathrm{C}$ with the final hold 
temperature set to $14^{\circ} \mathrm{C}$ ) in conjunction with Symbiodinium-specific ITS2 primers. Forward primer: 5'-GTG AAT TGC AGA ACT CCG TG-3'. Reverse primer: 5'-CCT CCG CTT ACT TAT ATG CTT-3' (Logan et al., 2010). The PCR products were refined using PCR purification kits (Invitrogen, Auckland, New Zealand) and the resulting product was sent for to Macrogen Inc. (Seoul, Korea) for sequencing. The ITS2 sequences [Appendix A.1] were analysed using the Basic Local Alignment Search Tool (BLAST). All chemicals were obtained from Life Technologies, Auckland, New Zealand, unless stated otherwise.

\subsubsection{Developing a method for measuring the $p H_{i}$ of Symbiodinium cells}

BCECF (Molecular Probes, Invitrogen, Auckland, New Zealand) was used to measure the $\mathrm{pH}_{\mathrm{i}}$ of Symbiodinium cells. The dye was dissolved in dimethyl sulfoxide (DMSO) at $1 \mathrm{mg} \mathrm{mL} \mathrm{m}^{-1}$ and stored at $-20^{\circ} \mathrm{C}$ until required. $\mathrm{BCECF}$ is non-fluorescent until it enters the cell, where it is cleaved by intracellular esterases. The fluorescence emission spectrum of BCECF then becomes pH-dependent [Fig. 2.1A]. With a $\mathrm{pK}_{\mathrm{a}}$ of 7.0, BCECF is a particularly useful dye for measuring changes in eukaryotic cells (usually $\mathrm{pH}_{\mathrm{i}} 6.8-7.4$ ). As such, it has been widely used to measure $\mathrm{pH}_{\mathrm{i}}$ (Dixon et al., 1989; Hervé et al., 2012; Ozkan and Mutharasan, 2002) and has been successfully used in conjunction with flow cytometry (FCM) in other model systems (Franck et al., 1996). It was selected here for its strong dual excitation properties that allow $\mathrm{pH}_{\mathrm{i}}$ to be measured without interference from chlorophyll auto-fluorescence ( $>640 \mathrm{~nm})$.
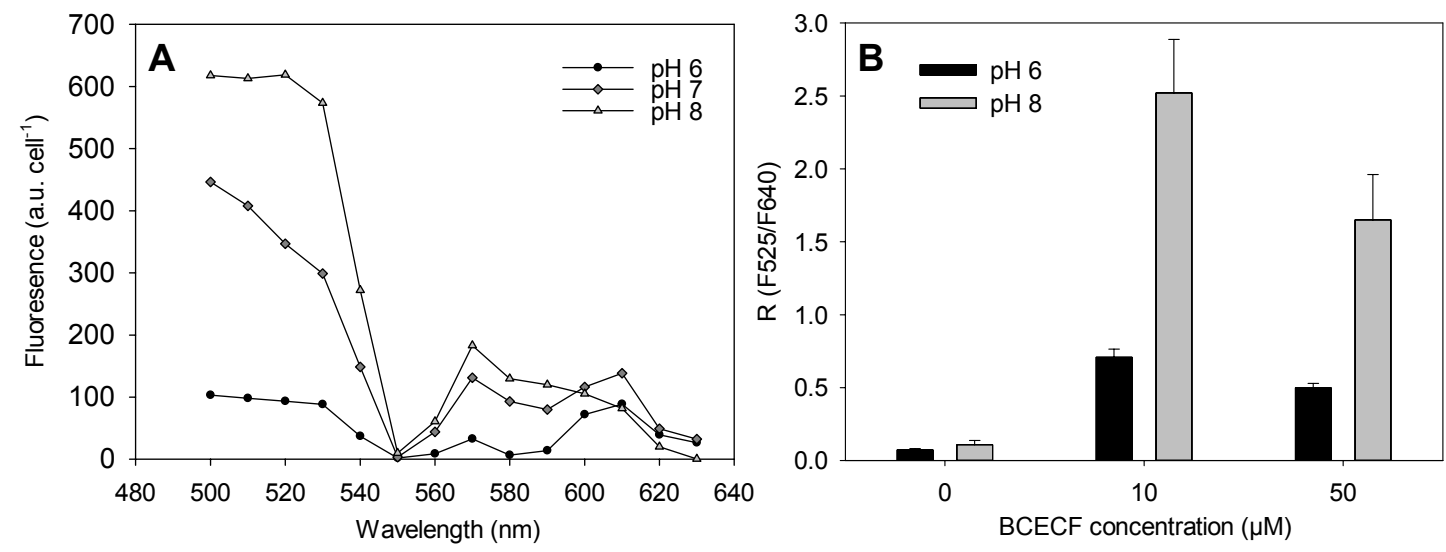

Fig. 2.1 Visualising the spectral emission of BCECF-AM ester at the acidic and the basic endpoints of the calibration ( $\mathrm{pH} 6$ and $\mathrm{pH}$ 8) and at the dyes $\mathrm{pK}_{\mathrm{a}}(\mathrm{pH} 7)$. (A) Typical lambda scans of BCECF inside Symbiodinium cells, imaged after excitation with a $473 \mathrm{~nm}$ laser with emission recorded every $10 \mathrm{~nm}$. (B) Optimising the concentration of BCECF-AM ester to produce the greatest shift in the ratio of fluorescence at the limiting ends of the calibration. 
Confocal microscopy (Fluoview 1000, Olympus, Pennsylvania, USA) was initially used to confirm that the BCECF was able to enter the cells [Fig. 2.2A], to check for dye homogeneity through the cell [Fig. 2.2B] and to check that neither centrifugation nor vortexing had damaged the cells. A $10 \mathrm{~mL}$ sample of cultured Symbiodinium cells (homologous type B1) was centrifuged for $5 \mathrm{~min}$, at $1000 \times \mathrm{g}$, at a temperature of $20^{\circ} \mathrm{C}$. The algal pellet was then re-suspended in FSW at a density of $1 \times 10^{6}$ cells $\mathrm{mL}^{-}$ 1. A $1 \mathrm{~mL}$ aliquot was then taken and incubated with $10 \mu \mathrm{M}$ of BCECF ester in the presence of $0.01 \%$ pluronic F-127 (Molecular Probes, Invitrogen, Auckland); a nonionic surfactant that reduces dye aggregation. Preliminary studies confirmed that this concentration of dye produced the greatest difference in fluorescence at both the acidic and basic endpoints of the calibration i.e. $\mathrm{pH} 6$ and 8 [Fig. 2.1B]. The dyeloaded sample was then placed on an orbital shaker set to 250 RPM and incubated in the dark for $20 \mathrm{~min}$. The sample was then thoroughly vortexed and $300 \mu \mathrm{L}$ was pipetted into a poly-d-lysine coated glass-bottom culture dish (MatTek Corporation, Ashland, Massachusetts, USA). The cells were left to settle for $15 \min$ before $50 \mu \mathrm{L}$ of carboxymethyl cellulose (CMC) was added to immobilise the cells. Individual Symbiodinium cells were imaged using a 1.45 NA $\times 100$ oil immersion lens, with sequential excitation provided by $405 \mathrm{~nm}$ and $473 \mathrm{~nm}$ lasers.
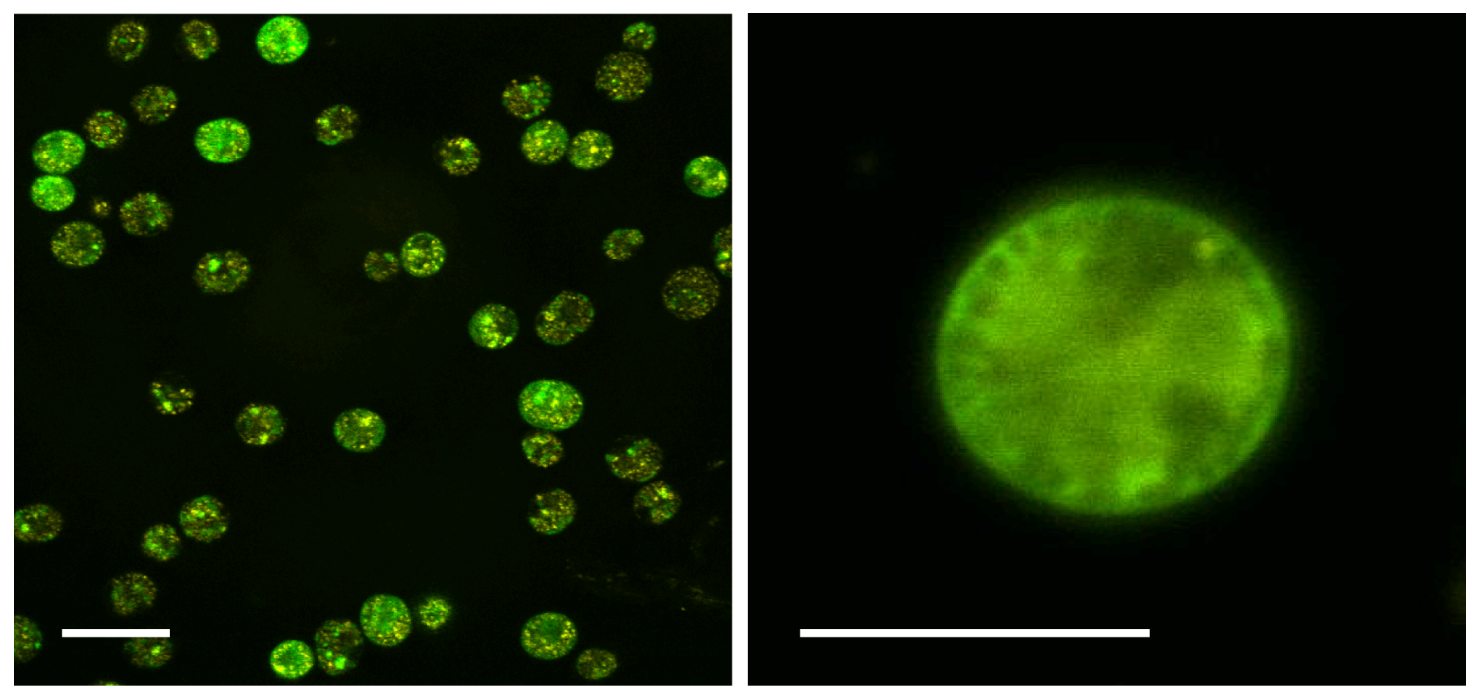

Fig. 2.2 Quantifying the $\mathrm{pH}_{\mathrm{i}}$ of Symbiodinium. (A) Confocal microscope image of Symbiodinium cells loaded with $10 \mu \mathrm{M}$ of the $\mathrm{pH}$-sensitive BCECF-AM ester, imaged after excitation with both 405 and $473 \mathrm{~nm}$ lasers, with fixed emission at $535 \pm 10 \mathrm{~nm}$. Scale bar represents $20 \mu \mathrm{m}$. (B) 'Z Z-stack' $(\mathrm{z}=5)$ image of a single Symbiodinium cell imaged under the aforementioned conditions. Scale bar represents $10 \mu \mathrm{m}$. While the dye consistently labelled cells, including their cytoplasm, note its uneven intracellular distribution. This was most likely caused by selective accumulation into certain organelles. 
Each cell was imaged ten times in the z-plane with fluorescence detection fixed at 535 $\pm 10 \mathrm{~nm}$ as this produced the greatest relative shift in fluoresence [Fig. 2.1A], and therefore the highest resolution of changes in $\mathrm{pH}_{\mathrm{i}}$. Confocal settings were kept constant between images to ensure that measurements were comparable between treatments. Visual comparisons between dye-loaded cells and control cells confirmed that the dye was able to enter the cells but that the fluorescence was not homogenous through the cell. This could either be an artefact caused by selective accumulation in certain organelles (e.g. the nucleus and mitochondria; Weinlich et al., 1998) or could reflect regional $\mathrm{pH}$ differences between organelles (e.g. acidic endosomal vacuoles; Casey et al., 2010). Furthermore, Symbiodinium cells contain auto-fluorescent 'inclusion bodies' that, when excited by blue light, have the potential to interfere with fluorescence measurements (Kazandjian et al., 2008). In this respect, FCM is a very useful tool because it averages the fluorescence signal across each cell and measures large numbers of cells simultaneously, reducing the effect of inter-cellular variability.

\subsubsection{In vivo calibration of $\mathrm{pH}_{i}$ with nigericin}

In vivo calibration of BCECF was carried out using a high-potassium buffer series in combination with the $\mathrm{K}^{+} / \mathrm{H}^{+}$ionophore nigericin. This is a widely used technique to calibrate pH-sensitive dyes (Weinlich et al., 1998; Buckler and Vaughan-Jones, 1990; Venn et al., 2009; Taylor et al., 2011; Suffrian et al., 2011). Nigericin eliminates the trans-membrane $\mathrm{K}^{+}$gradient making the plasma membrane permeable to the buffer surrounding the cells. The buffers were created by adding $60 \mathrm{mM} \mathrm{Na}^{+}, 200 \mathrm{mM} \mathrm{K}^{+}$, and $190 \mathrm{mM} \mathrm{Cl}^{-}$to distilled water in the presence of either $20 \mathrm{mM}$ 2-[N-morpholino] ethanesulfonic acid (MES) for acidic buffers (pH 6 - 6.8), or $20 \mathrm{mM}$ Tris for basic buffers ( $\mathrm{pH} 7$ - 8). Mannitol was added as appropriate to adjust the osmolarity of each solution to 1100 mosm $\mathrm{L}^{-1}$, to mimic the cnidarian intracellular environment of cnidarians (Herrera et al., 1989; Goiran et al., 1997; Venn et al., 2009). A series of pH solutions were created at $0.2 \mathrm{pH}$ unit intervals between $\mathrm{pH} 6$ and $\mathrm{pH} 8$, by the addition of $\mathrm{HCl}$ or $\mathrm{NaOH}$ as appropriate. The calibration was then performed using homologous Symbiodinium cells (ITS2 type B1) in culture. The cells were sampled and dye-loaded as described previously, before being resuspended in the calibration buffers mixed with $5 \mu \mathrm{L}$ of nigericin (Molecular Probes, Invitrogen, Auckland, New Zealand) and transferred to a flow cytometer (FACScan, Becton Dickinson, New 
Jersey, USA). The dye was excited with a $488 \mathrm{~nm}$ argon laser and fluorescence was captured in linear collection mode using the 515-545 nm (FL1) and 564-606 nm (FL2) filter channels. Prior optimisation of the FCM settings, based on forward scatter (FSC) a proxy for particle size, and chlorophyll- $a$ (Chl- $a$ ), ensured that only Symbiodinium cells were counted, excluding any remaining bacteria and/or cellular debris in the samples. 5,000 individual cells were recorded in each sample [Fig. 2.3].

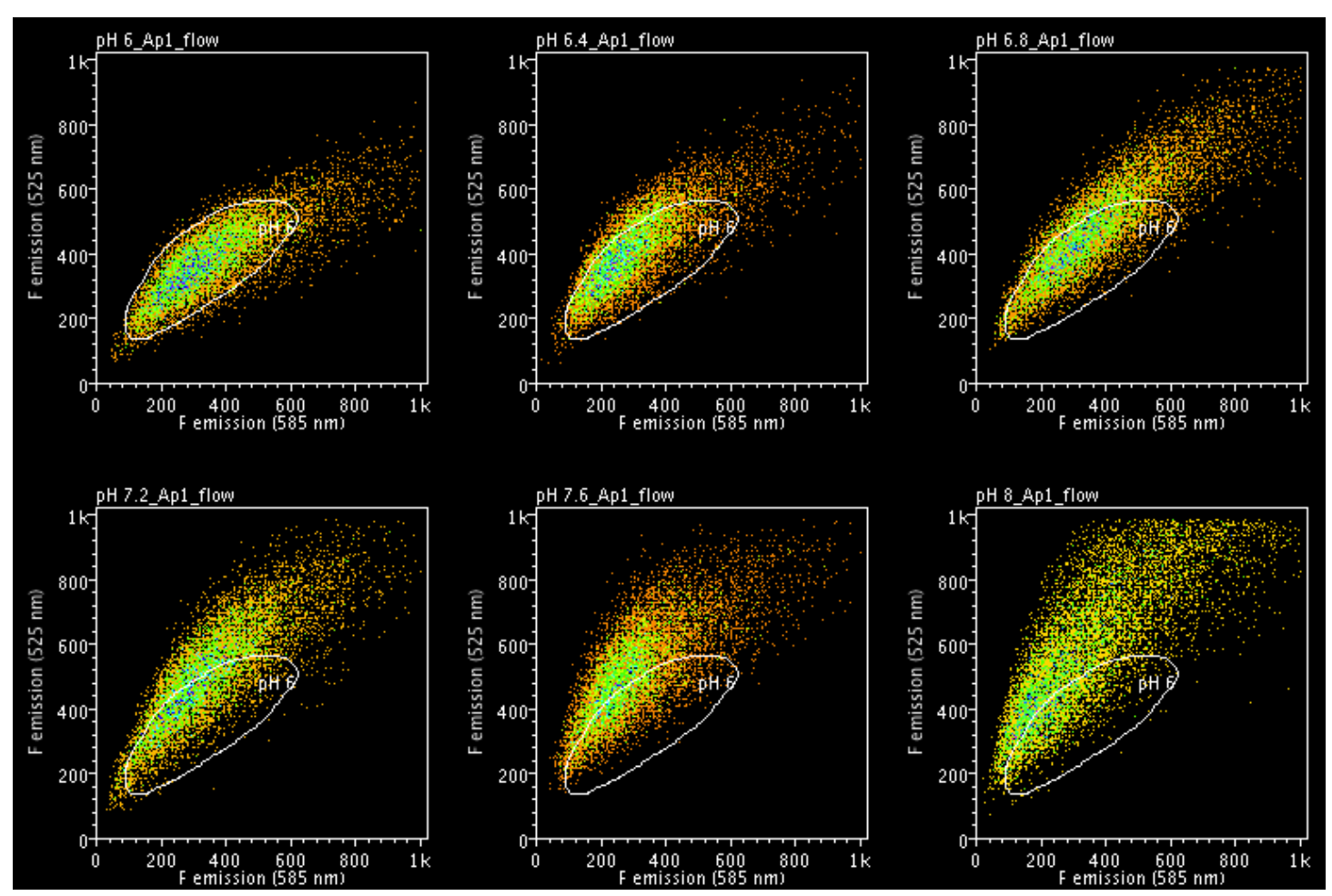

Fig. 2.3 In vivo flow cytometer calibration of Symbiodinium cells loaded with BCECF and resuspended in a range of calibration buffers in the presence of nigericin. Each dot represents a single Symbiodinium cell, and dots are coloured according to their density (5000 cells per plot; red for individual cells, yellow-orange for $>100$ cells, green-purple for $>500$ cells). The white gate is placed around the position of the population at $\mathrm{pH} 6$ to highlight the shift in fluorescence (y-axis; FL1 channel; 515-545 nm) caused by increasing intracellular $\mathrm{pH}$.

Initial processing of the FACScan files was completed in CellQuest Pro (BD Biosciences), with detailed analysis performed in the program Weasel (Walter + Eliza Hall Institute of Medical Research, Melbourne, Australia). For each individual cell the fluorescence intensity ratio (R) was calculated as emission at FL1 / FL2 [Fig 2.4A]. R was then related to $\mathrm{pH}$ by the following ratiometric equation: $\mathrm{pH}=\mathrm{pK}_{\mathrm{a}}-\log [\mathrm{R}-$ $\left.\mathrm{R}_{\mathrm{B}} / \mathrm{R}_{\mathrm{A}}-\mathrm{R} \times \mathrm{F}_{\mathrm{B}(\mathrm{FL} 1)} / \mathrm{F}_{\mathrm{A}(\mathrm{FL} 1)}\right]$, where $\mathrm{F}$ represents the mean fluorescence per cell in channel FL1 at the acidic (A) and basic ( ${ }_{\mathrm{B}}$ ) limits of the calibration [Fig. 2.4B]. Using the logarithmic form of the equation minimises the impacts of non-uniform loading, leakage of dye out of the cell and photo-bleaching (Bright et al., 1989). 

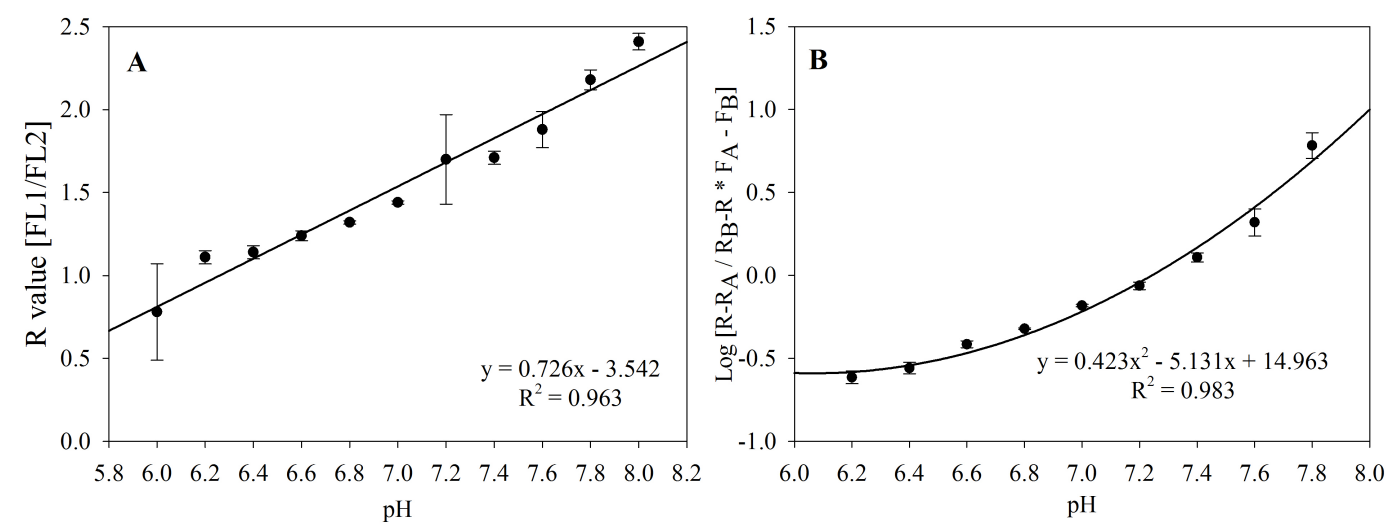

Fig. 2.4 In vivo calibration of intracellular $\mathrm{pH}$ in cultured B1 Symbiodinium cells. (A) The direct relationship between the fluorescence ratio (R; FL1 / FL2) of BCECF-AM and pH (mean values \pm S.E.M, $\mathrm{n}=3$ ). (B) $\mathrm{R}$ was related to $\mathrm{pH}$ according to the following logarithmic equation: $\mathrm{pH}=\mathrm{pK}_{\mathrm{A}}-\log \left[\mathrm{R}-\mathrm{R}_{\mathrm{A}} / \mathrm{R}_{\mathrm{B}}-\mathrm{R} * \mathrm{~F}_{\mathrm{A}} / \mathrm{F}_{\mathrm{B}}\right]$, where $\mathrm{F}$ is fluorescence intensity measured at in FL1 (515-545 nm), and the subscripts A and B represent the limiting values at the acidic and basic endpoints of the titration (i.e. $\mathrm{pH} 6$ and 8).

\subsubsection{Obtaining viable A. pulchella cells}

Viable endodermal cells (i.e. the host cell with its enclosed dinoflagellate symbiont) were isolated from A. pulchella [Fig. 2.5] using a protocol that was adapted from the method outlined in Gates et al. (1992).
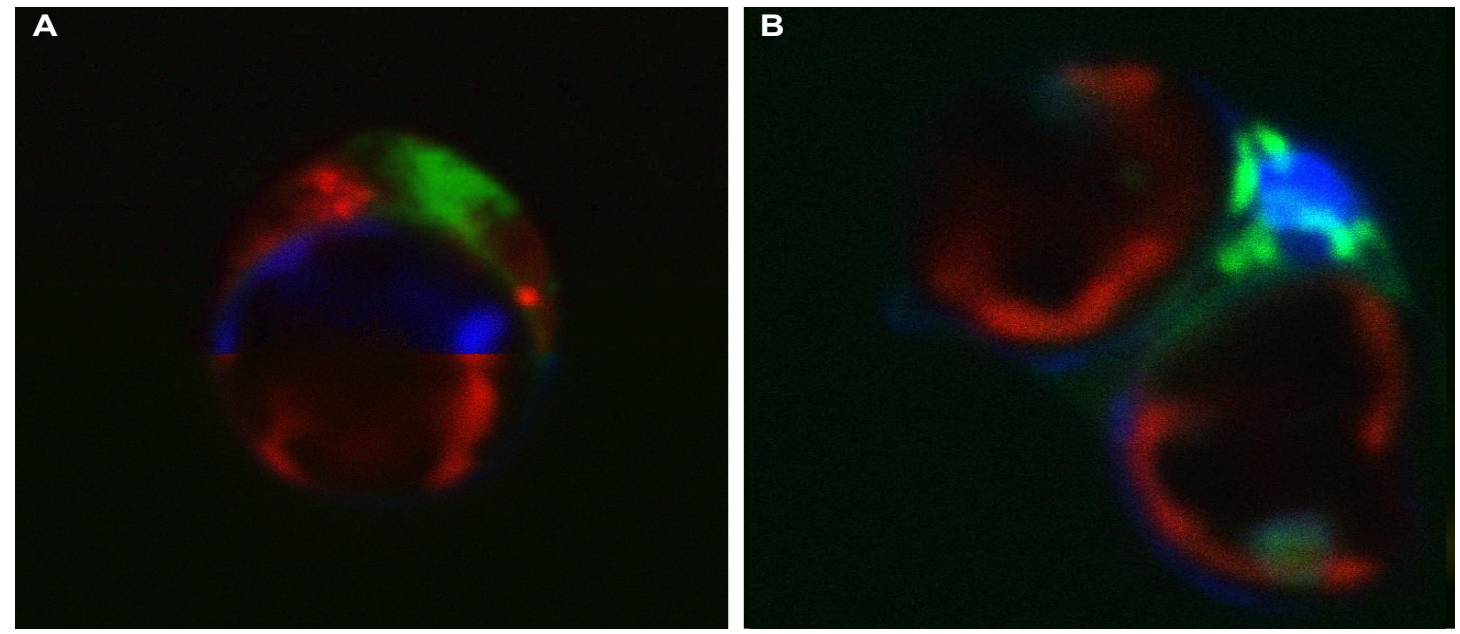

Fig. 2.5 Viable intact endodermal Aiptasia pulchella host cells. (A) Endodermal cell containing a single algal cell. (B) Endodermal cell containing two algal cells. Host cells stained with Fluorescein Diacetate (FDA), Rhodamine 123 (R123) and Hoechst 33342. Colours represent the following: green $=$ functional host mitochondria stained with FDA (ex: $473 \mathrm{~nm}$, em: 510-550 nm), blue = host nuclear material (ex: $405 \mathrm{~nm}, \mathrm{em}: 440-490 \mathrm{~nm})$ and red $=$ chl- $a$ autofluoresence. 
Anemones were initially bathed in calcium-free seawater (CaFSW), a relaxant, for an hour to relax the organism and ensure the tentacles were extended. The tentacles were then removed and cut into lengths of approximately $100 \mu \mathrm{m}$. These were transferred between a series of glass slides containing $10 \mu \mathrm{L}$ CaFSW to remove excess mucus, before being placed in a watch glass, where the excess seawater removed, and $0.05 \%$ trypsin in CaFSW was added. The watch glass was then covered with parafilm to avoid evaporation, placed on an orbital mixer and agitated at $180 \mathrm{rpm}$ for $40 \mathrm{~min}$. The cells were transferred to a poly-d-lysine coated dish and left for $15 \mathrm{~min}$ for the cells to attach. After this time, the excess trypsin was removed and the cells were washed in the desired fluorescent dye, and incubated for $20 \mathrm{~min}$ before being transferred to the confocal microscope for imaging. Initially cells were loaded with a combination of dyes, designed to test the viability and structural conformity of cells following isolation. These were: $5 \mu \mathrm{M}$ Fluorescein Diacetate (FDA), $5 \mu \mathrm{M}$ Rhodamine 123 (R123) and $5 \mu \mathrm{g} / \mathrm{mL}$ of Hoechst 33342 [Fig. 2.5].

\subsubsection{Measuring the $p H_{i}$ of A. pulchella cells}

Cells were isolated using the protocol described above, however this time the cells were loaded with $10 \mu \mathrm{M}$ SNARF-4F AM-ester in the presence of $0.01 \%$ pluronic F127 , and $5 \mu \mathrm{L}$ of nigericin.

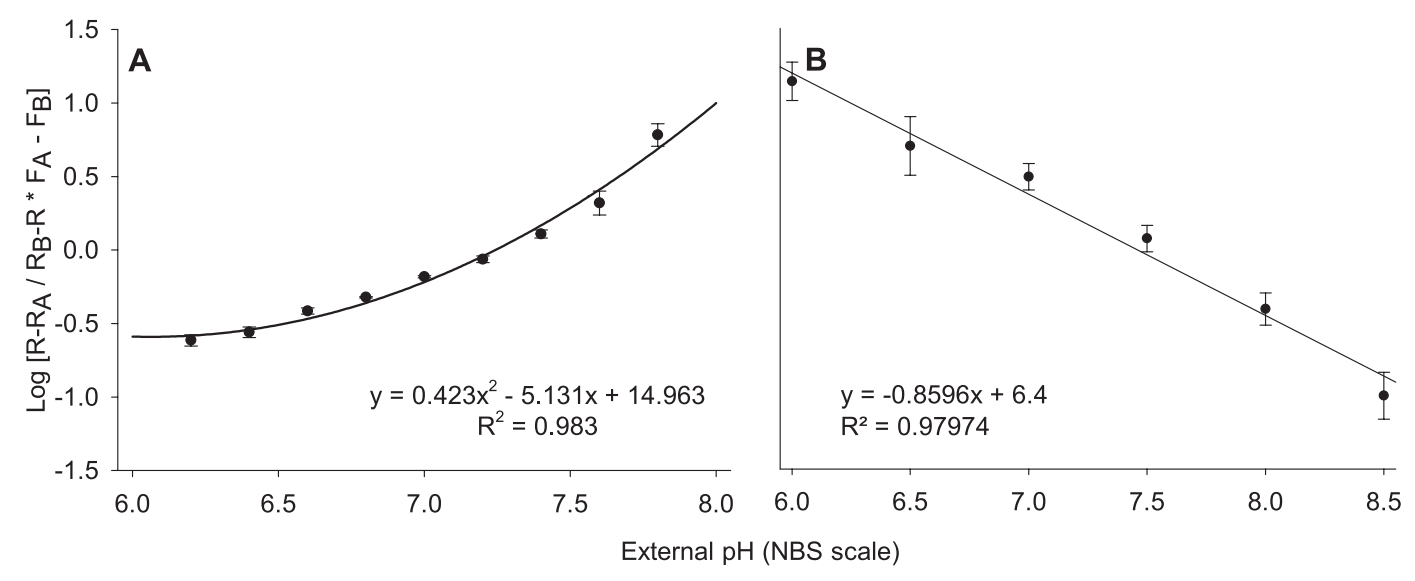

Fig. 2.6 In vivo calibration curve of SNARF-4F on the confocal microscope. (A) The direct relationship between $\mathrm{R}$ and $\mathrm{pH}$ (mean \pm S.E.M). (B) R-value $\left(\mathrm{F}_{(546 \mathrm{~nm})} / \mathrm{F}_{(635 \mathrm{~nm})}\right)$ log-transformed at each $\mathrm{pH}$ by the equation $\mathrm{pH}=\mathrm{pK}_{\mathrm{a}}-\log \left[\mathrm{R}-\mathrm{R}_{\mathrm{B}} / \mathrm{R}_{\mathrm{A}}-\mathrm{R} \times \mathrm{F}_{\mathrm{B}(635 \mathrm{~nm})} / \mathrm{F}_{\mathrm{A}(635 \mathrm{~nm})}\right]$, where $\mathrm{R}$ represents the ratio of fluorescence at $546 \pm 10 \mathrm{~nm} /$ fluorescence at $635 \pm 10 \mathrm{~nm}$, and $\mathrm{F}$ represents the mean fluorescence per cell at $635 \mathrm{~nm}$ at the acidic (A) and basic (B) endpoints of the titration (i.e. $\mathrm{pH} 6$ and 8.5). 
Calibration buffers were created at $0.5 \mathrm{pH}$ unit intervals between $\mathrm{pH} 6$ and $\mathrm{pH} 8.5$ as described previously. The fluorescent stain was then washed off with the calibration buffer and $50 \mu \mathrm{L}$ of CMC were added to immobilise the cells. The dish was transferred to the confocal microscope (Fluoview 1000, Olympus, Pennsylvania, USA) where the cells were excited with a $559 \mathrm{~nm}$ laser, and individual cells were imaged with the pinhole set at 1.51 units using a $\times 100$ oil immersion lens. Fluorescence emission was captured at $585 \pm 10 \mathrm{~nm}$ and $635 \mathrm{~nm} \pm 10 \mathrm{~nm}$ and recorded within the region of interest (ROI). Each cell was imaged 10 times in the zplane to produce the calibration curves [Fig. 2.6].

\subsubsection{Experimental design}

The effect of irradiance (12 h light adaptation at 80-100 $\mu \mathrm{mol}$ photons $\mathrm{m}^{-2} \mathrm{~s}^{-1}$ and $12 \mathrm{~h}$ of dark adaptation) on $\mathrm{pH}_{\mathrm{i}}$ was quantified in freshly isolated and cultured Symbiodinium cells, and in A. pulchella host cells. For freshly isolated algal cells, individual anemones $(\mathrm{n}=10$ per treatment) were exposed to light or dark before being homogenised in $500 \mu \mathrm{L}$ of FSW in a hand-held glass tissue grinder. The resulting slurry was transferred to a $1.5-\mathrm{mL}$ microcentrifuge tube and centrifuged for $5 \mathrm{~min}$ at $1000 \times g, 25^{\circ} \mathrm{C}$ to separate the algal fraction from host tissue. The supernatant was discarded and the Symbiodinium pellet washed twice in FSW before the pellet was resuspended in FSW at a final density of $1 \times 10^{6}$ cells $\mathrm{mL}^{-1}$ and incubated with $10 \mu \mathrm{M}$ of BCECF-AM ester and 0.01\% Pluronic F-127.

Cultured cells were grown in 250-mL flasks before being exposed to the same light or dark treatment as before $(n=3$ per treatment $)$. An aliquot $(10 \mathrm{~mL})$ was sampled from each flask, centrifuged for $5 \mathrm{~min}$ at $1000 \times \mathrm{g}$, and re-suspended in FSW to give a final density of $1 \times 10^{6}$ cells $\mathrm{mL}^{-1}$. The samples were then dye-loaded while maintaining them under their experimental conditions. Similarly, to quantify the $\mathrm{pH}_{\mathrm{i}}$ of host cells, individual anemones $(n=10$ per treatment) were exposed to light and dark as described above, after which viable endodermal cells were isolated following the protocol summarised above. In all cases, $\mathrm{pH}_{\mathrm{i}}$ was then quantified using the methods stated previously. 


\subsection{Results}

The $\mathrm{pH}_{\mathrm{i}}$ of freshly isolated Symbiodinium cells and A. pulchella host cells was $7.10 \pm$ 0.02 and $6.86 \pm 0.04$ (mean \pm S.E.M) in the dark, increasing significantly (two-way ANOVA, $\left.F_{1,51}=12.219, \mathrm{p}=0.001\right)$ to $7.25 \pm 0.01$ and $7.02 \pm 0.06$ in the light, respectively. Both the host cell and the symbiont responded in the same manner to irradiance $\left(\mathrm{F}_{1,51}=0.064, \mathrm{p}>0.05\right)$, though the $\mathrm{pH}_{\mathrm{i}}$ of the host cell was significantly lower than that of the symbiont at all times $\left(\mathrm{F}_{1,51}=26.325, \mathrm{p}<0.001\right)$.

In the cultured Symbiodinium cells, genotypic differences in $\mathrm{pH}_{\mathrm{i}}$ were apparent irrespective of the light/dark regime (two-way ANOVA, $\mathrm{F}_{5,24}=2.896, \mathrm{p}=0.035$ ). Post hoc analysis could not pinpoint where these genotypic differences lay (Tukey's HSD, $p>0.05$ for all comparisons), though of note types E2 and F1 generally had the lowest values in both the light and dark [Table 2.1]. Light again significantly enhanced $\mathrm{pH}_{\mathrm{i}}\left(\mathrm{F}_{1,24}=73.784, \mathrm{p}<0.001\right)$, with a similar response witnessed in all Symbiodinium types $\left(\mathrm{F}_{5,24}=1.192, \mathrm{p}=0.343\right)$.

Table 2.1 Cultured Symbiodinium types categorised by the internal transcribed spacer 2 (ITS2) region of the nuclear $\mathrm{rDNA}$, the host they were first isolated from, and the $\mathrm{pH}_{\mathrm{i}}$ after 12 $\mathrm{h}$ light adaptation and $12 \mathrm{~h}$ dark adaptation (mean \pm S.E.M; $\mathrm{n}=3$ ).

\begin{tabular}{|c|c|c|c|c|c|}
\hline $\begin{array}{c}\text { Culture } \\
\text { name }\end{array}$ & Original host & Location & $\begin{array}{l}\text { Clade } \\
\text { (ITS2) }\end{array}$ & $\begin{array}{c}\text { Light- } \\
\text { adapted } \mathrm{pH}_{\mathrm{i}}\end{array}$ & $\begin{array}{c}\text { Dark- } \\
\text { adapted } \mathrm{pH}_{\mathrm{i}}\end{array}$ \\
\hline $\begin{array}{l}\text { CCMP } \\
2467\end{array}$ & $\begin{array}{l}\text { Stylophora } \\
\text { pistillata }\end{array}$ & Gulf of Aqaba, Jordan & $\mathrm{A}(\mathrm{A} 1)$ & $7.33 \pm 0.03$ & $7.10 \pm 0.03$ \\
\hline Ap1 & $\begin{array}{l}\text { Aiptasia } \\
\text { pulchella }\end{array}$ & Okinawa, Japan & $\mathrm{B}(\mathrm{B} 1)$ & $7.32 \pm 0.01$ & $7.14 \pm 0.01$ \\
\hline FlCass & $\begin{array}{l}\text { Cassiopea } \\
\text { xamachana }\end{array}$ & Florida, USA & $\mathrm{E}(\mathrm{E} 1)$ & $7.27 \pm 0.04$ & $7.14 \pm 0.03$ \\
\hline $\begin{array}{c}\text { CCMP } \\
421\end{array}$ & $\begin{array}{l}\text { Free-living } \\
\text { dinoflagellate }\end{array}$ & $\begin{array}{l}\text { Wellington Harbour, } \\
\text { New Zealand }\end{array}$ & $\mathrm{E}(\mathrm{E} 2)$ & $7.21 \pm 0.04$ & $7.08 \pm 0.03$ \\
\hline $\mathrm{Mv}$ & $\begin{array}{c}\text { Montipora } \\
\text { verrucosa }\end{array}$ & Hawai'i, USA & $\mathrm{F}(\mathrm{F} 1)$ & $7.23 \pm 0.08$ & $7.06 \pm 0.17$ \\
\hline $\mathrm{Pd}$ & $\begin{array}{l}\text { Pocillopora } \\
\text { damicornis }\end{array}$ & Hawai'i, USA & $\mathrm{F}(\mathrm{F} 5)$ & $7.39 \pm 0.02$ & $7.12 \pm 0.27$ \\
\hline
\end{tabular}




\subsection{Discussion}

This study provides valuable information on $\mathrm{pH}_{\mathrm{i}}$ in $\mathrm{A}$. pulchella, an important model system for the study of the cnidarian-dinoflagellate symbiosis (Weis et al., 2008). However, more importantly, I describe a method for measuring $\mathrm{pH}_{\mathrm{i}}$ in Symbiodinium and show genotypic diversity in this parameter. While this method provides resolution at the level of the whole cell rather than the specifics of the intracellular environment, it enables the rapid measurement of large numbers of cells simultaneously.

The $\mathrm{pH}_{\mathrm{i}}$ values quantified in this study fall within those expected for eukaryotic cells, which typically maintain their cytosolic pH between 7 - 7.4 (Madshus, 1988), and are similar to light-adapted $\mathrm{pH}_{\mathrm{i}}$ values measured in other marine algae (Lane and Burris, 1981). Furthermore, the more alkaline $\mathrm{pH}_{\mathrm{i}}$ of Symbiodinium seen in the light than in the dark was consistent with the effect of light observed in higher plants (Yin et al., 1990). Light-induced alkalinisation is likely a by-product of physiological changes in the Symbiodinium cell's cytoplasm during photosynthesis. In particular, $\mathrm{CO}_{2}$ and $\mathrm{H}_{2} \mathrm{O}$ exist in equilibrium with $\mathrm{H}_{2} \mathrm{CO}_{3}$, so when $\mathrm{CO}_{2}$ is removed for photosynthesis it causes an increase in the conversion of $\mathrm{HCO}_{3}{ }^{-}$to $\mathrm{H}_{2} \mathrm{CO}_{3}$, a process that consumes protons $\mathrm{H}^{+}$ (Allemand et al., 1998). Conversely, the subsequent reduction of $\mathrm{pH}_{\mathrm{i}}$ in the dark is likely to be a consequence of respiration, as the products, $\mathrm{CO}_{2}$ and $\mathrm{H}_{2} \mathrm{O}$, react to form $\mathrm{HCO}_{3}{ }^{-}$and $\mathrm{H}^{+}$. It is therefore perhaps unsurprising that the $\mathrm{pH}_{\mathrm{i}}$ of Symbiodinium cells, the sites of photosynthesis in the symbiosis, is higher than that of the surrounding host cell in the light. Why this pattern is also present in the dark, however, is at present unclear. One possibility is that dark aerobic respiration may be greater in the host cell than the symbiont, resulting in a build up of $\mathrm{CO}_{2}$ in the cell and thus reducing $\mathrm{pH}_{\mathrm{i}}$. Alternatively, the higher $\mathrm{pH}_{\mathrm{i}}$ of the symbiont in the dark could be a consequence of residual dark or heterotrophic $\mathrm{CO}_{2}$ fixation. Interestingly, the $\mathrm{pH}_{\mathrm{i}}$ in the A. pulchella host cell mirrored the light-response seen in the symbiont. This has also been observed in host cells of the coral S. pistillata and the anemone Anemonia viridis (Venn et al., 2009), highlighting the inter-relationship between symbiont and host physiology. Indeed, recent research suggests that the $\mathrm{pH}$ of the host cell is directly dependent on the photosynthetic activity of its algal symbiont and, as such, any factor that either inhibits or enhances photosynthesis (e.g. irradiance) has the capability to influence the $\mathrm{pH}$ of the host cell (Laurent et al., 2013a). 
The physiological and genetic diversity within the genus Symbiodinium is now well known, though most studies have focused on photophysiological responses to environmental stresses (Fisher et al., 2012). We can now extend this physiological diversity to the $\mathrm{pH}_{\mathrm{i}}$. The basis for this difference is unknown as, while it might be expected that differences in photosynthetic performance and/or efficiency (Hennige et al., 2009) could lead to a difference in $\mathrm{pH}_{\mathrm{i}}$ in the light, genotypic differences were also maintained in the dark. Further research however, is needed to elucidate this matter, both in the Symbiodinium types tested here and across a range of types.

The cultures investigated here included two B1 strains, one that was freshly isolated from $A$. pulchella and the other that was grown ex hospite in culture. Interestingly, the light-adapted $\mathrm{pH}_{\mathrm{i}}$ was maintained significantly higher in the cultured Symbiodinium, despite both being exposed to identical light and temperature regimes. This is perhaps not surprising, as in hospite Symbiodinium are often DIC-limited (Goiran et al., 1996; Al-Moghrabi et al., 1996) and light-adapted $\mathrm{pH}_{\mathrm{i}}$ levels have been shown to correlate with the availability of carbon in the surrounding media (Nimer et al., 1997). It is also worth noting that the cultures in this study were grown in nutrient-enriched seawater, which would be much higher than those experienced in hospite (Koop et al., 2001), and so may not be entirely indicative of the implications of physiological diversity for symbiosis function. The novel techniques and findings presented in this chapter, do however build on the important work of Venn and coworkers (Venn et al., 2009), by providing a means of studying both partners in this ecologically important symbiosis, and addressing how the symbiosis may be impacted by the increasing global threat of ocean acidification. 


\section{Chapter 3: Intracellular $\mathrm{pH}$ and its response to $\mathrm{CO}_{2}$-driven seawater acidification in symbiotic versus non-symbiotic coral cells}

\subsection{Introduction}

Reef building corals depend on a symbiotic association with photosynthetic dinoflagellates of the genus Symbiodinium for survival. This intimate partnership evolved in the mid-Triassic period (Muscatine et al., 2005) and coral reefs have prospered in tropical oceans, particularly in areas characterised by high degrees of environmental stability (Hoegh-Guldberg, 1999). Corals have adapted to live within narrow physiological limits, and are highly sensitive to fluctuations in the surrounding environment (Jones et al., 1998). Rising sea surface temperatures (Hoegh-Guldberg et al., 2007) and the increasing acidity of the ocean (Orr et al., 2005) are threatening the stability of coral-dinoflagellate symbioses, leading to dire projections for the future of coral reefs (Pandolfi et al., 2011; Silverman et al., 2009). At present, our ability to accurately predict the response of corals to global climate change is severely hampered by our limited understanding of the cellular mechanisms that underpin coral-dinoflagellate symbiosis (Fabry et al., 2008; Weis et al., 2008; Davy et al., 2012), which ultimately frame how corals respond to environmental stress.

Intracellular $\mathrm{pH}\left(\mathrm{pH}_{\mathrm{i}}\right)$ is critical for virtually all elements of cellular homeostasis (Smith and Raven, 1979), directly influencing protein structure, enzymatic rates and membrane solubility (Madshus, 1988). The maintenance of $\mathrm{pH}$ within an optimal functional range therefore plays a critical role in determining the metabolic activity of the cell, and is specific to the metabolic pathway in question. Consequently, eukaryotic cells have evolved compartmentalised organelles to provide sites with specific $\mathrm{pH}$ conditions within the cell for different metabolic activities to occur (Casey et al., 2010). Disruptions to the $\mathrm{pH}_{\mathrm{i}}$ have serious physiological consequences (Pörtner et al., 2004; Fabry et al., 2008; Hofmann et al., 2013). Indeed, a drop as small as $0.1-0.2 \mathrm{pH}_{\mathrm{i}}$ units can induce metabolic depression (Reipschläger and Pörtner, 1996), so it is not surprising that changes in $\mathrm{pH}_{\mathrm{i}}$ are stringently avoided (Casey et al., 2010). In general, eukaryotic cells are protected from fluctuations in their $\mathrm{pH}_{\mathrm{i}}$ at two levels. Acute, localised changes in $\mathrm{pH}_{\mathrm{i}}$, such as those arising from metabolic 
reactions, are neutralised by manipulating the various weak acids and bases in the cytosol (Casey et al., 2010). Longer-term changes are buffered by more permanent mechanisms such as transmembrane exchangers (Boron, 2004). The mechanisms involved in $\mathrm{pH}$ regulation are not well understood in corals, and this is partly due to the intrinsic complexity associated with their endosymbiosis. By virtue of their intracellular location, the Symbiodinium cells can essentially be regarded as heavily fortified organelles belonging to the coral host cell. However, unlike other organelles, Symbiodinium cells, through their photosynthetic activity, are able to exert significant control over the $\mathrm{pH}$ of the surrounding host cell (Venn et al., 2009; Laurent et al., 2013a). Consequently, the response of corals to a change in ambient $\mathrm{CO}_{2} / \mathrm{pH}$, is likely to be influenced by their own physiological capacity and that of their symbionts (McCulloch et al., 2012).

In this chapter, I investigate how the presence/absence of symbionts affects the response of $\mathrm{pH}_{\mathrm{i}}$ to $\mathrm{CO}_{2}$-driven seawater acidification in cells isolated from the Hawaiian reef coral Pocillopora damicornis (Linnaeus, 1758). Using the fluorescent dye BCECF, in conjunction with live cell imaging, I characterise the response of $\mathrm{pH}_{\mathrm{i}}$ (National Bureau of Standards scale; NBS) in Symbiodinium cells freshly isolated from coral hosts, isolated non-symbiotic coral cells, and isolated coral host cells with their symbionts intact. The cells were exposed to control seawater $(\mathrm{pH} 7.8)$ and $\mathrm{CO}_{2}-$ acidified seawater, designed to expose the cells to a gradient of declining external $\mathrm{pH}$ $\left(\mathrm{pH}_{\mathrm{e}} 7.8\right.$ - 6.8) over $105 \mathrm{~min}$, to mimic diurnal changes in $\mathrm{pH}$ in reef water due to reef photosynthesis, respiration, and calcification (Hofmann et al., 2011; Price et al., 2012), which are particularly strong in Kaneohe Bay (Putnam, 2012). In both treatments, the cells were exposed to saturating white light in the presence and absence of the photosynthetic inhibitor DCMU, with measurements of both $\mathrm{pH}_{\mathrm{i}}$ and $\mathrm{pH}_{\mathrm{e}}$ taken every $15 \mathrm{~min}$ for $105 \mathrm{~min}$. These findings demonstrate that $\mathrm{CO}_{2}$ addition initiates very different responses in the $\mathrm{pH}_{\mathrm{i}}$ of the symbiont compared to that of the coral host cell. Crucially, the results of this chapter suggest that the photosynthetic activity of the symbiont plays a key role in determining the intracellular buffering capacity of its coral host. 


\subsection{Methods}

\subsubsection{Coral collection and maintenance}

One large normally pigmented adult $P$. damicornis colony was collected three weeks prior to experimentation (in February 2013) from a shallow fringing reef $(<3 \mathrm{~m})$ in Kaneohe Bay, Hawaii. This single colony was cut into 50 genetically identical fragments $(4 \times 2 \mathrm{~cm})$ that were secured to $3 \times 3 \mathrm{~cm}$ plastic tiles with underwater expoxy (Z-spar, Splash Zone compound) and placed in a $50 \mathrm{~L}$ holding tank supplied with flowing seawater from Kaneohe Bay. Seawater chemistry was monitored frequently according to the recommended best practices for ocean acidification research and reporting (Riebesell et al., 2010), with daily measurements of salinity (psu) as well as pH (NBS scale) taken via the m-cresol dye method, stipulated in SOP 6B (Dickson et al., 2007); total alkalinity (TA) was measured on a weekly basis (Dickson et al., 2007). These characteristics were stable for the duration of the experiment, with an average salinity of $35.5 \pm 0.1 \mathrm{ppt}$, $\mathrm{pH}$ of $7.8 \pm 0.1$ and a TA of $2166 \pm 25$ (mean \pm S.E.M, $\mathrm{n}=5$ ). It is important to note that the $p \mathrm{CO}_{2}$ of seawater in Kaneohe Bay is markedly higher than average oceanic conditions fluctuating between 450 and 650 ppm (Drupp et al., 2011; Putnam, 2012) and resulting in a lower ambient $\mathrm{pH}$. An ambient seasonal temperature of $22.6 \pm 0.3^{\circ} \mathrm{C}$ was maintained by a dual stage temperature controller (Aqualogic, TR115DN), while tanks were illuminated on a 12 h:12 h light/dark cycle by metal halide lights (Ice CapMetal Halide lights, $250 \mathrm{~W}$ DE $14 \mathrm{~K}$ bulbs, $250 \mathrm{~W}$ double-ended pendants), which, mounted on motorised light rails, moved back and forth to provide irradiances ranging between 3.85 and $328.85 \mu \mathrm{mol}$ photons $\mathrm{m}^{-2} \mathrm{~s}^{-1}$. This set-up ensured an even light field corresponding to an average irradiance of $125 \pm 10 \mu \mathrm{mol}$ photons $\mathrm{m}^{-2} \mathrm{~s}^{-1}$ was maintained over each coral fragment.

\subsubsection{Experimental Design}

Four experimental treatments were designed to investigate how $\mathrm{CO}_{2}$-addition influenced $\mathrm{pH}_{\mathrm{i}}$ (NBS scale) in cells isolated from the coral P. damicornis. Three symbiotic states were tested: (1) isolated Symbiodinium cells; (2) isolated nonsymbiotic host coral cells and (3) isolated host coral cells containing their symbiotic algae. Visual inspection (by both light and confocal microscopy) failed to establish 
conclusively whether isolated Symbiodinium cells were surrounded by an intact symbiosome membrane. Non-symbiotic host coral cells were classified as intact host cells not containing an algal symbiont. Typically $10 \mu \mathrm{m}$ in diameter and spherical, it is not known whether these cells were ecto- or endodermal in origin (see discussion). Finally, only symbiotic cells containing two algal cells were used for calculating the $\mathrm{pH}_{\mathrm{i}}$ change in symbiotic host coral cells. These were deemed the most suitable choice for two major reasons: (1) the host cell region of interest (ROI) is much larger in doublet cells than in host cells containing a single alga, making $\mathrm{pH}_{\mathrm{i}}$ measurements much easier (Venn et al., 2009); and (2) this cell type is found in much greater abundance than triplet cells (Houlbrèque et al., 2004). Furthermore, standardisation of symbiont number allowed for the possibility that this parameter influences host $\mathrm{pH}_{\mathrm{i}}$ (see discussion).

The cell and dye loading procedure was repeated five times for each treatment $(n=5)$ to achieve independent replicate cell preparations. Individual cells were then imaged every $15 \mathrm{~min}$ for $105 \mathrm{~min}$, with $\mathrm{pH}_{\mathrm{i}}$ calculated from the images taken. At each experimental time-point, $1.5 \mathrm{~mL}$ of seawater were carefully removed by pipette so as not to disrupt the cells and analysed for $\mathrm{pH}_{\mathrm{e}}(\mathrm{NBS}$ scale, $\mathrm{n}=5$ ) via the $\mathrm{m}$-cresol dye method described in SOP 6B (Dickson et al., 2007). The treatments were carried out under an external white light source, provided by a variable-irradiance fibre optic cable (Halogen Reflector lamp, 150W GX5.3 21V 1CT bulb, Philips, Somerset, New Jersey, USA) that produced a saturating irradiance of approximately $400 \mu \mathrm{mol}$ photons $\mathrm{m}^{-2} \mathrm{~s}^{-1}$ photosynthetically active radiation. Previous studies have shown that photosynthetic activity in the symbiont modifies the $\mathrm{pH}_{\mathrm{i}}$ of the host under normal $\mathrm{CO}_{2}$ conditions (Venn et al., 2009), so a preliminary measurement was performed with no additional $\mathrm{CO}_{2}$ added, in order to establish the control or baseline change in $\mathrm{pH}_{\mathrm{i}}$ caused by photosynthesis. This treatment was then repeated with $\mathrm{CO}_{2}$ addition $(5.0 \%$ setting on the incubation unit of the LSM 710 confocal microscope (Carl Zeiss, Oberkochen, Germany), resulting in a decreasing gradient of $\mathrm{pH}_{\mathrm{e}}$ over time. The negative controls were run in the light, as before, under zero and high $\mathrm{CO}_{2}$ conditions, but in the presence of $100 \mu \mathrm{M}$ DCMU in $0.1 \%$ acetone, a photosynthetic inhibitor that blocks the plastiquinone binding site of PSII and thus prevents the transfer of electrons and formation of ATP. DCMU is an effective inhibitor of photosynthesis 
that has been widely used in Symbiodinium research (Fitt et al., 1983; Iglesias-Prieto et al., 1992; Al-Horani et al., 2003; Takahashi et al., 2013).

\subsubsection{Isolation of cells and dye-loading procedure}

Coral fragments were selected randomly from the acclimation tank before the start of each experimental run. Cells were isolated immediately by gently brushing the tip of a partially submerged fragment in $50 \mathrm{~mL}$ of $0.22 \mu \mathrm{m}$ filtered seawater (FSW) using a soft bristle toothbrush. The resulting slurry was centrifuged for $5 \mathrm{~min}$ at $1700 \times g$. The supernatant was discarded and the pellet re-suspended in a further $50 \mathrm{~mL}$ FSW. An additional centrifugation step was introduced to wash the pellet and remove any residual host-generated mucus. This time when the supernatant was discarded, the pellet was resuspended in $1 \mathrm{~mL}$ FSW containing $10 \mu \mathrm{M}$ BCECF and $0.01 \%$ Pluronic F-127 with / without $100 \mu \mathrm{M}$ DCMU and $0.1 \%$ acetone depending on the treatment in question, to give a final concentration of approximately $1 \times 10^{6}$ cells $\mathrm{mL}^{-1}$. The dyeloaded cell suspension was then transferred to a $35 \mathrm{~mm}$ poly-d-lysine coated petri dish (MatTek Corporation, Ashland, Massachusetts, USA) and placed on the stage of a confocal microscope (LSM 710, Carl Zeiss, Oberkochen, Germany), where the cells were left to settle for $30 \mathrm{~min}$ in the dark at $22^{\circ} \mathrm{C}$. After dye loading, the cells were carefully washed twice in $1 \mathrm{~mL}$ FSW to remove any residual dye without dislodging cells from the surface of the dish. Finally, $6 \mathrm{~mL}$ FSW were added and the dish was placed in a closed-exchange live-cell chamber (PeCon, Erbach, Germany) before experimental treatments were carried out. All dyes used for microscopy were purchased from Invitrogen (Grand Island, New York, USA).

\subsubsection{Measurement of $\mathrm{pH}_{i}$ by confocal microscopy}

The fluorescent dye BCECF, in conjunction with confocal microscopy, has been widely used to study $\mathrm{pH}_{\mathrm{i}}$ in marine algae (Hervé et al., 2012) as its dual-excitation spectral properties allow fluorescence measurements to be taken that are not compounded by chlorophyll autofluoresence $(>640 \mathrm{~nm})$. In this study, confocal microscopy was conducted on a LSM 710 confocal microscope equipped with UV and visible laser lines. Cells loaded with BCECF were sequentially excited, first at $458 \mathrm{~nm}$, then at $488 \mathrm{~nm}$, both with laser strength set at $10 \%$ and pinhole set at 1.51 
units using an $\times 63$-fold oil immersion lens. Under both excitations, fluorescence emission was captured at $525 \pm 10 \mathrm{~nm}$ by imaging the z-stack profile of each cell 10 times in the $\mathrm{x} / \mathrm{y}$ plane. BCECF is able to enter both the host and the symbiont, and can therefore be used for imaging of both compartments of an intact symbiosis. However, the signal is much stronger in the host cell than in the symbiont, probably due to the thick cell wall that surrounds the symbiont. Therefore, prior optimisation of laser settings was essential to maximise the signal strength in the algae, without overexposing the host cell. In vivo calibration was carried out on each partner in the intact symbiosis to yield two separate calibration curves, one for the host [Fig 3.1A] and one for the symbiont [Fig. 3.1B]. The calibration series is dependent on the calculation of the fluorescence intensity ratio $\left(\mathrm{R} ; \mathrm{F}_{488} / \mathrm{F}_{458}\right)$ after cells are suspended in buffers of a known $\mathrm{pH}(\mathrm{pH} 6-8.5)$ in the presence of $5 \mu \mathrm{M}$ nigericin (Venn et al., 2009). This $\mathrm{R}$ value can then be linked to $\mathrm{pH}_{\mathrm{i}}$ by the logarithmic equation $\mathrm{pH}=\mathrm{pK}_{\mathrm{a}}+$ $\log \left[\left(\left(\mathrm{R}-\mathrm{R}_{\mathrm{A}}\right) /\left(\mathrm{R}_{\mathrm{B}}-\mathrm{R}\right)\right) *\left(\mathrm{~F}_{\mathrm{A}(458)} / \mathrm{F}_{\mathrm{B}(458)}\right]\right.$, where $\mathrm{pK}_{\mathrm{a}}$ represents the acid dissociation constant and $\mathrm{A}_{\mathrm{A}}$ and $\mathrm{B}_{\mathrm{B}}$ represent the acidic and basic endpoints of the titration. To check the level of background fluorescence in the sample, cells were loaded separately with $10 \mu \mathrm{M}$ of BCECF-free acid (in the presence of $0.1 \%$ DMSO, and $0.01 \%$ Pluronic F127), a membrane-impermeant form of the dye. Background fluorescence was negligible, with no accumulation in either the symbiont or host cells.

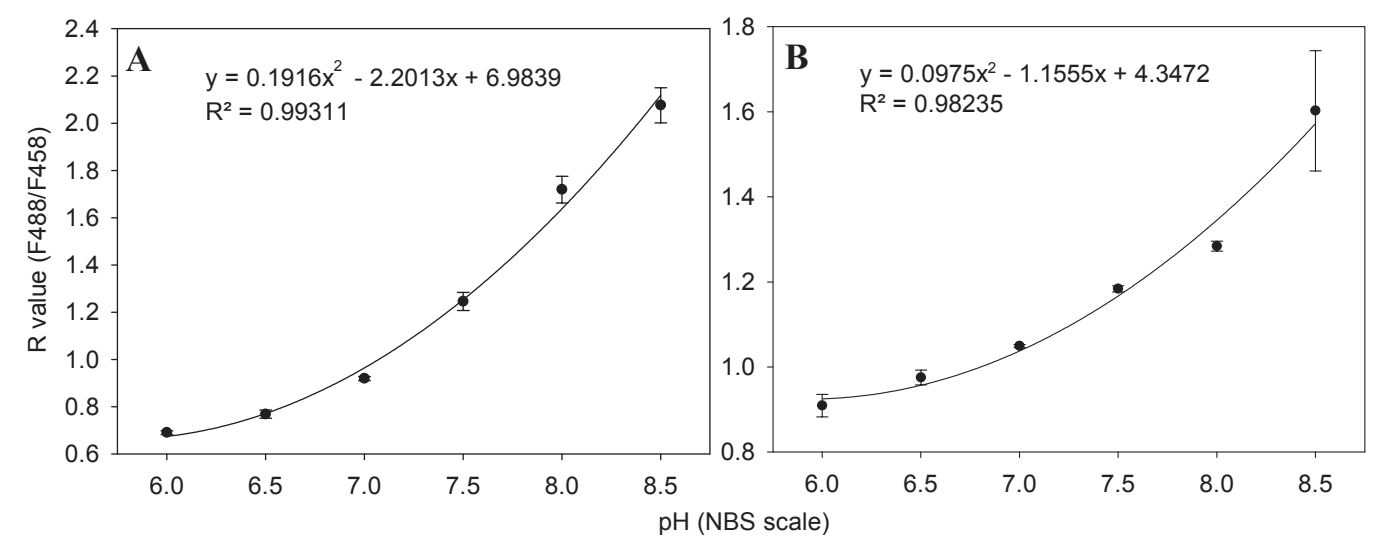

Fig. 3.1 Calibration of intracellular $\mathrm{pH}\left(\mathrm{pH}_{\mathrm{i}}\right)$ in (A) host coral cell and (B) Symbiodinium cells isolated from the coral Pocillopora damicornis using the fluorescent dye BCECF-AM ester. $\mathrm{pH}_{\mathrm{i}}$ was calculated from the ratio of fluorescence emission, $\mathrm{R}\left(\mathrm{F}_{488} / \mathrm{F}_{458}\right)$. $\mathrm{R}$ was then linked to $\mathrm{pH}_{\mathrm{i}}$ by the following logarithmic equation: $\mathrm{pH}=\mathrm{pK}_{\mathrm{a}}+\log \left[\left(\left(\mathrm{R}-\mathrm{R}_{\mathrm{A}}\right) /\left(\mathrm{R}_{\mathrm{B}}-\mathrm{R}\right)\right)^{*}\left(\mathrm{~F}_{\mathrm{A} 458} / \mathrm{F}_{\mathrm{B} 458}\right)\right.$, where $\mathrm{pK}_{\mathrm{a}}$ represents the acid dissociation constant and ${ }_{\mathrm{A}}$ and ${ }_{\mathrm{B}}$ represent the acidic and basic endpoints of the titration (in this case, 6 and 8.5). 


\subsubsection{Manipulation of $\mathrm{pH}_{e}$}

$\mathrm{pH}_{\mathrm{e}}$ was manipulated via in vitro addition of $99 \% \mathrm{CO}_{2}$ in a fully adjustable $\mathrm{CO}_{2} /$ temperature controlled live-cell chamber attached to an Axiovert 200 microscope. The amount of $\mathrm{CO}_{2}$ that was added was controlled using the Zen 2011 software (Carl Zeiss, Oberkochen, Germany), with the pre-defined volume mixed in a $\mathrm{CO}_{2}$ module and directly injected into the chamber. The final $\mathrm{pH}_{\mathrm{e}}$ and the time taken for the $\mathrm{pH}_{\mathrm{e}}$ to stabilise were dependent on the amount of $\mathrm{CO}_{2}$ added [Fig. 3.2]. The 5.0\% $\mathrm{CO}_{2}$ injection setting that produced a gradient of $\mathrm{pH}_{\mathrm{e}}$ that spanned one $\mathrm{pH}$ unit, and stabilised below pH 7 was selected for this study. This provided an optimal timeframe for monitoring $\mathrm{pH}$, as experiments lasting longer than two hours are often impacted by photo-bleaching or dye-leakage from the cells (Musgrove et al., 1986). The temperature of the microscope stage was maintained at a constant $22^{\circ} \mathrm{C}$ by a custommade Plexiglas incubator encasing the entire system.

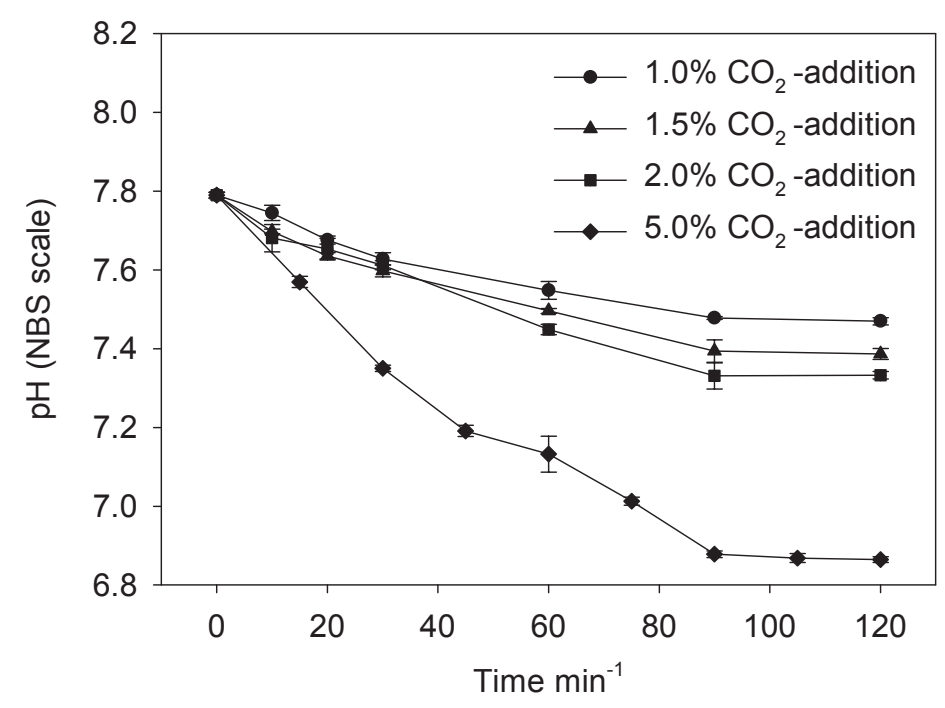

Fig. 3.2 Stability of the live-cell incubator. Values represent the $\mathrm{pH}$ of the surrounding seawater (mean \pm S.E.M, $\mathrm{n}=5$ ) over time.

\subsubsection{Statistics}

Actual $\mathrm{pH}$ values are provided, and can be visualised in Fig. 3.3. However data were analysed as the relative change in $\mathrm{pH}_{\mathrm{i}}$ [Fig. 3.5; the $\mathrm{pH}_{\mathrm{i}}$ value after acidification minus the mean $\mathrm{pH}_{\mathrm{i}}$ of the control at each time point]. The effect of the symbiotic state (between-subject factor), external $\mathrm{pH}$, and external $\mathrm{pH} \times$ symbiotic state (both within subject-factors) were analysed using a repeated measures analysis of variance 
(rmANOVA). Initial analysis of the dataset confirmed that there was a significant interaction between external $\mathrm{pH} \times$ symbiotic state $\times$ DCMU treatment (rmANOVA, $\left.\mathrm{F}_{(15.03,160.34)}=4.60, \mathrm{p}<0.001\right)$, so subsequent analyses were carried out on the two separate treatments (no DCMU and DCMU added). Likewise post hoc analysis was carried out at the treatment level using Bonferroni corrected paired t-test comparisons $(\alpha=0.001)$. The assumptions of normality were confirmed using the KolgomorovSmirnov Test. The sphericity of the data was tested using Mauchly's Sphericity Test. Epsilon-adjusted univariate F-test (Greenhouse-Geisser; G-G) values are reported. All data were analysed using JMP 10.0.0 (SAS Institute Inc., USA). 


\subsection{Results}

Initial analysis of the dataset confirmed that there was a significant interaction between external $\mathrm{pH} \times$ symbiotic state $\times$ DCMU treatment $\left(\operatorname{rmANOVA}, \mathrm{F}_{(15.03}, 160.34\right)$ $=4.60, \mathrm{p}<0.001)$, so subsequent analyses were carried out on the two separate treatments (no DCMU and DCMU added). The response of $\mathrm{pH}_{\mathrm{i}}$ to $\mathrm{pH}_{\mathrm{e}}$ was dependent on the symbiotic state of the cell in both the presence (rmANOVA, $\mathrm{F}_{(14.23,75.87)}=7.51$, $\mathrm{p}<0.001)$ and absence of DCMU (rmANOVA, $\left.\mathrm{F}_{(11.15,59.44)}=14.80, \mathrm{p}<0.001\right)$. Subsequent post hoc analyses revealed where the differences in the response of $\mathrm{pH}_{\mathrm{i}}$ to acidification lay [Table 3.1$]$.

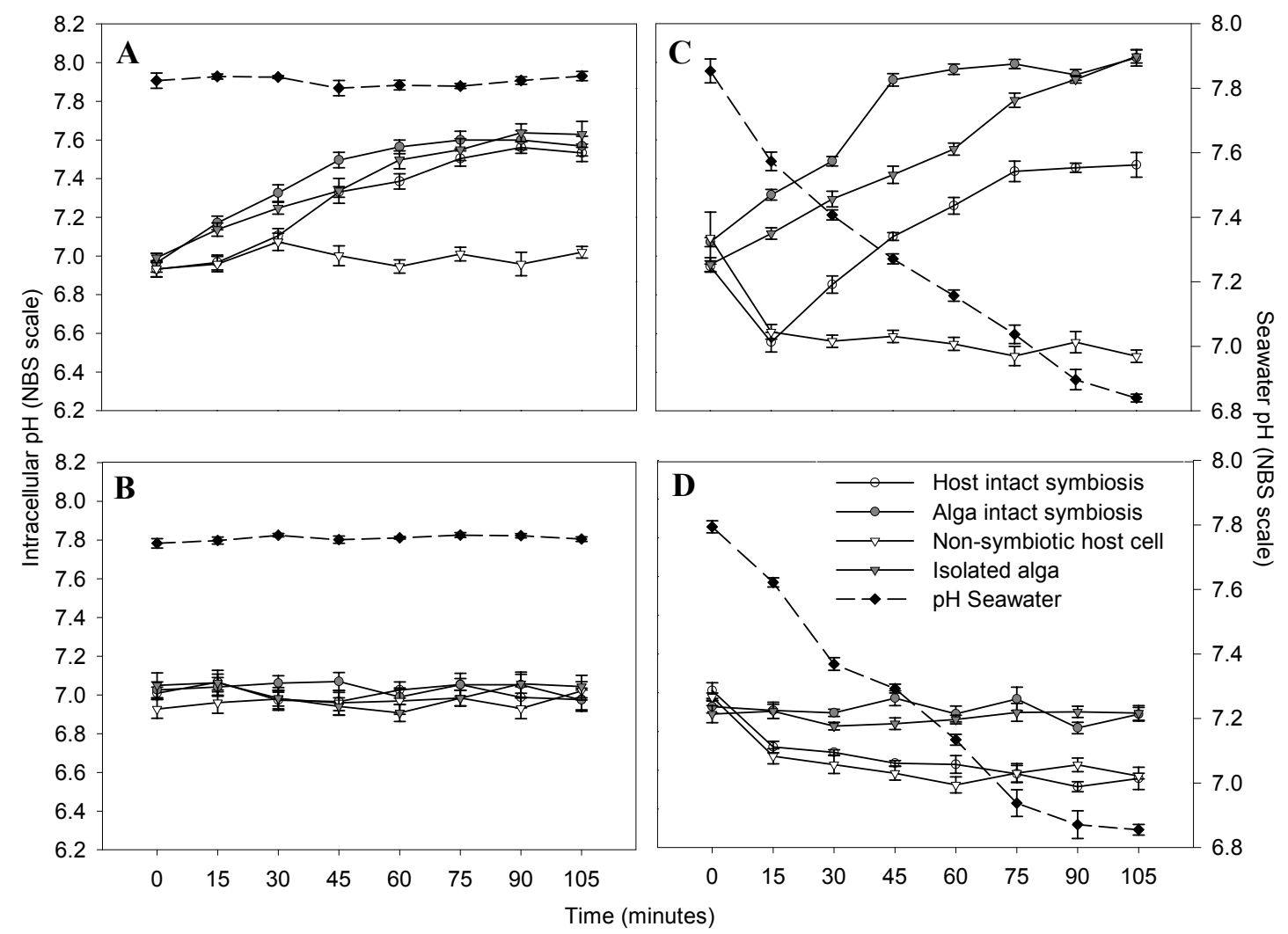

Fig. 3.3 Absolute change in the intracellular $\mathrm{pH}\left(\mathrm{pH}_{\mathrm{i}}\right)$ of four cell types isolated from the coral Pocillopora damicornis (Symbiodinium freshly isolated from host coral cell; isolated non-symbiotic host coral cell; isolated host coral cell and its symbiotic algae), under control (A-B) and $\mathrm{CO}_{2}$ acidified conditions (C-D) under two treatments (top): in the light without DCMU and (bottom) under light in the presence of the photosynthetic inhibitor DCMU. At each time point, the $\mathrm{pH}_{\mathrm{i}}$ (NBS scale) of each cell was measured using confocal microscopy (n $=5$ ) and the $\mathrm{pH}$ (NBS scale) of the surrounding seawater media was measured via the spectrophotometric $\mathrm{m}$-cresol dye method $(\mathrm{n}=5)$. Values plotted represent mean \pm S.E.M. The dashed line represents the $\mathrm{pH}_{\mathrm{e}}$ of the surrounding seawater and is plotted on the secondary $\mathrm{y}$ axis. 


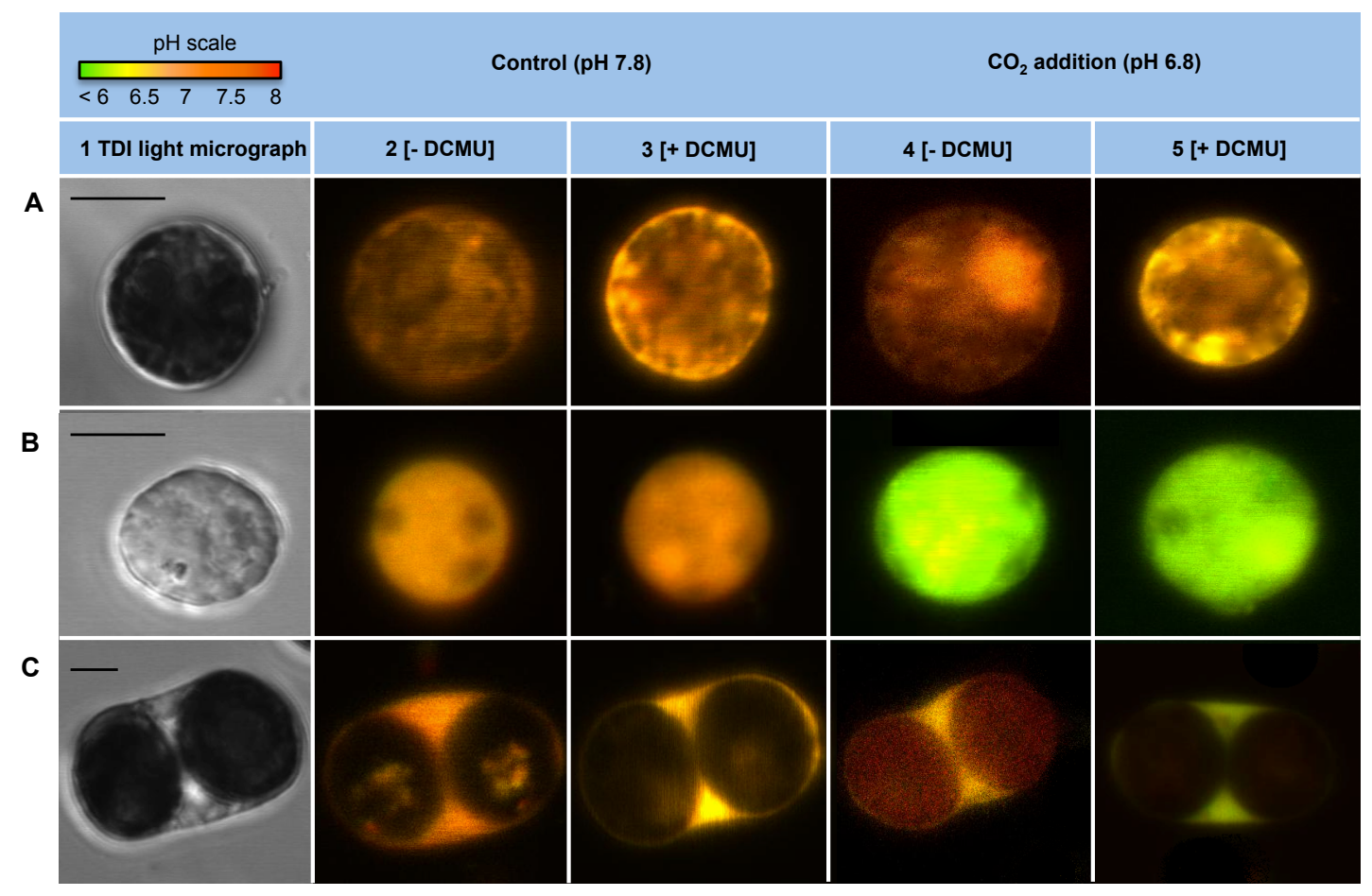

Fig. 3.4 Light and confocal microscopy images of the $\mathrm{pH}$-sensitive dye BCECF-AM ester, showing the cells, and intracellular $\mathrm{pH}\left(\mathrm{pH}_{\mathrm{i}}\right)$ of cells isolated from Pocillopora damicornis after 105 min of exposure to either control pH conditions (left) or increasing $\mathrm{CO}_{2}$ (right). (Rows A-C) Symbiotic state of the cell: (A) Symbiodinium freshly isolated from host coral cell; (B) isolated non-symbiotic host coral cell and (C) isolated host coral cell containing two symbiotic algae. (Column 1) TDI light micrograph; (Columns 2-5) Different treatments: (2) control conditions ( $\mathrm{pH} 7.8$ ) in the absence of DCMU [- DCMU]; (3) control conditions ( $\mathrm{pH}$ 7.8) in the presence of DCMU [+ DCMU]; (4) increasing $\mathrm{CO}_{2}(\mathrm{pH} 6.8)$ in the absence of DCMU [- DCMU]; (5) increasing $\mathrm{CO}_{2}(\mathrm{pH}$ 6.8) in the presence of DCMU [+ DCMU]. All experiments were conducted under saturating $\left(400 \mu \mathrm{mol}\right.$ photons $\left.\mathrm{m}^{-2} \mathrm{~s}^{-1}\right)$ PAR. Scale bars represent $5 \mu \mathrm{m}$.

The disparities in $\mathrm{pH}_{\mathrm{i}}$ were driven primarily by the opposing reactions of the host coral cells and the algal cells to acidification. Within 15 min of $\mathrm{CO}_{2}$ addition, the $\mathrm{pH}_{\mathrm{i}}$ of both the isolated symbiotic and non-symbiotic host coral cells decreased by approximately $0.4 \mathrm{pH}$ units, irrespective of whether DCMU was present [Fig. 3.5]. Following this initial drop, the response of $\mathrm{pH}_{\mathrm{i}}$ to further acidification was dependent on the symbiotic state of the host cell, and the DCMU treatment it was exposed to. There was no change in the $\mathrm{pH}_{\mathrm{i}}$ of the non-symbiotic host cell in either treatment [Fig. 3.5B]. Similarly, there was no change in the $\mathrm{pH}_{\mathrm{i}}$ of the symbiotic host cell in the presence of DCMU [Fig. 3.5B]. In contrast, without DCMU, the $\mathrm{pH}_{\mathrm{i}}$ of the host cell increased over time when in symbiosis with its dinoflagellate partner, returning to control levels within 75 min (when the $\mathrm{pH}_{\mathrm{e}}$ reached $\mathrm{pH}$ 7). The response of the $\mathrm{pH}_{\mathrm{i}}$ of the dinoflagellate symbiont to the addition of $\mathrm{CO}_{2}$ differed between the DCMU 
treatments [Fig. 3.4A; Fig. 3.5], irrespective of whether the alga was in isolation or in symbiosis [Table 3.1]. In the presence of DCMU there was no change in the $\mathrm{pH}_{\mathrm{i}}$ of either the isolated or symbiotic algae [Fig. 3.5B], whereas without DCMU both the isolated and symbiotic algae were both able to increase their $\mathrm{pH}_{\mathrm{i}}$ relative to control levels [Fig. 3.5A].

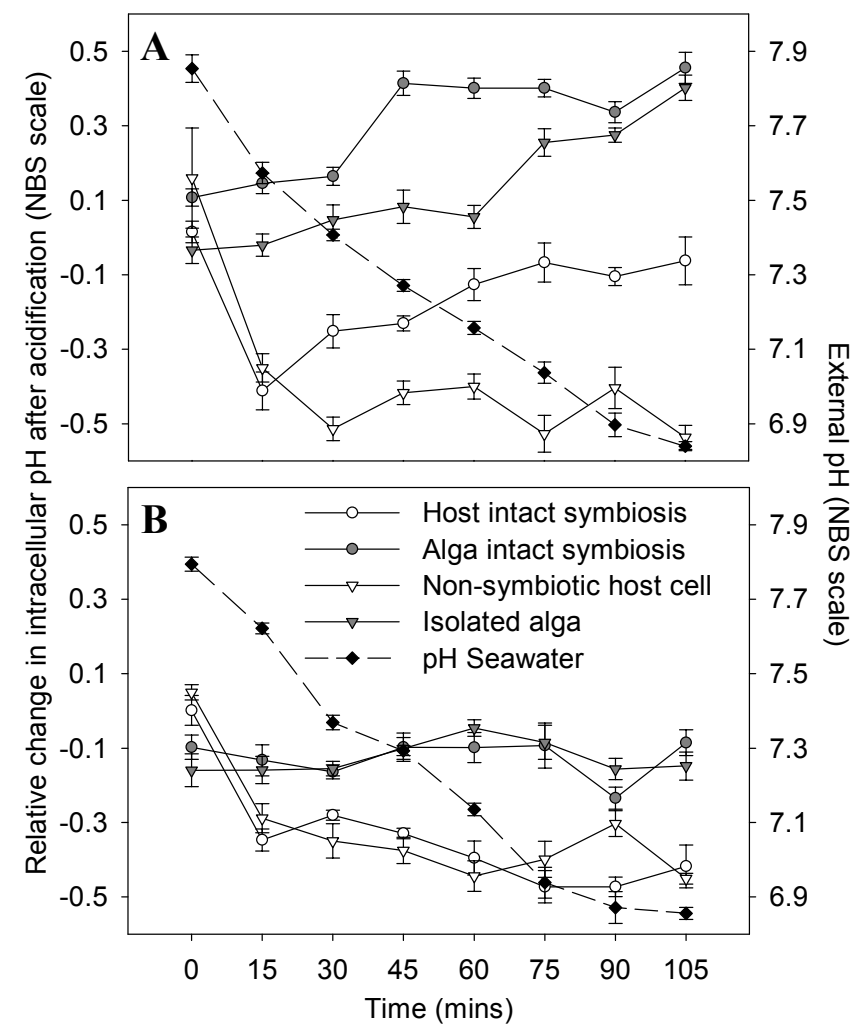

Fig. 3.5 The impact of $\mathrm{CO}_{2}$ addition on the intracellular $\mathrm{pH}\left(\mathrm{pH}_{\mathrm{i}}\right)$ in cells isolated from Pocillopora damicornis (Symbiodinium freshly isolated from host coral cell; isolated nonsymbiotic host coral cell; isolated host coral cell and its symbiotic algae). The figures show the relative change in $\mathrm{pH}_{\mathrm{i}}$ after acidification (the $\mathrm{pH}_{\mathrm{i}}$ value after acidification minus the mean $\mathrm{pH}_{\mathrm{i}}$ of the control at each timepoint \pm S.E.M; $\mathrm{n}=5$ ) under two treatments (A) saturating white $400 \mu \mathrm{mol}$ photons $\mathrm{m}^{-2} \mathrm{~s}^{-1}$ photosynthetically active radiation (PAR); (B) saturating white 400 $\mu \mathrm{mol}$ photons $\mathrm{m}^{-2} \mathrm{~s}^{-1}$ PAR in the presence of DCMU. The dashed line plotted on the secondary $\mathrm{y}$-axis represents the $\mathrm{pH}$ of the surrounding medium at each time point $(\mathrm{n}=5)$. 
Table 3.1 Post hoc results of paired t-tests following rmANOVA, showing the effect of 'symbiotic state $\mathrm{x}$ external $\mathrm{pH}$ ' on intracellular $\mathrm{pH}\left(\mathrm{pH}_{\mathrm{i}}\right)$ at each time-point. Asterisks indicate a significant interaction between the paired cell types $(* \mathrm{p}<0.001)$. Pairs are as follows: $1=$ non-symbiotic coral cell versus symbiotic coral cell; $2=$ non-symbiotic coral cell versus isolated algal cell; $3=$ non-symbiotic coral cell versus symbiotic algal cell; $4=$ symbiotic coral cell versus isolated algal cell; 5 = symbiotic coral cell versus symbiotic algal cell; and 6 $=$ symbiotic algal cell versus isolated algal cell. Only Bonferroni corrected significant interactions $(\alpha=0.001)$ are included.

\begin{tabular}{|c|c|c|c|c|c|c|c|c|c|}
\hline \multirow{2}{*}{ Treatment } & \multirow{2}{*}{ Pair } & \multicolumn{8}{|c|}{ p-value } \\
\hline & & $0 \mathrm{~min}$ & $15 \mathrm{~min}$ & $30 \mathrm{~min}$ & $45 \mathrm{~min}$ & $60 \mathrm{~min}$ & $75 \mathrm{~min}$ & $90 \mathrm{~min}$ & $105 \mathrm{~min}$ \\
\hline \multirow{6}{*}{$\begin{array}{c}\text { Light } \\
\text { (- DCMU) }\end{array}$} & 1 & - & - & - & - & $*$ & * & * & * \\
\hline & 2 & - & $*$ & $*$ & $*$ & $*$ & $*$ & $*$ & $*$ \\
\hline & 3 & - & * & * & $*$ & * & * & * & * \\
\hline & 4 & - & $*$ & * & * & - & $*$ & $*$ & $*$ \\
\hline & 5 & - & * & * & * & $*$ & $*$ & $*$ & $*$ \\
\hline & 6 & - & - & - & $*$ & * & - & - & - \\
\hline \multirow{6}{*}{$\begin{array}{c}\text { Light } \\
(+\mathrm{DCMU})\end{array}$} & 1 & - & - & - & - & - & - & - & - \\
\hline & 2 & - & - & - & $*$ & * & - & - & * \\
\hline & 3 & - & - & - & $*$ & $*$ & - & - & $*$ \\
\hline & 4 & - & - & - & * & * & * & * & - \\
\hline & 5 & - & - & - & * & $*$ & * & * & * \\
\hline & 6 & - & - & - & - & - & - & - & - \\
\hline
\end{tabular}

\subsection{Discussion}

Understanding the coral-dinoflagellate symbiosis is pivotal to accurately predicting the susceptibility of coral reefs to climate change and ocean acidification (Weis et al., 2008; Davy et al., 2012). Recent ecological research suggests that the symbiotic state may play a critical role in determining a coral's capacity to tolerate changes in seawater chemistry (Ohki et al., 2013). It is well established that photosynthesis in the dinoflagellate symbiont enhances host coral calcification rates in the light (Allemand et al., 2004). At the cellular level however, a more important role may be the ability of the symbiont to manipulate aspects of the host's physiology, such as cellular $\mathrm{pH}$ (Venn et al., 2009; Laurent et al., 2013a). As yet, no study has investigated how this relationship will be impacted by acidification. I addressed this knowledge gap by simultaneously quantifying $\mathrm{pH}_{\mathrm{i}}$ in both partners of the symbiosis in response to $\mathrm{CO}_{2}$ 
addition. The experimental design exposed isolated cells to a wide range of $\mathrm{pH}_{\mathrm{e}}$, at levels of $\mathrm{CO}_{2}$ much greater than those predicted to arise from ocean acidification. These treatments were not designed to replicate climate change scenarios, but rather to provide a means of determining how the symbiotic state influences the recovery of its coral host cell under induced cellular acidosis. The results of this study reveal that the photosynthetic activity of the symbiont increases the ability of the host cell to recover from cellular acidosis after exposure to high $\mathrm{CO}_{2} /$ low $\mathrm{pH}$. The responses seen in the various symbiotic states are summarised in Figure 3.6 below.

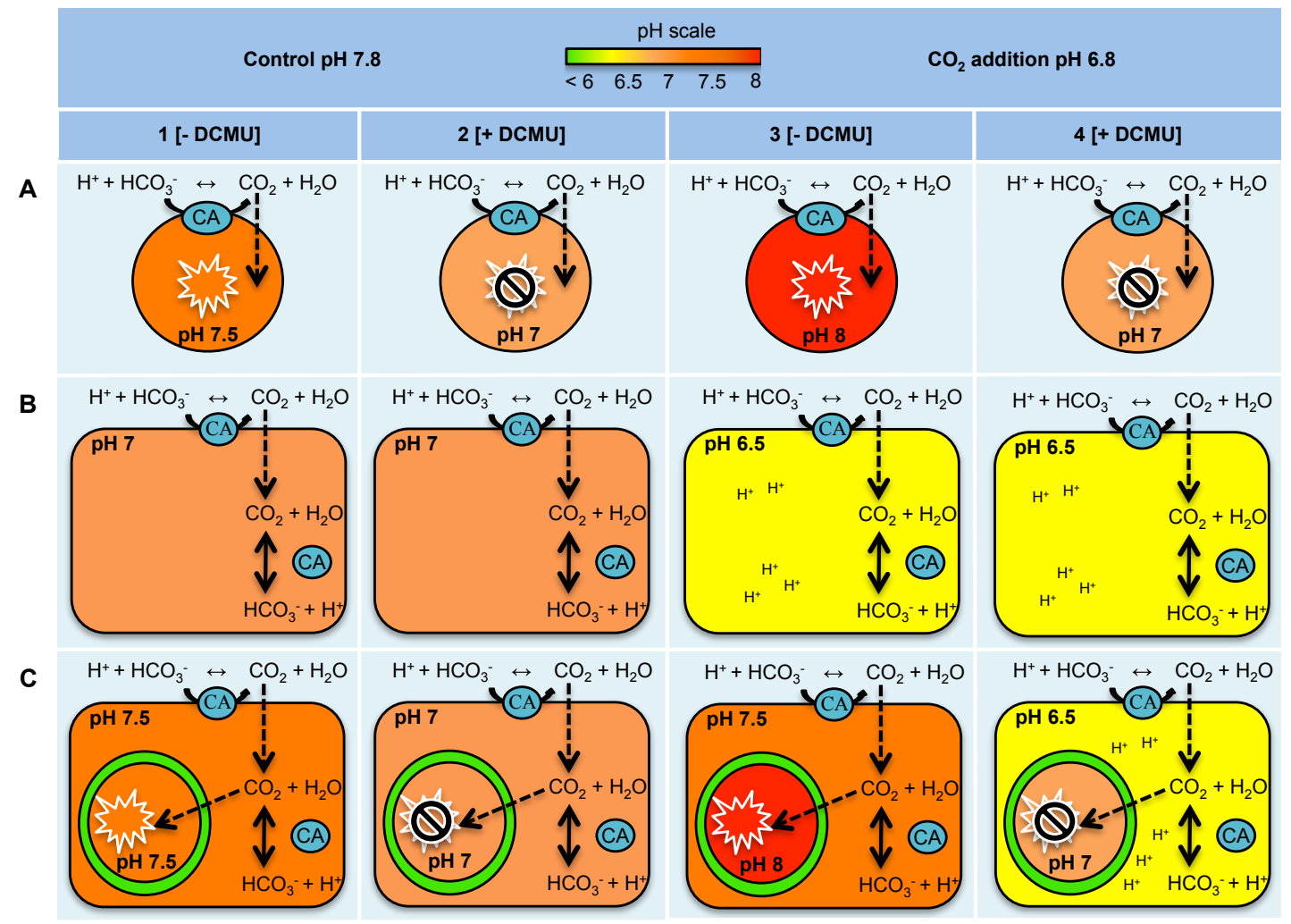

Fig. 3.6 Model of intracellular $\mathrm{pH}\left(\mathrm{pH}_{\mathrm{i}}\right)$ fluctuations in cells isolated from Pocillopora damicornis after $105 \mathrm{~min}$ of exposure to either control $\mathrm{pH}$ conditions (left) or increasing $\mathrm{CO}_{2}$ (right) according to the state of the equilibrium reaction that exists between $\mathrm{CO}_{2}+\mathrm{H}_{2} \mathrm{O} \leftrightarrow$ $\mathrm{H}_{2} \mathrm{CO}_{3} \leftrightarrow \mathrm{HCO}_{3}^{-}+\mathrm{H}^{+}$. (Rows A-C) Symbiotic state of the cell: (A) Symbiodinium freshly isolated from host coral cell; (B) isolated non-symbiotic host coral cell and (C) host coral cell containing symbiotic algae. (Columns 1-4) Different treatments: (1) control conditions (pH 7.8 ) in the absence of the DCMU [- DCMU]; (2) control conditions (pH 7.8) in the presence of DCMU [+ DCMU]; (3) increasing $\mathrm{CO}_{2}(\mathrm{pH}$ 6.8) in the absence of DCMU [- DCMU]; (4) increasing $\mathrm{CO}_{2}(\mathrm{pH}$ 6.8) in the presence of DCMU [+ DCMU]. Dashed arrows show passive $\mathrm{CO}_{2}$ diffusion. Sunburst symbol represents photosynthetic processes and $\mathrm{CA}$ represents carbonic anhydrase. Colours indicate $\mathrm{pH}$ as identified in the colour gradient above. With increasing seawater $\mathrm{CO}_{2}$ there is a shift in carbonate chemistry equilibrium, leading to an accumulation of internal $\mathrm{H}^{+}$in the absence of photosynthesis. 
$\mathrm{CO}_{2}$ and $\mathrm{H}_{2} \mathrm{O}$ exist in equilibrium with $\mathrm{H}_{2} \mathrm{CO}_{3}$, so when $\mathrm{CO}_{2}$ is removed for photosynthesis it causes an increase in the conversion of $\mathrm{HCO}_{3}{ }^{-}$to $\mathrm{H}_{2} \mathrm{CO}_{3}$, a process that consumes protons $\mathrm{H}^{+}$(Allemand et al., 1998). Conversely, an increase in $\mathrm{CO}_{2}$ will reverse the process, resulting in the production of $\mathrm{H}^{+}$and leading to cellular acidosis. The $\mathrm{pH}_{\mathrm{i}}$ of freshly isolated Symbiodinium cells is therefore strongly influenced by the availability of $\mathrm{CO}_{2}$ in the surrounding seawater (Nimer et al., 1999). Symbiodinium cells are clearly able to increase their $\mathrm{pH}_{\mathrm{i}}$ relative to a control, by up to $0.5 \mathrm{pH}$ units [Fig. 3.6A]. This alkalinisation demonstrates the capacity of Symbiodinium cells to strongly buffer the external environmental $\mathrm{pH}$ signal, probably due to a fertilising effect on photosynthesis in these normally $\mathrm{CO}_{2}$-limited algae (Nimer et al., 1999). An increase in photosynthetic productivity after $\mathrm{CO}_{2}$ addition has also been observed in other symbiotic associations, most notably in the temperate sea anemones Anemonia viridis (Suggett et al., 2012) and Anthopleura elegantissima (Towanda and Thuesen, 2012), and the benthic foraminiferan Marginopora vertebralis (Uthicke and Fabricius, 2012). The application of DCMU (a photosynthetic inhibitor) reversed the increase in $\mathrm{pH}_{\mathrm{i}}$, confirming that the change was a direct consequence of photosynthesis, as the inhibited photosynthetic machinery of the symbionts is not able to ameliorate the increasing $\mathrm{H}^{+}$concentration [Fig 3.6A].

$\mathrm{CO}_{2}$ supplementation initiated a markedly different response in the host coral cells compared to the symbiont. In the host cells, acidosis of the cytoplasm was observed within 15 min of $\mathrm{CO}_{2}$ addition, with a decline in $\mathrm{pH}_{\mathrm{e}}$ of $0.2 \mathrm{pH}$ units causing the $\mathrm{pH}_{\mathrm{i}}$ to fall $0.4 \mathrm{pH}$ units below the usual $\mathrm{pH}$ of the cell, irrespective of the presence or absence of DCMU and the symbiotic state of the cell [Fig 3.6B]. This strongly suggests that the host's intrinsic buffering capacity is, initially at least, overwhelmed by the accumulation of protons resulting from the passive diffusion of $\mathrm{CO}_{2}$, and active transport of bicarbonate $\left(\mathrm{HCO}_{3}{ }^{-}\right)$into the cell (Furla et al., 2000), which drives the aforementioned equilibrium reaction. The decline in $\mathrm{pH}_{\mathrm{i}}$ however, was halted after 15 min in both the symbiotic and non-symbiotic host cells. It is likely that this represents a time lag between the onset of acidosis and the activation of the regulatory membrane transporters. Indeed, such activity could explain the subsequent stability $(\sim \mathrm{pH} 6.6)$ of the $\mathrm{pH}_{\mathrm{i}}$ in non-symbiotic host cells, which was achieved irrespective of the surrounding seawater being subject to further acidification. Nevertheless, the $\mathrm{pH}_{\mathrm{i}}$ of these non-symbiotic host cells never recovered to pre-acidosis levels. In contrast, 
the $\mathrm{pH}_{\mathrm{i}}$ of symbiotic host cells showed a full recovery to control $\mathrm{pH}$ levels within 105 min of $\mathrm{CO}_{2}$-addition [Fig 3.6C]. Again, this recovery was negated in the presence of DCMU, confirming that the photosynthetic removal of $\mathrm{CO}_{2}$ by the symbiont (and hence the consumption of protons) was responsible for the increase in the host's $\mathrm{pH}_{\mathrm{i}}$.

These results confirm that the symbiont is able to exert a significant level of control over its host's cellular $\mathrm{pH}$, corroborating the findings of previous research on reef corals (Laurent et al., 2013a). Furthermore, they demonstrate that the photosynthetic activity of the symbionts plays a key role, at least in the short-term, in regulating the cellular response of their host to external $\mathrm{CO}_{2}$-driven acidification. Perhaps more importantly, however, the inability of non-symbiotic or photosyntheticallycompromised symbiotic host cells to recover from cellular acidosis in the short-term (at least under the experimental conditions here) suggests that they may be more susceptible than are host cells that contain fully functional Symbiodinium cells. However, whether the cells have the potential for recovery in the longer term, especially under constant $\mathrm{pH}$, warrants further investigation. While some caution needs to be exercised when interpreting the results for the non-symbiotic coral cells, as we cannot be sure of their precise origin (i.e. ectodermal or endodermal), it is notable that the symbiotic endodermal host cells responded in the same manner when photosynthesis was inhibited. This limited capacity to withstand acidosis in the absence of a functional symbiont could therefore be a general response. If this is the case, it raises the possibility that the number of Symbiodinium cells that a coral host cell contains may also influence the cellular response to acidification. In Stylophora pistillata, for example, the majority of host cells ( $\sim 60 \%)$ typically contain one algal cell, while fewer contain two $(\sim 35 \%)$ or more $(<5 \%)$ (Houlbrèque et al., 2004). Given that we focused on host cells that harboured two algal symbionts only, there is a need for future studies that clarify the influence of symbiont number on the $\mathrm{pH}_{\mathrm{i}}$, and the overall response at the organismal level.

The regulation of $\mathrm{pH}_{\mathrm{i}}$ in corals is an important area for future research as cellular acidosis has serious physiological repercussions for the fitness of the individual. At a biochemical level, acidosis disrupts ion transport, nutrient trafficking and carbon acquisition (Fabry, 2008), causing metabolic suppression (Pörtner et al., 2004) and inevitably leading to shortfalls in the energy available for other cellular processes 
(Reipschläger and Pörtner, 1996). In addition to these fundamental cellular attributes, regulating $\mathrm{pH}_{\mathrm{i}}$ is particularly important in reef-building corals for calcification. In the recently proposed 'proton flux hypothesis', Jokiel (2011) presented the first organismscale model of acid-base balance in corals (Jokiel, 2011). The hydroxide ions $\left(\mathrm{OH}^{-}\right)$ produced as an indirect by-product of $\mathrm{CO}_{2}$ removal (Furla et al., 2000) are proposed to play a critical role in calcification, neutralising protons released by $\mathrm{H}^{+} / \mathrm{Ca}^{2+}$ ion exchangers in the gastrovascular cavity, and thus facilitating a $\mathrm{pH}$ gradient high enough for the precipitation of calcium carbonate $\left(\mathrm{CaCO}_{3}\right)$ (Jokiel, 2011; Comeau et al., 2013). Acidosis of the host coral cells could therefore place further chemical and energetic constraints on corals by affecting their ability to calcify (Jokiel, 2011; Venn et al., 2013). It remains to be seen whether a non-symbiotic host cell can reverse the changes in $\mathrm{pH}_{\mathrm{i}}$ over a longer timeframe, though this might depend, in part, on its ability to up-regulate the expression of membrane transporters (Kaniewska et al., 2012), as this will afford greater control over $\mathrm{pH}_{\mathrm{i}}$. Indeed, several organisms are able to reverse initial decreases in $\mathrm{pH}_{\mathrm{i}}$ (Michaelidis et al., 2005; Stumpp et al., 2012).

The ability of corals to respond to $\mathrm{pH}_{\mathrm{e}}$ change is likely to depend on the response of both the symbionts and coral host (McCulloch et al., 2012). There is considerable diversity within the genus Symbiodinium (Pochon and Gates, 2010), which translates into substantial genotypic differences in physiology (Tchernov et al., 2004; Hennige et al., 2009; Brading et al., 2011). This experiment used genetically identical fragments from a single colony, which had two advantages: firstly, it minimised the baseline variation in host cellular activity; and secondly, it reduced the chances of sampling corals that contained very different Symbiodinium clades. However, future research should aim to determine whether the host and symbiont responses, and their relative abilities to buffer the effects of $\mathrm{CO}_{2}$-driven acidification, vary according to host and symbiont genotype. In addition, it will be important to determine whether the patterns observed in isolated coral cells are replicated in intact coral tissues, and whether longer-term incubations at more moderate levels of acidification (i.e. predicted climate change scenarios) induce similar responses to those reported here. Moreover, the findings here highlight the possibility that bleached corals may be more sensitive to cellular acidosis than are their non-bleached counterparts; this is an especially interesting topic for future research, and so shall form the foundation for the experiments in Chapter 4. 


\section{Chapter 4: Species-specific susceptibility to ocean acidification and cellular acidosis in reef corals is influenced by thermal sensitivity}

\subsection{Introduction}

Atmospheric $\mathrm{CO}_{2}$ levels have been increasing since the Industrial Revolution, but only now is the scale of the threat to marine ecosystems becoming apparent (Pandolfi et al., 2011; Silverman et al., 2012). Rising sea surface temperatures and the declining $\mathrm{pH}$ of the world's oceans are driving the global collapse of coral reefs, potentially leading to phase shifts away from calcifying species towards ecosystems dominated by algal- or soft-bodied organisms (Norström et al., 2009; Suggett et al., 2012; Bell et al., 2013; Inoue et al., 2013). Individually, the effects of increasing temperature and declining $\mathrm{pH}$ on reef-building corals are becoming well established. Chronic exposure to high temperatures often results in the photosynthetic dysfunction, and subsequent loss of single-celled symbiotic dinoflagellates (genus Symbiodinium) and/or their photosynthetic pigments (Fitt et al., 2000). This breakdown in symbiosis, a process termed "coral bleaching" (Weis et al., 2008), has a major impact on the coral's fitness, reducing photosynthetic activity and efficiency (Iglesias-Prieto et al., 1992; Fitt and Warner, 1995; Warner et al., 1996; Jones et al., 2000; Rodolfo-Metalpa et al., 2006), colony growth, reproductive output (Ward et al., 2000; Michalek-Wagner and Willis, 2001; Mendes and Woodley, 2002), and resilience to disease (Selig et al., 2006; Bruno and Selig, 2007; Mydlarz et al., 2010), all of which exacerbate mortality rates (Baird and Marshall, 2002).

There is substantial variation in bleaching susceptibility between (Loya et al., 2001; Marshall and Baird, 2000; McClanahan et al., 2004) and within coral species (Edmunds, 1994; Glynn et al., 2001; Yee et al., 2008). Traditionally these differences in thermal sensitivity have been attributed to the composition of the Symbiodinium population (Rowan et al., 1997; Rowan, 2004; Tchernov et al., 2004; Berkelmans and van Oppen, 2006; Ulstrup et al., 2006; Sampayo et al., 2008; van Oppen et al., 2009; Weis, 2010). At a cladal level, corals hosting Symbiodinium ITS2 clade D tend to be more resistant to thermal stress than corals of the same species harbouring clade $\mathrm{C}$ symbionts (Toller et al., 2001; Rowan, 2004; Tchernov et al., 2004; Berkelmans and 
van Oppen, 2006), and so there are disproportionately higher survival rates in clade D-containing corals following bleaching events (Glynn et al., 2001; Fabricius et al., 2004; van Oppen et al., 2005). There is also a great deal in variation in resilience at the sub-cladal level; corals containing types C78, C8/a and C15 for example, are often more tolerant of thermal stress than those hosting $\mathrm{C} 1, \mathrm{C} 8 \mathrm{a}, \mathrm{C} 79, \mathrm{C} 35 / \mathrm{a}$ and $\mathrm{C} 3$ (Sampayo et al., 2008; Fitt et al., 2009; Fisher et al., 2012). But, this is not always the case; Acropora tenuis juveniles containing ITS2 type D for example, are more susceptible to thermal stress compared with those hosting type C1 (Abrego et al., 2008). So, while it is true that the response of corals to elevated temperature can be influenced by the variation in the thermo-tolerance of different Symbiodinium genotypes (Berkelmans and van Oppen, 2006; Robison and Warner, 2006; Suggett et al., 2008; Ragni et al., 2010; Fisher et al., 2012; Howells et al., 2012), it is becoming clear that the host also plays an important part in determining the holobiont's resilience to thermal stress (Baird et al., 2009). At the simplest, anatomical level, a species' skeletal morphology (Kühl et al., 1995; Fabricius et al., 2006; Jimenez et al., 2011; Yost et al., 2013), and tissue pigmentation (Dove et al., 2001; Salih et al., 2006) can heavily influence its sensitivity to elevated temperatures. In addition, the ability to synthesise/acquire mycosporine-like amino acids and the capacity produce antioxidants vary substantially between species (Dunlap and Shick, 1998; Yakovleva et al., 2004; Richier et al., 2005). These differences in thermal sensitivity could have implications for the sensitivity to ocean acidification and cellular acidosis. The photosynthetic activity of Symbiodinium plays a key role in regulating the cellular response of its host cell to external $\mathrm{CO}_{2}$-driven acidification through the removal of $\mathrm{CO}_{2}$, and hence $\mathrm{H}^{+}$. When DCMU was used to block photosynthesis the host cell's ability to recover from cellular acidosis was compromised (Chapter 3). This raises the possibility that thermally sensitive corals (be it through the type of Symbiodinium cells that they contain, or through differences in the resilience of the host) may be more prone to cellular acidosis. Short-term acidosis reduces protein synthesis (Hand, 1991) and induces a period of metabolic suppression (Reipschläger and Pörtner, 1996; Langenbuch et al., 2006; Fabry, 2008; Rosa and Seibel, 2008). But, if this state is not reversed, the associated reductions in reproductive output and growth (Pörtner et al., 2004; Havenhand et al., 2008; Wood et al., 2008), will severely impact a corals competitive fitness over longer time-scales. 
Here, I take advantage of the differential thermal sensitivities of two coral species Pocillopora damicornis, a branching coral that is highly sensitive to heat stress, and the more robust perforate coral Montipora capitata (Jokiel and Brown, 2004; Yost et al., 2013) - to investigate whether a coral's thermal sensitivity can influence its sensitivity to cellular acidosis during exposure to high $\mathrm{CO}_{2} /$ low $\mathrm{pH}$. Specifically, I hypothesised that: (1) bleached corals would be more sensitive to cellular acidosis than their non-bleached counterparts; and (2) the threshold for this would differ between species according to their temperature tolerance. 


\subsection{Methods}

\subsubsection{Collection and manipulation of coral fragments}

M. capitata and P. damicornis colonies were collected from a shallow reef in Kaneohe Bay, Hawaii (21 $25^{\prime} 24.60^{\prime \prime}$ N, $157^{\circ} 47^{\prime} 40.13^{\prime \prime}$ W) in January 2014. Symbiont cells were not genotyped in these corals, but $M$. capitata is typically a flexible generalist, hosting ITS2 types C3, C17, C21, C31, and D1. In contrast, P. damicornis, normally hosts C1 and C3 (LaJeunesse et al., 2004; Padilla-Gamiño et al., 2012; Putnam et al., 2012). Pronounced annual and diurnal fluctuations in temperature exist in the bay [Fig. 4.1], so corals directly adjacent to each other were selected to ensure that both species had experienced similar thermal and irradiance histories. Individual coral fragments $(\sim 2 \times 3 \mathrm{~cm}, \mathrm{n}=50$ per species $)$ were cut, mounted onto $3 \times 3 \mathrm{~cm}$ plastic tiles using underwater expoxy (Z-spar, Splash Zone compound and placed in a 50-L tank and supplied with ambient flowing seawater for two weeks, a sufficient period of time for tissue to regrow over any skeleton that may have been exposed in the collection process. Four experimental tanks were set up, with each tank set to one of the following temperatures: $23.8 \pm 0.3^{\circ} \mathrm{C}$ (ambient), $25.5 \pm 0.4^{\circ} \mathrm{C}, 28 \pm 0.8^{\circ} \mathrm{C}$ and $31 \pm 0.3^{\circ} \mathrm{C}$. These values were selected to span the annual range of temperatures observed in Kaneohe Bay [Fig. 4.1A] and, in the case of $31^{\circ} \mathrm{C}$, provide a treatment high enough to initiate bleaching in P. damicornis (Jokiel and Brown, 2004).
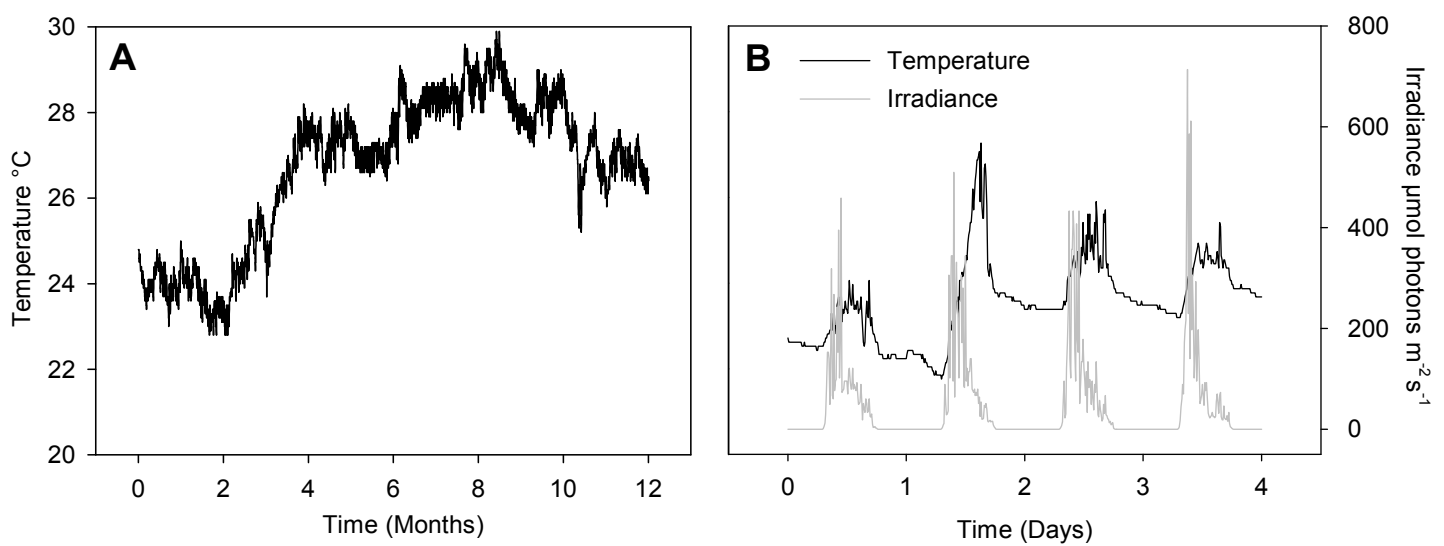

Fig. 4.1 Fluctuations in seawater temperature and irradiance from the collection site in Kaneohe Bay, Hawaii. [A] Daily temperature changes in Kaneohe Bay, Hawaii across the period of one year (January - December 2013) and [B] Daily temperature (black line, primary y-axis) and irradiance (grey line, secondary y-axis) collected four days prior to coral collection. Data obtained from NOAA: http://tidesandcurrents.noaa.gov/. 
Treatment tanks above ambient seawater temperature were heated using aquarium heaters (WON pro-heat IC heaters, Fredericksburg, Virginia, USA) and temperatures were monitored for the duration of the experiment using HOBO data loggers (Onset Corporation, Bourne, MA, USA). Seawater chemistry was uniform across the experimental tanks, with an average weekly salinity of $34.4 \pm 0.29 \mathrm{ppt}$, a pH of $7.88 \pm$ 0.02 (total scale, SOP 6a Dickson et al., 2007) and a TA of $2166.7 \pm 10.62\left(\mu \mathrm{mol} \mathrm{kg}{ }^{-1}\right.$ sw; SOP $3 b$ Dickson et al., 2007); values represent mean \pm S.E.M $(n=4)$. A period of $12 \mathrm{~h}$ light was provided by an actinic LED system (AI Sol, $72 \mathrm{~W} 100$ to $240 \mathrm{VAC} /$ 50-60Hz, C2 Development Inc., Ames, Iowa). The irradiance profile [Fig. 4.2] was designed to mimic that experienced by corals on the reef flat [Fig. 4.1B]. Lights were switched on at sunrise $(06: 15 \mathrm{~h})$ and ramped for $4 \mathrm{~h}$ until an irradiance of $600 \mu \mathrm{mol}$ photons $\mathrm{m}^{-2} \mathrm{~s}^{-1}$ was reached. Maximum irradiance was then maintained for $4 \mathrm{~h}$, before being slowly ramped back down to zero by sunset $(18: 15 \mathrm{~h})$. Four fragments of each species were haphazardly selected and placed in the ambient-temperature experimental tank. After $24 \mathrm{~h}$, three of the four fragments were transferred to the $25.5^{\circ} \mathrm{C}$ treatment tank, a process that was repeated sequentially over the following two days until one fragment was present in each thermal treatment tank. This ramping technique reduced the likelihood of acute temperature shock. The fragments were left in their final treatment tank for a further four days, so the whole experimental treatment took a week. This whole procedure was repeated five times for each species, to achieve independent replicate fragments (i.e. $\mathrm{n}=5$ ).

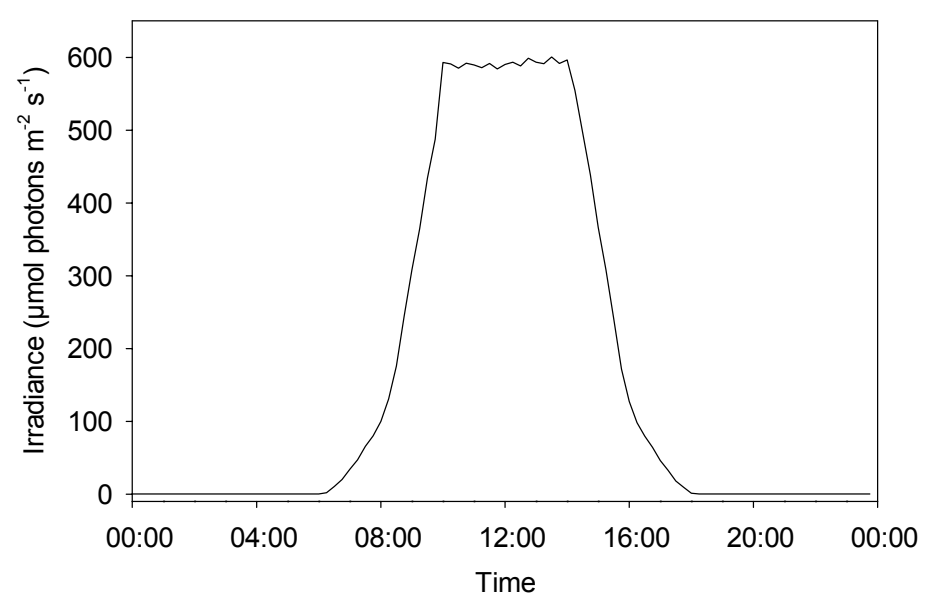

Fig. 4.2 Daily (24 h) irradiance curve. Lights were switched on at sunrise $(06: 15 \mathrm{~h})$ and ramped for $4 \mathrm{~h}$ until an irradiance of $600 \mu \mathrm{mol}$ photons $\mathrm{m}^{-2} \mathrm{~s}^{-1}$ was reached. Maximum irradiance was then maintained for $4 \mathrm{~h}$, before being slowly ramped back down to zero by sunset $(18: 15 \mathrm{~h})$. 


\subsubsection{Quantifying the effects of temperature stress on coral fragments}

After imaging the cells (described below), coral fragments were frozen at $-20^{\circ} \mathrm{C}(\mathrm{n}=$ 5 per species). These samples were subsequently analysed for chlorophyll- $a$ (chl- $a$ ) content and symbiont density, enabling comparisons to be made between the cellular and the physiological response to heat stress. The samples were defrosted, placed on ice and processed in the dark to prevent pigment degradation. Tissue was removed from the coral skeleton by air brushing into $30 \mathrm{~mL}$ of $0.22-\mu \mathrm{M}$ filtered seawater (FSW) and the resulting homogenate was centrifuged for $5 \mathrm{~min}$ at $4000 \times \mathrm{g}$. Once pelleted, the supernatant was discarded and the residue resuspended in either $10 \mathrm{~mL}$ or $3 \mathrm{~mL}$ FSW, depending on the apparent density of symbionts present. The slurry was vortexed before $1 \mathrm{~mL}$ was removed and frozen at $-20^{\circ} \mathrm{C}$ for subsequent Symbiodinium cell counts. The remaining homogenate was re-centrifuged at $4000 \times g$ for $5 \mathrm{~min}$, the supernatant discarded and the pellet dissolved in $3 \mathrm{~mL} 90 \%$ acetone. Samples were transferred to a $4^{\circ} \mathrm{C}$ fridge and left to extract for $24 \mathrm{~h}$. The samples were centrifuged at $10,000 \times g$ for 3 min after $24 \mathrm{~h}$, to remove any cellular debris. Triplicate aliquots of $300 \mu \mathrm{L}$ were removed from each sample and transferred to a 96well plate in preparation for analysis on the spectrophotometer (SpectraMax M2, Molecular Devices, Sunnyvale, California, USA). Absorbance was read at 663 and $630 \mathrm{~nm}$, with chl- $a$ concentrations subsequently calculated from the equations of Jeffrey and Humphrey (1975). These values were then normalised to symbiont density and expressed as pg cell ${ }^{-1}$. Cell counts $(n=10$ per sample) were conducted using an Improved Neubauer haemocytometer (Boeco, Hamburg, Germany), with values subsequently normalised to coral surface area following the paraffin wax dipping method outlined in Holmes (2008).

\subsubsection{Isolation of cells and quantification of $\mathrm{pH}_{i}$}

Cells were isolated following the protocol described in Chapter 3. Preliminary experiments determined that an injection of $1.3,1.2,1.1$ and $1 \%$ of $\mathrm{CO}_{2}(99 \%)$ was required at $23.8,25.5,28$ and $31{ }^{\circ} \mathrm{C}$, respectively, to produce a uniform $0.3 \mathrm{pH}$ unit decline within $30 \mathrm{~min}$ of $\mathrm{CO}_{2}$ addition to the external seawater (i.e. a $\mathrm{pH}_{\mathrm{e}}$ of 7.6). Each sample was maintained on the stage for $30 \mathrm{~min}$, with images collected at the end of the exposure time. This technique was highly reproducible $\left(\mathrm{pH}_{\mathrm{e}} 7.59 \pm 0.02, \mathrm{n}=\right.$ 
40), though for verification, $900 \mu \mathrm{L}$ seawater were removed at the end of each experiment and $\mathrm{pH}_{\mathrm{e}}$ was analysed in triplicate (total scale, $\mathrm{n}=3$ ) using the $\mathrm{m}$-cresol dye method described in SOP 6B (Dickson et al., 2007). All experiments were conducted at a photosynthesis-saturating irradiance of $400 \mu \mathrm{mol}$ photons $\mathrm{m}^{-2} \mathrm{~s}^{-1}$ (Appendix, Fig. A.2), with white light provided by a variable-irradiance fibre optic cable (Halogen Reflector lamp, 150 W GX5.3 21V 1CT bulb, Philips, Somerset, New Jersey, USA). Both host and symbiont $\mathrm{pH}_{\mathrm{i}}$ were determined from the ratio of fluorescence emitted at $525 \pm 10 \mathrm{~nm}$ after sequential excitation using the $458 \mathrm{~nm}$ and then the $488 \mathrm{~nm}$ laser $\left(\mathrm{R} ; \mathrm{F}_{458} / \mathrm{F}_{488}\right)$. BCECF fluorescence itself is influenced by temperature, so calibration curves were produced at each temperature, and the appropriate curve was applied during the image analysis [Fig. 4.3]. All isolation and quantification steps were carried out at the same temperature as the fragment had been previously exposed to, by using the control unit on the confocal microscope stage.

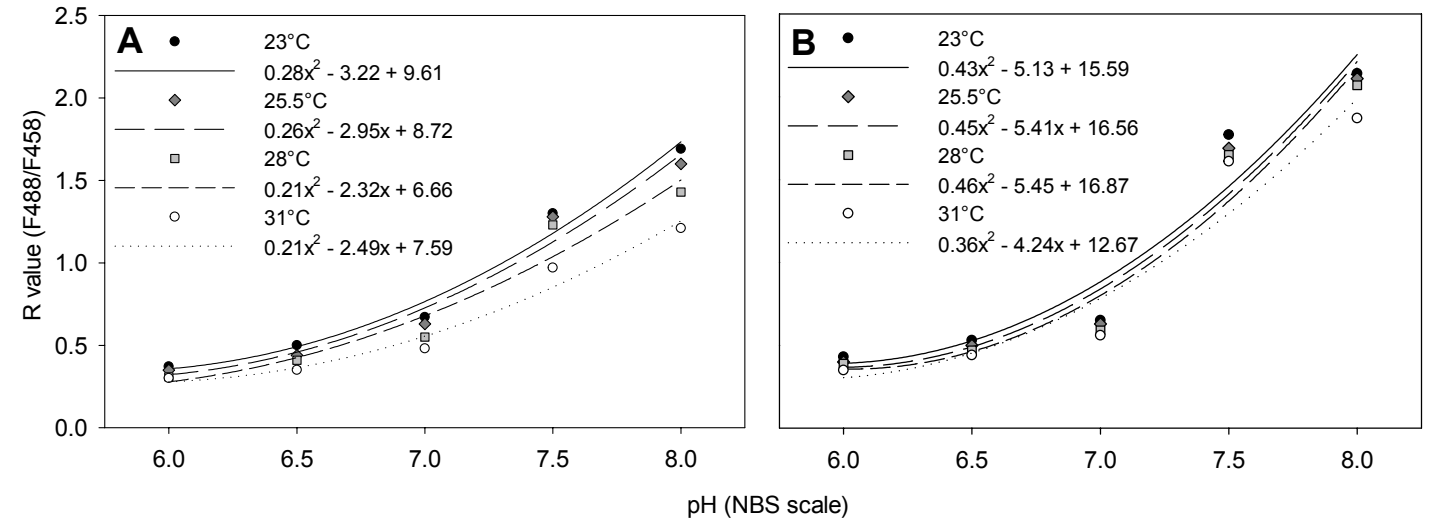

Fig. 4.3 Temperature-sensitive calibration of intracellular $\mathrm{pH}$ in (A) host coral cell and (B) symbiont cells isolated from the coral $P$. damicornis using the fluorescent dye BCECF-AM ester. Preliminary experiments determined no difference in the response of the dye between $P$. damicornis and M. capitata cells, but did detect a small reduction in the ratio of fluorescence emission, $\mathrm{R}\left(\mathrm{F}_{488} / \mathrm{F}_{458}\right)$ at high temperature. As such, we calculated and applied individual calibration curves for each temperature (equations plotted on the graphs above).

\subsubsection{Statistical analysis}

Symbiodinium cell density and the amount of chl- $a$ per cell were analysed by a twoway analysis of variance (ANOVA) with species (two levels) and temperature (four levels) as fixed factors. A three-way ANOVA with species (two levels), cell type (host or symbiont) and temperature (four levels) was used to examine the response of $\mathrm{pH}_{\mathrm{i}}$. All data met the assumptions of normality stated by the Kolgomorov-Smirnov Test and for each dataset, the homogeneity of variance was verified by Levene's test. 


\subsection{Results}

Symbiont density differed between the two coral species, regardless of the temperature treatment $\left(\mathrm{F}_{(1,40)}=65.310, \mathrm{P}<0.001\right)$. Indeed, the mean density of symbionts per $\mathrm{cm}^{2}$ in $M$. capitata was almost double that of $P$. damicornis in ambient seawater temperatures [Fig. 4.4A]. P. damicornis fragments paled markedly after exposure to the highest temperature [Appendix; A.3], losing an average of $70 \%$ of their symbionts relative to controls. In contrast, M. capitata lost an average of just 7\% of their symbionts. Despite this difference, there was no significant effect of temperature or species-temperature interaction on symbiont density [Table 4.1]. High temperatures did, however, cause a significant decline in the chl- $a$ content per symbiont cell $\left(\mathrm{F}_{(3,40)}=4.023, \mathrm{P}=0.015\right)$, consistent with pigment degradation as a result of damage to the photosystem II complex, and specifically the oxygen-evolving complex, the thylakoid membranes, and the D1 protein/D1 protein repair mechanism. More precisely, the highest temperature caused a $74 \%$ and $15.4 \%$ reduction in the cell-specific chl- $a$ content in $P$. damicornis and M. capitata, respectively (Tukey's HSD, $\mathrm{P}=0.011$ ), with the response to temperature being significantly different between species $\left(\mathrm{F}_{(1,40)}=5.804, \mathrm{P}=0.022\right)$; again the species-temperature interaction was not significant however [Table 4.1].

The importance of thermal resilience in determining $\mathrm{pH}_{\mathrm{i}}$ became apparent under $\mathrm{CO}_{2}$ addition. Symbiont and host cells in $P$. damicornis were much more susceptible to cellular acidosis than their counterparts in M. capitata [Fig. 4.4C; Table 4.1]. In fact, the magnitude of acidosis was almost double in cells isolated from P. damicornis. On average, when incubated at $\mathrm{pH}_{\mathrm{e}}$ 7.6, the $\mathrm{pH}_{\mathrm{i}}$ of isolated $P$. damicornis host cells was $7.403 \pm 0.072$ at $23.8^{\circ} \mathrm{C}$ compared to $6.555 \pm 0.025$ at $31^{\circ} \mathrm{C}$, a decline of $0.85 \mathrm{pH}_{\mathrm{i}}$ units. A similar pattern was observed in the symbiont cell, where $\mathrm{pH}_{\mathrm{i}}$ was $7.448 \pm$ 0.023 at $23.8^{\circ} \mathrm{C}$ versus $6.744 \pm 0.012$ at $31^{\circ} \mathrm{C}$. In contrast, this $\sim 7^{\circ} \mathrm{C}$ increase in temperature caused a $0.4 \mathrm{pH}_{\mathrm{i}}$ unit decline in M.capitata host cells (from $\mathrm{pH}_{\mathrm{i}} 7.348 \pm$ 0.068 to $6.946 \pm 0.045$ ), and had even less of an effect on the $\mathrm{pH}_{\mathrm{i}}$ of the symbiont, which dropped $0.3 \mathrm{pH}_{\mathrm{i}}$ units from $7.436 \pm 0.043$ at $23.8^{\circ} \mathrm{C}$ to $7.138 \pm 0.034$ at $31^{\circ} \mathrm{C}$. 

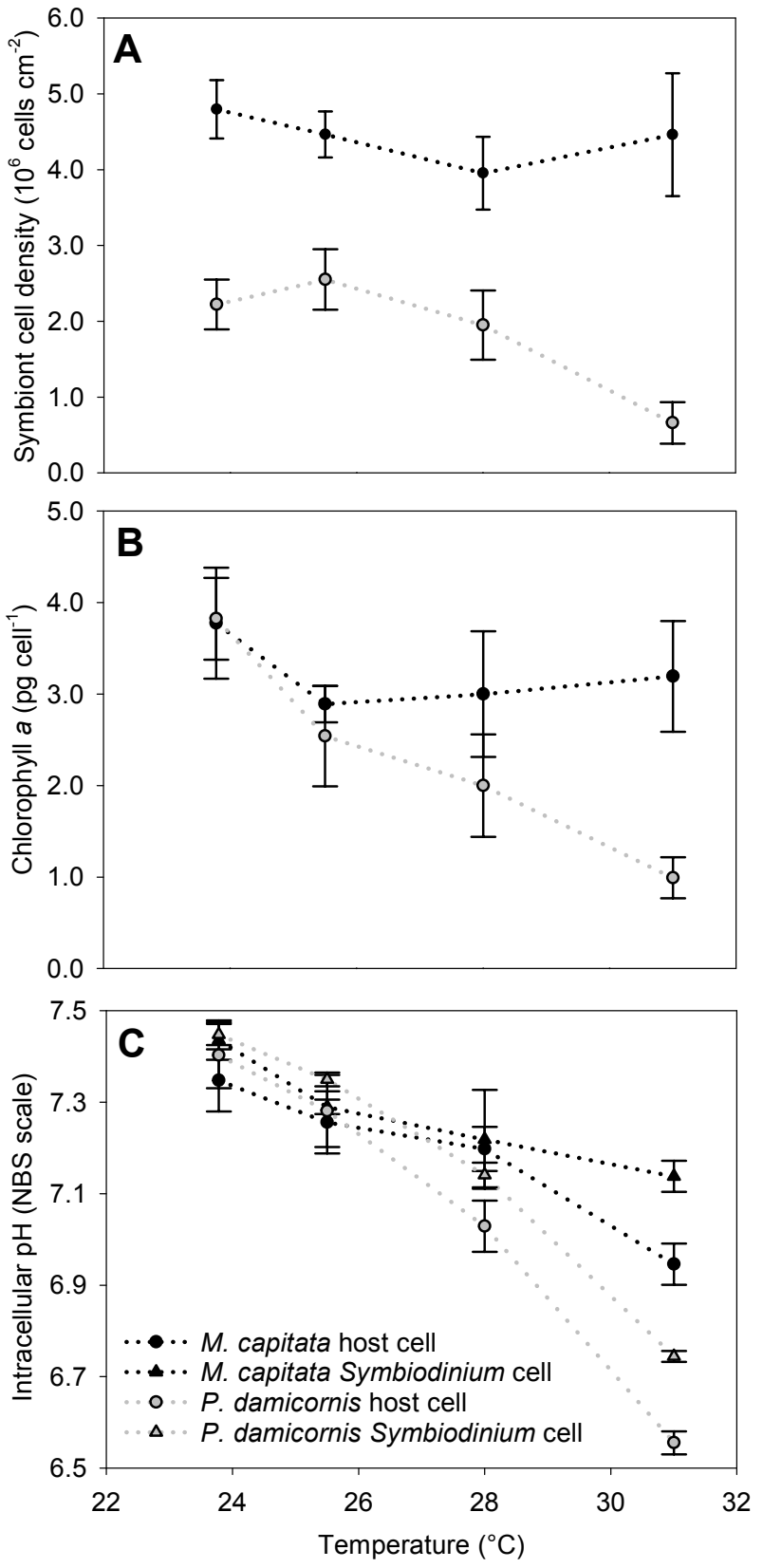

Fig. 4.4 Effect of temperature on [A] symbiont density $\left(10^{6}\right.$ cells $\left.\mathrm{cm}^{-2}\right)$, [B] chlorophyll- $a$ content per symbiont (pg cell ${ }^{-1}$ ) and [C] light-adapted intracellular $\mathrm{pH}$ (NBS scale) of host endodermal cells (circles) and Symbiodinium cells within host cells (triangles) following exposure to $\mathrm{CO}_{2}$-addition for half an hour (resulting in a $0.3 \mathrm{pH}$ unit drop in the external $\mathrm{pH}$ from 7.9 to 7.6) in two coral species, Montipora capitata (black) and Pocillopora damicornis (grey). Values represent mean \pm S.E.M for $\mathrm{n}=5$ independent replicates. 
Table 4.1 Two-way ANOVA results comparing the density of Symbiodinium cells per $\mathrm{cm}^{2}$ of coral surface area and the chlorophyll- $a$ content per symbiont cell in two species (Pocillopora damicornis and Montipora capitata) that were exposed to four temperatures $(23.8,25.5,28$, and $31^{\circ} \mathrm{C}$ ), and the results of a three-way ANOVA examining how cell type (host or symbiont), temperature and host species influence intracellular $\mathrm{pH}$. Where appropriate, significant differences were explored further by a Tukey's post hoc test. Asterisks denote significant interactions $(* \mathrm{p}<0.05, * * \mathrm{p}<0.001)$.

\begin{tabular}{|c|c|c|c|c|c|}
\hline Variable & Analysis & $\begin{array}{c}\text { Interaction } \\
\text { term }\end{array}$ & F-value & P-value & Tukey's test \\
\hline \multirow{3}{*}{$\begin{array}{l}\text { Symbiodinium } \\
\text { cells } \mathrm{cm}^{-2}\end{array}$} & \multirow{3}{*}{$\begin{array}{l}\text { Two-way } \\
\text { ANOVA }\end{array}$} & Species & $\mathrm{F}_{1,32}=65.310$ & $<0.001 * *$ & \\
\hline & & Temperature & $F_{3,32}=1.849$ & 0.158 & \\
\hline & & $\begin{array}{c}\text { Species } \times \\
\text { Temperature }\end{array}$ & $\mathrm{F}_{3,32}=1.634$ & 0.201 & \\
\hline \multirow{3}{*}{$\begin{array}{l}\text { Chlorophyll-a } \\
\text { pg cell }^{-1}\end{array}$} & \multirow{3}{*}{$\begin{array}{l}\text { Two-way } \\
\text { ANOVA }\end{array}$} & Species & $\mathrm{F}_{1,32}=5.804$ & $0.022 *$ & \multirow{3}{*}{$\begin{array}{c}23.8=25.5=28> \\
31.5^{\circ} \mathrm{C}\end{array}$} \\
\hline & & Temperature & $\mathrm{F}_{3,32}=4.023$ & $0.015^{*}$ & \\
\hline & & $\begin{array}{c}\text { Species } \times \\
\text { Temperature }\end{array}$ & $\mathrm{F}_{3,32}=1.832$ & 0.161 & \\
\hline \multirow{7}{*}{$\begin{array}{c}\text { Intracellular } \\
\mathrm{pH}\end{array}$} & \multirow{7}{*}{$\begin{array}{c}\text { Three-way } \\
\text { ANOVA }\end{array}$} & Species & $\mathrm{F}_{1,64}=21.507$ & $<0.001 * *$ & \multirow{7}{*}{$\begin{array}{c}23.8>25.5>28> \\
31.5^{\circ} \mathrm{C}\end{array}$} \\
\hline & & Cell type & $\mathrm{F}_{1,64}=15.662$ & $<0.001 * *$ & \\
\hline & & Temperature & $\mathrm{F}_{3,64}=105.569$ & $<0.001 * *$ & \\
\hline & & $\begin{array}{l}\text { Species } \times \\
\text { Cell type }\end{array}$ & $\mathrm{F}_{1,64}=0.171$ & 0.680 & \\
\hline & & $\begin{array}{c}\text { Species } \times \\
\text { Temperature }\end{array}$ & $\mathrm{F}_{3,64}=18.311$ & $<0.001 * *$ & \\
\hline & & $\begin{array}{l}\text { Cell type } \times \\
\text { Temperature }\end{array}$ & $\mathrm{F}_{3,64}=1.910$ & 0.137 & \\
\hline & & $\begin{array}{c}\text { Species } \times \\
\text { Cell type } \times \\
\text { Temperature }\end{array}$ & $\mathrm{F}_{3,64}=0.372$ & 0.773 & \\
\hline
\end{tabular}




\subsection{Discussion}

The goal of this study was to induce thermal stress in corals with differing bleaching susceptibilities, to measure how reduced photosynthetic performance impacts the $\mathrm{pH}_{\mathrm{i}}$ of both symbiont and host cells. The results of this study suggest that there is a clear link between temperature and sensitivity to cellular acidosis under acidification. Here, I argue that the $\mathrm{pH}_{\mathrm{i}}$ response observed under the high temperature treatment results from photosynthetic dysfunction in the symbiont, primarily by photo-inhibition and/or the degradation of chlorophyll- $a$.

The mechanism involved in regulating $\mathrm{pH}_{\mathrm{i}}$ under $\mathrm{CO}_{2}$-addition is likely to be similar to that described in Chapter 3, regardless of the temperature that the coral fragment was exposed to. Briefly, acidosis is likely to arise from the passive diffusion of $\mathrm{CO}_{2}$ into the cell. Once in the cytoplasm, $\mathrm{CO}_{2}$ dissociates into the intermediate compound carbonic acid $\left(\mathrm{H}_{2} \mathrm{CO}_{3}\right)$, and then further into bicarbonate $\left(\mathrm{HCO}_{3}{ }^{-}\right)$and $\mathrm{H}^{+}$, so creating a more acidic environment. Under 'normal' temperature conditions, photosynthesis removes some of the $\mathrm{CO}_{2}$, keeping the $\mathrm{pH}_{\mathrm{i}}$ constant or at least mitigating the influx of $\mathrm{H}^{+}$(Furla et al., 2000). Reductions in cell-specific chl- $a$ content and/or damage to PSII, however, reduce the activity and efficiency of photosynthesis (Iglesias-Prieto et al., 1992; Fitt and Warner, 1995; Warner et al., 1996; Jones et al., 2000; RodolfoMetalpa et al., 2006), thus preventing the removal of $\mathrm{CO}_{2}$ and hence $\mathrm{H}^{+}$, increasing the potential for cellular acidosis. The physiological responses of the two corals were markedly different, with a significant reduction in the symbiont cell-specific chl- $a$ content observed in P. damicornis but not in M. capitata, which could explain why cells isolated from the thermally sensitive P. damicornis showed less capacity to buffer against acidification than their counterparts in $M$. capitata. The degradation of algal pigments reflects damage to the photosystem II complex (Takahashi et al., 2004; Lesser 2011; Hill et al., 2012; Bhagooli, 2013), specifically affecting the oxygenevolving complex (Becker et al., 1990), the thylakoid membranes (Tchernov et al., 2004), and the D1 protein/D1 protein repair mechanism (Warner et al., 1999; Takahashi et al., 2004). Pigmentation loss and the expulsion of algal cells are not mutually exclusive in the bleaching response; a reduction in chlorophyll content can occur with or without a reduction in algal density (Hoegh-Guldberg and Smith, 1989; 
Kleppel et al., 1989; Porter et al., 1989; Lesser et al., 1990), but the outcome for $\mathrm{pH}_{\mathrm{i}}$ is the same; anything that disrupts the removal of $\mathrm{CO}_{2}$ will reduce a cell's ability to buffer changes in external $\mathrm{pH}\left(\mathrm{pH}_{\mathrm{e}}\right)$.

The impact of thermal stress on $\mathrm{pH}_{\mathrm{i}}$ may not only be related to the removal of $\mathrm{CO}_{2}$ and $\mathrm{H}^{+}$through photosynthesis, however, as a cell's capacity to regulate its $\mathrm{pH}_{\mathrm{i}}$ may be directly impacted by elevated temperature. Cellular acidosis is a common response to thermal stress in non-photosynthetic organisms, and is strongly linked to both oxidative stress and metabolic activity (Pörtner et al., 1999; Sartoris et al., 2003; Strobel et al., 2013). For example, exposure to temperatures $4^{\circ} \mathrm{C}$ above control levels caused a decline in $\mathrm{pH}_{\mathrm{i}}$ of $0.2 \mathrm{pH}$ units in the mantle tissue of the bivalve Limopsis marionensis (Pörtner et al., 1999), while $\mathrm{pH}_{\mathrm{i}}$ in the gill arches of the Atlantic cod Gadus morhua decreased by $0.025 \mathrm{pH}$ units per ${ }^{\circ} \mathrm{C}$ increase (Sartoris et al., 2003). There may be parallels between the responses observed in these studies and the acidosis observed here in coral cells, as oxidative stress and the increased formation of ROS are key components of coral bleaching (Lesser, 2006), causing significant damage to homeostatic mechanisms such as acid-base regulation (Strobel et al., 2013), non-photochemical quenching (Gorbunov et al., 2001) and antioxidant defense (Császár et al., 2009). Almost all cellular processes are up-regulated under thermal stress in accordance with Michaelis-Menten kinetics, leading to a shift in metabolic activity and an increase in ATP-demand (Lesser et al., 1997; DeSalvo et al., 2008; Seneca et al., 2010). Given this, the energy gained from photosynthesis in corals could play an important role in enabling both the host and symbiont to regulate their $\mathrm{pH}_{\mathrm{i}}$ and counter changes in the $\mathrm{pH}_{\mathrm{e}}$. Indeed, under 'normal' conditions, the energy required to regulate $\mathrm{pH}_{\mathrm{i}}$ relative to the energy gained from photosynthesis is minor; buffering a $0.4 \mathrm{pH}_{\mathrm{e}}$ unit decrease for example, is estimated to cost between 1-2 $\mathrm{kJ}$ $\mathrm{mol}^{-1} \mathrm{C}$, just a fraction of the $\sim 475 \mathrm{~kJ} \mathrm{~mol}^{-1} \mathrm{C}$ produced during photosynthesis (McCulloch et al., 2012). Amid the photosynthetic dysfunction and physiological disorder caused by thermal stress in corals, however, meeting the additional energy demand is likely to be far more problematic.

The mechanism(s) described here could partly explain why interactions between the two stressors are antagonistic - i.e. elevated temperatures compound the effect of 
ocean acidification (Anthony et al., 2008; Martin and Gattuso, 2009; Anlauf et al., 2011; Rodolfo-Metalpa et al., 2011; Gao et al., 2012; Byrne and Przeslawski, 2013). Such an inter-relationship has been reported previously for corals and other phototrophic organisms (Hendriks et al., 2010; Kroeker et al., 2010; Kroeker et al., 2013). For example, necrosis in the crustose coralline alga Lithophyllum cabiochae was initiated by exposure to high temperature but not $\mathrm{CO}_{2}$-addition; the cumulative effect of both, however, was a two- to threefold increase in mortality (Martin and Gattuso, 2009). A similar relationship has been observed in both adult and juvenile corals (Manzello, 2010; Anlauf et al., 2011; Rodolfo-Metalpa et al., 2011), though not in all species (e.g. the coral Cladocora caespitosa) (Rodolfo-Metalpa et al., 2010). At a community level, the two stressors are likely to reduce the resilience of the reef, leading to a reduction in coral cover, structural complexity and biodiversity (Jokiel et al., 2008; Anthony et al., 2011; Hale et al., 2011). Future work should incorporate corals from across the thermal-tolerance spectrum, to clarify the role of thermal resilience in determining the response to $\mathrm{CO}_{2}$. Ideally, this research would encompass a range of coral morphologies and Symbiodinium genotypes, both of which can influence thermal sensitivity (Rowan et al., 1997; Rowan, 2004; Jimenez et al., 2008; van Oppen et al., 2009; Fabricius et al., 2006; Sampayo et al., 2008; Jimenez et al., 2011). Furthermore, longer-term experiments are needed to test for recovery from and adaptation to the environmental changes applied in this study. Together, these approaches will better enable the modeling and prediction of how coral reefs will respond to future, combined warming and acidification scenarios. 


\section{Chapter 5: The photo-physiological response of a model cnidarian-dinoflagellate symbiosis to $\mathrm{CO}_{2}$-induced acidification at the cellular level}

\subsection{Introduction}

At 380 ppm, present-day atmospheric $\mathrm{CO}_{2}$ concentrations are higher than at any point in the past 740,000 years (Hoegh-Guldberg et al., 2007), and are predicted to reach 500-1,000 ppm by 2100 (Vuuren et al., 2011). It is estimated that approximately one third of all anthropogenic $\mathrm{CO}_{2}$ is sequestered by the oceans (Sabine et al., 2004). This continuous dissolution of $\mathrm{CO}_{2}$ lowers the $\mathrm{pH}$ of seawater and alters the speciation of dissolved inorganic carbon (DIC), in a process known as ocean acidification. Such changes are of great concern for marine ecosystems, but are particularly pertinent for those in which calcifying organisms play a major role (Fabry, 2008). Coral reefs, therefore, which are recognised for their high diversity and productivity (Bellwood and Hughes, 2001), have received considerable attention (Hall-Spencer et al., 2008; Fabricius et al., 2011; Crook et al., 2012). Predicting the response of reef-building corals to ocean acidification is complicated by the presence of the single-celled photosynthetic dinoflagellates (genus Symbiodinium) that they harbour within their gastrodermal tissue layer. The photosynthetic products that are supplied by these dinoflagellate symbionts are of great metabolic importance to their host, facilitating growth, reproduction and, ultimately, survival (Muscatine, 1990). Therefore, the adaptive capacity of corals is not only determined by the responses of the host but also those of the symbionts it contains (McCulloch et al., 2012). Understanding the cellular mechanisms that underpin the complex inter-relationship between the symbiont and host is a vital step towards understanding why the physiological response to $\mathrm{CO}_{2}$-addition differs so substantially between species (Anthony et al., 2008; Ries et al., 2009; Kroeker et al., 2010; Pandolfi et al., 2011). Of specific interest is characterising the response of intracellular $\left(\mathrm{pH}_{\mathrm{i}}\right)$ to ocean acidification (Schneider and Erez, 2006; Brownlee, 2009).

Acid-base regulation is an essential facet of cellular metabolism in all organisms (Busa and Nuccitelli, 1984), but is particularly important for symbiotic anthozoan cells that are subjected to significant fluctuations in $\mathrm{pH}_{\mathrm{i}}$ through the photosynthetic 
and respiratory activity of their symbionts (Venn et al., 2009; Laurent et al., 2013a). Deviation from the optimal $\mathrm{pH}_{\mathrm{i}}$, a process known as acidosis, often leads to cellular dysfunction (Pörtner et al., 2004), and while short-term acidosis can typically be recovered from (Fabry, 2008), longer periods of exposure can result in metabolic depression (Reipschläger and Pörtner, 1996) and reduced rates of protein synthesis (Hand, 1991), which are detrimental to fitness. Little is currently known about how the cnidarian-dinoflagellate symbiosis might respond to $\mathrm{CO}_{2}$-induced acidification at the cellular level. Indeed, there has been just one study to focus on this, in which short-term experimental perfusions $(<2 \mathrm{~h})$ of isolated, symbiotic gastrodermal cells from the sea anemone $A$. viridis in $\mathrm{HCl}$-acidified seawater (Laurent et al., 2013b). The results of this study revealed no detrimental effects on the $\mathrm{pH}_{\mathrm{i}}$ of the host cell. On the contrary, there is growing evidence that increased $\mathrm{CO}_{2}$ availability associated with ocean acidification could enhance primary productivity in Symbiodinium (Marubini et al., 2008; Brading et al., 2011; Suggett et al., 2012; Towanda and Thuesen, 2012; Jarrold et al., 2013), which could limit the potential for host cell acidosis (Chapter 3). This photosynthetically driven up-regulation of $\mathrm{pH}_{\mathrm{i}}$ under high $\mathrm{CO}_{2}$ has been postulated as one potential mechanism for countering the negative impacts of acidification on coral calcification (Ries et al., 2009). Yet, to date, no study has examined the longer-term impacts of $\mathrm{CO}_{2}$-addition on both host and symbiont $\mathrm{pH}_{\mathrm{i}}$ in the cnidarian-dinoflagellate symbiosis. This is an essential step if we are to fully appreciate the impacts that ocean acidification might have on this ecologically important association.

In this chapter, I investigate the relationship between photo-physiology and $\mathrm{pH}_{\mathrm{i}}$ under long-term $\mathrm{CO}_{2}$ addition. To achieve this, the sea anemone Aiptasia pulchella a model system for the study of cnidarian-dinoflagellate symbiosis (Weis et al., 2008), was exposed to conditions representative of the intermediate (520-700 ppm) and high-end (1000-1300 ppm) $\mathrm{CO}_{2}$ stabilisation scenarios (IPCC, 2014), over a two-month period. A suite of physiological responses were quantified at regular intervals: maximum dark-adapted fluorescent yield of PSII $\left(\mathrm{F}_{\mathrm{v}} / \mathrm{F}_{\mathrm{m}}\right)$, gross photosynthetic rate, respiration rate, symbiont population density, and $\mathrm{pH}_{\mathrm{i}}$ of both the dinoflagellate symbiont and host anemone. This study tested the prediction that, rather than causing cellular acidosis, the addition of $\mathrm{CO}_{2}$ would enhance photosynthetic performance, enabling both the host-symbiont association to withstand future ocean acidification scenarios. 


\subsection{Methods}

\subsubsection{Experimental organisms}

A long-term aquarium stock of the sea anemone A. pulchella, originating from an unknown location in the Pacific, was grown at $25{ }^{\circ} \mathrm{C}$ under a $12 \mathrm{~h}$ light: $12 \mathrm{~h}$ dark cycle, with $80-100 \mu \mathrm{mol}$ photons $\mathrm{m}^{-2} \mathrm{~s}^{-1}$ provided by cool white fluorescent lamps (Osram Dulux 36W/890 fluorescent bulbs), and fed freshly-hatched Artemia sp. nauplii every 3 days. These anemones contain Symbiodinium ITS2 type B1 (Chapter 2). One month prior to experimentation, 300 anemones (oral disc $\sim 1 \mathrm{~cm}$ diameter) were randomly selected and transferred to 2-L glass beakers (20 individuals per beaker) containing $1 \mu \mathrm{m}$ filtered seawater. The beakers were split evenly between three water baths (i.e. $n=5$ independent beakers per water bath), under the same light and temperature conditions described above. During this acclimation period, water was changed daily to ensure that $\mathrm{pH}(8.1 \pm 0.1)$ and salinity $(35.5 \pm 0.1 \mathrm{ppt})$ were kept constant. Nutrient concentrations were not monitored during the experiment, but levels are typically low (dissolved inorganic nitrogen (DIN) levels are approximately $\sim 2 \mu \mathrm{M}, \mathrm{NH}_{3}$ and $\mathrm{NO}_{3}{ }^{-} \sim 1 \mu \mathrm{M}, \mathrm{NO}_{2}{ }^{-}$and $\left.\mathrm{PO}_{4}{ }^{3-}<1 \mu \mathrm{M}\right)$, and relatively stable in the coastal waters around Wellington, New Zealand, from the seawater collection point (Dudley and Shima, 2010). Tanks were cleaned weekly and water temperatures were monitored using HOBO data loggers (Onset Corporation, Bourne, MA, USA).

\subsubsection{Experimental design}

Anemones were exposed to three $\mathrm{pH}$ treatments over a two-month period: $8.14 \pm$ $0.01,7.83 \pm 0.01$ and $7.54 \pm 0.02$ [Table 5.1]. These values correspond to $p \mathrm{CO}_{2}$ concentrations of $289.94 \pm 12.54 \mu \mathrm{atm}, 687.40 \pm 25.10 \mu \mathrm{atm}$ and $1459.92 \pm 65.51$ $\mu$ atm, respectively. Photosynthesis caused the seawater $\mathrm{pH}$ to fluctuate by $\sim 0.1 \mathrm{pH}$ unit over 24 hours, so water changes were performed daily. Addition of gaseous $\mathrm{CO}_{2}$ to seawater was performed in a 50-L black plastic reservoir, via a $\mathrm{CO}_{2}$ solenoid valve connected to a PINPOINT pH controller (American Marine Inc., Ridgefield, CT, USA). The final $\mathrm{pH}$ of the seawater was checked with an independent $\mathrm{pH}$ probe, adjusted accordingly if needed, and recorded before being added to the beakers. In addition to this, $\mathrm{pH}$ readings were taken daily before the water change, to provide a 
full record of the $\mathrm{pH}$ experienced in each beaker [Fig. 5.1]. Anemones were haphazardly selected for sampling at $0,1,2,4,6$ and 8 weeks. Not all of the anemones placed in each beaker were sampled during the experiment. At each timepoint, two anemones were removed from each beaker. One was used to quantify symbiont $\mathrm{pH}_{\mathrm{i}}$, in addition to a suite of photo-physiological parameters (described below), and the other was used to determine the host cell $\mathrm{pH}_{\mathrm{i}}$.

Table 5.1 Summary of the carbonate chemistry of the control and experimental $\mathrm{pH}$ treatments. $\mathrm{pH}$ and temperature were measured directly, with total alkalinity (TA) measurements provided by the National Institute of Water and Atmospheric Research (NIWA), NZ. The remaining carbon parameters were estimated using the program CO2SYS (Lewis and Wallace, 1998). Values represent daily mean \pm S.E.M $(n=60)$.

\begin{tabular}{|c|c|c|c|c|}
\hline $\begin{array}{c}\mathrm{pH} \\
\text { (NBS-Scale) }\end{array}$ & $\begin{array}{c}\text { Temperature } \\
\left({ }^{\circ} \mathrm{C}\right)\end{array}$ & $\begin{array}{c}\text { TA } \\
(\mu \mathrm{mol} \mathrm{kg-1)}\end{array}$ & $\mathrm{pCO}_{2}$ ( $\left.\mu \mathrm{atm}\right)$ & $\begin{array}{c}\mathrm{HCO}_{3} \\
\left.(\mu \mathrm{mol} \mathrm{kg})^{-1}\right)\end{array}$ \\
\hline $8.14 \pm 0.02$ & $25.46 \pm 0.07$ & $2258.81 \pm 4.06$ & $289.94 \pm 1.77$ & $1648.40 \pm 2.52$ \\
\hline $7.84 \pm 0.02$ & $25.78 \pm 0.06$ & $2258.81 \pm 4.06$ & $687.40 \pm 3.55$ & $1909.89 \pm 1.58$ \\
\hline $7.57 \pm 0.02$ & $25.84 \pm 0.06$ & $2258.81 \pm 4.06$ & $1459.92 \pm 9.27$ & $2066.22 \pm 1.18$ \\
\hline
\end{tabular}

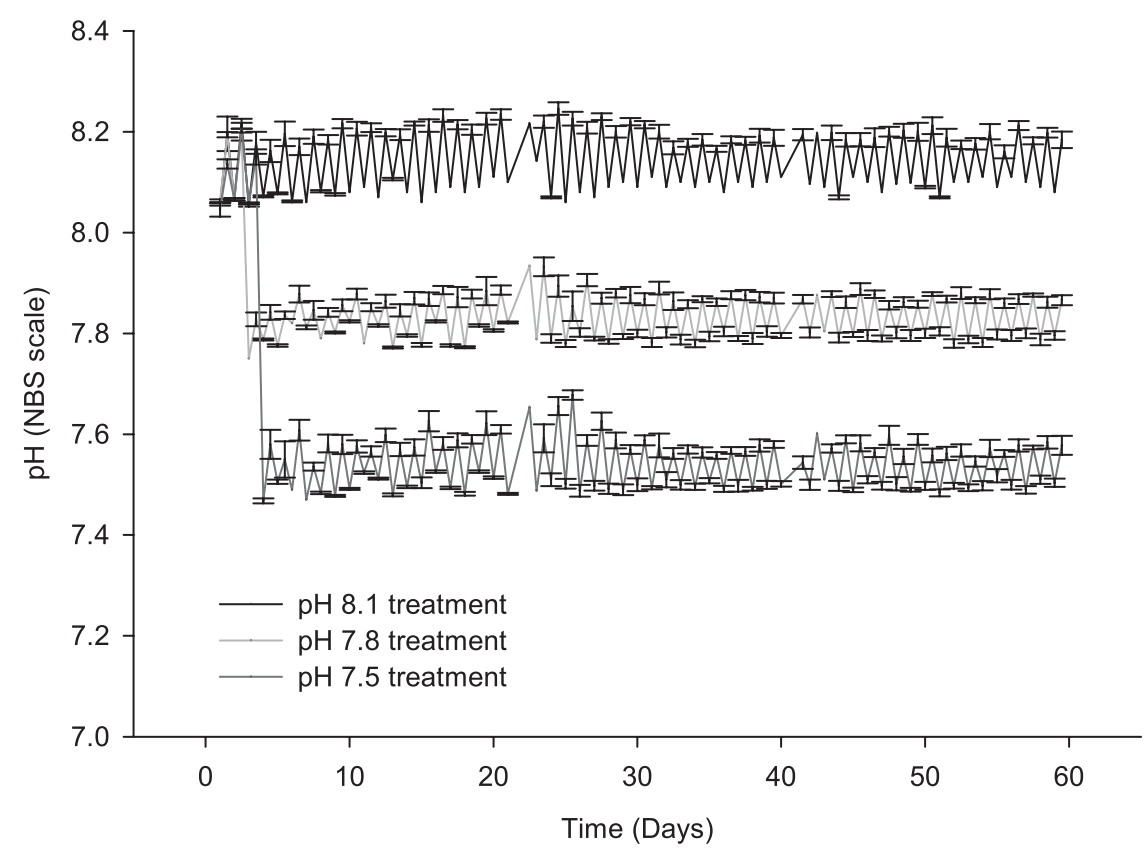

Fig. 5.1 Record of the $\mathrm{pH}$ changes in each beaker for the duration of the two-month experiment. These values represent the mean seawater $\mathrm{pH} \pm$ S.E.M $(n=5$ per treatment, $n=3$ treatments), upon addition to and 24-h after addition to the experimental beakers. 


\subsubsection{Photo-physiological responses}

Maximum dark-adapted yield of PSII $\left(\mathrm{F}_{\mathrm{v}} / \mathrm{F}_{\mathrm{m}}\right)$ of each anemone was measured $30 \mathrm{~min}$ before the lights were switched on, using pulse amplitude modulated fluorometry (Diving-PAM, Walz, Effeltrich, Germany; settings: measuring light $=8$, saturation intensity $=8$, saturation width $=0.8 \mathrm{~s}$, gain $=5$ and damping $=2$ ). Triplicate measurements were performed for each anemone, with readings taken $1 \mathrm{~cm}$ immediately above the oral disc, and 45 degrees either side of this point. Anemones were then placed singly with $0.22 \mu \mathrm{m}$ filtered seawater (FSW) into a $10-\mathrm{mL}$ glass chamber, and left to settle for an hour; this was sufficient time for attachment to a thin nylon mesh grid that overlaid a magnetic spin-bar. A glass lid, held in place by a rubber O-ring, sealed the chamber, into which a temperature probe and an oxygen electrode (FIBOX 3 - fiber-optic oxygen meter, PreSens, GmbH, Germany) were inserted such that both probes were positioned $\sim 1 \mathrm{~cm}$ above the anemone's oral disc. The chamber was then wrapped in aluminium foil to ensure that no light could enter and placed on top of a submersible magnetic stirrer, itself placed in a transparent water bath set to $25^{\circ} \mathrm{C}$. Respiratory oxygen consumption $\left(\mathrm{R} ; \mathrm{mL} \mathrm{O}_{2} \mathrm{~h}^{-1}\right.$ ) was measured every $10 \mathrm{sec}$ in darkness until a constant rate was observed (normally after $\sim 30 \mathrm{~min}$ ). The foil was then removed and the chamber illuminated at $400 \mu \mathrm{mol}$ photons $\mathrm{m}^{-2} \mathrm{~s}^{-1}$ by a $150 \mathrm{~W}$ sealed beam PAR38 lamp (Thorn Lighting Ltd., Durham, UK). This light level was chosen because it is well above the photosynthesissaturating irradiance for $A$. pulchella, which is typically between 200 and $250 \mu \mathrm{mol}$ photons $\mathrm{m}^{-2} \mathrm{~s}^{-1}$ (Muller-Parker, 1984) but is not high enough to cause photoinhibition, which usually begins at irradiances greater than $600 \mu \mathrm{mol}$ photons $\mathrm{m}^{-2} \mathrm{~s}^{-1}$ in this anemone (Lesser and Shick, 1989). Net photosynthetic oxygen evolution $\left(\mathrm{P}_{\text {net }}\right)$ was then measured until a constant rate was observed. Gross photosynthesis $\left(\mathrm{P}_{\text {gross }}\right)$ was calculated by adding $\mathrm{P}_{\text {net }}$ to $\mathrm{R}$, and the resulting values were used to determine the $\mathrm{P}_{\text {gross }}: \mathrm{R}$ ratio for each anemone on an idealized day (assuming $12 \mathrm{~h}$ light and $12 \mathrm{~h}$ dark), a proxy for autotrophic potential. It was assumed that $\mathrm{R}$ in the light was the same as in the dark (i.e. total daily respiration $=\mathrm{R} \times 24 \mathrm{~h}$ ). After the $\mathrm{O}_{2}$-flux measurements were complete, each anemone was then placed in a $1.5-\mathrm{mL}$ microcentrifuge tube and homogenised in $1.1 \mathrm{~mL}$ FSW using a plastic tissue grinder. From the resulting slurry, a $100 \mu \mathrm{L}$ aliquot was removed, and frozen at $-20^{\circ} \mathrm{C}$. This 
was later used to determine symbiont density ( $n=6$ counts per sample) using an Improved Neubauer haemocytometer (Boeco, Hamburg, Germany). The remaining 1 $\mathrm{mL}$ was centrifuged for $5 \mathrm{~min}$ at $1,000 \times g$ to separate the algal fraction from host tissue. Once isolated, the host supernatant was decanted and stored at $-20^{\circ} \mathrm{C}$ prior to analysis of the host protein content, using the Bradford assay (Bradford, 1976) and bovine serum albumin (BSA) as the standard. These values were subsequently used to normalise $\mathrm{P}_{\text {gross }}, \mathrm{R}$ and symbiont density values. The remaining algal pellet was resuspended in FSW at a final density of $1 \times 10^{6}$ cells $\mathrm{mL}^{-1}$, for analysis of symbiont $\mathrm{pH}_{\mathrm{i}}$ (see below). Light-adapted symbiont $\mathrm{pH}_{\mathrm{i}}$ and light-adapted host cell $\mathrm{pH}_{\mathrm{i}}$ were quantified according to the protocol described in Chapter 2.

\subsubsection{Statistics}

Repeated measures analysis of variance (rmANOVA) was used to test the response of each variable to $\mathrm{pH}$ over time. Post hoc analyses represent Bonferroni-corrected pairwise comparisons of estimated marginal means between each of the two enhanced$\mathrm{CO}_{2}$ treatments and the ambient $\mathrm{CO}_{2}$ control at a particular time-point. Epsilonadjusted Greenhouse-Geisser (G-G) values are reported whenever Mauchly's Sphericity Test returned a significant result. Linear regression analyses were performed to evaluate the relationship between symbiont and host $\mathrm{pH}_{\mathrm{i}}$. Data were examined for normality prior to parametric analysis using the Shapiro-Wilk Test, and were transformed where necessary to satisfy these requirements. All data were analysed using the PASW Statistics 20.0 package (IBM, Armonk, NY, USA).

\subsection{Results}

\subsubsection{Photo-physiological responses to $\mathrm{CO}_{2}$ addition}

In general, the addition of $\mathrm{CO}_{2}$ caused a significant increase in all but one of the photo-physiological parameters measured ( $\mathrm{P}_{\text {gross }}$ : $\mathrm{R}$ ratio) [Table 5.2]. Typically these increases were detected within 2-3 weeks of $\mathrm{CO}_{2}$ addition, and in most cases the increased response appeared to be proportional to the amount of $\mathrm{CO}_{2}$ added [Fig. 5.2]. However, in some cases, the full treatment effect was not fully apparent until week 8. 
Table 5.2 Statistical analysis of the response variables in Aiptasia pulchella when exposed to different $\mathrm{pH}$ treatments for two months. The F-statistic represents the overall rmANOVA interaction (time $\times \mathrm{pH}$ treatment) for each parameter and asterisks denote statistical significance at $* \mathrm{p}<0.05$ or $* * \mathrm{p}<0.001$.

\begin{tabular}{|ccc|}
\hline Response variable & F-statistic & P-value \\
\hline Symbiont density $\left(\times 10^{6}\right.$ cells $\mathrm{mg}^{-1}$ protein $)$ & $\mathrm{F}_{10,60}=5.006$ & $<0.001^{* *}$ \\
Max. Quantum yield $\left(\mathrm{F}_{\mathrm{v}} / \mathrm{F}_{\mathrm{m}}\right)$ & $\mathrm{F}_{10,60}=2.088$ & $0.039^{*}$ \\
$\mathrm{P}_{\text {gross }}\left(\mu \mathrm{g} \mathrm{O}_{2} \mathrm{mg}^{-1}\right.$ protein $\left.{ }^{-1}\right)$ & $\mathrm{F}_{3.90,23.403}=11.181$ & $<0.001^{* *}$ \\
$\mathrm{P}_{\text {gross }}\left(\mathrm{pg} \mathrm{O}_{2} \mathrm{cell}^{-1} \mathrm{~h}^{-1}\right)$ & $\mathrm{F}_{10,60}=2.204$ & $0.030^{*}$ \\
$\mathrm{R}\left(\mu \mathrm{g} \mathrm{O}_{2} \mathrm{mg}^{-1}\right.$ protein h$\left.^{-1}\right)$ & $\mathrm{F}_{10,60}=2.191$ & $0.031^{*}$ \\
$\mathrm{P}_{\text {gross }}: \mathrm{R}$ & $\mathrm{F}_{4.957,29.745}=0.597$ & 0.701 \\
Symbiont $\mathrm{pH}_{\mathrm{i}}$ & $\mathrm{F}_{10,60}=3.403$ & $0.001^{*}$ \\
Host cell $\mathrm{pH}_{\mathrm{i}}$ & $\mathrm{F}_{10,60}=3.436$ & $0.001^{*}$ \\
\hline
\end{tabular}

Moderate increases were observed from week 2 onwards in the intermediate treatment and densities were $32 \%$ higher than in the control by the end of the experiment [Fig. 5.2A]. High $\mathrm{CO}_{2}$ addition induced a greater response, with a $54 \%$ increase evident by week 2 , increasing to $81 \%$ by the end of the experiment. Maximum dark-adapted yield $\left(\mathrm{F}_{\mathrm{v}} / \mathrm{F}_{\mathrm{m}}\right)$ showed no response to the intermediate $\mathrm{CO}_{2}$ treatment but under high $\mathrm{CO}_{2}$ there was a significant increase in $\mathrm{F}_{\mathrm{v}} / \mathrm{F}_{\mathrm{m}}$ relative to both the control and the intermediate treatment at weeks 1,6 and 8 [Fig. 5.2B].

The response of total maximum gross photosynthetic rate $\left(\mathrm{P}_{\text {gross }}\right)$ to $\mathrm{CO}_{2}$ addition was pronounced [Fig. 5.2C; Table 5.2]. Under intermediate $\mathrm{CO}_{2}$ addition, a two-fold increase in $\mathrm{P}_{\text {gross }}$ was evident by week 2, which remained more or less constant thereafter. In comparison, exposure to high $\mathrm{CO}_{2}$ induced a 2.5-fold increase in $\mathrm{P}_{\text {gross }}$ after two weeks, and an almost 4-fold increase from week 6 onwards. These patterns were similar when $\mathrm{P}_{\text {gross }}$ was expressed on a cell-specific basis [Fig. 5.2D]. Over the duration of the experiment, cell-specific photosynthetic rate increased by $81.6 \%$ and $114 \%$ in the intermediate and high $\mathrm{CO}_{2}$ treatments, respectively. Total respiration (R) also responded to the addition of $\mathrm{CO}_{2}$ [Fig. 5.2E; Table 5.2]. $\mathrm{R}$ tended to increase in the intermediate $\mathrm{CO}_{2}$ treatment from at least week 2 onwards, but this increase was not significant. In contrast, there was a significant, two-fold increase in R from week 2 onwards in the high $\mathrm{CO}_{2}$ treatment. Given the more marked influence of $\mathrm{CO}_{2}$ 
addition on total photosynthesis than respiration, the ratio of $\mathrm{P}_{\text {gross }}$ to $\mathrm{R}$ increased, though variability in this parameter masked any statistical significance [Fig. 5.2F; Table 5.2].
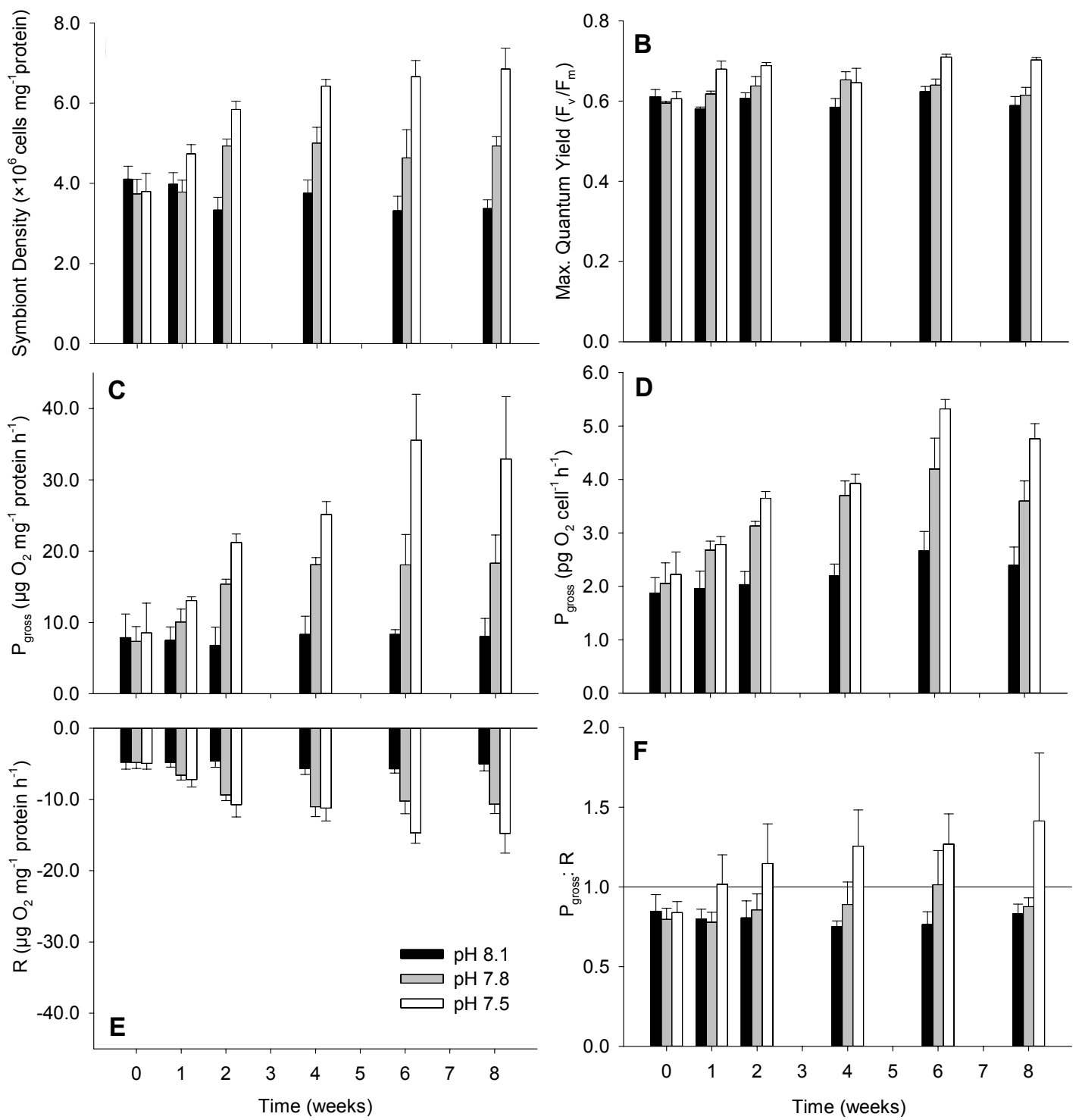

Fig. 5.2 Photo-physiological responses observed in Aiptasia pulchella after exposure to $\mathrm{pH}$ 8.1, $\mathrm{pH} 7.8$ and $\mathrm{pH} 7.5$ over two months. Response variables measured are as follows: [A] symbiont cell density $\left(\times 10^{6}\right.$ cells $\mathrm{mg}^{-1}$ protein); [B] maximum quantum yield of PSII $\left(\mathrm{F}_{\mathrm{v}} / \mathrm{F}_{\mathrm{m}}\right)$; [C] maximum rate of gross photosynthesis $\left(\mathrm{P}_{\text {gross }}, \mu \mathrm{g} \mathrm{O}_{2} \mathrm{mg}^{-1}\right.$ protein $\left.\mathrm{h}^{-1}\right)$; [D] maximum rate of gross photosynthesis per Symbiodinium cell $\left(\mathrm{pg} \mathrm{O}_{2}\right.$ cell $\left.^{-1} \mathrm{~h}^{-1}\right)$; $[\mathrm{E}]$ maximum respiration rate $\left(\mu \mathrm{g} \mathrm{O}_{2} \mathrm{mg}^{-1}\right.$ protein $\left.\mathrm{h}^{-1}\right)$; (F) ratio of the maximum rate of gross photosynthesis to respiration $\left(\mathrm{P}_{\text {gross: }}\right.$ : $\left.\mathrm{R}\right)$ for an idealized day ( $12 \mathrm{~h}$ light and $12 \mathrm{~h}$ dark); values above the line denote a potentially autotrophic symbiotic association where $P_{\text {gross: }}$ R $>1$. Data represent means \pm S.E.M for $\mathrm{n}=5$ individuals per time-point, and asterisks indicate significant differences between elevated $\mathrm{CO}_{2}$ treatments relative to the control at each time point (rmANOVA, pairwise post hoc with Bonferroni correction, $\left.{ }^{*} \mathrm{p}<0.05,{ }^{* *} \mathrm{p}<0.001\right)$. 


\subsubsection{Cellular $\mathrm{pH}_{i}$ response to $\mathrm{CO}_{2}$ addition}

The light-adapted $\mathrm{pH}_{\mathrm{i}}$ of both the symbiont [Fig. 5.3A] and host [Fig. 5.3B] was significantly modified via the addition of $\mathrm{CO}_{2}$ [Table 5.2]. Symbiont cells isolated from anemones exposed to the highest $\mathrm{CO}_{2}$ treatment showed the most rapid response, with $\mathrm{pH}_{\mathrm{i}}$ increasing $\sim 0.2 \mathrm{pH}$ units, from $7.25 \pm 0.05$ to $7.46 \pm 0.06$, within a week, and stabilising at this level for the remainder of the experiment. $\mathrm{The}^{\mathrm{pH}} \mathrm{H}_{\mathrm{i}}$ of symbiont cells exposed to intermediate $\mathrm{CO}_{2}$ levels showed the largest increase between weeks 1 and 4 , when it reached $7.37 \pm 0.09$; the $\mathrm{pH}_{\mathrm{i}}$ remained at a similar level for the remainder of the experiment.

There were discernible differences between the response of host $\mathrm{pH}_{\mathrm{i}}$ and symbiont $\mathrm{pH}_{\mathrm{i}}$ under acidification [Fig. 5.3]. Interestingly, exposure to intermediate $\mathrm{CO}_{2}$ had no effect on host cell $\mathrm{pH}_{\mathrm{i}}$ [Fig. 5.3B], with mean values comparable to those observed in the control anemones $(7.19 \pm 0.01$ versus $7.17 \pm 0.01)$ throughout the experiment. In stark contrast, the $\mathrm{pH}_{\mathrm{i}}$ of host cells exposed to high $\mathrm{CO}_{2}$ increased by almost $0.3 \mathrm{pH}$ units within a week, rising from $7.19 \pm 0.03$ to $7.48 \pm 0.02$, and remained relatively constant thereafter. Linear regression showed a strong predictive relationship between symbiont and host $\mathrm{pH}_{\mathrm{i}}(\mathrm{p}<0.001)$, and suggests that a $0.1 \mathrm{pH}$ unit increase in symbiont $\mathrm{pH}_{\mathrm{i}}$ is associated with a $0.63 \mathrm{pH}$ unit increase in host $\mathrm{pH}_{\mathrm{i}}$ [Fig. 5.3C]. 

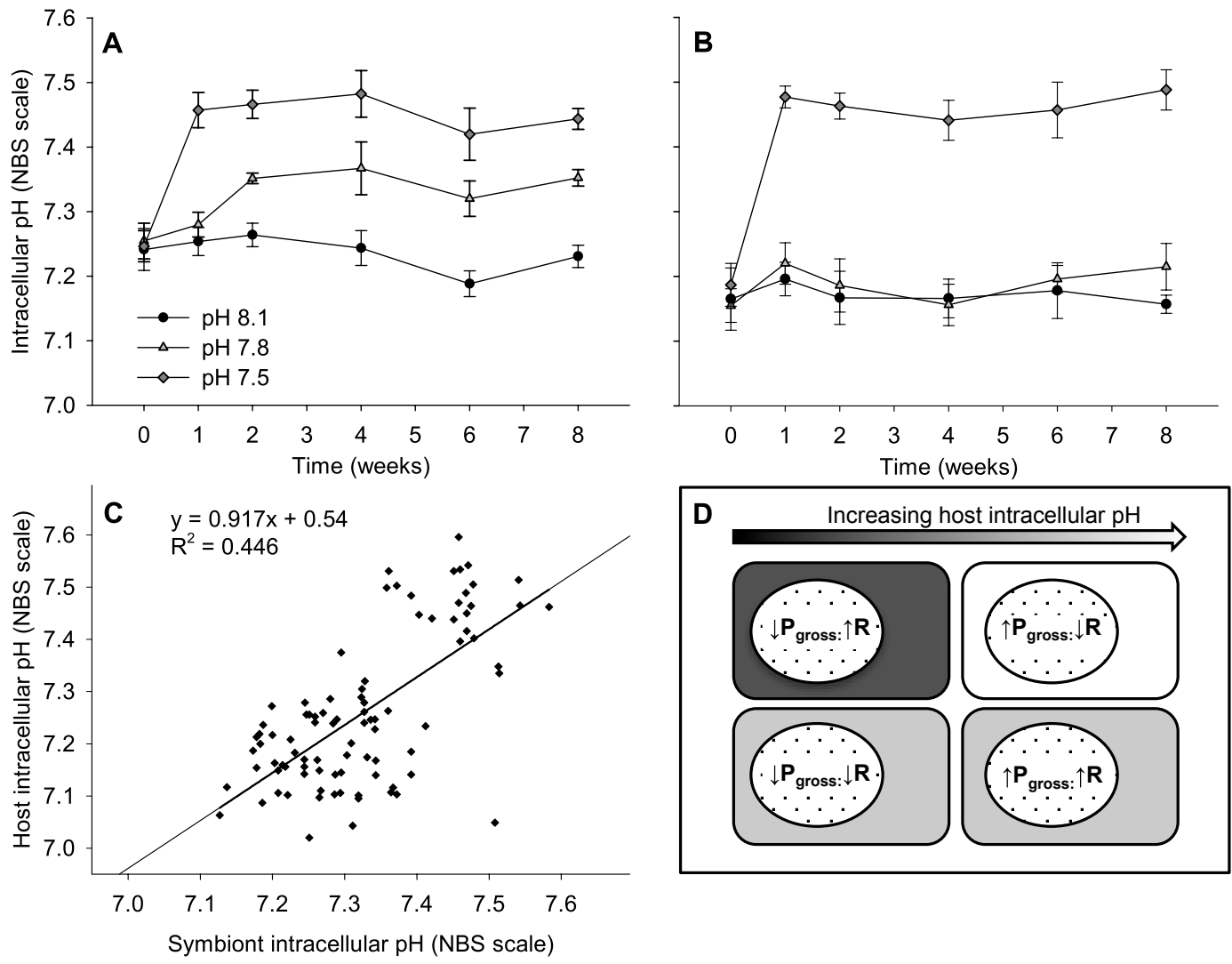

Fig. 5.3 The response of intracellular $\mathrm{pH}\left(\mathrm{pH}_{\mathrm{i}}\right)$ to $\mathrm{CO}_{2}$-driven acidification. [A] Symbiodinium and [B] symbiotic Aiptasia pulchella cells at normal $\mathrm{CO}_{2}$ levels $(\mathrm{pH} 8.1)$, and IPCC $\mathrm{CO}_{2}$ stabilisation scenarios IV $(\mathrm{pH} 7.8)$ and VI ( $\mathrm{pH} 7.5)$ over a two-month time-frame. [C] The linear relationship between host and symbiont $\mathrm{pH}_{\mathrm{i}}$. [D] Schematic to explain host cell $\mathrm{pH}_{\mathrm{i}}$ fluctuations as a function of gross photosynthesis $\left(\mathrm{P}_{\text {gross }}\right)$ and total symbiosis respiration $(\mathrm{R})$. Host cell is represented by the rectangle, and symbiont is represented by the dotted oval. From clockwise: if $\mathrm{P}_{\text {gross }}<\mathrm{R}$ then host $\mathrm{pH}_{\mathrm{i}}$ decreases; if $\mathrm{P}_{\text {gross }}>\mathrm{R}$ then host $\mathrm{pH}_{\mathrm{i}}$ increases; and if both $\mathrm{P}_{\text {gross }}$ and $\mathrm{R}$ either both increase or decrease in proportion to one another then there is no change in $\mathrm{pH}_{\mathrm{i}}$. Data represent means \pm S.E.M for $\mathrm{n}=5$ individuals per time-point and asterisks indicate significant differences between elevated $\mathrm{CO}_{2}$ treatments relative to the control at each time point (rmANOVA, pairwise post hoc with Bonferroni correction, ${ }^{*} \mathrm{p}<$ $\left.0.05,{ }^{* *} \mathrm{p}<0.001\right)$. 


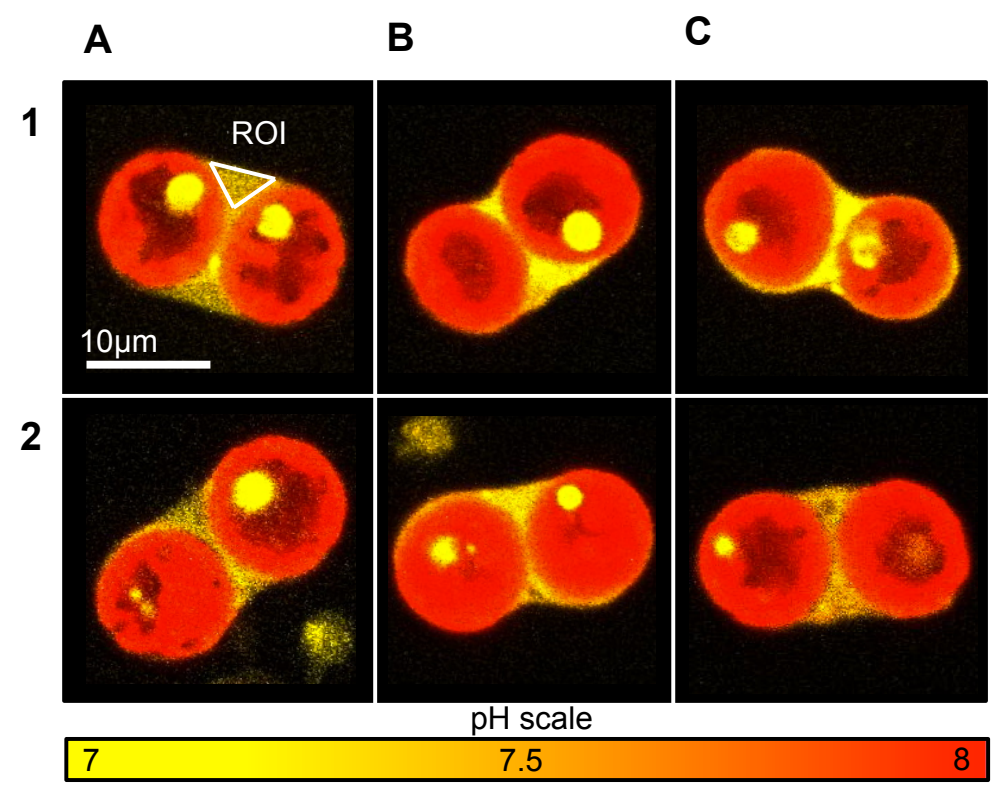

Fig. 5.4 Confocal microscope images of symbiotic endodermal cells isolated from Aiptasia pulchella and loaded with the pH-sensitive SNARF-4F fluorescent dye. (Columns $A-C$ ) $\mathrm{CO}_{2}$ treatment: (A) $\mathrm{pH} 8.1$, (B) $\mathrm{pH} 7.8$ and (C) $\mathrm{pH}$ 7.5. (Rows 1-2) Time of exposure to $\mathrm{CO}_{2}$ treatment: (1) before exposure to treatment and (2) after two months of exposure to each treatment. Colours indicate light-adapted $\left(400 \mu\right.$ mol photons $\left.\mathrm{m}^{-2} \mathrm{~s}^{-1} \mathrm{PAR}\right) \mathrm{pH}_{\mathrm{i}}$ in the host cell as identified in the colour gradient above. White triangle on image $1 \mathrm{~A}$ indicates the region of interest in the host cytoplasm used for $\mathrm{pH}$ measurements and scale bar represents $10 \mu \mathrm{m}$. Red represents chlorophyll autofluoresence in the Symbiodinium cells and is not related to $\mathrm{pH}_{\mathrm{i}}$. Similarly yellow fluorescence in the algal cell is not $\mathrm{pH}$-related and is likely to denote the position of the pyrenoid. Note the increase in alkalinity after two months of exposure to the highest $\mathrm{CO}_{2}$ treatment, represented by the shift from yellow to orange in the host cell.

\subsection{Discussion}

Ocean acidification - once referred to as "the other $\mathrm{CO}_{2}$ problem" (Doney et al., 2009) - is now recognised as a major selective force in determining ecosystem structure and function (Hall-Spencer et al., 2008; Christen et al., 2013; Godbold and Calosi, 2013). Marine organisms exhibit high variability in their physiological and cellular tolerance to $\mathrm{CO}_{2}$ addition (Fabry, 2008). While considered detrimental on the whole for calcifying organisms (Hoegh-Guldberg et al., 2007; Marubini et al., 2008; Kroeker et al., 2013), there is growing evidence that enhanced $\mathrm{CO}_{2}$ levels may benefit softbodied photosynthetic anthozoans (Suggett et al., 2012; Towanda and Thuesen, 2012; Inoue et al., 2013) through the alleviation of carbon limitation, that is thought typical of the symbiont population (Weis, 1993; Davy and Cook, 2001). The increased photosynthetic production that arises as a consequence of this likely has two major 
advantages for the host: (1) increased translocation of photosynthate for growth and reproduction (Brownlee, 2009); and (2) the prevention of cellular acidosis that arises from increased concentrations of $\mathrm{CO}_{2}$ and hence protons. The results of this chapter lend support to the potential success of non-calcifying symbiotic cnidarians in a $\mathrm{CO}_{2}$ enriched world, and confirm the positive relationship between $\mathrm{CO}_{2}$ supply, photosynthesis and the prevention of cellular acidosis in the model symbiotic cnidarian, A. pulchella.

Increases in symbiont density, photosynthetic health $\left(\mathrm{F}_{\mathrm{v}} / \mathrm{F}_{\mathrm{m}}\right)$, overall and cell-specific gross photosynthetic rate $\left(\mathrm{P}_{\text {gross }}\right)$, and respiration rate $(\mathrm{R})$ were commensurate with the $\mathrm{CO}_{2}$ concentration, signifying enhanced primary productivity and hence symbiont growth in response to the increased availability of dissolved inorganic carbon (DIC). Similar findings were reported for two temperate sea anemone species exposed to elevated $\mathrm{CO}_{2}$. Anemonia viridis sampled from high $\mathrm{CO}_{2}$ sites (corresponding to 1428 $\mu$ atm) along a naturally occurring $\mathrm{CO}_{2}$ vent, contained up to four-times more Symbiodinium cells than when at control sites (300 $\mu \mathrm{atm})$, resulting in enhanced rates of both $\mathrm{P}_{\text {gross }}$ and $\mathrm{R}$; though, as in the current study, $\mathrm{P}_{\text {gross }}$ increased more than $\mathrm{R}$ (Suggett et al., 2012). These patterns were mirrored in Anthopleura elegantissima after six weeks of incubation at $\mathrm{pH} 7.3$, although there was no accompanying change in symbiont density (Towanda and Thuesen, 2012). The increased primary productivity seen here in $A$. pulchella is unsurprising given that seawater ( $\mathrm{pH} 8.2$ ) contains less than half of the DIC $\left(2.2 \mathrm{mM} \mathrm{HCO}_{3}^{-}, 30 \mu \mathrm{M} \mathrm{CO}_{2}\right)$ required to saturate photosynthesis in this species under normal circumstances (5 mM DIC; Weis, 1993). Nevertheless, A. pulchella can still achieve its autotrophic potential (i.e. $\mathrm{P}_{\text {gross }}: \mathrm{R}>1$ ) with respect to carbon (Starzak et al., 2014), in part because of the activity of carbonconcentrating mechanisms (CCM's) that concentrate $\mathrm{CO}_{2}$ at the site of photosynthesis (Weis et al., 1989; Leggat et al., 1999). $\mathrm{CO}_{2}$ enrichment may therefore provide a further benefit through reducing the metabolic costs of maintaining CCM activity (Raven et al., 2012).

However, not all studies report increases in anemone productivity after $\mathrm{CO}_{2}$ addition. Six weeks of exposure to $\mathrm{pH} 7.6$ had no effect on symbiont density or physiological performance in the temperate anemone Anthopleura aureoradiata (Doherty, 2009). Similarly, two weeks of exposure to $\mathrm{pH} 7.4$ caused declines in symbiont density, but 
did not affect either $\mathrm{P}_{\text {gross }}$ or $\mathrm{R}$ in laboratory-maintained A. viridis (Jarrold et al., 2013); though our results suggest that a two-week time period may not always be long enough to observe significant changes in physiology. Differences in the organismal response to $\mathrm{CO}_{2}$ addition are potentially attributable to the type of Symbiodinium present and/or the amount light available for photosynthesis (Suggett et al., 2013; Comeau et al., 2014). There is certainly growing evidence for the former, with research suggesting that the response to $\mathrm{CO}_{2}$-addition may be type-specific (Buxton et al., 2009; Brading et al., 2011). For example, when a range of cultured Symbiodinium types were exposed to a two-fold increase in $\mathrm{CO}_{2}$ concentration (corresponding to $\mathrm{pH}$ 7.79 - the intermediate treatment in our study), there was an increase of $\sim 60 \%$ in the growth rate and photosynthetic capacity of types A13 and A2, respectively, while types A1 and B1 did not respond at all (Brading et al., 2011). Of note, this lack of response by Symbiodinium B1 in culture is different to our observations here, when this same type was in hospite, so future studies should consider how $\mathrm{CO}_{2}$ concentration may influence different host-symbiont combinations.

One of the key objectives of this study was to establish the response of $\mathrm{pH}_{\mathrm{i}}$ to $\mathrm{CO}_{2^{-}}$ addition, simultaneously in the host and symbiont. To achieve this, I measured the $\mathrm{pH}_{\mathrm{i}}$ of both partners at photosynthesis-saturating light levels $\left(400 \mu \mathrm{mol}\right.$ photons $\left.\mathrm{m}^{-2} \mathrm{~s}^{-1}\right)$. The light level chosen is important because irradiance can modify the response of cnidarians to $\mathrm{CO}_{2}$-driven acidification (Suggett et al., 2013; Comeau et al., 2014). The values measured in the control anemones were similar to those measured in Chapter 2 (Symbiodinium types ranged from $\mathrm{pH}$ 7.21-7.39, while the host and symbiont cells isolated from $A$. pulchella were $\mathrm{pH} 7.02 \pm 0.06$ and $7.25 \pm 0.01$, respectively). Lightadapted host $\mathrm{pH}_{\mathrm{i}}$ in this anemone species was, however, slightly lower than that measured in the cnidarians A. viridis $(\mathrm{pH} 7.41 \pm 0.22)$ and Stylophora pistillata (7.29 \pm 0.15 ) (Venn et al., 2009). Under normal conditions, photosynthesis in the symbiont results in an alkalinisation of the host cell (Venn et al., 2009), the magnitude of which is proportional to the irradiance (Laurent et al., 2013a). As such, we predicted that $\mathrm{CO}_{2}$ addition would increase the photosynthetic rate and hence symbiont $\mathrm{pH}_{\mathrm{i}}$, and trigger a similar increase in the host cell $\mathrm{pH}_{\mathrm{i}}$. The results of the high $\mathrm{CO}_{2}$ treatment ( $\mathrm{pH}$ 7.5) were consistent with this prediction, with both symbiont $\mathrm{pH}_{\mathrm{i}}$ and host $\mathrm{pH}_{\mathrm{i}}$ rising by $\sim 0.3 \mathrm{pH}$ units in proportion to the external $\mathrm{CO}_{2}$ concentration. However, the same cannot be said of the host cell $\mathrm{pH}_{\mathrm{i}}$ under the intermediate $\mathrm{CO}_{2}$ treatment $(\mathrm{pH}$ 
7.8), despite the Symbiodinium cell $\mathrm{pH}_{\mathrm{i}}$ increasing by $\sim 0.12 \mathrm{pH}$ units. While the high buffering capacity of the cnidarian cell likely plays a role (Laurent et al., 2013b), the results presented here suggest a strong link between the relative rates of photosynthesis and respiration in dictating the $\mathrm{pH}_{\mathrm{i}}$ of the host in response to external, $\mathrm{CO}_{2}$-induced $\mathrm{pH}$ change. In particular, the increase in alkalinity reported for the high $\mathrm{CO}_{2}$ treatment is potentially attributable to the elevated $\mathrm{P}_{\text {gross }}$ : $\mathrm{R}$ ratio seen under these conditions (in contrast to the intermediate $\mathrm{CO}_{2}$ treatment). This could indicate a partial decoupling of the rates of photosynthesis and respiration, which typically facilitate one another through the evolution of $\mathrm{O}_{2}$ and $\mathrm{CO}_{2}$ respectively (Harland and Davies, 1995), and a concomitant decrease in the intracellular $\mathrm{CO}_{2}$ concentration. The mechanism by which the $\mathrm{pH}_{\mathrm{i}}$ of the host cell may be increased by $\mathrm{CO}_{2}$ enrichment is summarised in Figure 5.4D.

In summary, these findings demonstrate that the photo-physiological response to predicted ocean acidification scenarios has the potential to alter the $\mathrm{pH}_{\mathrm{i}}$ of both host and symbiont simultaneously, and therefore affect the functioning of the cnidariandinoflagellate symbiosis. Of particular importance, these results suggest improved photosynthetic performance and an absence of cellular acidosis in the light in response to $\mathrm{CO}_{2}$-driven acidification. $\mathrm{pH}_{\mathrm{i}}$ in the dark was not measured, and it would be interesting to know what impact these different conditions have on night-time $\mathrm{pH}_{\mathrm{i}}$, though the results of Chapter 3 suggest that isolated host cells of the reef coral $P$. damicornis are more susceptible to acidification when the photosynthetic activity of their symbionts is inhibited by DCMU. The enhanced performance in the light, however, raises important questions about the future of non-calcareous symbiotic anthozoans in a high- $\mathrm{CO}_{2}$ ocean. In particular, several studies have reported that ocean acidification initiates a shift in ecosystem structure from a calcareous to a noncalcareous, algal-dominated community (Hall-Spencer et al., 2008; Suggett et al., 2012; Inoue et al., 2013) that has the potential to act as a significant carbon sink (Anthony et al., 2011; Russell et al., 2013). Similarly, these results, along with those of Suggett et al. (2012), suggest that symbiotic sea anemones could not only survive ocean acidification, but thrive under future conditions. However, it is important to bear in mind that ocean acidification is only once aspect of climate change; with the effects of global warming likely to influence the physiological response to elevated $\mathrm{CO}_{2}$ levels (Chapter 4). 


\section{Chapter 6: General Discussion}

\subsection{Summary}

This thesis aimed to determine the inter-relationship between photosynthesis, symbiont $\mathrm{pH}$ and host cell $\mathrm{pH}$ in the cnidarian-dinoflagellate symbiosis, and quantify how this is impacted by ocean acidification and thermal stress. Live confocal imaging was used to monitor fluxes in $\mathrm{pH}_{\mathrm{i}}$ of the symbiont and the host simultaneously, providing new insights into the cell biology of this ecologically significant association. My findings demonstrate that $\mathrm{pH}_{\mathrm{i}}$ in the host cell is tightly linked to the photosynthetic performance of the symbiont, and show that both host and symbiont display synchronicity with the diel light cycle (Chapters 2,3). This corroborates the findings of studies with the anemone Anemonia viridis and coral Stylophora pistillata (Venn et al., 2009; Laurent et al., 2013a; Laurent et al., 2013b). Of most significance, the results presented here suggest that if $\mathrm{CO}_{2}$-driven seawater acidification enhances photosynthetic productivity in the symbiont, then the host cells is better equipped to response to changes in external $\mathrm{pH}\left(\mathrm{pH}_{\mathrm{e}}\right)$. Host cell's that contain Symbiodinium that are able to use the additional $\mathrm{CO}_{2}$ in photosynthesis, are therefore less susceptible to cellular acidosis, after both short- and longer-term exposure to $\mathrm{CO}_{2}$ (Chapters 3-5). Conversely, host cells containing less productive and/or thermally sensitive symbionts may not be at greater risk of cellular acidosis (Chapter 4). These findings raise several important questions: what are the potential costs/benefits of $\mathrm{CO}_{2}$ supplementation for marine phototrophs, and what cellular mechanisms are likely to be affected? How will global warming influence the cellular response to $\mathrm{CO}_{2}$ ? And, what are the ecological implications of these findings for the survival of coral reefs?

\subsection{The cellular response to $\mathrm{CO}_{2}$ enrichment}

\subsubsection{What are the costs/benefits of CO2 supplementation for marine phototrophs?}

Photosynthetic organisms are dependent on a plentiful supply of $\mathrm{CO}_{2}$ to the enzyme Rubisco (the site of $\mathrm{CO}_{2}$-fixation), to maximise photosynthetic productivity. Yet the 
concentration of $\mathrm{CO}_{2}$ in seawater is low, being $<1 \%$ of all dissolved inorganic carbon (DIC) present in oceanic surface waters (Millero et al., 2002). The evolution of carbon concentrating mechanisms (CCM's) has enabled organisms to exploit the bicarbonate $\left(\mathrm{HCO}_{3}{ }^{-}\right)$reservoir, but these are energetically costly to maintain (Raven et al., 2012), so the majority of marine phototrophs remain DIC-limited (Levavassur et al., 1991; Riebesell et al., 1993; Nimer et al., 1997; Carpenter and Williams, 2007; Herfort et al., 2008). This is particularly the case in dinoflagellates, phototrophic proteobacteria and cyanobacteria, because they contain a type II form of Rubisco that is inefficient at discriminating between $\mathrm{O}_{2} / \mathrm{CO}_{2}$ (Tabita, 1995; Rowan et al., 1996; Søderberg and Hansen, 2007). $\mathrm{CO}_{2}$ accumulation resulting from fossil fuel burning could thereby alleviate DIC-limitation through the provision of an additional source of carbon for photosynthesis (Schippers et al., 2004; Rodolfo-Metalpa et al., 2010). Alternatively, it could promote an organism's fitness indirectly, by reducing the energetic costs of $\mathrm{HCO}_{3}{ }^{-}$acquisition (Beardall and Giordano, 2002; Raven et al., 2012). There have been mixed responses to $\mathrm{CO}_{2}$-addition in marine organisms (Ries et al., 2009; Kroeker et al., 2010; Kroeker et al., 2013). Macroalgae such as Dictyota dichotoma and Hildenbrandia rubra can survive in seawater as low as pH 6.7 (Porzio et al., 2011). And while seagrasses (Orth et al., 2008; Jiang et al., 2010), sea anemones (Suggett et al., 2012; Towanda and Thuesen, 2012) sponges (Bell et al., 2013; Goodwin et al., 2013) and some members of the phytoplankton (Hutchins et al., 2007; Fu et al., 2008) appear to thrive under intermediate and/or high $\mathrm{CO}_{2}$ conditions $\left(\mathrm{pH}_{\mathrm{e}}\right.$ 7.6 - 7.8), these same conditions typically have negative impacts on calcifying organisms such as hard corals (Schneider and Erez, 2006; Anthony et al., 2008; Sweatman et al., 2011), molluscs (Comeau et al., 2009; Rodolfo-Metalpa et al., 2011; Kroeker et al., 2013), foraminiferans (De Moel et al., 2009; Moy et al., 2009); coccolithophores (Beaufort et al., 2011) and crustose coralline algae (Jokiel et al., 2008; Kuffner et al., 2008; Martin and Gattuso, 2009). The increases in cell-specific productivity and symbiont density seen in the ITS2 type B1 Symbiodinium cells isolated from Aiptasia pulchella (Chapter 5) follow these general trends, and suggest that increased carbon fixation, in response to the available $\mathrm{CO}_{2}$ is responsible for the enhanced growth rate. These patterns are consistent with the response observed in type A19 Symbiodinium that were isolated from A. viridis (Suggett et al., 2012) and in cells from Anthopleura elegantissima (Towanda and Thuesen, 2012). They contrast however, with those in cultured Symbiodinium (types A1, A13, A2 and B1), which 
showed either no change in growth or photosynthesis (types A1 and B1); no change in growth but an increase in photosynthesis (type A2); or accelerated growth without a change in photosynthetic output (type A13) (Brading et al., 2011). The disparity in the responses between the cultured B1 and freshly isolated B1 cells used in this study probably arises from the different mechanisms of DIC acquisition that they employ. Ex hospite Symbiodinium mediate their DIC supply one of two ways; (1) through the uptake of $\mathrm{HCO}_{3}{ }^{-}$via a $\mathrm{Na}^{+}$-dependent $\mathrm{HCO}_{3}{ }^{-}$mechanism (Al-Moghrabi et al., 1996; Goiran et al., 1996; Leggat et al., 1999); or (2) via the passive diffusion of $\mathrm{CO}_{2}$ (Brading et al., 2013). Symbionts that employ the former mechanism may not be affected by $\mathrm{CO}_{2}$-driven acidification to the same degree as those that use the latter, because they can typically achieve (or come close to achieving) photosynthetic saturation from the $\mathrm{HCO}_{3}{ }^{-}$reservoir in ambient seawater. The situation is rather different for in hospite Symbiodinium because they are reliant firstly, on their host cell to acquire the initial DIC, and secondly, on having enough energy to fuel the $\mathrm{H}^{+}$ATPase proteins, which are thought to be responsible for the final transfer of DIC from host to symbiont (Bertucci et al., 2009). These additional stages mean that Symbiodinium are almost always DIC-limited in hospite in ambient seawater (Weis, 1993; Bénazet-Tambutté et al., 1996; Davy and Cook, 2001; Suggett et al., 2012; Towanda and Thuesen, 2012). The results presented in Chapter 5 support this assertion, and suggest that in type $\mathrm{B} 1$ at least, the enhanced availability of $\mathrm{CO}_{2}$ may alleviate these limiting conditions.

Variation in the response of different Symbiodinium types to $\mathrm{CO}_{2}$ is hardly surprising given the immense physiological diversity that exists within the genus (Baker, 2001; Baker, 2003; Berkelmans and van Oppen, 2006; Suggett et al., 2008; Ragni et al., 2010; Howells et al., 2012). Indeed, like all marine phototrophs (Riebesell, 2004), the degree of DIC required for photosynthetic saturation varies considerably between symbiont types. Symbiodinium type A20 for example, is saturated at ambient levels of DIC whereas type A13 is not (Brading et al., 2013). The reasons for these differences are unclear, but one suggestion is that it could be related to the efficiency of a cells' CCM (Brading et al., 2011). If the CCM's are highly efficient, then it is possible to achieve photosynthetic saturation at present day $\mathrm{CO}_{2}$ levels. In this case, adding $\mathrm{CO}_{2}$ will not increase the photosynthetic yield, but it could reduce the amount of energy required by the CCM's, resulting in the reallocation of energy into population growth 
(Rost et al., 2008). Conversely, if cells possess inefficient CCM's, then they will be more reliant on the passive diffusion of $\mathrm{CO}_{2}$ at ambient conditions, and $\mathrm{CO}_{2}$-addition is likely to result in an increase in photosynthetic productivity. The half-saturation constant of photosynthesis (widely used as an index of CCM function) is particularly low in type B1 Symbiodinium (Oakley et al., 2014). It is therefore plausible that the cells isolated from A. pulchella in this study possess inefficient CCM's, and so are under-saturated at present day, and even intermediate ocean acidification trajectories (Chapter 5). If this is the case, then organisms such as anemones could become an important sink for $\mathrm{CO}_{2}$ (Anthony et al., 2011) in the future, the implications of which are discussed further in section 6.3.

The stimulation of photosynthesis could further benefit organisms by reducing the potential for cellular acidosis under ocean acidification. The magnitude of lightadapted intracellular alkalinisation increased under both short ( $<$ two hours) and longer-term (two months) $\mathrm{CO}_{2}$-addition (Chapters 3, 5), providing further evidence that Symbiodinium cells are DIC-limited under normal in hospite conditions. Similar rises were observed in the free-living bloom-forming dinoflagellate Prorocentrum micans, where cytosolic and chloroplast $\mathrm{pH}_{\mathrm{i}}$ increased from $6.9 \pm 0.10$ and $7.14 \pm$ 0.12 , respectively, under DIC-limiting conditions (1.0 mM DIC) to $8.3 \pm 0.13$ and 7.7 \pm 0.11 under DIC-replete conditions (2.0 mM DIC) (Nimer et al., 1999). In both cases, incubating the cells with DCMU (a photosynthetic inhibitor) before exposing them to either $\mathrm{HCO}_{3}^{-}$addition (Nimer et al., 1999) or $\mathrm{CO}_{2}$ addition (Chapter 3) suppressed the degree of light-induced $\mathrm{pH}_{\mathrm{i}}$ alkalinisation, indicating that photosynthesis plays a fundamental role in protecting the intracellular environment from cellular acidosis. Moreover, it suggests that DIC-limited cells that can 'soak up' excess $\mathrm{CO}_{2}$ may be better placed to counter acidosis, and thus prevent metabolic suppression, providing that the removal of $\mathrm{CO}_{2}$ is greater than the influx of $\mathrm{CO}_{2}$ (Pörtner et al., 2004; Melzner et al., 2009; see Figure 6.1). Future studies should investigate these phenomena further (see section 6.4 for details), while it would also be interesting to clarify the interactions between $\mathrm{pH}_{\mathrm{i}}$ and $\mathrm{CO}_{2}$-driven acidification in the dark, because, despite the obvious importance of photosynthesis, it is by no means the only mechanism involved in $\mathrm{pH}_{\mathrm{i}}$ regulation. While no studies have assessed the mechanisms of $\mathrm{pH}_{\mathrm{i}}$ regulation in Symbiodinium cells, $\mathrm{Cl}^{-} / \mathrm{H}^{+}, \mathrm{Ca}^{2+} / \mathrm{H}^{+}$and $\mathrm{Na}^{+} / \mathrm{H}^{+}$ 
exchangers (NHE's) have all been documented in marine algae (Katz et al., 1992; Thaler et al., 1992; Okazaki et al., 1996; Balnokin et al., 1997; Plieth et al., 1997). In contrast, only one study to date has adopted a mechanistic approach for understanding pH regulation in cnidarian host cells. Laurent and co-workers (2013b) used amiloride and 5-(N-ethyl-N-isopropyl) amiloride (EIPA) inhibitors with confocal imaging to assess whether NHE's were involved in $\mathrm{pH}_{\mathrm{i}}$ regulation in A. viridis. Both symbiotic cells and non-symbiotic cells were bathed in seawater that had been adjusted to $\mathrm{pH}$ 7.4. Without the inhibitors, the $\mathrm{pH}_{\mathrm{i}}$ decreased to $6.70 \pm 0.07 \mathrm{pH}$ and $6.64 \pm 0.06 \mathrm{pH}$ units within $15 \mathrm{~min}$, respectively, but recovered to $\mathrm{pH} 7.02 \pm 0.02$ after $20 \mathrm{~min}$ in both cases. No recovery was observed in the presence of inhibitors, providing evidence that NHE's play an important role in determining the response to acidification. Interestingly, the authors of this study reported no difference in the buffering capacity between symbiotic and non-symbiotic cells in the dark (Laurent et al., 2013b). This contrasts with the results presented in Chapter 3, where symbiotic cells recovered from an initial $0.4 \mathrm{pH}$ unit drop, but non-symbiotic host cells did not. One potential reason for these differences is the $\mathrm{pH}_{\mathrm{e}}$ employed in the two studies: the former used a $\mathrm{pH}_{\mathrm{e}}$ of 7.4 whereas the final $\mathrm{pH}_{\mathrm{e}}$ in my study was 6.8 , creating a steeper proton gradient $\left(\mathrm{pH}_{\mathrm{e}}-\mathrm{pH}_{\mathrm{i}}=0.4\right.$ versus $0.8 \mathrm{pH}$ units $)$.

Proton fluxes, and the effect of ocean acidification on photosynthesis, take on renewed importance when they are considered in the context of calcification (Brownlee, 2009). Light-enhanced calcification is a well-established phenomenon, although the mechanism(s) involved in this process remain contentious (Gattuso et al., 1999; Al-Horani et al., 2003; Mass et al., 2007; Moya et al., 2008), not least because photosynthesis and skeletogenesis occur in separate cell layers (the oral endodermal cell layer and aboral endodermal cell layer, respectively). Mechanisms proposed to link the two are hotly debated and often contradict one another (Al-Horani et al., 2003). These include: (1) photosynthesis reducing the partial pressure of $\mathrm{CO}_{2}$ at the site of calcium carbonate $\left(\mathrm{CaCO}_{3}\right)$ deposition (Goreau, 1959); (2) calcification producing $\mathrm{H}^{+}$that the symbionts absorb, thus fuelling the assimilation of $\mathrm{HCO}_{3}{ }^{-}$and nutrients (McConnaughey and Whelan, 1991); (3) the increasing concentration of $\mathrm{OH}^{-}$ arising from photosynthesis, that enables the neutralisation of $\mathrm{H}^{+}$produced during $\mathrm{CaCO}_{3}$ deposition (Furla et al., 1998); (4) the phosphorylation of photosynthate 
produced during photosynthesis which fuels the ATP-demand of Ca-ATPases pumping calcium $\left(\mathrm{Ca}^{2+}\right)$ to the site of calcification (Al-Horani et al., 2003); and (5) the 'Proton Flux Hypothesis' (Jokiel, 2011), the theory that net calcification rates are dependent on the gradient in $\mathrm{pH}$ that exists between the external seawater and a 200 $300 \mu \mathrm{m}$ thick, oxygen-saturated 'boundary layer' that overlies the photosynthetic coral tissue (Kühl et al., 1995). This layer is maintained well above the $\mathrm{pH}$ of the surrounding seawater, reaching up to $\mathrm{pH} 8.6$ in Acropora sp. and Favia sp. (Kühl et al., 1995). Calcification is the result of an equilibrium reaction that exists between $\mathrm{HCO}_{3}{ }^{-}$and $\mathrm{Ca}^{2+}$, which combine to form $\mathrm{CaCO}_{3}$ and result in the release of $\mathrm{H}^{+}$. The rate of $\mathrm{CaCO}_{3}$ is therefore limited by the extrusion, and subsequent neutralisation of $\mathrm{H}^{+}$. Under 'normal' conditions the gradient between the boundary layer and the surrounding seawater is approximately $0.5 \mathrm{pH}$ units (Kühl et al., 1995). If $\mathrm{CO}_{2}$ is added to the surrounding seawater, however, the gradient increases between the two, causing a shift to the left of the equilibrium, rendering it more difficult for the coral to extrude $\mathrm{H}^{+}$and hence to calcify (Jokiel, 2011). If, as my results suggest, photosynthesis is fertilised by the addition of $\mathrm{CO}_{2}$ (Chapters 3, 5), then the increased removal of $\mathrm{H}^{+}$could mitigate some of the energetic costs associated with $\mathrm{H}^{+}$extrusion (Schneider and Erez, 2006; Ries et al., 2009; McCulloch et al., 2012). In addition, the energy derived from the increased rate of photosynthesis could contribute to the energetic demands of converting $\mathrm{HCO}_{3}^{-}$to $\mathrm{CO}_{3}{ }^{2-}$, potentially offsetting the reduction in the aragonite saturation state (Ries et al., 2009). This could explain why not all not all calcifying species exhibit negative calcification rates after $\mathrm{CO}_{2}$ addition (Hendriks et al., 2010; Kroeker et al., 2013). The temperate coral Oculina arbuscula, for example, showed no response to $\mathrm{CO}_{2}$ at 606 and 903 ppm, while the coralline red alga Neogoniolithon sp. and the calcareous green alga Halimeda incrassata achieved net growth at the same levels (Ries et al., 2009). In summary, it appears that future oceanic $\mathrm{CO}_{2}$ levels are likely to benefit non-calcifying marine phototrophs, but that reduced calcification may negate the benefits to calcifying marine phototrophs. However, neither of these outcomes considers the influence of global warming, the potential impacts of which are considered in the next section. 


\subsubsection{How will global warming influence the cellular response to $\mathrm{CO}_{2}$ ?}

The data presented in Chapter 4 suggest that exposure to elevated temperatures can significantly reduce a cell's ability to regulate its $\mathrm{pH}_{\mathrm{i}}$ under $\mathrm{CO}_{2}$-addition. The drop in $\mathrm{pH}_{\mathrm{i}}$ following an $8^{\circ} \mathrm{C}$ increase in seawater temperature was substantial, particularly in Pocillopora damicornis cells where $\mathrm{pH}_{\mathrm{i}}$ declined from $7.40 \pm 0.07$ at $23^{\circ} \mathrm{C}$ to $6.56 \pm$ 0.03 at $31^{\circ} \mathrm{C}$ in host cells, and from $7.45 \pm 0.02$ to $6.86 \pm 0.01$ in the symbionts. The reduction in $\mathrm{pH}_{\mathrm{i}}$ was much less in Montipora capitata, but still present, with $\mathrm{pH}_{\mathrm{i}}$ declining from $7.35 \pm 0.07$ to $6.95 \pm 0.05$ in host cells, and from $7.43 \pm 0.04$ to $7.14 \pm$ 0.03 in the symbionts. Quite how and why thermal stress induces acidosis, and whether or not this effect is reversible is unclear, but given that these patterns mirror those observed in host cells that are incubated with DCMU (Chapter 3), it is likely that photosynthesis plays a critical role in governing a cell's susceptibility to changes in $\mathrm{pH}_{\mathrm{e}}$. Under high temperatures, the photosynthetic machinery of the Symbiodinium cell is impaired, reducing the amount of carbon that is fixed, and triggering the production of damaging reactive oxygen and nitrogen species (ROS/RNS). This has two effects on the $\mathrm{pH}_{\mathrm{i}}$ : firstly, $\mathrm{CO}_{2}$ is not removed at a quick enough rate to mitigate the influx of $\mathrm{H}^{+}$, leading to cellular acidosis; and secondly, the energy remaining in the cell is directed towards the up-regulation of antioxidant production (e.g. superoxide dismutase, catalase, peroxidases) to counter the build-up of ROS, rather than to $\mathrm{pH}_{\mathrm{i}}$ regulation (Richier et al., 2005; DeSalvo et al., 2008; Császár et al., 2009; Seneca et al., 2010). Failure to suppress the production of ROS/RNS leads to metabolic suppression (Muller et al., 2007; DeSalvo et al., 2008) and, under prolonged circumstances, to apoptosis (Buttke and Sandstrom, 1994; Richier et al., 2006). It is conceivable that thermal stress could have similarly detrimental effects on the capacity for $\mathrm{pH}$ regulation, with negative consequences for holobiont fitness (Kaniewska et al., 2012). Resolving the interrelationship between the physiological impacts of thermal stress and the potentially beneficial role of $\mathrm{CO}_{2}$ addition should therefore be considered a high research priority for future studies, especially given the increased frequency and/or severity of bleaching events expected over the $21 \mathrm{st}$ century (Perry et al., 2013; Van Hooidonk et al., 2013). Furthermore, if a coral's thermal sensitivity does indeed influence its survivorship under ocean acidification, then understanding how and why bleaching thresholds differ between coral species (Loya et al., 2001; van Woesik et al., 2011) takes on renewed importance. 
A coral's thermal vulnerability is determined by the genetic constitution of its symbiont community (Rowan et al., 1997; Baker, 2001; Toller et al., 2001), in addition to many numerous host-derived factors including: coral colony morphology (Fabricius et al., 2006; Jimenez et al., 2011), tissue thickness (Hoegh-Guldberg 1999; Loya et al., 2001; Yost et al., 2013), and green fluorescent protein concentration (Bou-Abdallah et al., 2006). While I did not test the genetic diversity of the symbionts of the corals used in Chapter 4, it is likely that they contained different Symbiodinium types. $M$. capitata is a flexible generalist that typically contains a combination of types C3, C17, C21, C31 and/or D1, whereas P. damicornis is only able to host C1 and C3 (LaJeunesse et al., 2004; Padilla-Gamiño et al., 2012; Putnam et al., 2012). There is a high degree of variation that exists in thermal tolerance between Symbiodinium ITS2 types (Robison and Warner, 2006; Sampayo et al., 2008; Fitt et al., 2009; Fisher et al., 2012). Types A1 and F2, for example, are much more susceptible to thermal stress than are A1.1 and B1 (Robison and Warner, 2006), while both C1 and C3 have particularly low thermal stress thresholds (Fitt et al., 2009; Fisher et al., 2012). Corals containing C3, for example, exhibited declines in the maximum dark adapted yield of photosystem II $\left(\mathrm{F}_{\mathrm{v}} / \mathrm{F}_{\mathrm{m}}\right)$ of $63.8,67.5,76.6$ and $91.1 \%$ in Platygyra daedalea, Acropora millepora, Acropora formosa and Acropora aspera, respectively, after being subjected to an $8^{\circ} \mathrm{C}$ increase in temperature over a 4 day period (Fisher et al., 2012). The results presented in Chapter 4 were derived from a single colony of each species, so caution needs to be exercised when making generalisations, but there were clear differences in the two species' abilities to regulate $\mathrm{pH}_{\mathrm{i}}$ after thermal stress. Considering whether the type of symbiont that they contain influences the host cell's susceptibility to acidosis certainly offers an exciting avenue for future research, not least because corals may be able to alter the types of Symbiodinium that they host to increase their resilience to thermal stress (Buddemeier and Fautin, 1993; Berkelmans and van Oppen, 2006; Howells et al., 2012; Putnam et al., 2012). This could occur via the uptake of a new symbiont type from the external environment ("switching") following coral bleaching or the production of symbiontfree larvae, or through repopulation by a type that was previously kept at low background levels within the coral ("shuffling"). Convincing empirical evidence for switching is lacking in reef corals, but there is evidence of shuffling (Berkelmans and van Oppen, 2006; Mieog et al., 2007; van Oppen et al., 2009; Gilbert et al., 2010; Stat 
and Gates, 2011; Silverstein et al., 2012). My results suggest that, in warm, acidified oceans, a switch in symbiont dominance (either by switching or shuffling; Fig. 6.1A) will only benefit the coral if that symbiont type is thermally resilient and is able to increase its photosynthetic productivity in response to $\mathrm{CO}_{2}$-addition [Fig. 6.1B]. If the new symbiont is susceptible to heat stress [Fig. 6.1C] or has a lower photosynthetic rate [Fig. 6.1D] then it will provide less protection against ocean acidification. The worst-case scenario would eventuate if a coral acquired a symbiont that is thermally susceptible and has a low photosynthetic output [Fig. 6.1E]. Under this outcome, the host cell succumbing to acidosis appears to be inevitable.

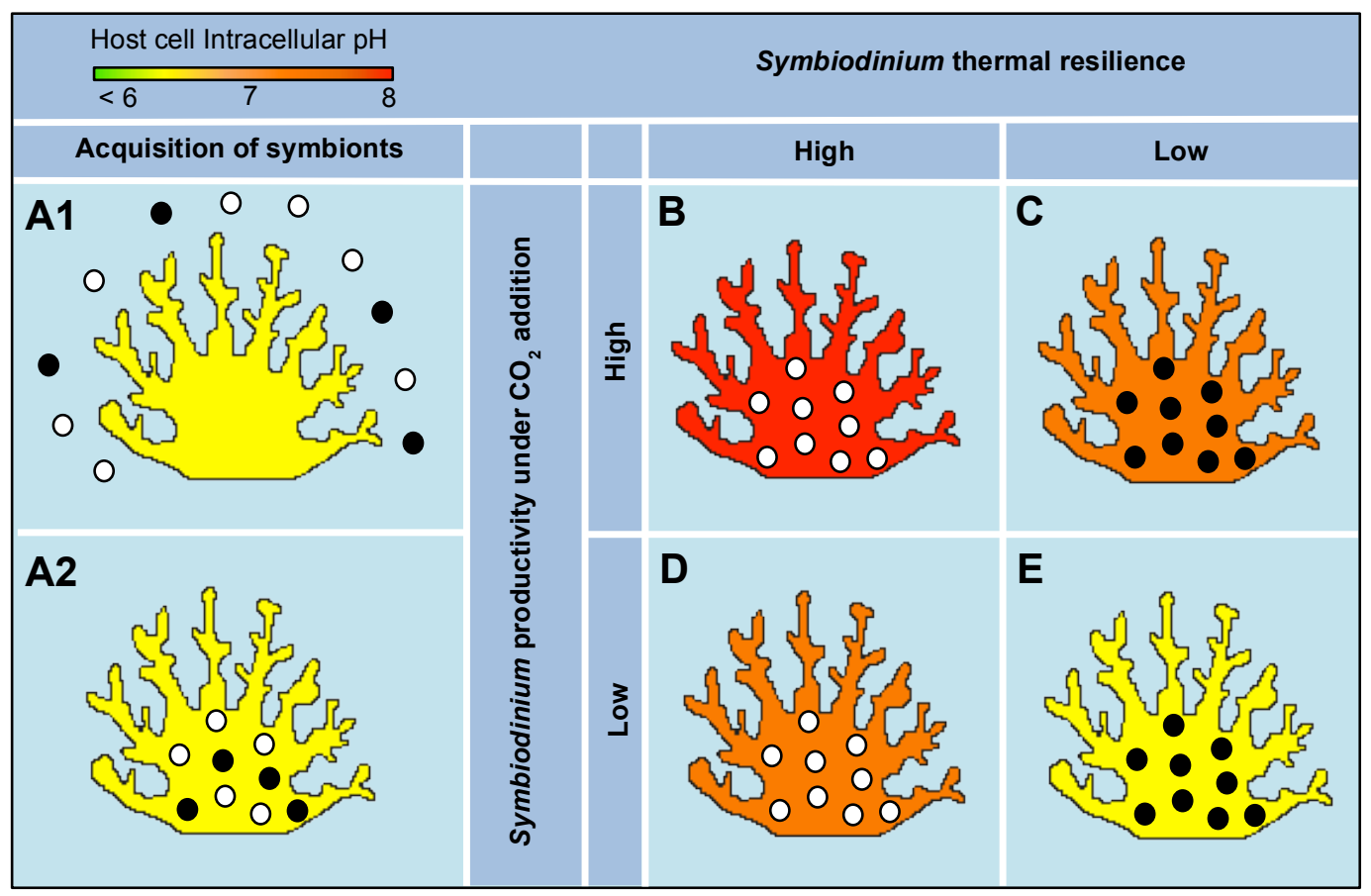

Fig. 6.1 Schematic diagram illustrating how intracellular $\mathrm{pH}\left(\mathrm{pH}_{\mathrm{i}}\right)$ fluctuations in the coral host cell are influenced by the thermal resilience and productivity of the Symbiodinium cells that they host. [A] Following a bleaching event corals can acquire Symbiodinium cells via [1] switching or [2] shuffling. If the symbiont has: [B] high thermal resilience and high productivity under $\mathrm{CO}_{2}$ addition, the $\mathrm{pH}_{\mathrm{i}}$ of the host cell can be elevated above normal levels $(\sim 8)$; if the symbiont has either [C] low thermal resilience and high productivity under $\mathrm{CO}_{2}$ addition; or [D] high thermal resilience and low productivity under $\mathrm{CO}_{2}$ addition, the $\mathrm{pH}_{\mathrm{i}}$ is maintained within normal levels $(\sim 7-7.4)$; but if the symbiont has $[\mathrm{E}]$ low thermal resilience and low productivity under $\mathrm{CO}_{2}$ addition, the host cell will experience cellular acidosis $(\sim$ 6.5). Note that the colour of the corals indicates the $\mathrm{pH}_{\mathrm{i}}$ of the host cell as identified in the colour gradient above, and Symbiodinium cells are coloured black/white according to their thermal tolerance $($ black $=$ thermally sensitive; white $=$ thermally resilient)

One such example of this is clade D Symbiodinium. Once heralded as a "nugget of hope" because of the additional $1-1.5^{\circ} \mathrm{C}$ thermal tolerance it affords A. millepora 
(Berkelmans and van Oppen, 2006), it has since been shown to reduce growth rates by $38 \%$, lipid stores by $26 \%$ and egg sizes by up to $28 \%$ (Jones and Berkelmans, 2010; 2011), due to its relatively low photosynthetic rate (Abrego et al., 2008), and is now deemed an "opportunist" (Stat and Gates, 2011). Under elevated temperatures alone, associating with clade D for a short period can be beneficial in that it can prevent mortality before a coral reverts back to its optimal symbiont cohort (Thornhill et al., 2006). However, under the combined stressors of both elevated temperature and ocean acidification, this advantage may be lost, leading to acidosis of the host cell. In conclusion, it appears that global warming, and symbiont productivity will profoundly influence the cellular response of coral cells to $\mathrm{CO}_{2}$. Given that the nature of the response will be both species- and symbiont specific, these findings have important ecological implications for the future of coral reefs in warm, acidified oceans.

\subsection{Implications for the future of coral reefs: a shift in dominance?}

The effects of ocean acidification and global warming will not be homogeneous in space or time (Hoegh-Guldberg et al., 2007; Pandolfi et al., 2011). High latitude reefs, for example, are likely to experience acidification earlier than reefs close to the Equator, because the aragonite saturation horizon (ASH) is shallower in these regions (Fabry et al., 2009). Conversely, equatorial reefs will be subjected to earlier, and more severe coral bleaching episodes (Van Hooidonk et al., 2013). Between these areas lie the tropics, home to the majority of the world's coral reefs, and the habitats that are at the greatest risk from the combined effects of sea surface temperature rises and ocean acidification. Within these areas, variation in local and regional ecosystem drivers such as eutrophication (Szmant, 2002; Fabricius et al., 2005; Wiedenmann et al., 2012; Bell et al., 2014; Vega Thurber et al., 2014), over-fishing (Jackson et al., 2001; Hughes et al., 2007), pollution (Hughes et al., 2010) and disease (Richardson, 1998) all shape the community structure of reefs. Coral reefs that are already degraded are beginning to show signs of "phase shifts" (Norström et al., 2009) to "alternate stable states" [Fig. 6.2] such as those dominated by macroalgae (Hughes, 1994; Aronson and Precht, 2006); sponges (Goodwin et al., 2011; Bell et al., 2013); sea anemones (Chen and Dai, 2004, Tkachenko et al., 2007) and corallimorpharians (Chadwick-Furman and Spiegel, 2000; Rajasuriya and Karunarathna, 2000; Work et al., 2008). 


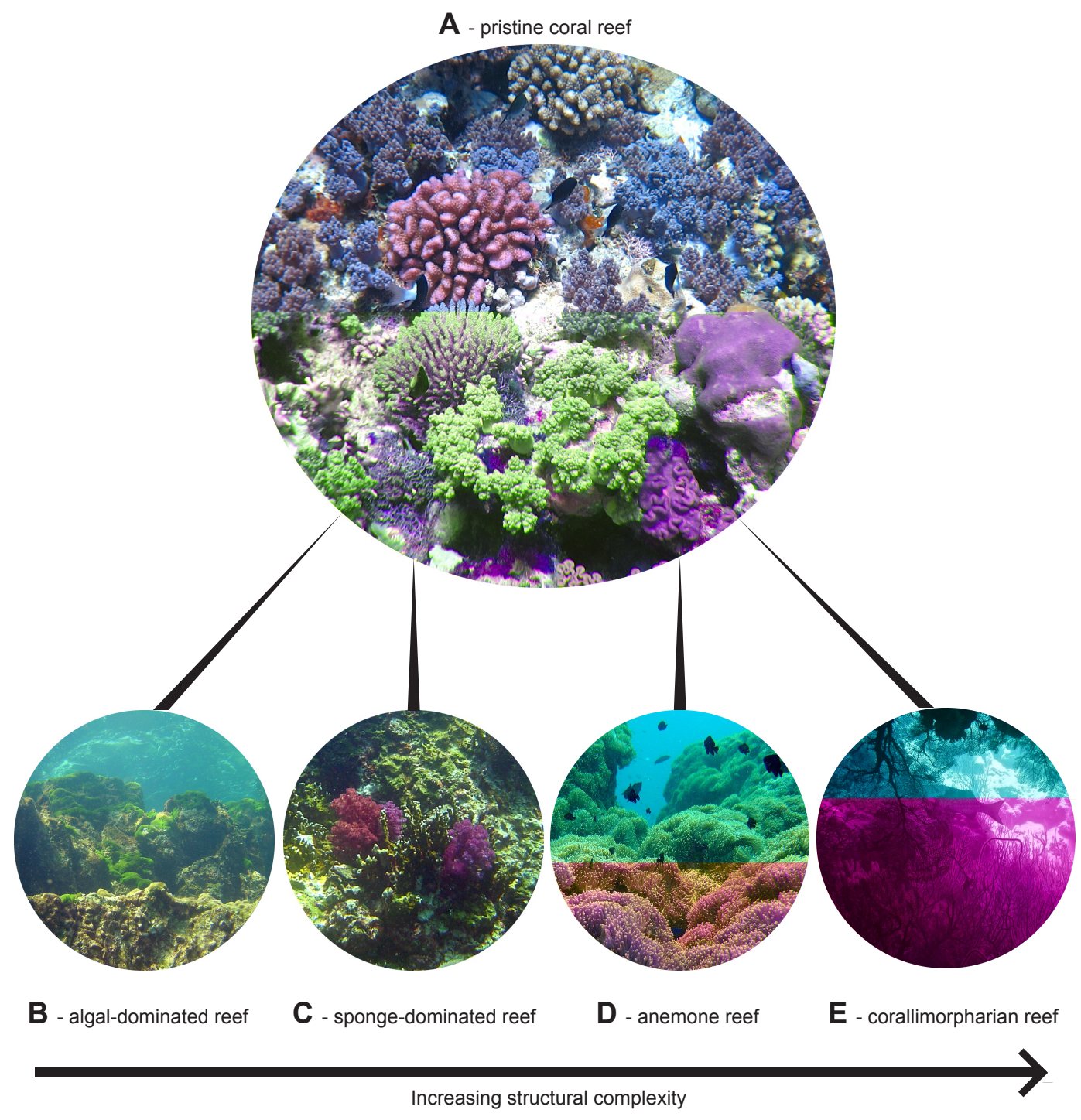

Fig. 6.2 Alternative stable states. [A] A scleractinian-dominated reef (Great Barrier Reef, Australia) may shift to either: [B] an algal dominated ecosystem (Western Rocky Island, Myanmar); [C] a sponge-dominated reef (Richelieu Rock, Thailand); [D] an anemonedominated reef (Hin Muang, Thailand); or [E] a corallimorpharian reef (Hienghene, New Caledonia). Photographs B, C and D provided by T.D. Hawkins.

The prospect of anemone-dominated reefs [Fig 6.2D] is particularly interesting in light of the positive and rapid response ( $<$ two weeks) of A. pulchella to $\mathrm{CO}_{2}$-addition (Chapter 5). The concurrent, and sustained increase in gross $\left(\mathrm{P}_{\text {gross }}\right)$ and cell-specific photosynthesis across the two-month experimental period suggests that anemones are not only well equipped to colonise any space that becomes available, but also to retain it. This has important implications for protecting the biodiversity of reefs; maintaining a degree of structural complexity and providing refuge from predators (Holbrook and Schmitt, 2005) by reducing algal cover (Taylor and Littler, 1982). Under specific high-nutrient conditions, some anemones are not only able to colonise space rapidly, 
but can actively outcompete live coral. Mesactinia genesis, for example, increases its rate of reproduction and the size of its acrorhagi tentacles (Williams, 1991), and actively attacks nearby Acropora muricata colonies (Liu et al., 2009). Surprisingly then, anemone reefs are relatively rare in the tropics. Those that do persist are dominated by the giant anemone Condylactis sp. (Tkachenko et al., 2007), and tend to form in areas characterised by high nutrient and sedimentation rates (Chen and Dai, 2004; Liu et al., 2009) such as around Taiwan, where they can reach percentage covers as high as $40 \%$ (Tkachenko et al., 2007). Rising sea surface temperatures, however, could inadvertently provide an opportunity for anemone-dominated reefs to increase in prevalence, including in higher latitude areas as they warm (Guinotte et al., 2003; Veron, 2011). A poleward migration of tropical coral reef species has largely been dismissed, because the shallowing of the ASH would prevent corals from calcifying at higher latitudes (Kleypas et al., 1999), but there has been little consideration of the implications that this may hold for non-calcifying phototrophs. If, as my results suggest, phototrophic organisms are able to benefit from $\mathrm{CO}_{2}$ addition, and the increase in primary productivity is enough to prevent the negative aspects of acidification, namely acidosis (Chapter 3, 5), then it is possible that soft-bodied phototrophic cnidarians could dominate at marginal latitudes that are undersaturated with aragonite in the future. There is direct support for this hypothesis. Firstly, in natural Mediterranean $\mathrm{CO}_{2}$ vent communities, A. viridis abundances increased twofold at sites with $p \mathrm{CO}_{2}$ values of 500 - $1250 \mathrm{ppm}$ relative to control sites, and then doubled again at the site of the highest $p \mathrm{CO}_{2}$ of $1450 \mathrm{ppm}$ (Suggett et al., 2012). Secondly, in three temperate anemones, Anthopleura aureoradiata (Doherty, 2009), A. elegantissima (Towanda and Thuesen, 2012) and A. viridis (Jarrold et al., 2013), experimental $\mathrm{CO}_{2}$-addition either had no effect (Doherty, 2009), or increased photosynthetic output (Towanda and Thuesen, 2012; Jarrold et al., 2013). A further key piece of evidence can be derived from the geological records spanning the two major mass extinctions of coral reefs - at the end of the Triassic and Cretaceous periods (Stanley, 2003; Veron, 2008). Both of these mass extinction events were characterised by extremely high $\mathrm{CO}_{2}$ levels - up to eight times higher than those experienced today (Hautmann, 2004). The persistence of corals despite a 6-8 million year absence from the fossil record (Veron, 2008) led to the 'naked coral hypothesis', the theory that corals are able to survive the increase in acidity, just not in the calcified form we recognise today (Stanley, 2003; Medina et al., 2006; Kitahara et al., 
2014). Fine and Tchernov (2007) tested this theory using the Mediterranean corals Oculina patagonica and Madracis pharencis. Both corals were able to survive $\mathrm{CO}_{2}$ enrichment scenarios much higher than those predicted for $2100\left(\mathrm{pH}_{\mathrm{e}} 7.3-7.6\right)$ by shifting to a soft-bodied polyp form, functioning in manner similar to the anemones in this study. Selecting this life-history strategy would render the polyps at greater risk of predation in the short-term, but could increase survivorship of corals in the longerterm, where the deterioration in reef health (and habitat complexity) would reduce the abundance and diversity of predators (Guinotte and Fabry, 2008). In this respect, it will be important for future studies to consider the effects of global climate change and ocean acidification on predator-prey dynamics (Suggett et al., 2012).

\subsection{Limitations of the present study, and priorities for future work}

This thesis provides a number of methodological advances that can be used in future studies to determine the cellular implications of ocean acidification and global climate change. In Chapter 2, I provide a simple, quick and cheap method for analysing $\mathrm{pH}_{\mathrm{i}}$ at the level of the whole Symbiodinium cell. But, while this is technique is adequate for measuring average $\mathrm{pH}_{\mathrm{i}}$, it is not able to provide information on areas of differential $\mathrm{pH}_{\mathrm{i}}$ within the cell. Given that $\mathrm{pH}_{\mathrm{i}}$ varies substantially between cellular organelles in other organisms (Roos and Boron, 1981; Kurkdjian and Guern, 1989; Casey et al., 2010), increasing the resolution of this approach should be a priority for future research. Furthermore, attention should be focused on accurately measuring the vacuolar space of the symbiosome (i.e. the perialgal vacuole) in the intact symbiosis, because this region serves as the functional interface between the host and symbiont, and thus plays a critical role in the translocation of metabolites. Previous studies have noted the presence of an acidic ring, which is thought to be less than $\mathrm{pH} 5.7$ (Rands et al., 1993; Venn et al., 2009; Laurent et al., 2013a), but this should be resolved. The technique developed here was, however, sensitive enough to measure the intrinsic differences between light- and dark-adapted $\mathrm{pH}_{\mathrm{i}}$ in six Symbiodinium genotypes (Chapter 2). A great deal of physiological variation exists between and within Symbiodinium types (Warner et al., 1996; Bhagooli and Hidaka, 2003; Fabricius et al., 2004; Takahashi et al., 2009; Ragni et al., 2010), so it would be pertinent for future studies to assess a wider range of types in order to fully encompass both the genetic 
and physiological diversity in this genus. Given the importance of the symbiont in determining its host cell's sensitivity to acidification (Chapters 3-5), it will be especially important to quantify how a symbiont's genotype affects the buffering capacity of it's host cell. In this regard, it would be particularly interesting to consider whether thermally tolerant types, such as C15 (Fitt et al., 2009; Fisher et al., 2012), may be able to offer greater resistance to their host under ocean acidification (Chapter 4; Fig. 6.1). Moreover, given that the measurements in this study were conducted on doublet cells (host cells containing two algal symbionts) only, it will be important to investigate whether the number of Symbiodinium cells that a coral host cell contains can influence the host's cellular response to acidification. For example, does a triplet host cell (i.e. a host cell containing three algal symbionts) have a greater capacity to withstand acidification than a host cell containing a single alga? And, if indeed they do, how does the average carrying capacity of the host cells across the holobiont influence its susceptibility to acidification? The average number of symbiont cells per anthozoan host cell (the cell-specific density; CSD) varies from 1.11 in Condylactis gigantea, Montastrea cavernosa and Agaricia sp. to 2.19 in A. viridis, with the mean of 33 different species being $1.54 \pm 0.30$ (Muscatine et al., 1998). Could a high CSD in $A$. pulchella contribute to its success under $\mathrm{CO}_{2}$-addition? And can corals exert control over their symbiont population density as a means of regulating their $\mathrm{pH}_{\mathrm{i}}$ ? These are both interesting questions for the future.

The majority of the work in this thesis used isolated cells, yet bathing cells in seawater does not necessarily replicate the conditions that a cell would experience in intact coral tissues. There is a great deal of variation in $\mathrm{pH}$ within the coral biome; cells facing the gastrovascular cavity, for example, can be exposed to seawater of up to $\mathrm{pH} 9$ (Al-Horani et al., 2003). In this respect, it would be interesting to extend this work to different tissue layers. Quantifying the $\mathrm{pH}_{\mathrm{i}}$ of ectodermal cells, for example, will improve our understanding of carbon speciation and DIC-transport, while measuring the $\mathrm{pH}_{\mathrm{i}}$ of cells in the aboral tissue layer may shed light on the fluxes of DIC that connect photosynthesis and calcification (Brownlee, 2009). 


\subsection{Conclusions}

This thesis provides the first simultaneous measurements of $\mathrm{pH}_{\mathrm{i}}$ in Symbiodinium and their host coral cells, using a novel live-cell imaging technique, which will facilitate future investigations into the role of $\mathrm{pH}_{\mathrm{i}}$ in symbiotic partnerships. My findings further the pioneering work of Venn and co-authors (2009), by considering the impact of $\mathrm{CO}_{2}$-addition and thermal stress on $\mathrm{pH}_{\mathrm{i}}$ dynamics. I demonstrate inter- and intrataxonomic differences in the susceptibility of organisms to cellular acidosis; specifically I confirm previous observations that $\mathrm{CO}_{2}$-addition can have benefits for soft-bodied non-calcifying organisms such as anemones, in contrast to the negative impacts for corals. Furthermore, I show that thermal stress enhances an individual's sensitivity to acidosis, and that the magnitude of this sensitivity is increased/reduced according to its thermal resilience. The interactions between photosynthesis, symbiont $\mathrm{pH}$ and host cell $\mathrm{pH}$ drive the cellular mechanisms that underpin symbiosis. Understanding the biology behind these interactions is essential if we are to understand how coral and/or Symbiodinium physiology contributes to symbiosis collapse (Weis et al., 2008; Venn et al., 2008; Davy et al., 2012), and indeed, if we are to make accurate predictions about the future status of coral reefs. 


\section{References}

Abrego, D., Ulstrup, K.E., Willis, B.L., van Oppen, M.J., 2008. Species-specific interactions between algal endosymbionts and coral hosts define their bleaching response to heat and light stress. Proc. R. Soc. B. 275, 2273-2282.

Aerts, R.J., Durston, A.J., Moolenaar, W.H., 1985. Cytoplasmic pH and the regulation of the Dictyostelium cell cycle. Cell 43, 653-657.

Airi, V., Gizzi, F., Falini, G., Levy, O., Dubinsky, Z., Goffredo, S., 2014. Reproductive efficiency of a mediterranean endemic zooxanthellate coral decreases with increasing temperature along a wide latitudinal gradient. PLoS One 9, e91792.

Aizawa, K., Miyachi, S., 1986. Carbonic anhydrase and $\mathrm{CO}_{2}$ concentrating mechanisms in microalgae and cyanobacteria. Fems Microbiol. Lett. 39, 215-233.

Al-Horani, F., Al-Moghrabi, S., De Beer, D., 2003. The mechanism of calcification and its relation to photosynthesis and respiration in the scleractinian coral Galaxea fascicularis. Mar. Biol. 142, 419-426.

Al-Moghrabi, S., Goiran, C., Allemand, D., Speziale, N., Jaubert, J., 1996. Inorganic carbon uptake for photosynthesis by the symbiotic coral-dinoflagellate association. II. Mechanisms for bicarbonate uptake. J. Exp. Mar. Biol. Ecol. 199, 227-248.

Albright, R., Mason, B., Miller, M., Langdon, C., 2010. Ocean acidification compromises recruitment success of the threatened Caribbean coral Acropora palmata. Proc. Nat. Acad. Sci. 107, 20400-20404.

Albright, R., 2011. Reviewing the effects of ocean acidification on sexual reproduction and early life history stages of reef-building corals. J. Mar. Biol. Article ID 473615, 1-14.

Allemand, D., Furla, P., Tambutté, S.B., 1998. Mechanisms of carbon acquisition for endosymbiont photosynthesis in Anthozoa. Botany 76, 925-941.

Allemand, D., Ferrier-Pagès, C., Furla, P., Houlbrèque, F., Puverel, S., Reynaud, S., Tambutté, E., Tambutté, S., Zoccola, D., 2004. Biomineralisation in reef-building corals: from molecular mechanisms to environmental control. C. R. Palevol. 3, 453467.

Altamia, M.A., Wood, N., Fung, J., Dedrick, S., Linton, E.W., Concepcion, G.P., Haygood, M.G., Distel, D.L., 2014. Genetic differentiation among isolates of Teredinibacter turnerae, a widely occurring intracellular endosymbiont of shipworms. Mol. Ecol. 23, 1418-1432.

Anlauf, H., D'Croz, L., O'Dea, A., 2011. A corrosive concoction: the combined effects of ocean warming and acidification on the early growth of a stony coral are multiplicative. J. Exp. Mar. Biol. Ecol. 397, 13-20.

Anthony, K., Kline, D., Diaz-Pulido, G., Dove, S., Hoegh-Guldberg, O., 2008. Ocean acidification causes bleaching and productivity loss in coral reef builders. Proc. Natl. Acad. Sci. 105, 17442-17446. 
Anthony, K., Maynard, J.A., Diaz-Pulido, G., Mumby, P.J., Marshall, P.A., Cao, L., HoeghGuldberg, O., 2011. Ocean acidification and warming will lower coral reef resilience. Glob. Change Biol. 17, 1798-1808.

Aronson, R.B., Precht, W.F., 2006. Conservation, precaution, and Caribbean reefs. Coral Reefs 25, 441-450.

Babcock, R.C., Bull, G.D., Harrison, P.L., Heyward, A.J., Oliver, J.K., Wallace, C.C., Willis, B.L., 1986. Synchronous spawnings of 105 scleractinian coral species on the Great Barrier Reef. Mar. Biol. 90, 379-394.

Badger, M., 2003. The roles of carbonic anhydrases in photosynthetic $\mathrm{CO}_{2}$ concentrating mechanisms. Photosynth. Res. 77, 83-94.

Baird, A., Marshall, P., 2002. Mortality, growth and reproduction in scleractinian corals following bleaching on the Great Barrier Reef. Mar. Ecol. Prog. Ser. 237, 133-141.

Baird, A., Bhagooli, R., Ralph, P., Takahashi, S., 2009. Coral bleaching: the role of the host. Trends Ecol. Evol. 24, 16-20.

Baker, A.C., 2001. Ecosystems: reef corals bleach to survive change. Nature 411, 765-766.

Baker, A.C., 2003. Flexibility and specificity in coral-algal symbiosis: diversity, ecology, and biogeography of Symbiodinium. Annu. Rev. Ecol. Evol. Syst. 34, 661-689.

Baker, A.C., Starger, C.J., McClanahan, T.R., Glynn, P.W., 2004. Coral reefs: corals' adaptive response to climate change. Nature 430, 741-741.

Banaszak, A.T., Trench, R.K., 1995. Effects of ultraviolet (UV) radiation on marine microalgal-invertebrate symbioses. II. The synthesis of mycosporine-like amino acids in response to exposure to UV in Anthopleura elegantissima and Cassiopeia xamachana. J. Exp. Mar. Biol. Ecol. 194, 233-250.

Banaszak, T., LaJeunesse, T.C., Trench, R.K., 2000. The synthesis of mycosporine-like amino acids (MAAs) by cultured, symbiotic dinoflagellates. J. Exp. Mar. Biol. Ecol. $249,219-233$.

Barbier, E.B., 2012. Progress and challenges in valuing coastal and marine ecosystem services. Rev. Environ. Econ. Policy 6, 1-19.

Baroli, I., Melis, A., 1996. Photoinhibition and repair in Dunaliella salina acclimated to different growth irradiances. Planta 198, 640-646.

Bates, N., Orchowska, M., Garley, R., Mathis, J., 2013. Summertime calcium carbonate undersaturation in shelf waters of the western Arctic Ocean - how biological processes exacerbate the impact of ocean acidification. Biogeosciences 10, 52815309 .

Beardall, J., Giordano, M., 2002. Ecological implications of microalgal and cyanobacterial $\mathrm{CO}_{2}$ concentrating mechanisms, and their regulation. Funct. Plant Biol. 29, 335-347.

Beaufort, L., Probert, I., de Garidel-Thoron, T., Bendif, E., Ruiz-Pino, D., Metzl, N., Goyet, C., Buchet, N., Coupel, P., Grelaud, M., 2011. Sensitivity of coccolithophores to carbonate chemistry and ocean acidification. Nature 476, 80-83. 
Beger, M., Sommer, B., Harrison, P.L., Smith, S.D., Pandolfi, J.M., 2013. Conserving potential coral reef refuges at high latitudes. Divers. Distrib. 20, 245-257.

Bell, J.J., Davy, S.K., Jones, T., Taylor, M.W., Webster, N.S., 2013. Could some coral reefs become sponge reefs as our climate changes? Glob. Change Biol. 19, 2613-2624.

Bell, P.R., Elmetri, I., Lapointe, B.E., 2014. Evidence of large-scale chronic eutrophication in the Great Barrier Reef: Quantification of chlorophyll $a$ thresholds for sustaining coral reef communities. Ambio 43, 361-376.

Bellwood, D.R., Hughes, T.P., 2001. Regional-scale assembly rules and biodiversity of coral reefs. Science 292, 1532-1535.

Bénazet-Tambutté, S., Allemand, D., Jaubert, J., 1996. Permeability of the oral epithelial layers in cnidarians. Mar. Biol. 126, 43-53.

Berkelmans, R., van Oppen, M.J.H., 2006. The role of zooxanthellae in the thermal tolerance of corals: a 'nugget of hope' for coral reefs in an era of climate change. Proc. R. Soc. B. 273, 2305-2312.

Bertucci, A., Tambutté, E., Tambutté, S., Allemand, D., Zoccola, D., 2009. Symbiosisdependent gene expression in coral-dinoflagellate association: cloning and characterization of a P-type $\mathrm{H}^{+}$-ATPase gene. Proc. R. Soc. B. 277, 87-95.

Bertucci, A., Tambutté, S., Supuran, C.T., Allemand, D., Zoccola, D., 2011. A new coral carbonic anhydrase in Stylophora pistillata. Marine Biotechnol. 13, 992-1002.

Bhagooli, R., Hidaka, M., 2003. Comparison of stress susceptibility of in hospite and isolated zooxanthellae among five coral species. J. Exp. Mar. Biol. Ecol. 291, 181-197.

Bhagooli, R., 2013. Inhibition of Calvin-Benson cycle suppresses the repair of photosystem II in Symbiodinium: implications for coral bleaching. Hydrobiologia 714, 183-190.

Bongaerts, P., Riginos, C., Ridgway, T., Sampayo, E.M., van Oppen, M.J., Englebert, N., Vermeulen, F., Hoegh-Guldberg, O., 2010. Genetic divergence across habitats in the widespread coral Seriatopora hystrix and its associated Symbiodinium. PLoS One 5, e10871.

Boron, W.F., 2004. Regulation of intracellular pH. Adv. Physiol. Educ. 28, 160-179.

Bou-Abdallah, F., Chasteen, N.D., Lesser, M.P., 2006. Quenching of superoxide radicals by green fluorescent protein. Biochim. Biophys. Acta. 1760, 1690-1695.

Bouchard, J.N., Yamasaki, H., 2009. Implication of nitric oxide in the heat-stress-induced cell death of the symbiotic alga Symbiodinium microadriaticum. Mar. Biol. 156, 22092220 .

Bozzo, G., Colman, B., 2000. The induction of inorganic carbon transport and external carbonic anhydrase in Chlamydomonas reinhardtii is regulated by external $\mathrm{CO}_{2}$ concentration. Plant Cell Environ. 23, 1137-1144.

Bradford, M.M., 1976. A rapid and sensitive method for the quantitation of microgram quantities of protein utilizing the principle of protein-dye binding. Anal. Biochem. 72, 248-254. 
Brading, P., Warner, M.E., Davey, P., Smith, D.J., Achterberg, E.P., Suggett, D.J., 2011. Differential effects of ocean acidification on growth and photosynthesis among phylotypes of Symbiodinium (Dinophyceae). Limnol. Oceanogr. 56, 927-938.

Brading, P., Warner, M.E., Smith, D.J., Suggett, D.J., 2013. Contrasting modes of inorganic carbon acquisition amongst Symbiodinium (Dinophyceae) phylotypes. New Phytol. $200,432-442$.

Bright, G., Fisher, G., Rogowska, J., Taylor, D., 1989. Fluorescence ratio imaging microscopy. Methods Cell Biol. 30, 157-192.

Brownlee, C., 2009. pH regulation in symbiotic anemones and corals: A delicate balancing act. Proc. Nat. Acad. Sci. 106, 16541-16542.

Bruno, J.F., Selig, E.R., 2007. Regional decline of coral cover in the Indo-Pacific: timing, extent, and subregional comparisons. PLoS One 2, e711.

Buddemeier, R.W., Fautin, D.G., 1993. Coral bleaching as an adaptive mechanism. Bioscience 43, 320-326.

Burriesci, M.S., Raab, T.K., Pringle, J.R., 2012. Evidence that glucose is the major transferred metabolite in dinoflagellate-cnidarian symbiosis. J. Exp. Biol. 215, 34673477 .

Busa, W., Nuccitelli, R., 1984. Metabolic regulation via intracellular pH. Am. J. Physiol. Reg. I. 246, 409-438.

Buttke, T.M., Sandstrom, P.A., 1994. Oxidative stress as a mediator of apoptosis. Immunol. Today $15,7-10$.

Buxton, L., Badger, M., Ralph, P., 2009. Effects of moderate heat stress and dissolved inorganic carbon concentration on photosynthesis and respiration of Symbiodinium sp. (Dinophyceae) in culture and in symbiosis. J. Phycol. 45, 357-365.

Byrne, M., Przeslawski, R., 2013. Multistressor impacts of warming and acidification of the ocean on marine invertebrates' life histories. Integr. Comp. Biol. 53, 582-596.

Cantin, N.E., Cohen, A.L., Karnauskas, K.B., Tarrant, A.M., McCorkle, D.C., 2010. Ocean warming slows coral growth in the central Red Sea. Science 329, 322-325.

Carpenter, R.C., Williams, S.L., 2007. Mass transfer limitation of photosynthesis of coral reef algal turfs. Mar. Biol. 151, 435-450.

Casey, J.R., Grinstein, S., Orlowski, J., 2010. Sensors and regulators of intracellular pH. Nat. Rev. Mol. Cell Bio. 11, 50-61.

Chadwick-Furman, N.E., Spiegel, M., 2000. Abundance and clonal replication in the tropical corallimorpharian Rhodactis rhodostoma. Invertebr. Biol. 119, 351-360.

Chan, N., Connolly, S.R., 2013. Sensitivity of coral calcification to ocean acidification: a meta-analysis. Glob. Change Biol. 19, 282-290.

Chang, S.S., Trench, R., 1984. The isoelectric forms, quaternary structure and amino acid composition of peridinin-chlorophyll $a$-proteins from the symbiotic dinoflagellate Symbiodinium microadriaticum Freudenthal. Proc. R. Soc. B. 222, 259-271. 
Chen, C.A., Dai, C.-F., 2004. Local phase shift from Acropora-dominant to Condylactisdominant community in the Tiao-Shi Reef, Kenting National Park, southern Taiwan. Coral Reefs 23, 508-508.

Chen, M.C., Cheng, Y.M., Hong, M.C., Fang, L.S., 2004. Molecular cloning of Rab5 (ApRab5) in Aiptasia pulchella and its retention in phagosomes harboring live zooxanthellae. Biochem. Biophys. Res. Commun. 324, 1024-1033.

Chen, M.C., Hong, M.C., Huang, Y.S., Liu, M.C., Cheng, Y.M., Fang, L.S., 2005. ApRab11, a cnidarian homologue of the recycling regulatory protein Rab11, is involved in the establishment and maintenance of the Aiptasia-Symbiodinium endosymbiosis. Biochem. Biophys. Res. Commun. 338, 1607-1616.

Chi, J., Parrow, M.W., Dunthorn, M., 2014. Cryptic sex in Symbiodinium (Alveolata, Dinoflagellata) is supported by an inventory of meiosis genes. J. Eukaryot. Microbiol. $61,322-327$.

Chin, A., Lison de Loma, T., Reytar, K., Planes, S., Gerhardt, K., Clua, E., Burke, L., Wilkinson, C., 2011. Status of Coral Reefs of the Pacific and Outlook: 2011. Global Coral Reef Monitoring Network. pp. 260.

Christen, N., Calosi, P., McNeill, C.L., Widdicombe, S., 2013. Structural and functional vulnerability to elevated $p \mathrm{CO}_{2}$ in marine benthic communities. Mar. Biol. 160, 21132128 .

Cigliano, M., Gambi, M., Rodolfo-Metalpa, R., Patti, F., Hall-Spencer, J., 2010. Effects of ocean acidification on invertebrate settlement at volcanic $\mathrm{CO}_{2}$ vents. Mar. Biol. 157, 2489-2502.

Coleman, J.R., Colman, B., 1981. Inorganic carbon accumulation and photosynthesis in a blue-green alga as a function of external pH. Plant Physiol. 67, 917-921.

Comeau, S., Gorsky, G., Jeffree, R., Teyssié, J.-L., Gattuso, J.-P., 2009. Impact of ocean acidification on a key Arctic pelagic mollusc (Limacina helicina). Biogeosciences 6, 1877-1882.

Comeau, S., Carpenter, R.C., Edmunds, P.J., 2013. Coral reef calcifiers buffer their response to ocean acidification using both bicarbonate and carbonate. Proc. R. Soc. B. 280, 1471-2954.

Comeau, S., Carpenter, R.C., Edmunds, P.J., 2014. Effects of irradiance on the response of the coral Acropora pulchra and the calcifying alga Hydrolithon reinboldii to temperature elevation and ocean acidification. J. Exp. Mar. Biol. Ecol. 453, 28-35.

Cook, C.B., D'Elia, C.F., 1987. Are natural populations of zooxanthellae ever nutrientlimited? Symbiosis 4, 199-211.

Cook, C.B., Muller-Parker, G., D'Elia, C.F., 1992. Ammonium enhancement of dark carbon fixation and nitrogen limitation in symbiotic zooxanthellae: Effects of feeding and starvation of the sea anemone Aiptasia pallida. Limnol. Oceanogr. 37, 131-139.

Crook, E., Potts, D., Rebolledo-Vieyra, M., Hernandez, L., Paytan, A., 2012. Calcifying coral abundance near low-pH springs: implications for future ocean acidification. Coral Reefs 31, 239-245. 
Crossland, C., Barnes, D., 1977. Nitrate assimilation enzymes from two hard corals, Acropora acuminata and Goniastrea australensis. Comp. Biochem. Phys. B. 57, 151-157.

Császár, N.B.M., Ralph, P.J., Frankham, R., Berkelmans, R., van Oppen, M.J.H., 2010. Estimating the potential for adaptation of corals to climate warming. PLoS One 5, e9751.

Cunning, R., Baker, A.C., 2013. Excess algal symbionts increase the susceptibility of reef corals to bleaching. Nature Clim. Change 3, 259-262.

Darzynkiewicz, Z., Juan, G., Bedner, E., 2001. Determining cell cycle stages by flow cytometry. In: Bonifacino JS et al. (Ed.), Current Protocols in Cell Biology. New York: John Wiley \& Sons, Inc. pp. 1-18.

Davies, J.M., Brownlee, C., Jennings, D., 1990. Measurement of intracellular pH in fungal hyphae using BCECF and digital imaging microscopy: Evidence for a primary proton pump in the plasmalemma of a marine fungus. J. Cell Sci. 96, 731-736.

Davy, S.K., Cook, C.B., 2001. The relationship between nutritional status and carbon flux in the zooxanthellate sea anemone Aiptasia pallida. Mar. Biol. 139, 999-1005.

Davy, S.K., Allemand, D., Weis, V.M., 2012. Cell biology of cnidarian-dinoflagellate symbiosis. Microbiol. Mol. Biol. Rev. 76, 229-261.

de Bary, A., 1879. Die erscheinungen der symbiose. In: KJ Trübner (Ed.), Vortrag auf der versammlung deutscher naturforscher und aerzte zu cassel. Strassburg. pp. 1-30.

De Moel, H., Ganssen, G., Peeters, F., Jung, S., Brummer, G., Kroon, D., Zeebe, R., 2009. Planktic foraminiferal shell thinning in the Arabian Sea due to anthropogenic ocean acidification? Biogeosci. Discuss. 6, 1917-1925.

De'ath, G., Lough, J.M., Fabricius, K.E., 2009. Declining coral calcification on the great barrier reef. Science 323, 116-119.

DeSalvo, M., Voolstra, C., Sunagawa, S., Schwarz, J., Stillman, J., Coffroth, M.A., Szmant, A., Medina, M., 2008. Differential gene expression during thermal stress and bleaching in the Caribbean coral Montastraea faveolata. Mol. Ecol. 17, 3952-3971.

Díaz-Almeyda, E., Thomé, P., El Hafidi, M., Iglesias-Prieto, R., 2011. Differential stability of photosynthetic membranes and fatty acid composition at elevated temperature in Symbiodinium. Coral Reefs 30, 217-225.

Dickson, A.G., Sabine, C.L., Christian, J.R., 2007. Guide to best practices for ocean $\mathrm{CO}_{2}$ measurements. PICES Special Publication 3, 191-192.

Diekmann, M., Falkengren-Grerup, U., 2002. Prediction of species response to atmospheric nitrogen deposition by means of ecological measures and life history traits. J. Ecol. 90, 108-120.

Dixon, G., Brownlee, C., Merrett, M., 1989. Measurement of internal $\mathrm{pH}$ in the coccolithophore Emiliania huxleyi using 2',7'-bis-(2-carboxyethyl)-5 (and-6) carboxyfluorescein acetoxymethylester and digital imaging microscopy. Planta 178, 443-449. 
Doherty, M., 2009. Ocean acidification: Comparative impacts on the photophysiology of a temperate symbiotic sea anemone and a tropical coral. Unpublished MSc Thesis, Victoria University, Wellington, New Zealand, 168pp.

Doney, S.C., Fabry, V.J., Feely, R.A., Kleypas, J.A., 2009. Ocean acidification: the other $\mathrm{CO}_{2}$ problem. Annu. Rev. Mar. Sci. 1, 169-192.

Doropoulos, C., Ward, S., Diaz-Pulido, G., Hoegh-Guldberg, O., Mumby, P.J., 2012. Ocean acidification reduces coral recruitment by disrupting intimate larval-algal settlement interactions. Ecol. Lett. 15, 338-346.

Douglas, A., 2003. Coral bleaching - how and why? Mar. Pollut. Bull. 46, 385-392.

Dove, S., Ortiz, J.C., Enriquez, S., Fine, M., Fisher, P., Iglesias-Prieto, R., Thornhill, D., Hoegh-Guldberg, O., 2006. Response of holosymbiont pigments from the scleractinian coral Montipora monasteriata to short-term heat stress. Limnol. Oceanogr. 51, 1149-1158.

Drupp, P., De Carlo, E.H., Mackenzie, F.T., Bienfang, P., Sabine, C.L., 2011. Nutrient inputs, phytoplankton response, and $\mathrm{CO}_{2}$ variations in a semi-enclosed subtropical embayment, Kaneohe Bay, Hawaii. Aquat. Geochem. 17, 473-498.

Dunlap, W.C., Shick, J.M., 1998. Ultraviolet radiation-absorbing mycosporine-like amino acids in coral reef organisms: a biochemical and environmental perspective. J. Phycol. 34, 418-430.

Dupont, S., Havenhand, J., Thorndyke, W., Peck, L.S., Thorndyke, M., 2008. Near-future level of $\mathrm{CO}_{2}$-driven ocean acidification radically affects larval survival and development in the brittlestar Ophiothrix fragilis. Mar. Ecol. Prog. Ser. 373, 285-294.

Eakin, C.M., Morgan, J.A., Heron, S.F., Smith, T.B., Liu, G., Alvarez-Filip, L., Baca, B., Bartels, E., Bastidas, C., Bouchon, C., 2010. Caribbean corals in crisis: record thermal stress, bleaching, and mortality in 2005. PLoS One 5, e13969.

Edmunds, P., 1994. Evidence that reef-wide patterns of coral bleaching may be the result of the distribution of bleaching-susceptible clones. Mar. Biol. 121, 137-142.

Edmunds, P.J., Brown, D., Moriarty, V., 2012. Interactive effects of ocean acidification and temperature on two scleractinian corals from Moorea, French Polynesia. Glob. Change Biol. 18, 2173-2183.

Embley, T.M., Martin, W., 2006. Eukaryotic evolution, changes and challenges. Nature 440, 623-630.

Evenhuis, C., Lenton, A., Cantin, N., Lough, J., 2014. Modeling coral calcification accounting for the impacts of coral bleaching and ocean acidification. Biogeosciences Discuss. 11, 187-249.

Fabricius, K., Mieog, J., Colin, P., Idip, D., van Oppen, M., 2004. Identity and diversity of coral endosymbionts (zooxanthellae) from three Palauan reefs with contrasting bleaching, temperature and shading histories. Mol. Ecol. 13, 2445-2458.

Fabricius, K.E., 2005. Effects of terrestrial runoff on the ecology of corals and coral reefs: review and synthesis. Mar. Pollut. Bull. 50, 125-146. 
Fabricius, K.E., 2006. Effects of irradiance, flow, and colony pigmentation on the temperature microenvironment around corals: Implications for coral bleaching? Limnol. Oceanogr. 51, 30-37.

Fabricius, K.E., Langdon, C., Uthicke, S., Humphrey, C., Noonan, S., De'ath, G., Okazaki, R., Muehllehner, N., Glas, M.S., Lough, J.M., 2011. Losers and winners in coral reefs acclimatized to elevated carbon dioxide concentrations. Nature Clim. Change. 1, 165169.

Fabry, V.J., Seibel, B.A., Feely, R.A., Orr, J.C., 2008. Impacts of ocean acidification on marine fauna and ecosystem processes. ICES. J. Mar. Sci. 65, 414-432.

Fabry, V.J., McClintock, J.B., Mathis, J.T., Grebmeier, J.M., 2009. Ocean acidification at high latitudes: The bellweather. Oceanography 22, 160-171.

Falkowski, P.G., Dubinsky, Z., Muscatine, L., Porter, J.W., 1984. Light and the bioenergetics of a symbiotic coral. Bioscience 34, 705-709.

Feely, R.A., 2004. Impact of anthropogenic $\mathrm{CO}_{2}$ on the $\mathrm{CaCO}_{3}$ system in the oceans. Science 305, 362-366.

Feely, R.A., Sabine, C.L., Hernandez-Ayon, J.M., Ianson, D., Hales, B., 2008. Evidence for upwelling of corrosive "acidified" water onto the continental shelf. Science 320, 1490-1492.

Fine, M., Tchernov, D., 2007. Scleractinian coral species survive and recover from decalcification. Science 315, 1811-1811.

Fitt, W., Trench, R., 1983. The relation of diel patterns of cell division to diel patterns of motility in the symbiotic dinoflagellate Symbiodinium microadriaticum Freudenthal in culture. New Phytol. 94, 421-432.

Fitt, W., Rees, T., Yellowlees, D., 1995. Relationship between $\mathrm{pH}$ and the availability of dissolved inorganic nitrogen in the zooxanthella-giant clam symbiosis. Limnol. Oceanogr. 40, 976-982.

Fitt, W., Warner, M., 1995. Bleaching patterns of four species of Caribbean reef corals. Biol. Bull. 189, 298-307.

Fitt, W., Brown, B., Warner, M., Dunne, R., 2001. Coral bleaching: interpretation of thermal tolerance limits and thermal thresholds in tropical corals. Coral Reefs 20, 51-65.

Fitt, W., Gates, R., Hoegh-Guldberg, O., Bythell, J., Jatkar, A., Grottoli, A., Gomez, M., Fisher, P., Lajuenesse, T., Pantos, O., 2009. Response of two species of Indo-Pacific corals, Porites cylindrica and Stylophora pistillata, to short-term thermal stress: The host does matter in determining the tolerance of corals to bleaching. J. Exp. Mar. Biol. Ecol. 373, 102-110.

Frade, P., De Jongh, F., Vermeulen, F., Van Bleijswijk, J., Bak, R., 2008. Variation in symbiont distribution between closely related coral species over large depth ranges. Mol. Ecol. 17, 691-703.

Franck, P., Petitipain, N., Cherlet, M., Dardennes, M., Maachi, F., Schutz, B., Poisson, L., Nabet, P., 1996. Measurement of intracellular $\mathrm{pH}$ in cultured cells by flow cytometry with BCECF-AM. J. Biotech. 46, 187-195. 
Fransolet, D., Roberty, S., Plumier, J.-C., 2012. Establishment of endosymbiosis: The case of cnidarians and Symbiodinium. J. Exp. Mar. Biol. Ecol. 420, 1-7.

Freudenthal, H.D., 1962. Symbiodinium gen. nov. and Symbiodinium microadriaticum sp. nov., a zooxanthella: taxonomy, life cycle, and morphology. J. Euk. Microbiol. 9, 4552.

Fu, F.-X., Warner, M.E., Zhang, Y., Feng, Y., Hutchins, D.A., 2007. Effects of increased temperature and $\mathrm{CO}_{2}$ on photosynthesis, growth, and elemental ratios in marine Synechococcus and Prochlorococcus (Cyanobacteria). J. Phycol. 43, 485-496.

Furla, P., Allemand, D., Orsenigo, M.N., 2000. Involvement of $\mathrm{H}^{+}$-ATPase and carbonic anhydrase in inorganic carbon uptake for endosymbiont photosynthesis. Am. J. Physiol. Regul. Integr. Comp. Physiol. 278, 870-881.

Ganot, P., Moya, A., Magnone, V., Allemand, D., Furla, P., Sabourault, C., 2011. Adaptations to endosymbiosis in a cnidarian-dinoflagellate association: differential gene expression and specific gene duplications. PLoS genetics 7, e1002187.

Gao, K., Xu, J., Gao, G., Li, Y., Hutchins, D.A., Huang, B., Wang, L., Zheng, Y., Jin, P., Cai, X., 2012. Rising $\mathrm{CO}_{2}$ and increased light exposure synergistically reduce marine primary productivity. Nature Clim. Change 2, 519-523.

Gates, R.D., Muscatine, L., 1992. Three methods for isolating viable anthozoan endoderm cells with their intracellular symbiotic dinoflagellates. Coral Reefs 11, 143-145.

Gattuso, J.-P., Allemand, D., Frankignoulle, M., 1999. Photosynthesis and calcification at cellular, organismal and community levels in coral reefs: a review on interactions and control by carbonate chemistry. Amer. Zool. 39, 160-183.

Gehl, K.A., Colman, B., 1985. Effect of external $\mathrm{pH}$ on the internal $\mathrm{pH}$ of Chlorella saccharophila. Plant Physiol. 77, 917-921.

Genkai-Kato, M., Yamamura, N., 1999. Evolution of mutualistic symbiosis without vertical transmission. Theor. Popul. Biol. 55, 309-323.

Gibson, R., Atkinson, R., Gordon, J., Smith, I., Hughes, D., 2011. Impact of ocean warming and ocean acidification on marine invertebrate life history stages: vulnerabilities and potential for persistence in a changing ocean. Oceanogr. Mar. Biol. Annu. Rev. 49, 142 .

Gilbert, S.F., McDonald, E., Boyle, N., Buttino, N., Gyi, L., Mai, M., Prakash, N., Robinson, J., 2010. Symbiosis as a source of selectable epigenetic variation: taking the heat for the big guy. Philos. T. Soc. B. 365, 671-678.

Giordano, M., Beardall, J., Raven, J.A., 2005. $\mathrm{CO}_{2}$ concentrating mechanisms in algae: mechanisms, environmental modulation, and evolution. Annu. Rev. Plant Biol. 56, 99-131.

Glynn, P.W., Mate, J.L., Baker, A.C., Calderon, M.O., 2001. Coral bleaching and mortality in panama and ecuador during the 1997-1998 El Niño Southern Oscillation Event: spatial/temporal patterns and comparisons with the 1982-1983 event. Bull. Mar. Sci. $69,79-109$. 
Godbold, J.A., Calosi, P., 2013. Ocean acidification and climate change: advances in ecology and evolution. Proc. R. Soc. B. 368, 20120448.

Goiran, C., Al-Moghrabi, S., Allemand, D., Jaubert, J., 1996. Inorganic carbon uptake for photosynthesis by the symbiotic coral/dinoflagellate association I. Photosynthetic performances of symbionts and dependence on sea water bicarbonate. J. Exp. Mar. Biol. Ecol. 199, 207-225.

Goiran, C., Allemand, D., Galgani, I., 1997. Transient $\mathrm{Na}^{+}$stress in symbiotic dinoflagellates after isolation from coral-host cells and subsequent immersion in seawater. Mar. Biol. $129,581-589$.

Goodwin, C., Picton, B., Van Soest, R., 2011. Hymedesmia (Porifera: Demospongiae: Poecilosclerida) from Irish and Scottish cold-water coral reefs, with a description of five new species. J. Mar. Biol. Assoc. U.K. 91, 979-997.

Gorbunov, M.Y., Kolber, Z.S., Lesser, M.P., Falkowski, P.G., 2001. Photosynthesis and photoprotection in symbiotic corals. Limnol. Oceanogr. 46, 75-85.

Gordon, B.R., Leggat, W., 2010. Symbiodinium-invertebrate symbioses and the role of metabolomics. Mar. Drugs 8, 2546-2568.

Goreau, T.F., Goreau, N.I., 1959. The physiology of skeleton formation in corals. II. Calcium deposition by hermatypic corals under various conditions in the reef. Biol. Bull. 239250 .

Gruber, N., Hauri, C., Lachkar, Z., Loher, D., Frölicher, T.L., Plattner, G.-K., 2012. Rapid progression of ocean acidification in the California Current System. Science 337, 220-223.

Guinotte, J.M., Orr, J., Cairns, S., Freiwald, A., Morgan, L., George, R., 2006. Will humaninduced changes in seawater chemistry alter the distribution of deep-sea scleractinian corals? Front. Ecol. Environ. 4, 141-146.

Guinotte, J.M., Fabry, V.J., 2008. Ocean acidification and its potential effects on marine ecosystems. Ann. N. Y. Acad. Sci. 1134, 320-342.

Hackett, J.D., Anderson, D.M., Erdner, D.L., Bhattacharya, D., 2004. Dinoflagellates: a remarkable evolutionary experiment. Amer. J. Bot. 91, 1523-1534.

Hale, R., Calosi, P., McNeill, L., Mieszkowska, N., Widdicombe, S., 2011. Predicted levels of future ocean acidification and temperature rise could alter community structure and biodiversity in marine benthic communities. Oikos 120, 661-674.

Hall-Spencer, J.M., Rodolfo-Metalpa, R., Martin, S., Ransome, E., Fine, M., Turner, S.M., Rowley, S.J., Tedesco, D., Buia, M.-C., 2008. Volcanic carbon dioxide vents show ecosystem effects of ocean acidification. Nature 454, 96-99.

Hand, S.C., 1991. Metabolic dormancy in aquatic invertebrates. In Advances in comparative and environmental physiology, Springer Berlin Heidelberg. pp. 1-50.

Harii, S., Yasuda, N., Rodriguez-Lanetty, M., Irie, T., Hidaka, M., 2009. Onset of symbiosis and distribution patterns of symbiotic dinoflagellates in the larvae of scleractinian corals. Mar. Biol. 156, 1203-1212. 
Harland, A., Davies, P., 1995. Symbiont photosynthesis increases both respiration and photosynthesis in the symbiotic sea anemone Anemonia viridis. Mar. Biol. 123, 715722 .

Hautmann, M., 2004. Effect of end-Triassic $\mathrm{CO}_{2}$ maximum on carbonate sedimentation and marine mass extinction. Facies 50, 257-261.

Havenhand, J.N., Buttler, F.-R., Thorndyke, M.C., Williamson, J.E., 2008. Near-future levels of ocean acidification reduce fertilization success in a sea urchin. Curr. Biol. 18, 651652.

Hawkins, T.D., Davy, S.K., 2012. Nitric oxide production and tolerance differ among Symbiodinium types exposed to heat stress. Plant Cell Physiol. 53, 1889-1898.

Hawkins, T.D., Bradley, B.J., Davy, S.K., 2013. Nitric oxide mediates coral bleaching through an apoptotic-like cell death pathway: evidence from a model sea anemonedinoflagellate symbiosis. FASEB J. 27, 4790-4798.

Hendriks, I.E., Duarte, C.M., Álvarez, M., 2010. Vulnerability of marine biodiversity to ocean acidification: a meta-analysis. Est. Coast. Shelf Sci. 86, 157-164.

Hennige, S., Suggett, D., Warner, M., McDougall, K., Smith, D., 2009. Photobiology of Symbiodinium revisited: bio-physical and bio-optical signatures. Coral Reefs 28, 179195.

Herfort, L., Thake, B., Taubner, I., 2008. Bicarbonate stimulation of calcification and photosynthesis in two hermatypic corals. J. Phycol. 44, 91-98.

Herrera, F.C., López, I., Egea, R., Zanders, I.P., 1989. Short-term osmotic responses of cells and tissues of the sea anemone, Condylactis gigantea. Comp. Biochem. Physiol. A $92,377-384$.

Hervé, V., Derr, J., Douady, S., Quinet, M., Moisan, L., Lopez, P.J., 2012. Multiparametric analyses reveal the $\mathrm{pH}$-dependence of silicon biomineralization in diatoms. PLoS One 7, e46722.

Hill, R., Larkum, A.W., Frankart, C., Kühl, M., Ralph, P.J., 2004. Loss of functional Photosystem II reaction centres in zooxanthellae of corals exposed to bleaching conditions: using fluorescence rise kinetics. Photosynth. Res. 82, 59-72.

Hill, R., Larkum, A.W., Prášil, O., Kramer, D., Szabó, M., Kumar, V., Ralph, P., 2012. Lightinduced dissociation of antenna complexes in the symbionts of scleractinian corals correlates with sensitivity to coral bleaching. Coral Reefs 31, 963-975.

Hoegh-Guldberg, O., Smith, G.J., 1989. The effect of sudden changes in temperature, light and salinity on the population density and export of zooxanthellae from the reef corals Stylophora pistillata Esper and Seriatopora hystrix Dana. J. Exp. Mar. Biol. Ecol. 129, 279-303.

Hoegh-Guldberg, O., 1999. Climate change, coral bleaching and the future of the world's coral reefs. Mar. Freshwater Res. 50, 839-866.

Hoegh-Guldberg, O., Mumby, P.J., Hooten, A.J., Steneck, R.S., Greenfield, P., Gomez, E., Harvell, C.D., Sale, P.F., Edwards, A.J., Caldeira, K., Knowlton, N., Eakin, C.M., Iglesias-Prieto, R., Muthiga, N., Bradbury, R.H., Dubi, A., Hatziolos, M.E., 2007. 
Coral reefs under rapid climate change and ocean acidification. Science 318, 17371742.

Hoegh-Guldberg, O., 2011. Coral reef ecosystems and anthropogenic climate change. Regional Environmental Change 11, 215-227.

Hofmann, G.E., Todgham, A.E., 2010. Living in the now: physiological mechanisms to tolerate a rapidly changing environment. Annu. Rev. Physiol., 72, 127-145.

Hofmann, G.E., Smith, J.E., Johnson, K.S., Send, U., Levin, L.A., Micheli, F., Paytan, A., Price, N.N., Peterson, B., Takeshita, Y., Matson, P.G., Crook, E.D., Kroeker, K.J., Gambi, M.C., Rivest, E.B., Frieder, C.A., Yu, P.C., Martz, T.R., 2011. Highfrequency dynamics of ocean $\mathrm{pH}$ : a multi-ecosystem comparison. PLoS One 6, e28983.

Hofmann, L.C., Straub, S., Bischof, K., 2013. Elevated $\mathrm{CO}_{2}$ levels affect the activity of nitrate reductase and carbonic anhydrase in the calcifying rhodophyte Corallina officinalis. J. Exp. Bot. 64, 899-908.

Holbrook, S.J., Schmitt, R.J., 2005. Growth, reproduction and survival of a tropical sea anemone (Actiniaria): benefits of hosting anemonefish. Coral Reefs 24, 67-73.

Holcomb, M., Cohen, A.L., Gabitov, R.I., Hutter, J.L., 2009. Compositional and morphological features of aragonite precipitated experimentally from seawater and biogenically by corals. Geochim. Cosmochim. Ac. 73, 4166-4179.

Holmes, G., 2008. Estimating three-dimensional surface areas on coral reefs. J. Exp. Mar. Biol. Ecol. 365, 67-73.

Houlbrèque, F., Tambutté, E., Allemand, D., Ferrier-Pagès, C., 2004. Interactions between zooplankton feeding, photosynthesis and skeletal growth in the scleractinian coral Stylophora pistillata. J. Exp. Biol. 207, 1461-1469.

Howells, E., Beltran, V., Larsen, N., Bay, L., Willis, B., Van Oppen, M., 2012. Coral thermal tolerance shaped by local adaptation of photosymbionts. Nature Clim. Change 2, 116120.

Howells, E.J., Willis, B.L., Bay, L.K., Oppen, M.J., 2013. Spatial and temporal genetic structure of Symbiodinium populations within a common reef-building coral on the Great Barrier Reef. Mol. Ecol. 22, 3693-3708.

Hughes, T.P., 1994. Catastrophes, phase shifts, and large-scale degradation of a Caribbean coral reef. Science 265, 1547-1551.

Hughes, T.P., Baird, A.H., Bellwood, D.R., Card, M., Connolly, S.R., Folke, C., Grosberg, R., Hoegh-Guldberg, O., Jackson, J., Kleypas, J., 2003. Climate change, human impacts, and the resilience of coral reefs. Science 301, 929-933.

Hughes, T.P., Graham, N.A., Jackson, J.B., Mumby, P.J., Steneck, R.S., 2010. Rising to the challenge of sustaining coral reef resilience. TREE 25, 633-642.

Hughes, T.P., Huang, H., Young, M.A., 2013a. The wicked problem of China's disappearing coral reefs. Conserv. Biol. 27, 261-269. 
Hughes, T.P., Linares, C., Dakos, V., van de Leemput, I.A., van Nes, E.H., 2013b. Living dangerously on borrowed time during slow, unrecognized regime shifts. TREE 28, 149-155.

Hunter, R.C., Beveridge, T.J., 2005. Application of a pH-sensitive fluoroprobe (c-SNARF-4) for $\mathrm{pH}$ microenvironment analysis in Pseudomonas aeruginosa biofilms. Appl. Environ. Microbiol. 71, 2501-2510.

Hutchins, D., Fu, F.-X., Zhang, Y., Warner, M., Feng, Y., Portune, K., Bernhardt, P., Mulholland, M., 2007. $\mathrm{CO}_{2}$ control of Trichodesmium $\mathrm{N}_{2}$ fixation, photosynthesis, growth rates, and elemental ratios: Implications for past, present, and future ocean biogeochemistry. Limnol. Oceanogr. 52, 1293-1304.

Iglesias-Prieto, R., Matta, J.L., Robins, W.A., Trench, R.K., 1992. Photosynthetic response to elevated temperature in the symbiotic dinoflagellate Symbiodinium microadriaticum in culture. Proc. Natl. Acad. Sci. 89, 10302-10305.

Iglesias-Prieto, R., Trench, R.K., 1994. Acclimation and adaptation to irradiance in symbiotic dinoflagellates. I. Responses of the photosynthetic unit to changes in photon flux density. Mar. Ecol. Prog. Ser. 113, 163-175.

Iglesias-Prieto, R., Trench, R., 1997. Acclimation and adaptation to irradiance in symbiotic dinoflagellates. II. Response of chlorophyll-protein complexes to different photonflux densities. Mar. Biol. 130, 23-33.

Iglesias-Prieto, R., Beltran, V., LaJeunesse, T., Reyes-Bonilla, H., Thome, P., 2004. Different algal symbionts explain the vertical distribution of dominant reef corals in the eastern Pacific. Proc. R. Soc. B. 271, 1757-1763.

Inoue, S., Kayanne, H., Yamamoto, S., Kurihara, H., 2013. Spatial community shift from hard to soft corals in acidified water. Nature Clim. Change 3, 683-687.

IPCC, 2014. Summary for Policymakers. In: Climate Change 2014: Impacts, Adaptation, and Vulnerability. Part A: Global and Sectoral Aspects. Contribution of Working Group II to the Fifth Assessment Report of the Intergovernmental Panel on Climate Change. pp. 1-32.

Jackson, A.E., Miller, D., Yellowlees, D., 1989. Phosphorus metabolism in the coralzooxanthellae symbiosis: characterization and possible roles of two acid phosphatases in the algal symbiont Symbiodinium sp. Proc. R. Soc. B. 238, 193-202.

Jarrold, M.D., Calosi, P., Verberk, W.C., Rastrick, S.P., Atfield, A., Spicer, J.I., 2013. Physiological plasticity preserves the metabolic relationship of the intertidal noncalcifying anthozoan-Symbiodinium symbiosis under ocean acidification. J. Exp. Mar. Biol. Ecol. 449, 200-206.

Jeffrey, S., Humphrey, G., 1975. New spectrophotometry equations for determining chlorophyll $a$, chlorophyll $b$, chlorophyll $c-1$ and chlorophyll $c-2$ in higher plants, algae and natural phytoplankton. Biochimie Physiol. Pflanzen 167, 191-194.

Jiang, P.L., Pasaribu, B., Chen, C.S., 2014. Nitrogen-deprivation elevates lipid levels in Symbiodinium spp. by lipid droplet accumulation: morphological and compositional analyses. PLoS One 9, e87416. 
Jimenez, I.M., Kühl, M., Larkum, A.W., Ralph, P.J., 2008. Heat budget and thermal microenvironment of shallow water corals: Do massive corals get warmer than branching corals? Limnol. Oceanogr. 53, 1548-1561.

Jimenez, I.M., Kühl, M., Larkum, A.W., Ralph, P.J., 2011. Effects of flow and colony morphology on the thermal boundary layer of corals. J. R. Soc. Interface. 8, 17851795 .

Johnson, V.R., Russell, B.D., Fabricius, K.E., Brownlee, C., Hall-Spencer, J.M., 2012. Temperate and tropical brown macroalgae thrive, despite decalcification, along natural $\mathrm{CO}_{2}$ gradients. Glob. Change Biol. 18, 2792-2803.

Jokiel, P.L., Brown, E.K., 2004. Global warming, regional trends and inshore environmental conditions influence coral bleaching in Hawaii. Glob. Change Biol. 10, 1627-1641.

Jokiel, P.L., Rodgers, K.S., Kuffner, I.B., Andersson, A.J., Cox, E.F., Mackenzie, F.T., 2008. Ocean acidification and calcifying reef organisms: a mesocosm investigation. Coral Reefs 27, 473-483.

Jokiel, P.L., 2011. Ocean acidification and control of reef coral calcification by boundary layer limitation of proton flux. Bull. Mar. Sci. 87, 639-657.

Jones, A., Berkelmans, R., 2010. Potential costs of acclimatization to a warmer climate: growth of a reef coral with heat tolerant vs. sensitive symbiont types. PLoS One 5, e10437.

Jones, R.J., Hoegh-Guldberg, O., Larkum, A.W.D., Schreiber, U., 1998. Temperature-induced bleaching of corals begins with impairment of the $\mathrm{CO}_{2}$ fixation mechanism in zooxanthellae. Plant Cell Environ. 21, 1219-1230.

Jones, R.J., Ward, S., Amri, A.Y., Hoegh-Guldberg, O., 2000. Changes in quantum efficiency of Photosystem II of symbiotic dinoflagellates of corals after heat stress, and of bleached corals sampled after the 1998 Great Barrier Reef mass bleaching event. Mar. Freshwater Res. 51, 63-71.

Kaniewska, P., Campbell, P.R., Kline, D.I., Rodriguez-Lanetty, M., Miller, D.J., Dove, S., Hoegh-Guldberg, O., 2012. Major cellular and physiological impacts of ocean acidification on a reef building coral. PLoS One 7. e34659.

Karagiannis, J.Y., PG., 2001. Intracellular pH homeostasis during cell-cycle progression and growth state transition in Schizosaccharomyces pombe. J. Cell Biol. 114, 2929-2941.

Kawaguti, S., Sakumoto, D., 1948. The effect of light on the calcium deposition of corals. Bull. Oceanogr. Inst. Taiwan 4, 65-70.

Kazandjian, A., Shepherd, V.A., Rodriguez-Lanetty, M., Nordemeier, W., Larkum, A.W.D., Quinnell, R.G., 2008. Isolation of symbiosomes and the symbiosome membrane complex from the zoanthid Zoanthus robustus. Phycologia 47, 294-306.

Kellogg, R.B., Patton, J.S., 1983. Lipid droplets, medium of energy exchange in the symbiotic anemone Condylactis gigantea: a model coral polyp. Mar. Biol. 75, 137-149.

Kerswell, A.P., Jones, R.J., 2003. Effects of hypo-osmosis on the coral Stylophora pistillata: nature and cause of 'low-salinity bleaching'. Mar. Ecol. Prog. Ser. 253, 145-154. 
Kitahara, M.V., Lin, M.-F., Forrêt, S., Huttley, G., Miller, D.J., Chen, C.A., 2014. The "naked coral" hypothesis revisited - evidence for and against scleractinian monophyly. PLoS One 9, e94774.

Kleypas, J.A., Buddemeier, R.W., Archer, D., Gattuso, J.-P., Langdon, C., Opdyke, B.N., 1999. Geochemical consequences of increased atmospheric carbon dioxide on coral reefs. Science 284, 118-120.

Kleypas, J.A., Langdon, C., 2006. Coral reefs and changing seawater carbonate chemistry. Coast. Estuar. Stud. 61, 73-110.

Knowlton, N., Jackson, J.B., 2008. Shifting baselines, local impacts, and global change on coral reefs. PLoS Biology 6, e54.

Knowlton, N., Brainard, R.E., Fisher, R., Moews, M., Plaisance, L., Caley, M.J., 2010. Coral reef biodiversity. In (Ed.) Life in the World's Oceans: Diversity, Distribution, and Abundance. Wiley-Blackwell. pp. 65-77.

Koop, K., Booth, D., Broadbent, A., Brodie, J., Bucher, D., Capone, D., Coll, J., Dennison, W., Erdmann, M., Harrison, P., 2001. ENCORE: the effect of nutrient enrichment on coral reefs. Synthesis of results and conclusions. Mar. Pollut. Bull. 42, 91-120.

Krämer, W.E., Caamaño-Ricken, I., Richter, C., Bischof, K., 2012. Dynamic regulation of photoprotection determines thermal tolerance of two phylotypes of Symbiodinium clade A at two photon fluence rates. J. Photochem. Photobiol. 88, 398-413.

Kroeker, K.J., Kordas, R.L., Crim, R.N., Singh, G.G., 2010. Meta-analysis reveals negative yet variable effects of ocean acidification on marine organisms. Ecol. Lett. 13, 14191434.

Kroeker, K.J., Kordas, R.L., Crim, R., Hendriks, I.E., Ramajo, L., Singh, G.S., Duarte, C.M., Gattuso, J.-P., 2013. Impacts of ocean acidification on marine organisms: quantifying sensitivities and interaction with warming. Glob. Change Biol. 19, 1884-1896.

Krüeger, T., Gates, R.D., 2012. Cultivating endosymbionts - Host environmental mimics support the survival of Symbiodinium C15 ex hospite. J. Exp. Mar. Biol. Ecol. 413, 169-176.

Kuffner, I.B., Andersson, A.J., Jokiel, P.L., Rodgers, K.S., Mackenzie, F.T., 2007. Decreased abundance of crustose coralline algae due to ocean acidification. Nat. Geosci. 1, 114117.

Kühl, M., Cohen, Y., Dalsgaard, T., Jorgensen, B., Revsbech, N., 1995. Microenvironment and photosynthesis of zooxanthellae in scleractinian corals studied with microsensors for $\mathrm{O}_{2}, \mathrm{pH}$ and light. Mar. Ecol. Prog. Ser. 117, 159-172.

Kurihara, H., 2008. Effects of $\mathrm{CO}_{2}$-driven ocean acidification on the early developmental stages of invertebrates. Mar. Ecol. Prog. Ser. 373, 275-284.

Kurkdjian, A., Guern, J., 1989. Intracellular pH: measurement and importance in cell activity. Ann. Rev. Plant Biol. 40, 271-303.

Kushmaro, A., Rosenberg, E., Fine, M., Ben Haim, Y., Loya, Y., 1998. Effect of temperature on bleaching of the coral Oculina patagonica by Vibrio AK-1. Mar. Ecol. Prog. Ser. $171,131-137$. 
LaJeunesse, T., Trench, R., 2000. Biogeography of two species of Symbiodinium (Freudenthal) inhabiting the intertidal sea anemone Anthopleura elegantissima (Brandt). Biol. Bull. 199, 126-134.

LaJeunesse, T.C., Thornhill, D.J., Cox, E.F., Stanton, F.G., Fitt, W.K., Schmidt, G.W., 2004. High diversity and host specificity observed among symbiotic dinoflagellates in reef coral communities from Hawaii. Coral Reefs 4, 596-603.

LaJeunesse, T.C., Fitt, W.K., Schmidt, G.W., 2010a. The reticulated chloroplasts of zooxanthellae (Symbiodinium) and differences in chlorophyll localization among life cycle stages. Coral Reefs 29, 627-627.

LaJeunesse, T.C., Pettay, D.T., Sampayo, E.M., Phongsuwan, N., Brown, B., Obura, D.O., Hoegh-Guldberg, O., Fitt, W.K., 2010b. Long-standing environmental conditions, geographic isolation and host-symbiont specificity influence the relative ecological dominance and genetic diversification of coral endosymbionts in the genus Symbiodinium. J. Biogeogr. 37, 785-800.

Lajeunesse, T.C., Parkinson, J.E., Reimer, J.D., 2012. A genetics-based description of Symbiodinium minutum sp. nov. and S. psygmophilum sp. nov. (Dinophyceae), two dinoflagellates symbiotic with cnidaria. J. Phycol. 48, 1380-1391.

Lane, A.E., Burris, J.E., 1981. Effects of environmental $\mathrm{pH}$ on the internal $\mathrm{pH}$ of Chlorella pyrenoidosa, Scenedesmus quadricauda, and Euglena mutabilis. Plant Physiol. 68, 439-442.

Langenbuch, M., Bock, C., Leibfritz, D., Pörtner, H.-O., 2006. Effects of environmental hypercapnia on animal physiology: A 13C NMR study of protein synthesis rates in the marine invertebrate Sipunculus nudus. Comp. Biochem. Physiol., Part A: Mol. Integr. Physiol. 144, 479-484.

Laurent, J., Tambutté, S., Tambutté, É., Allemand, D., Venn, A., 2013a. The influence of photosynthesis on host intracellular $\mathrm{pH}$ in scleractinian corals. J. Exp. Biol. 216, 1398-1404.

Laurent, J., Venn, A., Tambutté, É., Ganot, P., Allemand, D., Tambutté, S., 2013b. Regulation of intracellular $\mathrm{pH}$ in cnidarians: response to acidosis in Anemonia viridis. FEBS J. 281, 683-695.

Leggat, W., Badger, M.R., Yellowlees, D., 1999. Evidence for an inorganic carbonconcentrating mechanism in the symbiotic dinoflagellate Symbiodinium sp. Plant Physiol. 4, 1247-1255.

Lesser, M., Shick, J., 1989. Effects of irradiance and ultraviolet radiation on photoadaptation in the zooxanthellae of Aiptasia pallida: primary production, photoinhibition, and enzymic defenses against oxygen toxicity. Mar. Biol. 102, 243-255.

Lesser, M., Stochaj, W., Tapley, D., Shick, J., 1990. Bleaching in coral reef anthozoans: effects of irradiance, ultraviolet radiation, and temperature on the activities of protective enzymes against active oxygen. Coral Reefs 8, 225-232.

Lesser, M., 1997. Oxidative stress causes coral bleaching during exposure to elevated temperatures. Coral Reefs 16, 187-192. 
Lesser, M.P., 2006. Oxidative stress in marine environments: biochemistry and physiological ecology. Annu. Rev. Physiol. 68, 253-278.

Lesser, M.P., 2011. Coral bleaching: causes and mechanisms. In (Ed.) Coral reefs: An ecosystem in transition. Springer, pp. 405-419.

Levavassur, G., Edwards, G.E., Osmond, C.B., Ramus, J., 1991. Inorganic carbon limitation of photosynthesis in Ulva rotundata (Chlorophyta). J. Phycol. 27, 667-672.

Lewis, E., Wallace, D., Allison, L., 1998. Program developed for $\mathrm{CO}_{2}$ system calculations. Brookhaven National Lab., Dept. of Applied Science, Upton, NY, USA; Oak Ridge National Lab., Carbon Dioxide Information Analysis Center, TN, USA.

Lien, Y.-T., Fukami, H., Yamashita, Y., 2012. Symbiodinium clade C dominates zooxanthellate corals (Scleractinia) in the temperate region of Japan. Zool. Sci. 29, 173-180.

Liu, P.J., Lin, S.M., Fan, T.Y., Meng, P.J., Shao, K.T., Lin, H.J., 2009. Rates of overgrowth by macroalgae and attack by sea anemones are greater for live coral than dead coral under conditions of nutrient enrichment. Limnol. Oceanogr. 54, 1167-1175.

Liu, W., Ming, Y., Huang, Z., Li, P., 2012. Impacts of florfenicol on marine diatom Skeletonema costatum through photosynthesis inhibition and oxidative damages. Plant Physiol. Biochem. 60, 165-170.

Logan, D.D., LaFlamme, A.C., Weis, V.M., Davy, S.K., 2010. Flow-cytometric characterization of the cell-surface glycans of symbiotic dinoflagellates (Symbiodinium sp.) J. Phycol. 46, 525-533.

Loya, Y., Sakai, K., Yamazato, K., Nakano, Y., Sambali, H., Van Woesik, R., 2001. Coral bleaching: the winners and the losers. Ecol. Lett. 4, 122-131.

Luo, Y.J., Wang, L.H., Chen, W.N., Peng, S.E., Tzen, J.C., Hsiao, Y.Y., Huang, H.J., Fang, L.S., Chen, C.S., 2009. Ratiometric imaging of gastrodermal lipid bodies in coraldinoflagellate endosymbiosis. Coral Reefs 28, 289-301.

Madshus, I.H., 1988. Regulation of intracellular pH in eukaryotic cells. Biochem. J. 250, 1-8.

Manzello, D., 2010. Coral growth with thermal stress and ocean acidification: lessons from the eastern tropical Pacific. Coral Reefs 29, 749-758.

Markell, D.A., Trench, R.K., 1993. Macromolecules exuded by symbiotic dinoflagellates in culture: amino acid and sugar composition. J. Phycol. 29, 64-68.

Marshall, P., Baird, A., 2000. Bleaching of corals on the Great Barrier Reef: differential susceptibilities among taxa. Coral Reefs 19, 155-163.

Martin, S., Gattuso, J.-P., 2009. Response of Mediterranean coralline algae to ocean acidification and elevated temperature. Glob. Change Biol. 15, 2089-2100.

Marubini, F., Ferrier-Pagès, C., Furla, P., Allemand, D., 2008. Coral calcification responds to seawater acidification: a working hypothesis towards a physiological mechanism. Coral Reefs 27, 491-499. 
Mass, T., Einbinder, S., Brokovich, E., Shashar, N., Vago, R., Erez, J., Dubinsky, Z., 2007. Photoacclimation of Stylophora pistillata to light extremes: metabolism and calcification. Mar. Ecol. Prog. Ser. 334, 93-102.

McClanahan, T., 2000. Bleaching damage and recovery potential of Maldivian coral reefs. Mar. Pollut. Bull. 40, 587-597.

McClanahan, T., Baird, A., Marshall, P., Toscano, M., 2004. Comparing bleaching and mortality responses of hard corals between southern Kenya and the Great Barrier Reef, Australia. Mar. Pollut. Bull. 48, 327-335.

McClanahan, T.R., Ateweberhan, M., Muhando, C.A., Maina, J., Mohammed, M.S., 2007. Effects of climate and seawater temperature variation on coral bleaching and mortality. Ecol. Monogr. 77, 503-525.

McFall-Ngai, M.J., 2001. Identifying 'prime suspects': symbioses and the evolution of multicellularity. Comp. Biochem. Physiol., Part B: Biochem. Mol. Biol. 129, 711723.

McGinty, E.S., Pieczonka, J., Mydlarz, L.D., 2012. Variations in reactive oxygen release and antioxidant activity in multiple Symbiodinium types in response to elevated temperature. Microbial Ecol. 64, 1000-1007.

McMahon, K.W., Berumen, M.L., Thorrold, S.R., 2012. Linking habitat mosaics and connectivity in a coral reef seascape. Proc. Nat. Acad. Sci. 109, 15372-15376.

McNeil, B.I., Matear, R.J., 2008. Southern Ocean acidification: a tipping point at 450-ppm atmospheric $\mathrm{CO}_{2}$. Proc. Nat. Acad. Sci. 105, 18860-18864.

Medina, M., Collins, A.G., Takaoka, T.L., Kuehl, J.V., Boore, J.L., 2006. Naked corals: skeleton loss in Scleractinia. Proc. Nat. Acad. Sci. 103, 9096-9100.

Meehl, G.A., Covey, C., Taylor, K.E., Delworth, T., Stouffer, R.J., Latif, M., McAvaney, B., Mitchell, J.F., 2007. The WCRP CMIP3 multimodel dataset: A new era in climate change research. B. Am. Meteorol. Soc. 88, 1383-1394.

Melzner, F., Gutowska, M., Langenbuch, M., Dupont, S., Lucassen, M., Thorndyke, M.C., Bleich, M., Pörtner, H.-O., 2009. Physiological basis for high $\mathrm{CO}_{2}$ tolerance in marine ectothermic animals: pre-adaptation through lifestyle and ontogeny? Biogeosci. Discuss. 6, 2313-2331.

Mendes, J., Woodley, J., 2002. Effect of the 1995-1996 bleaching event on polyp tissue depth, growth, reproduction and skeletal band formation in Montastraea annularis. Mar. Ecol. Prog. Ser. 235, 93-102.

Michaelidis, B., Ouzounis, C., Paleras, A., Pörtner, H.O., 2005. Effects of long-term moderate hypercapnia on acid-base balance and growth rate in marine mussels Mytilus galloprovincialis. Mar. Ecol. Prog. Ser. 293, 109-118.

Michalek-Wagner, K., Willis, B., 2001. Impacts of bleaching on the soft coral Lobophytum compactum. I. Fecundity, fertilization and offspring viability. Coral Reefs 19, 231239.

Mieog, J.C., Oppen, M.J.H., Cantin, N.E., Stam, W.T., Olsen, J.L., 2007. Real-time PCR reveals a high incidence of Symbiodinium clade D at low levels in four scleractinian 
corals across the Great Barrier Reef: implications for symbiont shuffling. Coral Reefs $26,449-457$.

Millero, F.J., Pierrot, D., Lee, K., Wanninkhof, R., Feely, R., Sabine, C.L., Key, R.M., Takahashi, T., 2002. Dissociation constants for carbonic acid determined from field measurements. Deep-Sea Res. 49, 1705-1723.

Mills, E., Shechtman, K., Loya, Y., Rosenberg, E., 2013. Bacteria appear to play important roles both causing and preventing the bleaching of the coral Oculina patagonica. Mar. Ecol. Prog. Ser. 489, 155-162.

Minic, Z., Herve, G., 2004. Biochemical and enzymological aspects of the symbiosis between the deep-sea tubeworm Riftia pachyptila and its bacterial endosymbiont. Eur. J. Biochem. 271, 3093-3102.

Moy, A.D., Howard, W.R., Bray, S.G., Trull, T.W., 2009. Reduced calcification in modern Southern Ocean planktonic foraminifera. Nature Geosci. 2, 276-280.

Moya, A., Ferrier-Pagès, C., Furla, P., Richier, S., Tambutté, E., Allemand, D., Tambutté, S., 2008. Calcification and associated physiological parameters during a stress event in the scleractinian coral Stylophora pistillata. Comp. Biochem. Phys. A. 151, 29-36.

Muller-Parker, G., 1984. Photosynthesis-irradiance responses and photosynthetic periodicity in the sea anemone Aiptasia pulchella and its zooxanthellae. Mar. Biol. 82, 225-232.

Muller-Parker, G., D'Elia, C.F., 1997. Interactions between corals and their symbiotic algae. In: Birkeland, C. (Ed.), Life and Death of Coral Reefs. Chapman and Hall, New York, pp. 96-112.

Muller-Parker, G., Davy, S.K., 2001. Temperate and tropical algal-sea anemone symbioses. Invertebr. Biol. 120, 104-123.

Muscatine, L., Hand, C., 1958. Direct evidence for the transfer of materials from symbiotic algae to the tissues of a coelenterate. Proc. Nat. Acad. Sci. 44, 1259.

Muscatine, L., Karakashian, S.J., Karakashian, M.W., 1967. Soluble extracellular products of algae symbiotic with a ciliate, a sponge and a mutant Hydra. Comp. Biochem. Phys. $20,1-12$.

Muscatine, L., Porter, J.W., 1977. Reef corals: mutualistic symbioses adapted to nutrient-poor environments. Bioscience 27, 454-460.

Muscatine, L., 1990. The role of symbiotic algae in carbon and energy flux in reef corals. In: Dubinsky Z (Ed.), Coral Reefs. Elsevier, Amsterdam, The Netherlands. pp 75- 87.

Muscatine, L., Tambutte, E., Allemand, D., 1997. Morphology of coral desmocytes, cells that anchor the calicoblastic epithelium to the skeleton. Coral Reefs 16, 205-213.

Muscatine, L., Goiran, C., Land, L., Jaubert, J., Cuif, J.P., Allemand, D., 2005. Stable isotopes $(\delta \mathrm{C}-13$ and $\delta \mathrm{N}-15)$ of organic matrix from coral skeleton. Proc. Natl. Acad. Sci. 102, 1525-1530.

Musgrove, E., Rugg, C., Hedley, D., 1986. Flow cytometric measurement of cytoplasmic pH: a critical evaluation of available fluorochromes. Cytometry 7, 347-355. 
Mydlarz, L.D., McGinty, E.S., Harvell, C.D., 2010. What are the physiological and immunological responses of coral to climate warming and disease? J. Exp. Biol. 213, 934-945.

Nimer, N.A., Iglesias-Rodriguez, M.D., Merrett, M.J., 1997. Bicarbonate utilization by marine phytoplankton species. J. Phycol. 33, 625-631.

Nimer, N.A., Brownlee, C., Merrett, M.J., 1999. Extracellular carbonic anhydrase facilitates carbon dioxide availability for photosynthesis in the marine dinoflagellate Prorocentrum micans. J. Plant Physiol. 120, 105-112.

Nir, O., Gruber, D.F., Shemesh, E., Glasser, E., Tchernov, D., 2014. Seasonal mesophotic coral bleaching of Stylophora pistillata in the northern Red Sea. PLoS One 9, e84968.

Norström, A.V., Nyström, M., Lokrantz, J., Folke, C., 2009. Alternative states on coral reefs: beyond coral-macroalgal phase shifts. Mar. Ecol. Prog. Ser. 376, 295-306.

Nyholm, S.V., McFall-Ngai, M., 2004. The winnowing: establishing the squid-Vibrio symbiosis. Nature Rev. Microbiol. 2, 632-642.

Oakley, C.A., Schmidt, G.W., Hopkinson, B.M., 2014. Thermal responses of Symbiodinium photosynthetic carbon assimilation. Coral Reefs 33, 501-512.

Ohki, S., Irie, T., Inoue, M., Shinmen, K., Kawahata, H., Nakamura, T., Kato, A., Nojiri, Y., Suzuki, A., Sakai, K., 2013. Symbiosis increases coral tolerance to ocean acidification. Biogeosciences Discuss. 10, 7013-7030.

Orij, R., Urbanus, M.L., Vizeacoumar, F.J., Giaever, G., Boone, C., Nislow, C., Brul, S., Smits, G.J., 2012. Genome-wide analysis of intracellular pH reveals quantitative control of cell division rate by $\mathrm{pH}_{\mathrm{c}}$ in Saccharomyces cerevisiae. Genome Biol. 13, 80-95.

Orr, J.C.F., V. J. Aumont, O. Bopp, L. Doney, S. C. Feely, R. A. Gnanadesikan, A. Gruber, N. Ishida, A. Joos, F. Key, R.M. Lindsay, K. Maier-Reimer, E. Matear, R. Monfray, P. Mouchet, A. Najjar, R. G. Plattner, G-K. Rodgers, K. B. Sabine, C.L. Sarmiento, J. L. Schlitzer, R. Slater, R. D. Totterdell, I.J. Weirig, M-F. Yamanaka, Y. Yool, A., 2005. Anthropogenic ocean acidification over the twenty-first century and its impact on calcifying organisms. Nature 437, 681-686.

Overmann, J., 2006. (Ed.) Molecular basis of symbiosis. New York, Springer-Verlag. pp. 310.

Ozkan, P., Mutharasan, R., 2002. A rapid method for measuring intracellular pH using BCECF-AM. Biochim. Biophys. Acta. 1572, 143-148.

Padilla-Gamiño, J.L., Pochon, X., Bird, C., Concepcion, G.T., Gates, R.D., 2012. From parent to gamete: vertical transmission of Symbiodinium (Dinophyceae) ITS2 sequence assemblages in the reef building coral Montipora capitata. PLoS One 7, e38440.

Pandolfi, J.M., Connolly, S.R., Marshall, D.J., Cohen, A.L., 2011. Projecting coral reef futures under global warming and ocean acidification. Science 333, 418-422.

Patton, J., Burris, J., 1983. Lipid synthesis and extrusion by freshly isolated zooxanthellae (symbiotic algae). Mar. Biol. 75, 131-136. 
Pawlowski, J., Holzmann, M., Fahrni, J., Pochon, X., Lee, J.J., 2001. Molecular identification of algal endosymbionts in large miliolid foraminifera: II. Dinoflagellates. J. Eukaryot. Microbiol. 48, 368-373.

Pearson, P., Palmer, M., 2000. Atmospheric carbon dioxide concentrations over the past 60 million years. Nature 406, 695-699.

Perez, S., Weis, V., 2006. Nitric oxide and cnidarian bleaching: an eviction notice mediates breakdown of a symbiosis. J. Exp. Biol. 209, 2804-2810.

Perry, C.T., Murphy, G.N., Kench, P.S., Smithers, S.G., Edinger, E.N., Steneck, R.S., Mumby, P.J., 2013. Caribbean-wide decline in carbonate production threatens coral reef growth. Nat. Commun. 4, 1402.

Pettay, D.T., Lajeunesse, T.C., 2009. Microsatellite loci for assessing genetic diversity, dispersal and clonality of coral symbionts in 'stress-tolerant' clade D Symbiodinium. Mol. Ecol. Resour. 9, 1022-1025.

Pochon, X., Montoya-Burgos, J.I., Stadelmann, B., Pawlowski, J., 2006. Molecular phylogeny, evolutionary rates, and divergence timing of the symbiotic dinoflagellate genus Symbiodinium. Mol. Phylogenet. Evol. 38, 20-30.

Pochon, X., Gates, R.D., 2010. A new Symbiodinium clade (Dinophyceae) from soritid foraminifera in Hawai'i. Mol. Phylogenet. Evol 56, 492-497.

Poore, A.G., Graba-Landry, A., Favret, M., Brennand, H.S., Byrne, M., Dworjanyn, S.A., 2013. Direct and indirect effects of ocean acidification and warming on a marine plant-herbivore interaction. Oecologia 173, 1113-1124.

Porter, J.W., Fitt, W.K., Spero, H.J., Rogers, C.S., White, M.W., 1989. Bleaching in reef corals: physiological and stable isotopic responses. Proc. Nat. Acad. Sci. 86, 93429346.

Pörtner, H.-O., Peck, L., Zielinski, S., Conway, L., 1999. Intracellular pH and energy metabolism in the highly stenothermal Antarctic bivalve Limopsis marionensis as a function of ambient temperature. Polar Biol. 22, 17-30.

Pörtner, H.O., Langenbuch, M., Reipschläger, A., 2004. Biological impact of elevated ocean $\mathrm{CO}_{2}$ concentrations: Lessons from animal physiology and earth history. J. Oceanogr. $60,705-718$.

Pörtner, H.O., Langenbuch, M., Michaelidis, B., 2005. Synergistic effects of temperature extremes, hypoxia, and increases in $\mathrm{CO}_{2}$ on marine animals: From Earth history to global change. J. Geophys. Res. 110, C09S10.

Porto, I., Granados, C., Restrepo, J.C., Sanchez, J.A., 2008. Macroalgal-associated dinoflagellates belonging to the genus Symbiodinium in Caribbean reefs. PLoS One 3, e2160.

Porzio, L., Buia, M.C., Hall-Spencer, J.M., 2011. Effects of ocean acidification on macroalgal communities. J. Exp. Mar. Biol. Ecol. 400, 278-287.

Pouyssègur, J., Franchi, A., L'Allemain, G., Paris, S., 1985. Cytoplasmic pH, a key determinant of growth factor-induced DNA synthesis in quiescent fibroblasts. FEBS Lett. 190, 115-119. 
Price, N.N., Martz, T.R., Brainard, R.E., Smith, J.E., 2012. Diel variability in seawater pH relates to calcification and benthic community structure on coral reefs. PLoS One 7, e43843.

Putnam, H.M., 2012. Resilience and acclimatization potential of reef corals under predicted climate change stressors. University of Hawai'i at Manoa, ProQuest, Dissertations Publishing, 3569106.

Putnam, H.M., Stat, M., Pochon, X., Gates, R.D., 2012. Endosymbiotic flexibility associates with environmental sensitivity in scleractinian corals. Proc. R. Soc. B 279, 43524361.

Ragni, M., Airs, R.L., Hennige, S.J., Suggett, D.J., Warner, M.E., Geider, R.J., 2010. PSII photoinhibition and photorepair in Symbiodinium (Pyrrhophyta) differs between thermally tolerant and sensitive phylotypes. Mar. Ecol. Prog. Ser. 406, 57-70.

Rajasuriya, A., Karunarathna, C., 2000. Postbleaching status of the coral reefs of Sri Lanka. In: Souter D, Obura D, Lindén O (Ed.) In: Coral reef degradation in the Indian Ocean: Status report 2000. CORDIO, Department of Biology and Environmental Science, University of Kalmar, Kalmar, pp. 54.

Rands, M.L., Loughman, B.C., Douglas, A.E., 1993. The symbiotic interface in an algainvertebrate symbiosis. Proc. R. Soc. B. 253, 161-165.

Raven, J.A., Smith, F.A., 1980. Intracellular pH regulation in the giant-celled marine alga Chaetomorpha darwinii. J. Exp. Bot. 31, 1357-1369.

Raven, J.A., Giordano, M., Beardall, J., Maberly, S.C., 2012. Algal evolution in relation to atmospheric $\mathrm{CO}$ 2: carboxylases, carbon-concentrating mechanisms and carbon oxidation cycles. Proc. R. Soc. B. 367, 493-507.

Reimer, J.D., Todd, P.A., 2009. Preliminary molecular examination of zooxanthellate zoanthid (Hexacorallia, Zoantharia) and associated zooxanthellae (Symbiodinium sp.) diversity in Singapore. Raffles B. Zool. 22, 103-120.

Reipschläger, A., Pörtner, H., 1996. Metabolic depression during environmental stress: the role of extracellular versus intracellular pH in Sipunculus nudus. J. Exp. Biol. 199, 1801-1807.

Reynaud, S., Leclercq, N., Romaine-Lioud, S., Ferrier-Pagés, C., Jaubert, J., Gattuso, J.-P., 2003. Interacting effects of $\mathrm{CO}_{2}$ partial pressure and temperature on photosynthesis and calcification in a scleractinian coral. Glob. Change Biol. 9, 1660-1668.

Richardson, L.L., 1998. Coral diseases: what is really known? TREE 13, 438-443.

Richier, S., Furla, P., Plantivaux, A., Merle, P.-L., Allemand, D., 2005. Symbiosis-induced adaptation to oxidative stress. J. Exp. Biol. 208, 277-285.

Richier, S., Sabourault, C., Courtiade, J., Zucchini, N., Allemand, D., Furla, P., 2006. Oxidative stress and apoptotic events during thermal stress in the symbiotic sea anemone, Anemonia viridis. FEBS J. 273, 4186-4198.

Riebesell, U., Wolf-Gladrow, D., Smetacek, V., 1993. Carbon dioxide limitation of marine phytoplankton growth rates. Nature 361, 249-251. 
Riebesell, U., 2004. Effects of $\mathrm{CO}_{2}$ enrichment on marine phytoplankton. J. Oceanogr. 60, 719-729.

Riebesell, U., Fabry, V.J., Hansson, L., Gattuso, J.-P., 2010. Guide to best practices for ocean acidification research and data reporting: Publications Office of the European Union Luxembourg.

Ries, J.B., Cohen, A.L., McCorkle, D.C., 2009. Marine calcifiers exhibit mixed responses to $\mathrm{CO}_{2}$-induced ocean acidification. Geology 37, 1131-1134.

Roberts, J.M., Wheeler, A.J., Freiwald, A., 2006. Reefs of the deep: the biology and geology of cold-water coral ecosystems. Science 312, 543-547.

Robison, J.D., Warner, M.E., 2006. Differential impacts of photoacclimation and thermal stress on the photobiology of four different phylotypes of Symbiodinium (Pyrrhophyta). J. Phycol. 42, 568-579.

Rodolfo-Metalpa, R., Richard, C., Allemand, D., Bianchi, C., Morri, C., Ferrier-Pagès, C., 2006. Response of zooxanthellae in symbiosis with the Mediterranean corals Cladocora caespitosa and Oculina patagonica to elevated temperatures. Mar. Biol. $150,45-55$.

Rodolfo-Metalpa, R., Martin, S., Ferrier-Pagès, C., Gattuso, J.-P., 2010. Response of the temperate coral Cladocora caespitosa to mid-and long-term exposure to $p \mathrm{CO}_{2}$ and temperature levels projected in 2100. Biogeosci. Discuss. 7, 289-300.

Rodolfo-Metalpa, R., Houlbrèue, F., Tambutté, É., Boisson, F., Baggini, C., Patti, F.P., Jeffree, R., Fine, M., Foggo, A., Gattuso, J., 2011. Coral and mollusc resistance to ocean acidification adversely affected by warming. Nature Clim. Change 1, 308-312.

Rodriguez-Lanetty, M., Krupp, D.A., Weis, V.M., 2004. Distinct ITS types of Symbiodinium in Clade $\mathrm{C}$ correlate with cnidarian/dinoflagellate specificity during onset of symbiosis. Mar. Ecol. Prog. Ser. 275, 97-102.

Roos, A., Boron, W.F., 1981. Intracellular pH. Physiol. Rev. 61, 296-434.

Rosa, R., Seibel, B.A., 2008. Synergistic effects of climate-related variables suggest future physiological impairment in a top oceanic predator. Proc. Nat. Acad. Sci. 105, 2077620780.

Rost, B., Zondervan, I., Wolf-Gladrow, D., 2008. Sensitivity of phytoplankton to future changes in ocean carbonate chemistry: current knowledge, contradictions and research directions. Mar. Ecol. Prog. Ser. 373, 227-237.

Roth, L.E., K. W. Jeon, and G. Stacey, 1988. Homology in endosymbiotic systems: the term "symbiosome". In: R. Palacios and D. P. S. Verma (Ed.), Molecular genetics of plantmicrobe interactions. APS Press, St. Paul, Minn., 220-225.

Rowan, R., Whitney, S.M., Fowler, A., Yellowlees, D., 1996. Rubisco in marine symbiotic dinoflagellates: form II enzymes in eukaryotic oxygenic phototrophs encoded by a nuclear multigene family. Plant Cell. 8, 539-553.

Rowan, R., Knowlton, N., Baker, A., Jara, J., 1997. Landscape ecology of algal symbionts creates variation in episodes of coral bleaching. Nature 388, 265-269. 
Rowan, R., 2004. Coral bleaching: thermal adaptation in reef coral symbionts. Nature 430, $742-742$.

Rowan, R.K., N, 1995. Intraspecific diversity and ecological zonation in coral-algal symbiosis. Proc. Natl. Acad. Sci. 92, 2850-2853.

Russell, B.D., Connell, S.D., Uthicke, S., Muehllehner, N., Fabricius, K.E., Hall-Spencer, J.M., 2013. Future seagrass beds: Can increased productivity lead to increased carbon storage? Mar. Pollut. Bull. 73, 463-469.

Sabine, C.L., Feely, R.A., Gruber, N., Key, R.M., Lee, K., Bullister, J.L., Wanninkhof, R., Wong, C.S., Wallace, D.W.R., Tilbrook, B., Millero, F.J., Peng, T.-H., Kozyr, A., Ono, T., Rios, A.F., 2004. The oceanic sink for anthropogenic $\mathrm{CO}_{2}$. Science 305, 367-371.

Sagan, L., 1967. On the origin of mitosing cells. J. Theor. Biol. 14, 225-274.

Salih, A., Larkum, A., Cox, G., Kuhl, M., Hoegh-Guldberg, O., 2000. Fluorescent pigments in corals are photoprotective. Nature 408, $850-853$.

Sampayo, E.M., Ridgway, T., Bongaerts, P., Hoegh-Guldberg, O., 2008. Bleaching susceptibility and mortality of corals are determined by fine-scale differences in symbiont type. Proc. Nat. Acad. Sci. 105, 10444-10449.

Santos, S., Gutierrez-Rodriguez, C., Lasker, H., Coffroth, M., 2003. Symbiodinium sp. associations in the gorgonian Pseudopterogorgia elisabethae in the Bahamas: high levels of genetic variability and population structure in symbiotic dinoflagellates. Mar. Biol. 143, 111-120.

Santos, S.R., Coffroth, M.A., 2003. Molecular genetic evidence that dinoflagellates belonging to the genus Symbiodinium Freudenthal are haploid. Biol. Bull. 204, 10-20.

Sarkis, S., van Beukering, P.J., McKenzie, E., Brander, L., Hess, S., Bervoets, T., Looijenstijn-van der Putten, L., Roelfsema, M., 2013. Coral reefs: a summary. Coral reefs of the United Kingdom overseas territories 4, 1-201.

Sartoris, F.-J., Bock, C., Serendero, I., Lannig, G., Pörtner, H.-O., 2003. Temperaturedependent changes in energy metabolism, intracellular $\mathrm{pH}$ and blood oxygen tension in the Atlantic cod. J. Fish Biol. 62, 1239-1253.

Savage, A., Trapido-Rosenthal, H., Douglas, A., 2002. On the functional significance of molecular variation in Symbiodinium, the symbiotic algae of Cnidaria: photosynthetic response to irradiance. Mar. Ecol. Prog. Ser. 244, 27-37.

Schippers, P., Lürling, M., Scheffer, M., 2004. Increase of atmospheric $\mathrm{CO}_{2}$ promotes phytoplankton productivity. Ecol. Lett. 7, 446-451.

Schmidt, G., Fitt, W., Hoegh-Guldberg, O., 2004. Closely related Symbiodinium sp. differ in relative dominance in coral reef host communities across environmental, latitudinal and biogeographic gradients. Mar. Ecol. Prog. Ser. 284, 147-161.

Schneider, K., Erez, J., 2006. The effect of carbonate chemistry on calcification and photosynthesis in the hermatypic coral Acropora eurystoma. Limnol. Oceanogr. $1284,1284-1293$. 
Schwarz, J., Weis, V., Potts, D., 2002. Feeding behavior and acquisition of zooxanthellae by planula larvae of the sea anemone Anthopleura elegantissima. Mar. Biol. 140, 471478.

Schwarz, J.A., Krupp, D.A., Weis, V.M., 1999. Late larval development and onset of symbiosis in the scleractinian coral Fungia scutaria. Biol. Bull. 196, 70-79.

Selig, E.R., Drew Harvell, C., Bruno, J.F., Willis, B.L., Page, C.A., Casey, K.S., Sweatman, H., 2006. Analyzing the relationship between ocean temperature anomalies and coral disease outbreaks at broad spatial scales. Coast. Estuar. Stud. 61, 111-128.

Seneca, F.O., Forêt, S., Ball, E.E., Smith-Keune, C., Miller, D.J., van Oppen, M.J., 2010. Patterns of gene expression in a scleractinian coral undergoing natural bleaching. J. Mar. Biotechnol. 12, 594-604.

Silverman, J., Lazar, B., Cao, L., Caldeira, K., Erez, J., 2009. Coral reefs may start dissolving when atmospheric $\mathrm{CO}_{2}$ doubles. Geophys. Res. Lett. 36, L05606.

Silverstein, R.N., Correa, A.M.S., Baker, A.C., 2012. Specificity is rarely absolute in coralalgal symbiosis: implications for coral response to climate change. Proc. R. Soc. B. 279, 2609-2618.

Smith, F.A., Raven, J.A., 1979. Intracellular pH and its regulation. Annu. Rev. Plant Physiol. Plant Mol. Biol. 30, 289-311.

Smith, G.J., Muscatine, L., 1999. Cell cycle of symbiotic dinoflagellates: variation in G1 phase-duration with anemone nutritional status and macronutrient supply in the Aiptasia pulchella-Symbiodinium pulchrorum symbiosis. Mar. Biol. 134, 405-418.

Smith, S., 1978. Coral-reef area and the contributions of reefs to processes and resources of the world's oceans. Nature 273, 225-226.

Sobrino, C., Neale, P.J., Lubián, L.M., 2005. Interaction of UV radiation and inorganic carbon supply in the inhibition of photosynthesis: spectral and temporal responses of two marine picoplankters. Photochem. Photobiol. 81, 384-393.

Søderberg, L., Hansen, P.J., 2007. Growth limitation due to high pH and low inorganic carbon concentrations in temperate species of the dinoflagellate genus Ceratium. Mar. Ecol. Prog. Ser. 351, 103.

Stanley Jr, G.D., 2003. The evolution of modern corals and their early history. Earth-Sci. Rev. $60,195-225$.

Starzak, D.E., 2012. The influence of symbiont diversity on the functional biology of a model sea anemone. Unpublished PhD Thesis, Victoria University, Wellington, New Zealand, $179 \mathrm{pp}$.

Starzak, D.E., Quinnell, R.G., Nitschke, M.R., Davy, S.K., 2014. The influence of symbiont type on photosynthetic carbon flux in a model cnidarian-dinoflagellate symbiosis. Mar. Biol., 3, 711-724.

Stat, M., Carter, D., Hoegh-Guldberg, O., 2006. The evolutionary history of Symbiodinium and scleractinian hosts - symbiosis, diversity, and the effect of climate change. Perspect. Plant Ecol. 8, 23-43. 
Stat, M., Morris, E., Gates, R.D., 2008. Functional diversity in coral-dinoflagellate symbiosis. Proc. R. Soc. B. 105, 9256-9261.

Stat, M., Gates, R.D., 2011. Clade D Symbiodinium in scleractinian corals: a "nugget" of hope, a selfish opportunist, an ominous sign, or all of the above? J. Mar. Biol. Article ID $730715,1-9$.

Strobel, A., Leo, E., Pörtner, H.O., Mark, F.C., 2013. Elevated temperature and $p \mathrm{CO}_{2}$ shift metabolic pathways in differentially oxidative tissues of Notothenia rossii. Comp. Biochem. Physiol., Part B: Biochem. Mol. Biol. 166, 48-57.

Stumpp, M., Hu, M.Y., Melzner, F., Gutowska, M.A., Dorey, N., Himmerkus, N., Holtmann, W.C., Dupont, S.T., Thorndyke, M.C., Bleich, M., 2012. Acidified seawater impacts sea urchin larvae $\mathrm{pH}$ regulatory systems relevant for calcification. Proc. Natl. Acad. Sci. 109, 18192-18197.

Sudek, M., Aeby, G., Davy, S., 2012. Localized bleaching in Hawaii causes tissue loss and a reduction in the number of gametes in Porites compressa. Coral Reefs 31, 351-355.

Suggett, D.J., Warner, M.E., Smith, D.J., Davey, P., Hennige, S., Baker, N.R., 2008. Photosynthesis and production of hydrogen peroxide by Symbiodinium (Pyrrhophyta) phylotypes with different thermal tolerances. J. Phycol. 44, 948-956.

Suggett, D.J., Hall-Spencer, J.M., Rodolfo-Metalpa, R., Boatman, T.G., Payton, R., Tye Pettay, D., Johnson, V.R., Warner, M.E., Lawson, T., 2012. Sea anemones may thrive in a high $\mathrm{CO}_{2}$ world. Glob. Change Biol. 18, 3015-3025.

Suggett, D.J., Dong, L.F., Lawson, T., Lawrenz, E., Torres, L., Smith, D.J., 2013. Light availability determines susceptibility of reef building corals to ocean acidification. Coral reefs, 32, 327-337.

Sutton, D., Hoegh-Guldberg, O., 1990. Host-zooxanthella interactions in four temperate marine invertebrate symbioses: assessment of effect of host extracts on symbionts. Biol. Bull. 178, 175-186.

Sweatman, H., Delean, S., Syms, C., 2011. Assessing loss of coral cover on Australia's Great Barrier Reef over two decades, with implications for longer-term trends. Coral Reefs 30, 521-531.

Szmant, A., Gassman, N., 1990. The effects of prolonged "bleaching" on the tissue biomass and reproduction of the reef coral Montastrea annularis. Coral Reefs 8, 217-224.

Tabita, F.R., 1995. The biochemistry and metabolic regulation of carbon metabolism and $\mathrm{CO}_{2}$ fixation in purple bacteria, anoxygenic photosynthetic bacteria. Springer, pp. 885914.

Takahashi, S., Nakamura, T., Sakamizu, M., van Woesik, R., Yamasaki, H., 2004. Repair machinery of symbiotic photosynthesis as the primary target of heat stress for reefbuilding corals. Plant and Cell Physiol. 45, 251-255.

Takahashi, S., Murata, N., 2008. How do environmental stresses accelerate photoinhibition? Trends Plant Sci. 13, 178-182. 
Takahashi, S., Whitney, S.M., Badger, M.R., 2009. Different thermal sensitivity of the repair of photodamaged photosynthetic machinery in cultured Symbiodinium species. Proc. Nat. Acad. Sci. 106, 3237-3242.

Takahashi, S., Yoshioka-Nishimura, M., Nanba, D., Badger, M.R., 2013. Thermal acclimation of the symbiotic alga Symbiodinium spp. alleviates photobleaching under heat stress. Plant Physiol. 161, 477-485.

Taylor, P.R., Littler, M.M., 1982. The roles of compensatory mortality, physical disturbance, and substrate retention in the development and organization of a sand-influenced, rocky-intertidal community. Ecology 63, 135-146.

Tchernov, D., Gorbunov, M.Y., De Vargas, C., Narayan Yadav, S., Milligan, A.J., Häggblom, M., Falkowski, P.G., 2004. Membrane lipids of symbiotic algae are diagnostic of sensitivity to thermal bleaching in corals. Proc. Natl. Acad. Sci. 101, 13531-13535.

Teh, L.S., Teh, L.C., Sumaila, U.R., 2013. A global estimate of the number of coral reef fishers. PLoS One 8, e65397.

Thornhill, D.J., LaJeunesse, T.C., Kemp, D.W., Fitt, W.K., Schmidt, G.W., 2006. Multi-year, seasonal genotypic surveys of coral-algal symbioses reveal prevalent stability or postbleaching reversion. Mar. Biol. 148, 711-722.

Thornhill, D.J., Xiang, Y., Fitt, W.K., Santos, S.R., 2009. Reef endemism, host specificity and temporal stability in populations of symbiotic dinoflagellates from two ecologically dominant Caribbean corals. PLoS One 4, e6262.

Tkachenko, K.S., Wu, B.-J., Fang, L.-S., Fan, T.-Y., 2007. Dynamics of a coral reef community after mass mortality of branching Acropora corals and an outbreak of anemones. Mar. Biol. 151, 185-194.

Toller, W.W., Rowan, R., Knowlton, N., 2001. Zooxanthellae of the Montastraea annularis species complex: patterns of distribution of four taxa of Symbiodinium on different reefs and across depths. Biol. Bull. 201, 348-359.

Towanda, T., Thuesen, E.V., 2012. Prolonged exposure to elevated $\mathrm{CO}_{2}$ promotes growth of the algal symbiont Symbiodinium muscatinei in the intertidal sea anemone Anthopleura elegantissima. Biology Open 1, 615-621.

Trench, R., 1971a. The physiology and biochemistry of zooxanthellae symbiotic with marine coelenterates. I. The assimilation of photosynthetic products of zooxanthellae by two marine coelenterates. Proc. R. Soc. B. 177, 225-235.

Trench, R.K., 1971b. The physiology and biochemistry of zooxanthellae symbiotic with marine coelenterates. II. liberation of fixed $14 \mathrm{C}$ by zooxanthellae in vitro. Proc. R. Soc. B. 177, 237-250.

Trench, R., 1971c. The physiology and biochemistry of zooxanthellae symbiotic with marine coelenterates. III. The effect of homogenates of host tissues on the excretion of photosynthetic products in vitro by zooxanthellae from two marine coelenterates. Proc. R. Soc. B 177, 251-264.

Trench, R., 1974. Nutritional potentials in Zoanthus sociathus (Coelenterata, Anthozoa). Helgolander Wiss. Meeresunters. 26, 174-216. 
Trench, R.K., 1979. The cell biology of plant-animal symbiosis. Annu. Rev. Plant Physiol. $30,485-531$.

Turley, C., Roberts, J., Guinotte, J., 2007. Corals in deep-water: will the unseen hand of ocean acidification destroy cold-water ecosystems? Coral Reefs 26, 445-448.

Ulstrup, K., Ralph, P., Larkum, A., Kühl, M., 2006. Intra-colonial variability in light acclimation of zooxanthellae in coral tissues of Pocillopora damicornis. Mar. Biol. $149,1325-1335$.

Ulstrup, K.E., Van Oppen, M., 2003. Geographic and habitat partitioning of genetically distinct zooxanthellae (Symbiodinium) in Acropora corals on the Great Barrier Reef. Mol. Ecol. 12, 3477-3484.

Uthicke, S., Fabricius, K.E., 2012. Productivity gains do not compensate for reduced calcification under near-future ocean acidification in the photosynthetic benthic foraminifer species Marginopora vertebralis. Glob. Change Biol. 18, 2781-2791.

Van Hooidonk, R., Maynard, J., Planes, S., 2013. Temporary refugia for coral reefs in a warming world. Nature Clim. Change 3, 508-511.

Van Oppen, M., Mieog, J., Sanchez, C., Fabricius, K., 2005. Diversity of algal endosymbionts (zooxanthellae) in octocorals: the roles of geography and host relationships. Mol. Ecol. 14, 2403-2417.

van Oppen, M.J., Palstra, F.P., Piquet, A.M.-T., Miller, D.J., 2001. Patterns of coraldinoflagellate associations in Acropora: significance of local availability and physiology of Symbiodinium strains and host-symbiont selectivity. Proc. R. Soc. B. $268,1759-1767$.

Van Oppen, M.J., 2004. Mode of zooxanthella transmission does not affect zooxanthella diversity in acroporid corals. Mar. Biol. 144, 1-7.

van Oppen, M.J., Burghardt, I., 2009. Zooxanthellae (Symbiodinium, Dinophyceae) symbioses on coral reefs. Microbiol. Australia 30, 67-71.

Van Woesik, R., Sakai, K., Ganase, A., Loya, Y., 2011. Revisiting the winners and the losers a decade after coral bleaching. Mar. Ecol. Prog. Ser. 434, 67-76.

Vega, I., Damborenea, M., Gamarra-Luques, C., Koch, E., Cueto, J., Castro-Vazquez, A., 2006. Facultative and obligate symbiotic associations of Pomacea canaliculata (Caenogastropoda, Ampullariidae). Biocell 30, 367-375.

Venn, A., Tambutté, E., Holcomb, M., Allemand, D., Tambutté, S., 2011. Live tissue imaging shows reef corals elevate $\mathrm{pH}$ under their calcifying tissue relative to seawater. PLoS One 6, e20013.

Venn, A.A., Loram, J.E., Douglas, A.E., 2008. Photosynthetic symbioses in animals. J. Exp. Bot. 59, 1069-1080.

Venn, A.A., Tambutté, E., Lotto, S., Zoccola, D., Allemand, D., Tambutté, S., 2009. Imaging intracellular $\mathrm{pH}$ in a reef coral and symbiotic anemone. Proc. Natl. Acad. Sci. 106, 16574-16579. 
Venn, A.A., Tambutte, E., Holcomb, M., Laurent, J., Allemand, D., Tambutte, S., 2013. Impact of seawater acidification on $\mathrm{pH}$ at the tissue-skeleton interface and calcification in reef corals. Proc. Nat. Acad. Sci. 110, 1634-1639.

Veron, J.E., 2008. Mass extinctions and ocean acidification: biological constraints on geological dilemmas. Coral Reefs 27, 459-472.

Veron, J.E., 2011. Ocean acidification and coral reefs: An emerging big picture. Diversity 3, 262-274.

Villanoy, C., David, L., Cabrera, O., Atrigenio, M., Siringan, F., Aliño, P., Villaluz, M., 2012. Coral reef ecosystems protect shore from high-energy waves under climate change scenarios. Clim. Change 112, 493-505.

Vuuren, D., Edmonds, J., Kainuma, M., Riahi, K., Thomson, A., Hibbard, K., Hurtt, G., Kram, T., Krey, V., Lamarque, J.-F., Masui, T., Meinshausen, M., Nakicenovic, N., Smith, S., Rose, S., 2011. The representative concentration pathways: an overview. Clim. Chang. 109, 5-31.

Wakefield, T.S., Kempf, S.C., 2001. Development of host- and symbiont-specific monoclonal antibodies and confirmation of the origin of the symbiosome membrane in a cnidarian-dinoflagellate symbiosis. Biol. Bull. 200, 127-143.

Walker, N.A., Smith, F.A., 1975. Intracellular pH in Chara corallina measured by DMO distribution. Plant Sci. Lett. 4, 125-132.

Wang, J., Douglas, A., 1998. Nitrogen recycling or nitrogen conservation in an algainvertebrate symbiosis? J. Exp. Biol. 201, 2445-2453.

Wang, L.H., Liu, Y.H., Ju, Y.M., Hsiao, Y.Y., Fang, L.S., Chen, C.S., 2008. Cell cycle propagation is driven by light-dark stimulation in a cultured symbiotic dinoflagellate isolated from corals. Coral Reefs 27, 823-835.

Ward, S., Harrison, P., Hoegh-Guldberg, O., 2002. Coral bleaching reduces reproduction of scleractinian corals and increases susceptibility to future stress, Proceedings of the Ninth International Coral Reef Symposium, Bali, 23-27 October 2000, 1123-1128.

Warner, M., Fitt, W., Schmidt, G., 1996. The effects of elevated temperature on the photosynthetic efficiency of zooxanthellae in hospite from four different species of reef coral: a novel approach. Plant Cell Environ. 19, 291-299.

Weinlich, M., Theiss, C., Lin, C., Kinne, R., 1998. BCECF in single cultured cells: inhomogeneous distribution but homogeneous response. J. Exp. Biol. 201, 57-62.

Weis, V., Davy, S., Hoegh-Guldberg, O., Rodriguez-Lanetty, M., Pringle, J., 2008. Cell biology in model systems as the key to understanding corals. TREE. 23, 369-376.

Weis, V.M., Smith, G.J., Muscatine, L., 1989. A " $\mathrm{CO}_{2}$ supply" mechanism in zooxanthellate cnidarians: role of carbonic anhydrase. Mar. Biol. 100, 195-202.

Weis, V.M., 1991. The induction of carbonic anhydrase in the symbiotic sea anemone Aiptasia pulchella. Biol. Bull. 180, 496-504. 
Weis, V.M., 1993. Effect of dissolved inorganic carbon concentration on the photosynthesis of the symbiotic sea anemone Aiptasia pulchella Carlgren: Role of carbonic anhydrase. J. Exp. Mar. Biol. Ecol. 174, 209-225.

Weis, V.M., Reynolds, W.S., Krupp, D.A., 2001. Host-symbiont specificity during onset of symbiosis between the dinoflagellates Symbiodinium spp. and planula larvae of the scleractinian coral Fungia scutaria. Coral Reefs 20, 301-308.

Weis, V.M., 2008. Cellular mechanisms of cnidarian bleaching: stress causes the collapse of symbiosis. J. Exp. Biol. 211, 3059-3066.

Weis, V.M., 2010. The susceptibility and resilience of corals to thermal stress: adaptation, acclimatization or both? Mol. Ecol. 19, 1515-1517.

Whitehead, L., Douglas, A., 2003. Metabolite comparisons and the identity of nutrients translocated from symbiotic algae to an animal host. J. Exp. Biol. 206, 3149-3157.

Wiedenmann, J., D'Angelo, C., Smith, E.G., Hunt, A.N., Legiret, F.-E., Postle, A.D., Achterberg, E.P., 2012. Nutrient enrichment can increase the susceptibility of reef corals to bleaching. Nature Clim. Change 3, 160-164.

Wilkerson, F.P., Muscatine, L., 1984. Uptake and assimilation of dissolved inorganic nitrogen by a symbiotic sea anemone. Proc. R. Soc. B. 221, 71-86.

Williams, R., 1991. Acrorhagi, catch tentacles and sweeper tentacles: a synopsis of 'aggression' of actiniarian and scleractinian Cnidaria. Hydrobiologia 216, 539-545.

Wood, A.P., Kelly, D.P., 1989. Isolation and physiological characterisation of Thiobacillus thyasiris sp. nov., a novel marine facultative autotroph and the putative symbiont of Thyasira flexuosa. Arch. Microbiol. 152, 160-166.

Wood, H.L., Spicer, J.I., Widdicombe, S., 2008. Ocean acidification may increase calcification rates, but at a cost. Proc. R. Soc. B. 275, 1767-1773.

Wood, R., 2001. Biodiversity and the history of reefs. Geol. J. 36, 251-263.

Wood-Charlson, E.M., Hollingsworth, L.L., Krupp, D.A., Weis, V.M., 2006. Lectin/glycan interactions play a role in recognition in a coral/dinoflagellate symbiosis. Cell. Microbiol. 8, 1985-1993.

Work, T.M., Aeby, G.S., Maragos, J.E., 2008. Phase shift from a coral to a corallimorphdominated reef associated with a shipwreck on Palmyra Atoll. PLoS One 3, e2989.

Yakovleva, I., Bhagooli, R., Takemura, A., Hidaka, M., 2004. Differential susceptibility to oxidative stress of two scleractinian corals: antioxidant functioning of mycosporineglycine. Comp. Biochem. Phys. B. 139, 721-730.

Yamamoto-Kawai, M., McLaughlin, F.A., Carmack, E.C., Nishino, S., Shimada, K., 2009. Aragonite undersaturation in the Arctic Ocean: effects of ocean acidification and sea ice melt. Science 326, 1098-1100.

Yee, S.H., Santavy, D.L., Barron, M.G., 2008. Comparing environmental influences on coral bleaching across and within species using clustered binomial regression. Ecol. Model. $218,162-174$. 
Yellowlees, D., Rees, T.A.V., Leggat, W., 2008. Metabolic interactions between algal symbionts and invertebrate hosts. Plant Cell Environ. 31, 679-694.

Yin, Z.-H., Neimanis, S., Wagner, U., Heber, U., 1990. Light-dependent pH changes in leaves of C3 plants. Planta 182, 244-252.

Yost, D.M., Wang, L.H., Fan, T.Y., Chen, C.S., Lee, R.W., Sogin, E., Gates, R.D., 2013. Diversity in skeletal architecture influences biological heterogeneity and Symbiodinium habitat in corals. Zoology (Jena) 116, 262-269.

Zhang, J., Campbell, R.E., Ting, A.Y., Tsien, R.Y., 2002. Creating new fluorescent probes for cell biology. Nat. Rev. Mol. Cell Bio. 3, 906-918.

Zoccola, D., Tambutté, E., Kulhanek, E., Puverel, S., Scimeca, J.C., Allemand, D., Tambutté, S., 2004. Molecular cloning and localization of a PMCA P-type calcium ATPase from the coral Stylophora pistillata. Biochim. et Biophys. Acta 1663, 117-126. 


\title{
A: Appendices
}

\section{A.1 ITS2 sequences for the cultured Symbiodinium}

\author{
Culture name: CCMP 2467 (A1) \\ GCGCCGAACTGCATTCAAATGACTTCATGCTAGGAAGTGTTAAGAACCACATGAGCTTTT \\ GTTTCGCCAACTGAAACGACATGAGATGTTGATCAGTCACAACAGCAAGCAAAACTTGAT \\ ATTTAGCATGCCAGTGCCACTTGCAGAAGCATGCAGCAACACTGCTCCTGATAACAAGAG \\ CAGCAGAAAATGAAAGTAGAAGCACTGAAGCAGACATGCTCTCAGGCATATCCCAAGAG \\ CGCAATGCACGTTCAAGAGGCCATTGGTTCACGGAGTTCTGCAATTCACAAAAGT
}

Culture name: Ap1 (B1)

GGACGATCGTATTACTAGCTGTACACATGCCACGGGAGTTCTGCAATTCACAGGACAGCT GCGCGCTTGAGCTGCACGATGCAAGCAAAGCTTGGAACAACAGTACGCTCAAGCTTGGCG CATGGGCCAGGCAGCAAACAAGCCATTTACGAACACAAAAGCGATCGATGACTTGTTGGA AAGCGAAGCAGCAATGCAGACATACATGCTGCTTGCAAGCACAGGTAGATAATGCTAAGC ACTGAAGCAGACCTGCTCTCAGGAAATCCCGAGAGCGCAATGCGCGTTCAGGAGGCCATC GGTTCACGGAGTTCGGCAATTCACAAAAATTTT

Culture name: FlCass (E1)

TCCCTTGATCTGACTTCATGCTAAGATTGGTATTTGAGCACCAATTGCTTGGCAGGCTGGC ATGATTGGGCCAAAACGGACACACGTGCCCAGTGATGCGCGACAAATCAGTCCAGCTTAC CTCCCGGTTTGTGTTCAGCGCGCCGCTGCAAATTCTGATGCAGCAGCGCACAAAGAGGCT CAAGGCTTCTCCAGG

Culture name: CCMP 421 (E2)

CCGGTTTGCTGCTGACTCTGCTAAGATTGGTTATTTGAGCACCAATTGCTTGGCAGGCTGG CATGATTGGGCCAAAACGGACACACGTGCCCAGTGATGCGCGACAAATCAGTCCAGCTTA CCTCCCGGTTTGTGTTCAGCGCGCCGCTGCAAATTCTGATGCAGCAGCGCGCAAAGAGGC TCAAGGCTTCTCCAGGAAGCCCGCACTGCGAAGATATGAAAAGCACTGAAGCAGACATAC TCTCAGGCGTGTCCCAAGAGTGCAATGCGAGTTCAGGGTGCTATTGGTTCACGGGCTTCCA CATATCCACCAAAAAGGAAAAAAAAAAGGGAAAAAGGGGGGGGGAAAA

Culture name: $\mathrm{Mv}(\mathrm{F} 1)$

CGGGGGGATCGTTTGATCTGACTTCCTGCCTAGAAGGCATGCGCCTAACATCCCCATCACT TTGCAAGCATTGGCAGCGTTACTCAAGAAAATACACATTTTCAGGCGGAGAACTCGAAAC GCATTCGCGCAAAGCTCTTTGCAAGTCTCATACTCATCACAATCAACCCCATTCGACTATC TGATCTCAATCGGCTGCACAGAGGGCGCCACGAGCAC

Culture name: Pd (F5)

GCGGGCAAATCGAATTCACAAGATCATCTTGCCACGAGAGTTCTGCAATTCACACAGCAG CTGCAAGCATAAACAGCGTCACTCAAGCAATACCACTTTAAGGTGGAATCTTGAATAGCA GCGCGCAAAGCTTTTGCAAGACCAAATCATTCAATAAGCCACTGAGTAGACATTCAATGG CTCACAGGGGCGCAAGACAGAAACACAATCTGTCCGCAAGATTGGGCAAGCTAAGCACT GAAGCAGACATACTCTCAGGAAATCCCAAGAGTGCAACGTACGTTCAGGAGGCCATTGGT TCACGGAGTTCTGCAATTCACAAAACA 


\section{A.2 Photosynthesis-irradiance curves}

Photosynthesis-irradiance curves were conducted prior to experimentation to calculate the saturating irradiance for photosynthesis in both species. This value was subsequently used during intracellular $\mathrm{pH}\left(\mathrm{pH}_{\mathrm{i}}\right)$ measurements. Briefly, fragments were randomly selected and placed inside a $250 \mathrm{~mL}$ plastic chamber. A glass lid, held in place by a rubber O-ring, sealed the chamber, into which a temperature probe and a fibre-optic oxygen sensor were inserted such that both probes were positioned $\sim 2 \mathrm{~cm}$ above the coral surface (Ocean Optics, Dunedin, Florida, USA). A constant water temperature of $25^{\circ} \mathrm{C}$ was maintained by recirculating water around the chamber, and water motion was generated by a submersible magnetic stirrer. $\mathrm{O}_{2}$-evolution $\left(\mathrm{mL} \mathrm{O}_{2}\right.$ $\left.\mathrm{h}^{-1}\right)$ was measured over five light levels $\left(100,150,250,400\right.$ and $500 \mu \mathrm{mol}$ photons $\mathrm{m}^{-}$ $\left.2 \mathrm{~s}^{-1}\right)$. The desired light level was achieved by manipulating the power and position of a variable-irradiance fibre optic light (Halogen Reflector lamp, $150 \mathrm{~W}$ GX5.3 21V 1CT bulb, Philips, Somerset, New Jersey, USA), and the final irradiance was checked using a $4 \pi$ quantum light meter connected to a data logger (Li-Cor Biosciences, Lincoln, Nebraska, USA). Oxygen readings were taken every $10 \mathrm{~s}$ for a minimum of $20 \mathrm{~min}$, or until a clear slope was observed, and the data were recorded using the Neofox Viewer software (Ocean Optics, Dunedin, Florida, USA). Coral fragments were then frozen at $-20^{\circ} \mathrm{C}$ for subsequent chl- $a$ analysis (protocol described in section 4.2.2), which was used to normalise oxygen evolution $\left(\mu \mathrm{g} \mathrm{O} \mathrm{mg}^{-1} \mathrm{chl} \mathrm{h}^{-1}\right)$.

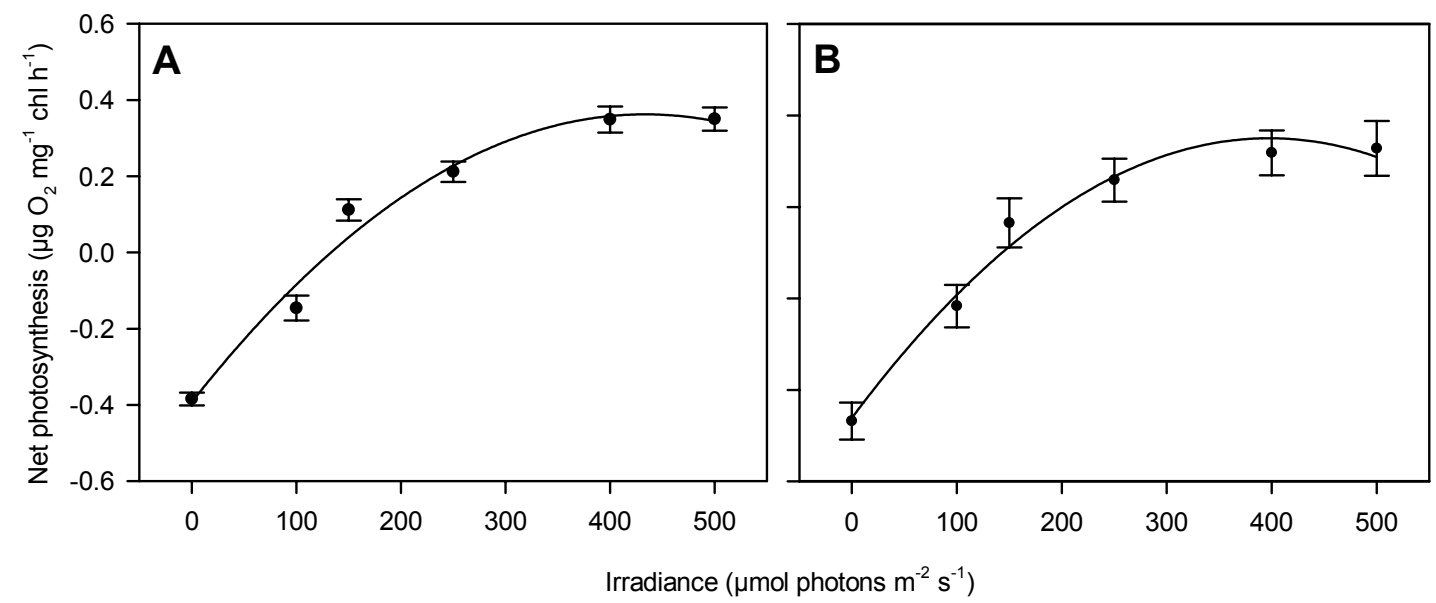

Fig. A.2 Photosynthesis-irradiance curves for [A] P. damicornis and [B] M. capitata. Values represent net photosynthesis (mean \pm S.E.M, $\mathrm{n}=3$ replicates per species). 


\section{A.3 Visual bleaching in Pocillopora damicornis and Montipora capitata}
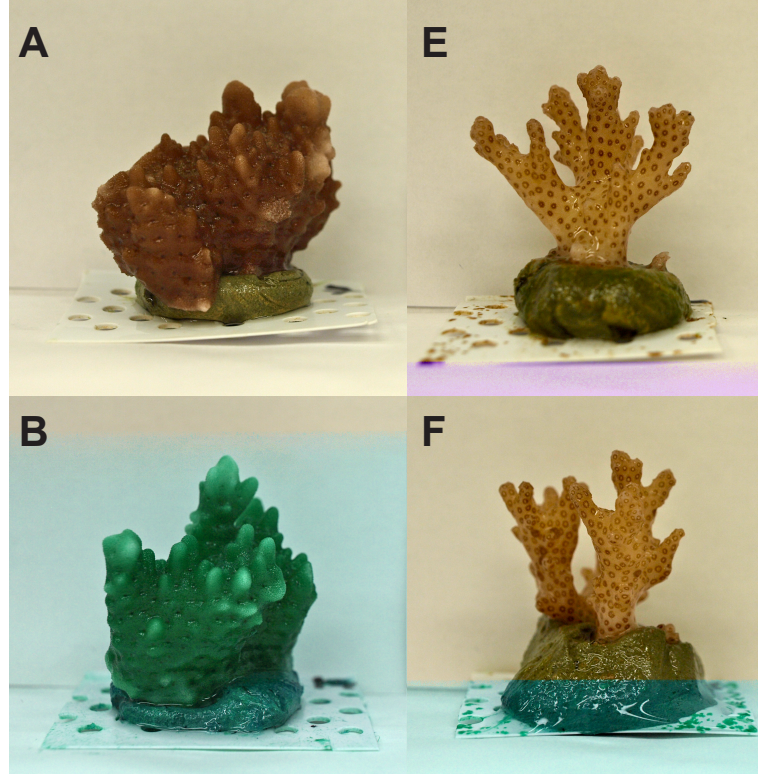

$\mathbf{F}$

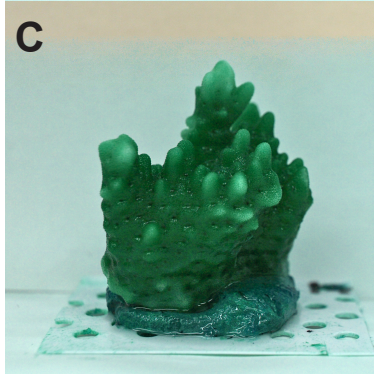

G

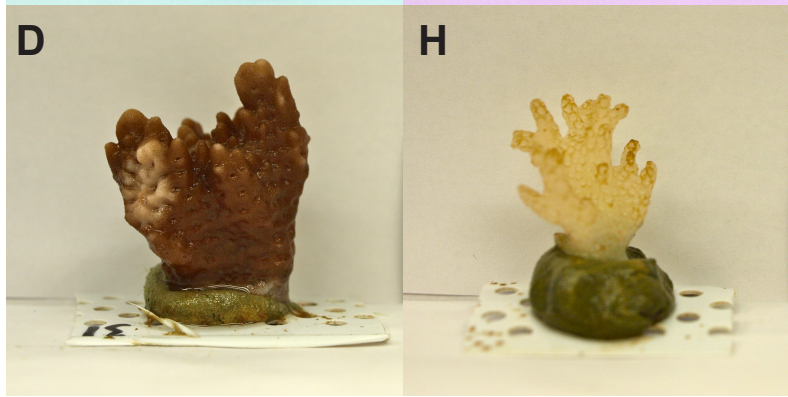

Fig. A.3 Visual effect of temperature on [A-D] Montipora capitata and [E-H] Pocillopora damicornis fragments. Images are ordered (top-bottom) via increasing temperature treatment. Note the severe loss of pigmentation in $[\mathrm{H}]-$ the $31^{\circ} \mathrm{C}$ treatment. 


\section{B: Additional Work}

\section{B.1 Determining the effect of pH on the cell cycle in Symbiodinium}

The original proposal for Chapter 4 was to investigate how the Symbiodinium cell cycle is affected by acidification. Regulation of $\mathrm{pH}_{\mathrm{i}}$ plays an important role in cellular differentiation, specifically in the interphase (I) stage of the cell cycle (Aerts et al., 1985). A rise in alkalinity is responsible for the transition between the resting phase of I $\left(G_{0}\right)$, the gap phase of $I\left(G_{1}\right)$ and subsequently into the synthesis $(S)$ phase, during which DNA replication occurs (Madshus, 1988). The role of $\mathrm{pH}_{\mathrm{i}}$ was first detected in quiescent fibroblast cells, where it was determined that a $\mathrm{pH}_{\mathrm{i}}$ of greater than 7.2 was to initiate $\mathrm{S}$ (Pouyssègur et al., 1985). Similarly, a $0.25 \mathrm{pH}_{\mathrm{i}}$ unit rise between $\mathrm{S}$ stage and final mitosis, was demonstrated for the both the slime mold Dictyostelium discoideum (Aerts et al., 1985), and the yeast species Saccharomyces cerevisiae (Orij et al., 2012). However this was not the case in Schizosaccharomyces pombe, which kept a constant $\mathrm{pH}_{\mathrm{i}}$ of 7.3 throughout the cell cycle (Karagiannis, 2001). Symbiodinium cells exhibit phased division rates, peaking at dawn upon illumination (Fitt and Trench, 1983). However, little is known about control of the cell cycle, other than that it does not appear to be linked to nutrient limitation by the host (Smith and Muscatine, 1999), and that light is likely to play an important role in the S phase of the cycle (Wang et al., 2008). These prelimary experiments were carried out at an $\mathrm{pH}_{\mathrm{e}}$ of 7. These conditions were not intended to replicate ocean acidication predictions (IPCC, 2014) but rather to investigate the dynamics of the Symbiodinium cell cycle.

Stock cultures of two Symbiodinium types, CCMP 2467 and Ap1 (identified in Chapter 2) were grown in $\mathrm{f} / 2$-enriched $\mathrm{FSW}$, in a water bath set to $25^{\circ} \mathrm{C}$ and an irradiance of 80-100 $\mu \mathrm{mol}$ photons $\mathrm{m}^{-2} \mathrm{~s}^{-1}$ (Osram Dulux 36W/890 fluorescent bulbs). When logarithmic growth was achieved, $1 \mathrm{~mL}$ aliquots were removed and added to six $250 \mathrm{~mL}$ beakers, each containing $200 \mathrm{~mL}$ of FSW. The beakers were then sealed with rubber stoppers ( $n=3$, per species, per treatment). At a density of $\sim 100,000$ cells $\mathrm{mL}^{-1}$ two holes were cut in the stoppers and two hand-blown glass tubes, of differing lengths $(5 \mathrm{~cm}$ and $10 \mathrm{~cm})$ were inserted. $\mathrm{CO}_{2}$-insulated tubing connected the shorter glass tube to one of two treatment reservoir tanks, while the longer glass tube led to a 
waste tank. Together, the two glass rods created a vacuum within the flask, enabling water to be dripped into the cultures at a constant flow rate. A pH of $7.05 \pm 0.1$ was maintained in the reservoir tank by a $\mathrm{CO}_{2}$ solenoid valve, which was connected to a PINPOINT pH controller (American Marine Inc., Ridgefield, CT, USA). Cultures were exposed to the new conditions for $48 \mathrm{~h}$. Samples were then taken every $3 \mathrm{~h}$ over a $72 \mathrm{~h}$ period. At each time point $10 \mathrm{~mL}$ were removed from each flask. A $1 \mathrm{~mL}$ aliquot was stored at $-20^{\circ} \mathrm{C}$ for subsequent cell counts using an Improved Neubauer haemocytometer (Boeco, Hamburg, Germany) and a light microscope $(\times 400$ magnification). The resulting values were used to determine the cell-specific growth rate $(\mu)$ and the $\%$ of cells dividing (mitotic index; MI). The remaining $9 \mathrm{~mL}$ were centrifuged for $5 \mathrm{~min}$ at $800 \times \mathrm{g}$ until an algal pellet was formed. The supernatant was discarded and the pellet was resuspended in $1 \mathrm{~mL}$ of $70 \%$ ethanol. Samples were stored on ice under high light in order to bleach the sample of chlorophyll. They were then stored in a $4^{\circ} \mathrm{C}$ fridge for later analysis.
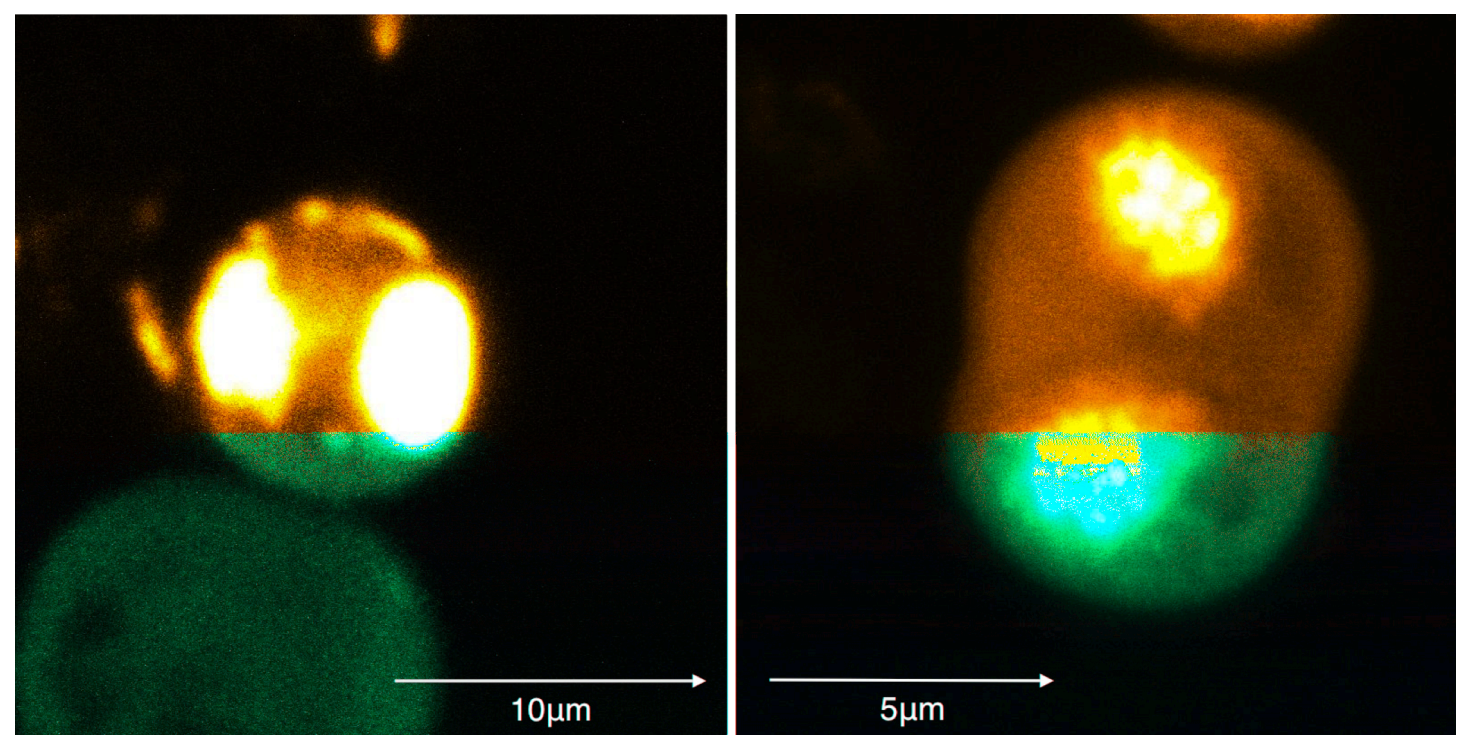

Fig. B.1 Confocal visualisation of Propidium Iodide (PI) staining solution in Symbiodinium cells. Images depict different cell cycle phases [A] Synthesis (S) phase, during which DNA replication occurs and [B] Mitotic division (M) phase before cytokinesis cleaves the two cells. Where fluorescence is enhanced PI is binding to genetic material (ex: 473, em: 600-700 nm).

The number of cells at each stage of the cell cycle (G1, S and G2) was calculated using a protocol adapted from Pozarowski and Darzynkiewicz (2004). Samples were centrifuged for $5 \mathrm{~min}$ at $800 \times \mathrm{g}$ and all ethanol was thoroughly decanted before the cells were re-suspended in $1 \mathrm{~mL}$ of PI staining solution $(0.1 \%$ Triton $\mathrm{X}-100,10$ $\mu \mathrm{g} / \mathrm{mL}$ PI and $100 \mu \mathrm{g} / \mathrm{mL}$ DNase-free RNase A in PBS) and left in the dark for 10 
min. The samples were then transferred to a FACSAN flow cytometer (FACScan, Becton-Dickinson, Franklin Lakes, NJ, USA) where they were excited with a $488 \mathrm{~nm}$ argon laser. Fluorescence was collected in the FL3 filter channel (red; 610-700 nm). The technique relies on the relative fluorescence of the PI stain upon binding to DNA (Fig. B.1); i.e. the strength of the signal received from single cells in interphase (one nucleus; not dividing) should be exactly half of that when the cell is in G2 (when two nuclei are present). Data were analysed using the FlowJo software package (Tree Star Inc., Ashland, OR, USA) with Watson's Pragmatic algorithm selected to separate the cyclical stages (Watson et al., 1987). The final dataset was analysed as the relative change in the $\%$ of cells (calculated as the mean $\%$ of cells after acidification minus the mean \% of cells in the control) in three phases of the cell cycle - G1, S and G2 using one-way ANOVA. Additional analysis was carried out on the incremental cell population $(t+1)-t$ in order to establish the number of new cells entering a particular stage at each time point. The assumptions of normality were confirmed using the Kolgomorov-Smirnov Test and sphericity of the data was tested using Mauchly's Sphericity Test.

In general, division rates were higher in the B1 (Ap1) than the A1 strain (CCMP $\left.2467 ; \mathrm{F}_{(1,43.97)}=8.17, \mathrm{p}=0.007\right)$. Both cultures exhibited phased division rates, with the $\%$ of cells in mitosis significantly higher in the light than the dark $\left(\mathrm{F}_{(1,43.65)}=5.35\right.$, $\mathrm{p}=0.026$ ). The addition of $\mathrm{CO}_{2}$ had a significant impact on cell cycle dynamics (Fig. B.2). The $\%$ of cells in G1 was significantly higher in the control treatment for both Ap1 $\left(\mathrm{F}_{(1,14)}=6.72, \mathrm{p}=0.021\right)$ and $\operatorname{CCMP} 2467\left(\mathrm{~F}_{(1,22)}=11.13, \mathrm{p}<0.003\right)$. In contrast, there was a significantly lower \% of cells in the $\mathrm{S}$ phase in the control treatment. Again, this pattern was observed in both the Ap1 $\left(\mathrm{F}_{(1,14)}=11.373, \mathrm{p}=\right.$ 0.005) and CCMP $2467\left(\mathrm{~F}_{(1,22)}=18.96, \mathrm{p}<0.001\right)$ cultures. Acidification however, had no effect on the $\%$ of cells in $\mathrm{G} 2$ in either Ap1 $\left(\mathrm{F}_{(1,14)}=2.72, \mathrm{p}=0.122\right)$ or CCMP $2467\left(\mathrm{~F}_{(1,23)}=0.019, \mathrm{p}=0.891\right)$. Examination of the incremental increases in cells at each phase revealed that transitions between $\% \mathrm{~S}$ and $\% \mathrm{G} 2$ are tightly linked (Fig. B.2), but that both stages are negatively correlated with the \% of cells in G1, regardless of the $\mathrm{pH}$ treatment and symbiont genotype. In addition, the amplitude of the hourly increments was smaller towards end of experiment. 

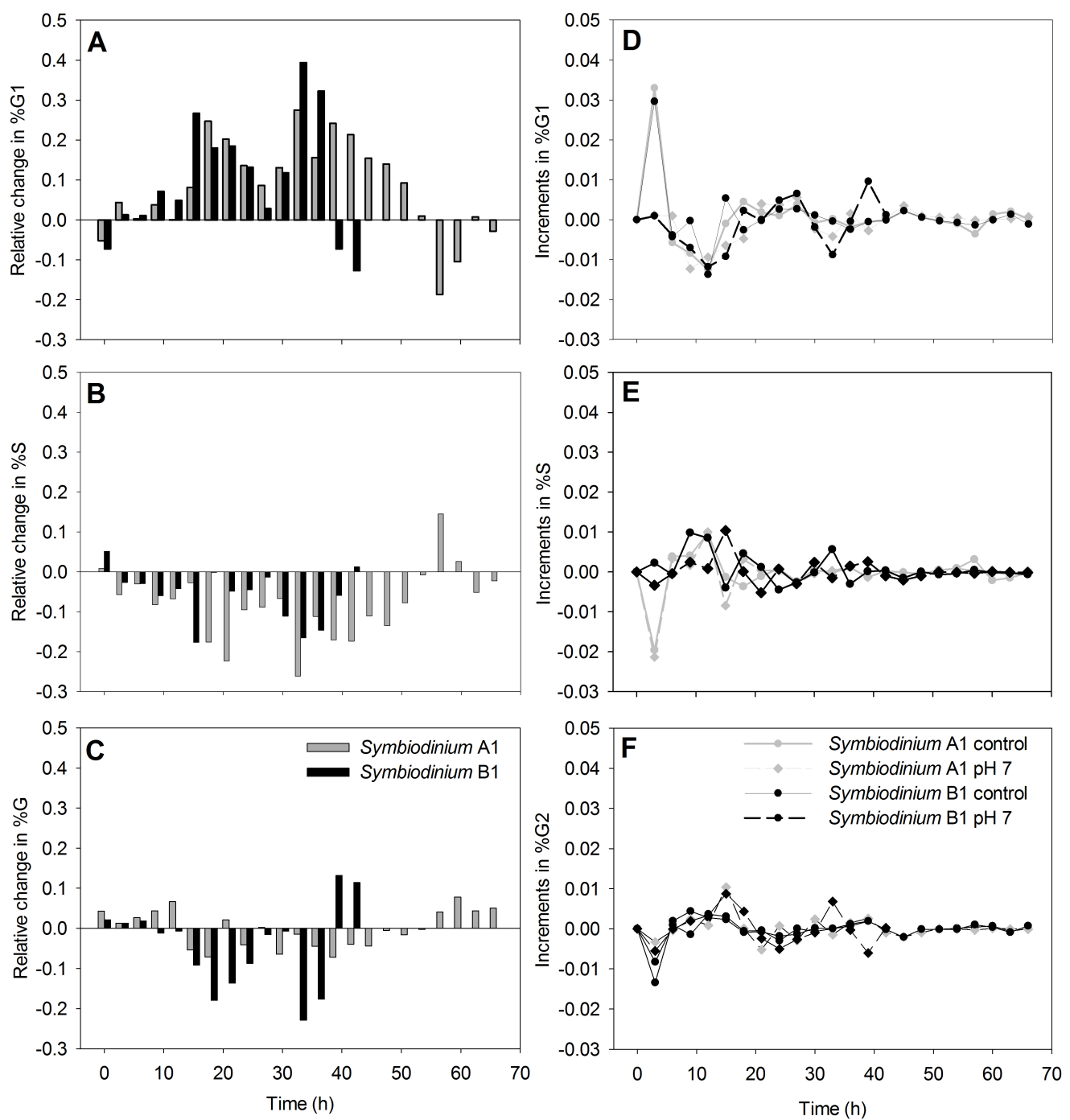

Fig. B.2 The effect of acidification on the cell cycle dynamics of two Symbiodinium cultures, CCMP2467 (A1; black) and Ap1 (B1; grey). Data represent the relative change in the \% of cells in three phases of the cell cycle - [A] the gap phase of interphase (G1), [B] the synthesis stage (S) when DNA replication occurs and $[\mathrm{C}]$ gap phase two (G2) preceding cytokinesis, and mitotic division, and the incremental increase in cells entering [D] G1, [E] S and [F] G2. 


\title{
Intracellular pH of symbiotic dinoflagellates
}

\author{
E. M. Gibbin · S. K. Davy
}

Received: 6 March 2013/ Accepted: 24 May 2013

(C) Springer-Verlag Berlin Heidelberg 2013

\begin{abstract}
Intracellular $\mathrm{pH}\left(\mathrm{pH}_{\mathrm{i}}\right)$ is likely to play a key role in maintaining the functional success of cnidariandinoflagellate symbiosis, yet until now the $\mathrm{pH}_{\mathrm{i}}$ of the symbiotic dinoflagellates (genus Symbiodinium) has never been quantified. Flow cytometry was used in conjunction with the ratiometric fluorescent dye BCECF to monitor changes in $\mathrm{pH}_{\mathrm{i}}$ over a daily light/dark cycle. The $\mathrm{pH}_{\mathrm{i}}$ of Symbiodinium type B1 freshly isolated from the model sea anemone Aiptasia pulchella was $7.25 \pm 0.01$ (mean $\pm \mathrm{SE}$ ) in the light and $7.10 \pm 0.02$ in the dark. A comparable effect of irradiance was seen across a variety of cultured Symbiodinium genotypes (types A1, B1, E1, E2, F1, and F5) which varied between $\mathrm{pH}_{\mathrm{i}} 7.21-7.39$ in the light and 7.06-7.14 in the dark. Of note, there was a significant genotypic difference in $\mathrm{pH}_{\mathrm{i}}$, irrespective of irradiance.
\end{abstract}

Keywords $\mathrm{pH}_{\mathrm{i}} \cdot$ Symbiodinium $\cdot$ Cnidariandinoflagellate symbiosis $\cdot$ Zooxanthellae

\section{Introduction}

Coral reefs are both ecologically and socio-economically important, and their success is founded on the mutualistic endosymbiosis between corals and dinoflagellate algae of

Communicated by Biology Editor Dr. Anastazia Banaszak

Electronic supplementary material The online version of this article (doi:10.1007/s00338-013-1048-7) contains supplementary material, which is available to authorized users.

E. M. Gibbin · S. K. Davy $(\varangle)$

School of Biological Sciences, Victoria University of

Wellington, Kelburn Parade, Wellington 6140, New Zealand

e-mail: simon.davy@vuw.ac.nz the genus Symbiodinium (Hoegh-Guldberg 1999). However, despite the importance of the cnidarian-dinoflagellate symbiosis, we know very little about its underlying cell biology (Weis et al. 2008; Davy et al. 2012). This hampers our understanding of how coral reefs function, both under 'normal' conditions and projected scenarios of environmental stress. The genus Symbiodinium is exceptionally diverse, with nine genetically distinct clades (A-I), which are further differentiated into sub-clades termed 'types' (Pochon and Gates 2010). There is substantial variation in physiology between genotypes, particularly with respect to their photosynthetic response to light (Hennige et al. 2009) and thermal tolerance (Fisher et al. 2012). These physiological differences have the potential to confer significant advantages/disadvantages to a coral and can influence a host's resistance to stress (Baker et al. 2004). Yet despite this, one of the most fundamental attributes of the symbiotic algal cell, its internal $\mathrm{pH}$, was, until now, unknown.

Virtually, all metabolic activity is $\mathrm{pH}$-dependent. $\mathrm{pH}$ also plays a key role in controlling progression through the cell cycle, protein synthesis, and the synthesis of both DNA and RNA (Madshus 1988). Furthermore, the establishment of a proton gradient across a cell membrane creates an electrochemical potential, which is important for maintaining the flux of ions between cells, and in inter-cell signalling (Casey et al. 2009). Little, however, is known of the role of $\mathrm{pH}$ in the function of the cnidarian-dinoflagellate symbiosis, despite its potential significance in the regulation of inorganic carbon and nitrogen fluxes between the host and symbiont (Fitt et al. 1995; Brownlee 2009; Venn et al. 2009), and the coordination of host and symbiont cell proliferation (Davy et al. 2012). Moreover, $\mathrm{pH}_{\mathrm{i}}$ is also known to affect the formation of crystals during coral calcification (Venn et al. 2012). Indeed, only recently has the $\mathrm{pH}_{\mathrm{i}}$ of the host cell been measured, with the 
photosynthetic activity of the symbionts causing an alkalinisation of the host cell (Venn et al. 2009), proportional to the irradiance intensity experienced by the symbiont (Laurent et al. 2012). The aim of this study was to develop a method for measuring the $\mathrm{pH}_{\mathrm{i}}$ of Symbiodinium cells, to measure $\mathrm{pH}_{\mathrm{i}}$ over a daily light cycle in a range of Symbiodinium types, and to compare the $\mathrm{pH}_{\mathrm{i}}$ of Symbiodinium with that of its host cell in the sea anemone Aiptasia pulchella, an important model for coral research.

\section{Methods}

Cultured A. pulchella anemones, hosting Symbiodinium ITS2 type B1, were grown at $25{ }^{\circ} \mathrm{C}$ under $80-100 \mu \mathrm{mol}$ photons $\mathrm{m}^{-2} \mathrm{~s}^{-1}$ of white light (Osram Dulux 36W/890 fluorescent bulbs) on a $12 \mathrm{~h}$ light: $12 \mathrm{~h}$ dark cycle and fed Artemia sp. nauplii every 3 days. The anemones were not fed for the week prior to sampling. Six Symbiodinium types (A1, B1, E1, E2, F1, and F5) were also examined in culture; these types were identified via the method of Stat et al. (2008). The cultures, originally isolated from a range of invertebrate hosts (Table 1), were grown to densities of $2 \times 10^{5}$ cells $\mathrm{mL}^{-1}$ in $0.22 \mu \mathrm{m}$ filtered seawater (FSW) enriched with $\mathrm{f} / 2$ medium and sampled while the cells were in logarithmic growth phase.

The ratiometric fluorescent dye BCECF-AM ester was used to measure $\mathrm{pH}_{\mathrm{i}}$ of Symbiodinium via flow cytometry, with the dispersant Pluronic F-127 being employed during the loading procedure to reduce dye aggregation (see below for loading protocol). BCECF-AM has been widely used to measure $\mathrm{pH}_{\mathrm{i}}($ Ozkan and Mutharasan 2002) and has been successfully used in conjunction with flow cytometry in other model systems (Franck et al. 1996). It was selected here for its strong dual excitation properties that allow $\mathrm{pH}_{\mathrm{i}}$ to be measured without interference from any chlorophyll autofluorescence $(>640 \mathrm{~nm})$. Confocal microscopy was initially used to confirm that the dye was able to enter the cells (Fig. 1a) and to check for dye homogeneity through the cell (Fig. 1b). It was apparent that, despite the use of a dispersant, BCECF-AM-derived fluorescence was not evenly distributed within each cell. This could either be an

Table 1 Cultured Symbiodinium types categorised by the internal transcribed spacer 2 (ITS2) region of the nuclear rDNA, the host they were first isolated from, and the $\mathrm{pH}_{\mathrm{i}}$ after $12 \mathrm{~h}$ light adaptation and $12 \mathrm{~h}$ dark adaptation (mean $\pm \mathrm{SE} ; n=3$ )

\begin{tabular}{llllll}
\hline Culture name & Original host & Location & Clade (ITS2 type) & Light-adapted $\mathrm{pH}_{\mathrm{i}}$ & Dark-adapted $\mathrm{pH}_{\mathrm{i}}$ \\
\hline CCMP 2467 & Stylophora pistillata & Gulf of Aqaba, Jordan & A (A1) & $7.33 \pm 0.03$ & $7.10 \pm 0.03$ \\
Ap1 & Aiptasia pulchella & Okinawa, Japan & B (B1) & $7.32 \pm 0.01$ & $7.14 \pm 0.01$ \\
FlCass & Cassiopea xamachana & Florida, USA & E (E1) & $7.27 \pm 0.04$ & $7.14 \pm 0.03$ \\
CCMP 421 & Free-living dinoflagellate & Wellington Harbour, New Zealand & E (E2) & $7.21 \pm 0.04$ & $7.08 \pm 0.03$ \\
Mv & Montipora verrucosa & Hawai'i, USA & F (F1) & $7.23 \pm 0.08$ & $7.06 \pm 0.17$ \\
Pd & Pocillopora damicornis & Hawai'i, USA & F (F5) & $7.39 \pm 0.02$ & $7.12 \pm 0.27$ \\
\hline
\end{tabular}

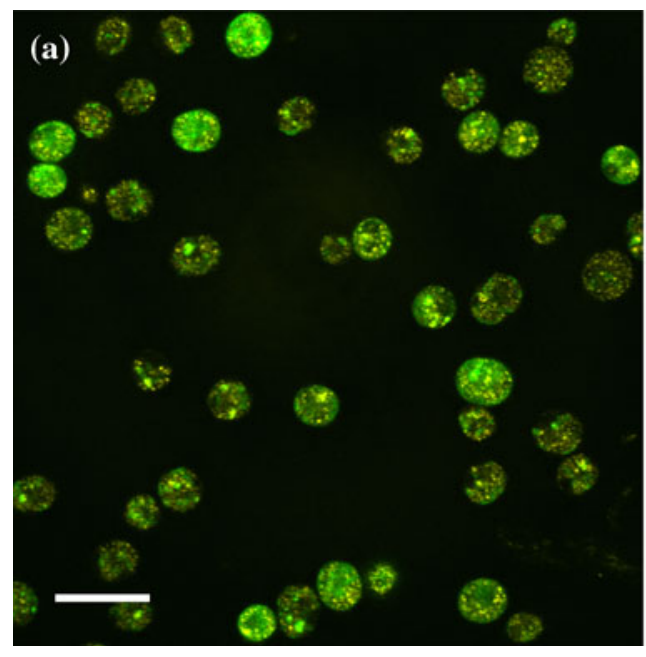

Fig. 1 Quantifying the $\mathrm{pH}_{\mathrm{i}}$ of Symbiodinium. a Confocal microscope image of Symbiodinium cells loaded with $10 \mu \mathrm{M}$ of the $\mathrm{pH}$-sensitive BCECF-AM ester, imaged after excitation with both 405 and $473 \mathrm{~nm}$ lasers, with fixed emission at $535 \pm 10 \mathrm{~nm}$. Scale bar represents $20 \mu \mathrm{m}$. b Single Symbiodinium cell imaged under the aforementioned

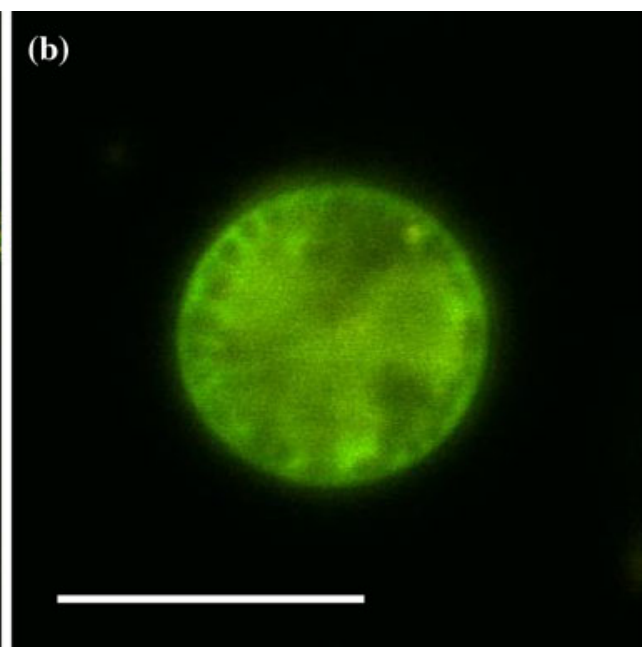

conditions. Scale bar represents $10 \mu \mathrm{m}$. While the dye consistently labelled cells, including their cytoplasm, note its uneven intra-cellular distribution. This was most likely caused by selective accumulation into certain organelles 
artefact caused by selective accumulation in certain organelles (e.g. the nucleus and mitochondria; Weinlich et al. 1998) or could reflect regional $\mathrm{pH}$ differences between organelles (e.g. acidic endosomal vacuoles; Casey et al. 2009). Furthermore, Symbiodinium cells contain autofluorescent 'inclusion bodies' that, when excited by blue light, have the potential to interfere with fluorescence measurements (Kazandjian et al. 2008). When calibrating the dye with flow cytometry (Electronic Supplementary Material, ESM S1), we therefore used the logarithmic form of the in vivo calibration equation, as this minimises the impacts of non-uniform loading, as well as leakage of dye out of the cell and photo-bleaching (Bright et al. 1989). It is also important to note that flow cytometry averages the fluorescence signal across each cell and measures large numbers of cells simultaneously, so reducing errors caused by intra- and inter-cellular variability.

The effect of irradiance $(12 \mathrm{~h}$ light adaptation at 80-100 $\mu \mathrm{mol}$ photons $\mathrm{m}^{-2} \mathrm{~s}^{-1}$ and $12 \mathrm{~h}$ of dark adaptation) on $\mathrm{pH}_{\mathrm{i}}$ was quantified in freshly isolated and cultured Symbiodinium cells, and in A. pulchella host cells. For freshly isolated algal cells, individual anemones $(n=10$ per treatment) were exposed to light or dark before being homogenised in $500 \mu \mathrm{L}$ of FSW in a hand-held glass tissue grinder. The resulting slurry was transferred to a $1.5-\mathrm{mL}$ Eppendorf tube and centrifuged for $5 \mathrm{~min}$ at $1,000 \times g$, $25{ }^{\circ} \mathrm{C}$ to separate the algal fraction from host tissue. The supernatant was discarded, and the Symbiodinium pellet washed twice in FSW. The pellet was re-suspended in FSW at a final density of $1 \times 10^{6}$ cells $\mathrm{mL}^{-1}$ and incubated with $10 \mu \mathrm{M}$ of BCECF-AM ester and $0.01 \%$ Pluronic F-127 for $20 \mathrm{~min}$ on an orbital shaker set to $250 \mathrm{rpm}$. The analysis of $\mathrm{pH}_{\mathrm{i}}$ was conducted on a FACScan flow cytometer. Samples were excited with a $488 \mathrm{~nm}$ argon laser, and Symbiodinium cells were gated on particle size (FSC) and chlorophyll fluorescence (>670 nm, FL3) to exclude cellular debris. BCECF-AM fluorescence was measured in linear mode in the 515-545 nm (FL1) and 564-606 nm (FL2) filter channels, with 5,000 individual cells recorded per sample. Cultured cells were grown in 250-mL flasks before being exposed to the same light or dark treatment as before ( $n=3$ per treatment). An aliquot $(10 \mathrm{~mL})$ was sampled from each flask, centrifuged for $5 \mathrm{~min}$ at $1,000 \times g$, and re-suspended in FSW to give a final density of $1 \times 10^{6}$ cells $\mathrm{mL}^{-1}$. The samples were then dye-loaded and analysed as before, while maintaining them under their experimental conditions.

To quantify the $\mathrm{pH}_{\mathrm{i}}$ of host cells, individual anemones ( $n=10$ per treatment) were exposed to light and dark as described above, before intact endodermal cells were isolated using the enzymatic maceration procedure described by Gates and Muscatine (1992). The cells were loaded with $10 \mu \mathrm{M}$ of the cell-permeant acetoxymethyl ester acetate of
SNARF-4F, in the presence of $0.01 \%$ Pluronic F-127 for $20 \mathrm{~min}$, before being pipetted onto poly-D-lysine glass culture dishes and transferred to the confocal microscope (Fluoview 1000, Olympus, Pennsylvania, USA), where they were analysed via the method of Venn et al. (2009). SNARF has previously been used in coral endodermal cells (Venn et al. 2009) and provides a higher resolution than does BCECF-AM; it could be used on this occasion due to the lack of interference from chlorophyll autofluorescence in animal cells lacking symbionts. Detailed information of the in vivo calibration is provided in ESM S2.

\section{Results and discussion}

The $\mathrm{pH}_{\mathrm{i}}$ of freshly isolated Symbiodinium cells and $A$. pulchella host cells was $7.10 \pm 0.02$ and $6.86 \pm 0.04$ (mean $\pm \mathrm{SE}$ ) in the dark, increasing significantly (two-way ANOVA, $\left.F_{1,51}=12.219, p=0.001\right)$ to $7.25 \pm 0.01$ and $7.02 \pm 0.06$ in the light, respectively. Both the host cell and the symbiont responded in the same manner to irradiance $\left(F_{1,51}=0.064, p>0.05\right)$, though the $\mathrm{pH}_{\mathrm{i}}$ of the host cell was significantly lower than that of the symbiont at all times $\left(F_{1,51}=26.325, p<0.0001\right)$.

In the cultured Symbiodinium cells, genotypic differences in $\mathrm{pH}_{\mathrm{i}}$ were apparent irrespective of the light/dark regime (two-way ANOVA, $F_{5,24}=2.896, p=0.035$ ). Post hoc analysis could not pinpoint where these genotypic differences lay (Tukey's HSD, $p>0.05$ for all comparisons), though, of note, types E2 and F1 generally had the lowest values in both the light and dark (Table 1). Light again significantly enhanced $\mathrm{pH}_{\mathrm{i}}\left(F_{1,24}=73.784, p<0.0001\right)$, with a similar response witnessed in all Symbiodinium types $\left(F_{5,24}=1.192, p=0.343\right)$.

Our study provides valuable information on $\mathrm{pH}_{\mathrm{i}}$ in $A$. pulchella, an important model system for the study of the cnidarian-dinoflagellate symbiosis (Weis et al. 2008). However, more importantly, we describe a method for measuring $\mathrm{pH}_{\mathrm{i}}$ in Symbiodinium and show genotypic diversity in this parameter. While this method provides resolution at the level of the whole cell rather than the specifics of the intra-cellular environment, it enables the rapid measurement of large numbers of cells simultaneously.

The $\mathrm{pH}_{\mathrm{i}}$ values quantified in this study fall within those expected for eukaryotic cells, which typically maintain their cytosolic pH between 7 and 7.4 (Madshus 1988), and are similar to light-adapted $\mathrm{pH}_{\mathrm{i}}$ values measured in other marine algae (Lane and Burris 1981). Furthermore, the more alkaline $\mathrm{pH}_{\mathrm{i}}$ of Symbiodinium seen in the light than in the dark was consistent with the effect of light observed in higher plants (Yin et al. 1990). Light-induced alkalinisation is likely a by-product of physiological changes in the Symbiodinium cell's cytoplasm during photosynthesis. In 
particular, $\mathrm{CO}_{2}$ and $\mathrm{H}_{2} \mathrm{O}$ exist in equilibrium with carbonic acid $\left(\mathrm{H}_{2} \mathrm{CO}_{3}\right)$, so when $\mathrm{CO}_{2}$ is removed for photosynthesis, it causes an increase in the conversion of bicarbonate $\left(\mathrm{HCO}_{3}{ }^{-}\right)$to $\mathrm{H}_{2} \mathrm{CO}_{3}$, a process that consumes protons $\left(\mathrm{H}^{+}\right)$ (Allemand et al. 1998). Conversely, the subsequent reduction of $\mathrm{pH}_{\mathrm{i}}$ in the dark is likely to be a consequence of respiration, as the products, $\mathrm{CO}_{2}$ and $\mathrm{H}_{2} \mathrm{O}$, react to form $\mathrm{HCO}_{3}{ }^{-}$and $\mathrm{H}^{+}$. It is therefore perhaps unsurprising that the $\mathrm{pH}_{\mathrm{i}}$ of Symbiodinium cells, the sites of photosynthesis in the symbiosis, is higher than that of the surrounding host cell in the light. Why this pattern is also present in the dark, however, is at present unclear. One possibility is that dark aerobic respiration may be greater in the host cell than the symbiont, resulting in a build-up of $\mathrm{CO}_{2}$ in the cell and thus reducing $\mathrm{pH}_{\mathrm{i}}$. Alternatively, the higher $\mathrm{pH}_{\mathrm{i}}$ of the symbiont in the dark could be a consequence of residual dark or heterotrophic $\mathrm{CO}_{2}$ fixation. Interestingly, the $\mathrm{pH}_{\mathrm{i}}$ in the $A$. pulchella host cell mirrored the light-response seen in the symbiont. This has also been observed in host cells of the coral Stylophora pistillata and the anemone Anemonia viridis (Venn et al. 2009), highlighting the inter-relationship between symbiont and host physiology. Indeed, recent research suggests that the $\mathrm{pH}$ of the host cell is directly dependent on the photosynthetic activity of its algal symbiont, and, as such, any factor that either inhibits or enhances photosynthesis (e.g. irradiance) has the capability to influence the $\mathrm{pH}$ of the host cell (Laurent et al. 2012).

The physiological and genetic diversity within the genus Symbiodinium is now well known, though most studies have focused on photophysiological responses to environmental stresses (Fisher et al. 2012). We can now extend this physiological diversity to the $\mathrm{pH}_{\mathrm{i}}$. The basis for this difference is unknown as, while it might be expected that differences in photosynthetic performance and/or efficiency (Hennige et al. 2009) could lead to a difference in $\mathrm{pH}_{\mathrm{i}}$ in the light, we found that genotypic differences were also maintained in the dark. Further research is needed to elucidate this matter, however, both in the Symbiodinium types tested here and across a wider range of types. Moreover, the implications of this physiological diversity for symbiosis function warrant investigation.

The methods and findings in our study build on the important work of Venn and co-workers (Venn et al. 2009), by providing a means of studying both partners in this ecologically important symbiosis, and addressing the many questions surrounding carbon transport (Brownlee 2009) and how the symbiosis may be impacted by the increasing global threat of ocean acidification.

Acknowledgments This work was funded by a Commonwealth PhD Scholarship to EMG. We thank Prof. Kevin Gould for his comments on an earlier draft of this paper, Thomas Hawkins for help with confocal microscopy, Shaun Wilkinson for assistance with statistical analysis, and Thomas Krueger for the identification of Symbiodinium types.

\section{References}

Allemand D, Furla P, Tambutté SB (1998) Mechanisms of carbon acquisition for endosymbiont photosynthesis in Anthozoa. Botany 76:925

Baker AC, Starger CJ, McClanahan TR, Glynn PW (2004) Coral reefs: corals' adaptive response to climate change. Nature 430:741

Bright G, Fisher G, Rogowska J, Taylor D (1989) Fluorescence ratio imaging microscopy. Methods Cell Biol 30:157-192

Brownlee C (2009) pH regulation in symbiotic anemones and corals: a delicate balancing act. Proc Natl Acad Sci USA 106:16541-16542

Casey JR, Grinstein S, Orlowski J (2009) Sensors and regulators of intracellular pH. Nat Rev Mol Cell Bio 11:50-61

Davy SK, Allemand D, Weis VM (2012) Cell biology of cnidariandinoflagellate symbiosis. Microbiol Mol Biol Rev 76:229-261

Fisher P, Malme M, Dove S (2012) The effect of temperature stress on coral' Symbiodinium associations containing distinct symbiont types. Coral Reefs:1-13

Fitt WK, Rees TAV, Yellowlees D (1995) Relationship between $\mathrm{pH}$ and the availability of dissolved inorganic nitrogen in the zooxanthellagiant clam symbiosis. Limnol Oceanogr 40:976-982

Franck P, Petitipain N, Cherlet M, Dardennes M, Maachi F, Schutz B, Poisson L, Nabet P (1996) Measurement of intracellular pH in cultured cells by flow cytometry with BCECF-AM. J Biotechnol 46:187-195

Gates RD, Muscatine L (1992) Three methods for isolating viable anthozoan endoderm cells with their intracellular symbiotic dinoflagellates. Coral Reefs 11:143-145

Hennige S, Suggett D, Warner M, McDougall K, Smith D (2009) Photobiology of Symbiodinium revisited: bio-physical and biooptical signatures. Coral Reefs 28:179-195

Hoegh-Guldberg O (1999) Climate change, coral bleaching and the future of the world's coral reefs. Mar Freshw Res 50: 839-866

Kazandjian A, Shepherd VA, Rodriguez-Lanetty M, Nordemeier W, Larkum AW, Quinnell RG (2008) Isolation of symbiosomes and the symbiosome membrane complex from the zoanthid Zoanthus robustus. Phycologia 47:294-306

Lane AE, Burris JE (1981) Effects of environmental pH on the internal $\mathrm{pH}$ of Chlorella pyrenoidosa, Scenedesmus quadricau$d a$, and Euglena mutabilis. Plant Physiol 68:439-442

Laurent J, Tambutté S, Tambutté E, Allemand D, Venn A (2012) The influence of photosynthesis on host intracellular $\mathrm{pH}$ in scleractinian corals. J Exp Biol. doi: 10.1242/jeb.082081

Madshus IH (1988) Regulation of intracellular pH in eukaryotic cells. Biochem J 250:1

Ozkan P, Mutharasan R (2002) A rapid method for measuring intracellular pH using BCECF-AM. Biochim Biophys Acta 1572: $143-148$

Pochon X, Gates RD (2010) A new Symbiodinium clade (Dinophyceae) from soritid foraminifera in Hawai'i. Mol Phylogenet Evol 56:492-497

Stat M, Morris E, Gates RD (2008) Functional diversity in coraldinoflagellate symbiosis. Proc Natl Acad Sci USA 105:9256-9261

Venn AA, Tambutté E, Lotto S, Zoccola D, Allemand D, Tambutté S (2009) Imaging intracellular $\mathrm{pH}$ in a reef coral and symbiotic anemone. Proc Natl Acad Sci USA 106:16574-16579

Venn AA, Tambutté E, Holcomb M, Laurent J, Allemand D, Tambutté S (2012) Impact of seawater acidification on $\mathrm{pH}$ at the 
tissue-skeleton interface and calcification in reef corals. Proc Natl Acad Sci USA 110:1634-1639

Weinlich M, Theiss C, Lin C, Kinne R (1998) BCECF in single cultured cells: inhomogeneous distribution but homogeneous response. J Exp Biol 201:57-62
Weis VM, Davy SK, Hoegh-Guldberg O, Rodriguez-Lanetty M, Pringe JR (2008) Cell biology in model systems as the key to understanding corals. TREE 23:369-376

Yin Z-H, Neimanis S, Wagner U, Heber U (1990) Light-dependent $\mathrm{pH}$ changes in leaves of C3 plants. Planta 182:244-252 



\title{
Intracellular $\mathrm{pH}$ and its response to $\mathrm{CO}_{2}$-driven seawater acidification in symbiotic versus non-symbiotic coral cells
}

\author{
Emma M. Gibbin ${ }^{1}$, Hollie M. Putnam², Simon K. Davy ${ }^{1, *}$ and Ruth D. Gates ${ }^{2}$
}

\begin{abstract}
Regulating intracellular $\mathrm{pH}\left(\mathrm{pH}_{\mathrm{i}}\right)$ is critical for optimising the metabolic activity of corals, yet the mechanisms involved in $\mathrm{pH}$ regulation and the buffering capacity within coral cells are not well understood. Our study investigated how the presence of symbiotic dinoflagellates affects the response of $\mathrm{pH}_{\mathrm{i}}$ to $P_{\mathrm{CO}_{2}}$-driven seawater acidification in cells isolated from Pocillopora damicornis. Using the fluorescent dye BCECF-AM, in conjunction with confocal microscopy, we simultaneously characterised the $\mathrm{pH}_{\mathrm{i}}$ response in host coral cells and their dinoflagellate symbionts, in symbiotic and non-symbiotic states under saturating light, with and without the photosynthetic inhibitor DCMU. Each treatment was run under control $(\mathrm{pH} 7.8)$ and $\mathrm{CO}_{2-}$ acidified seawater conditions (decreasing $\mathrm{pH}$ from 7.8 to 6.8). After 105 min of $\mathrm{CO}_{2}$ addition, by which time the external $\mathrm{pH}\left(\mathrm{pH}_{\mathrm{e}}\right)$ had declined to 6.8 , the dinoflagellate symbionts had increased their $\mathrm{pH}_{\mathrm{i}}$ by $0.5 \mathrm{pH}$ units above control levels when in the absence of DCMU. In contrast, in both symbiotic and non-symbiotic host coral cells, 15 min of $\mathrm{CO}_{2}$ addition $\left(0.2 \mathrm{pH}\right.$ unit drop in $\mathrm{pH}_{\mathrm{e}}$ ) led to cytoplasmic acidosis equivalent to $0.3-0.4 \mathrm{pH}$ units irrespective of whether DCMU was present. Despite further seawater acidification over the duration of the experiment, the $\mathrm{pH}_{\mathrm{i}}$ of non-symbiotic coral cells did not change, though in host cells containing a symbiont cell the $\mathrm{pH}_{\mathrm{i}}$ recovered to control levels when photsynthesis was not inhibited. This recovery was negated when cells were incubated with DCMU. Our results reveal that photosynthetic activity of the endosymbiont is tightly coupled with the ability of the host cell to recover from cellular acidosis after exposure to high $\mathrm{CO}_{2} /$ low $\mathrm{pH}$.
\end{abstract}

KEY WORDS: Symbiodinium, Acidosis, Climate change

\section{INTRODUCTION}

Reef-building corals depend on a symbiotic association with photosynthetic dinoflagellates of the genus Symbiodinium for survival. This intimate partnership evolved in the mid-Triassic period (Muscatine et al., 2005) and coral reefs have prospered in tropical oceans, particularly in areas characterised by high degrees of environmental stability (Hoegh-Guldberg, 1999). Consequently, corals have adapted to live within narrow physiological limits, and are highly sensitive to fluctuations in the surrounding environment (Jones et al., 1998). Rising sea surface temperatures (HoeghGuldberg et al., 2007) and the increasing acidity of the ocean (Orr et al., 2005) are threatening the stability of coral-dinoflagellate symbioses, leading to dire projections for the future of coral reefs (Pandolfi et al., 2011; Silverman et al., 2009). At present, our ability

${ }^{1}$ School of Biological Sciences, Victoria University of Wellington, Kelburn Parade, Wellington 6140, New Zealand. ${ }^{2}$ Hawaii Institute of Marine Biology, University of Hawaii, PO Box 1346, Kaneohe, HI 96744, USA

*Author for correspondence (simon.davy@vuw.ac.nz)

Received 4 November 2013; Accepted 3 March 2014 to accurately predict the response of corals to global climate change is severely hampered by our limited understanding of the cellular mechanisms that underpin coral-dinoflagellate symbiosis (Fabry et al., 2008; Weis et al., 2008; Davy et al., 2012), which ultimately frame how corals respond to environmental stress.

Intracellular $\mathrm{pH}\left(\mathrm{pH}_{\mathrm{i}}\right)$ is crucial for virtually all elements of cellular homeostasis (Smith and Raven, 1979), directly influencing protein structure, enzymatic rates and membrane solubility (Madshus, 1988). The maintenance of $\mathrm{pH}$ within an optimal functional range therefore plays a critical role in determining the metabolic activity of the cell, and is specific to the metabolic pathway in question. Thus, eukaryotic cells have evolved compartmentalised organelles to provide sites with specific $\mathrm{pH}$ conditions within the cell for different metabolic activities to occur (Casey et al., 2010). Disruption of $\mathrm{pH}_{\mathrm{i}}$ has serious physiological consequences (Pörtner et al., 2004; Fabry et al., 2008; Hofmann et al., 2013). Indeed, a drop as small as $0.1-0.2 \mathrm{pH}_{\mathrm{i}}$ units can induce metabolic depression (Reipschläger and Pörtner, 1996), so it is not surprising that changes in $\mathrm{pH}_{\mathrm{i}}$ are stringently avoided (Casey et al., 2010). In general, eukaryotic cells are protected from fluctuations in their $\mathrm{pH}_{\mathrm{i}}$ at two levels. Acute, localised changes in $\mathrm{pH}_{\mathrm{i}}$, such as those arising from metabolic reactions, are neutralised by manipulating the various weak acids and bases in the cytosol (Casey et al., 2010). Longer-term changes are buffered by more permanent mechanisms such as transmembrane exchangers (Boron, 2004). The mechanisms involved in $\mathrm{pH}$ regulation are not well understood in corals, and this is partly due to the intrinsic complexity associated with their endosymbiosis. By virtue of their intracellular location, the Symbiodinium cells can essentially be regarded as heavily fortified organelles belonging to the coral host cell. However, unlike other organelles, Symbiodinium cells, through their photosynthetic activity, are able to exert significant control over the $\mathrm{pH}$ of the host cell (Venn et al., 2009; Laurent et al., 2013). Consequently, the response of corals to a change in ambient $\mathrm{CO}_{2} / \mathrm{pH}$ is likely to be influenced by their own physiological capacity and that of their symbionts (McCulloch et al., 2012).

Here, we investigated how the presence/absence of symbionts affects the response of $\mathrm{pH}_{\mathrm{i}}$ to $\mathrm{CO}_{2}$-driven seawater acidification in cells isolated from the Hawaiian reef coral Pocillopora damicornis (Linnaeus 1758). Using the fluorescent dye BCECF-AM, in conjunction with live cell imaging, we characterised the response of $\mathrm{pH}_{\mathrm{i}}$ (NBS scale) in Symbiodinium cells freshly isolated from coral hosts, isolated non-symbiotic coral cells, and isolated coral host cells with their symbionts enclosed. The cells were exposed to control seawater ( $\mathrm{pH} 7.8$ ) and $\mathrm{CO}_{2}$-acidified seawater, designed to expose the cells to a gradient of declining external $\mathrm{pH}\left(\mathrm{pH}_{\mathrm{e}} 7.8-6.8\right)$ over a 105 min period, to mimic diurnal changes in $\mathrm{pH}$ in reef water due to reef photosynthesis, respiration and calcification (Hofmann et al., 2011; Price et al., 2012), which are particularly strong in Kaneohe Bay, Hawaii (Putnam, 2012). In both treatments, the cells were exposed to saturating white light in the presence and absence of the 


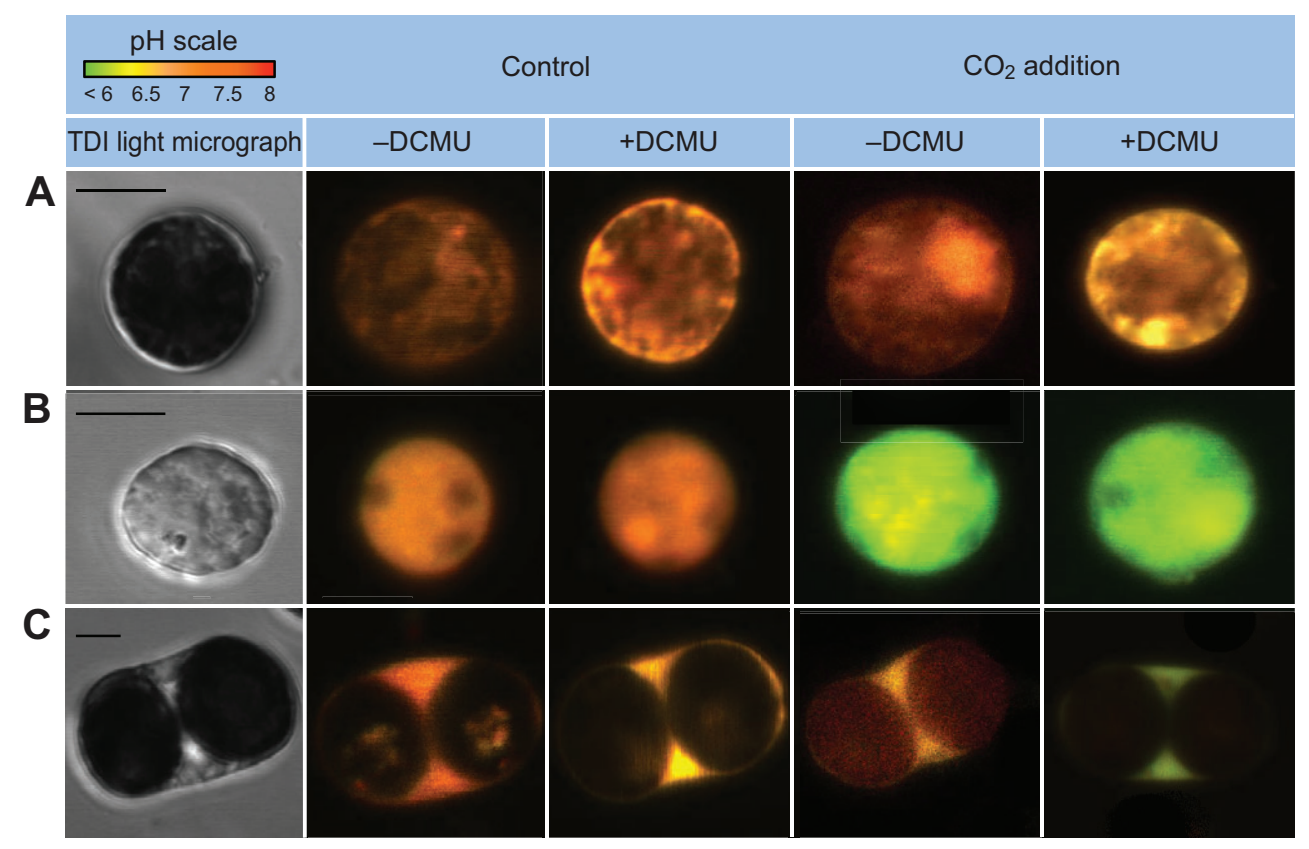

Fig. 1. Light and confocal microscopy images of host Pocillopora damicornis cells and Symbiodinium cells. The pH-sensitive dye BCECF-AM ester was used to monitor intracellular $\mathrm{pH}\left(\mathrm{pH}_{\mathrm{i}}\right)$ of cells isolated from $P$. damicornis after $105 \mathrm{~min}$ of exposure to either control $\mathrm{pH}$ conditions (left) or increasing $\mathrm{CO}_{2}$ (right). (A-C) Symbiotic state of the cell: (A) Symbiodinium freshly isolated from host coral cell; (B) isolated non-symbiotic host coral cell; and (C) isolated host coral cell containing two symbiotic algae. The columns show the time-delayed integration (TDI) light micrograph and images from the different treatments (from left to right): control conditions ( $\mathrm{pH} 7.8$ ) in the absence of the photosynthetic inhibitor DCMU (-DCMU); control conditions (pH 7.8) in the presence of DCMU (+DCMU); increasing $\mathrm{CO}_{2}(\mathrm{pH} 6.8)$ in the absence of DCMU (-DCMU); and increasing $\mathrm{CO}_{2}(\mathrm{pH} 6.8)$ in the presence of DCMU (+DCMU). All experiments were conducted under saturating $\left(400 \mu \mathrm{mol}\right.$ photons $\left.\mathrm{m}^{-2} \mathrm{~s}^{-1}\right)$ photosynthetically active radiation (PAR). Scale bars represent $5 \mu \mathrm{m}$.

photosynthetic inhibitor DCMU, with measurements of both $\mathrm{pH}_{\mathrm{i}}$ and $\mathrm{pH}_{\mathrm{e}}$ taken every $15 \mathrm{~min}$. Our findings demonstrate that $\mathrm{CO}_{2}$ addition initiates a very different response in the $\mathrm{pH}_{\mathrm{i}}$ of the symbiont compared with that of the coral host cell. Crucially, we show that the photosynthetic activity of the symbiont plays a key role in determining the intracellular buffering capacity of its coral host cell to changes in $\mathrm{pH}_{\mathrm{e}}$.

\section{RESULTS}

We analysed the relative change in $\mathrm{pH}_{\mathrm{i}}$ (calculated as the $\mathrm{pH}_{\mathrm{i}}$ after acidification minus the mean control $\mathrm{pH}_{\mathrm{i}}$ ) in three symbiotic states - Symbiodinium cells freshly isolated from coral hosts, isolated nonsymbiotic coral cells, and isolated coral host cells with their symbionts enclosed (Fig. 1) - across a gradient of $\mathrm{pH}_{\mathrm{e}}$ under light, in the presence and absence of the photosynthetic inhibitor DCMU (Fig. 2). Actual changes in $\mathrm{pH}$ are provided in supplementary material Fig. S1. Initial analysis of the dataset confirmed that there was a significant interaction between external $\mathrm{pH} \times$ symbiotic state $\times$ DCMU treatment [repeated measures (rm)ANOVA, $\left.F_{15.03,160.34}=4.60, P<0.001\right]$, so subsequent analyses were carried out on the two separate treatments (no DCMU and DCMU added). The response of $\mathrm{pH}_{\mathrm{i}}$ to $\mathrm{pH}_{\mathrm{e}}$ was dependent on the symbiotic state of the cell in both the presence (rmANOVA, $F_{14.23,75.87}=7.51, P<0.001$ ) and absence of DCMU (rmANOVA, $F_{11.15,59.4}=14.80, P<0.001$ ). Subsequent post hoc analyses revealed where the differences in the response of $\mathrm{pH}_{\mathrm{i}}$ to acidification lay (Table 1).

The disparities in $\mathrm{pH}_{\mathrm{i}}$ were driven primarily by the opposing reactions of the host coral cells and the algal cells to acidification. Within $15 \mathrm{~min}$ of $\mathrm{CO}_{2}$ addition, the $\mathrm{pH}_{\mathrm{i}}$ of both the isolated symbiotic and non-symbiotic host coral cells decreased by $0.3-$ $0.4 \mathrm{pH}$ units, irrespective of whether DCMU was present (Fig. 2). Following this initial drop, the response of $\mathrm{pH}_{\mathrm{i}}$ to further acidification was dependent on the symbiotic state of the host cell, and the DCMU treatment it was exposed to. There was no change in the $\mathrm{pH}_{\mathrm{i}}$ of the non-symbiotic host cell in either treatment (Fig. 2). Similarly, there was no change in the $\mathrm{pH}_{\mathrm{i}}$ of the symbiotic host cell in the presence of DCMU (Fig. 2B). In contrast, without DCMU, the $\mathrm{pH}_{\mathrm{i}}$ of the host cell increased over time when in symbiosis with its dinoflagellate partner, returning to control levels within $75 \mathrm{~min}$ (when the $\mathrm{pH}_{\mathrm{e}}$ reached $\mathrm{pH}$ 7). The response of the $\mathrm{pH}_{\mathrm{i}}$ of the dinoflagellate symbiont to the addition of $\mathrm{CO}_{2}$ differed between the DCMU treatments (Fig. 2), irrespective of whether the alga was in isolation or in symbiosis (Table 1). In the presence of DCMU there was no change in the $\mathrm{pH}_{\mathrm{i}}$ of either the isolated or symbiotic algae (Fig. 2B), whereas without DCMU both the isolated and symbiotic algae were able to increase their $\mathrm{pH}_{\mathrm{i}}$ relative to control levels (Fig. 2A).

\section{DISCUSSION}

Understanding the coral-dinoflagellate symbiosis is pivotal to accurately predicting the susceptibility of coral reefs to climate change and ocean acidification (Weis et al., 2008; Davy et al., 2012). Recent ecological research suggests that the symbiotic state may play a critical role in determining a coral's capacity to tolerate changes in seawater chemistry (Ohki et al., 2013). It is well established that photosynthesis in the dinoflagellate symbiont enhances host coral calcification rates in the light (Allemand et al., 2004). At the cellular level, however, a more important role may be the ability of the symbiont to manipulate aspects of the host's physiology, such as cellular pH (Venn et al., 2009; Laurent et al., 2013). As yet, no study has investigated how this relationship will be impacted by acidification. We addressed this knowledge gap by simultaneously quantifying $\mathrm{pH}_{\mathrm{i}}$ in both partners of the symbiosis in response to $\mathrm{CO}_{2}$ addition. Our experimental design exposed isolated 


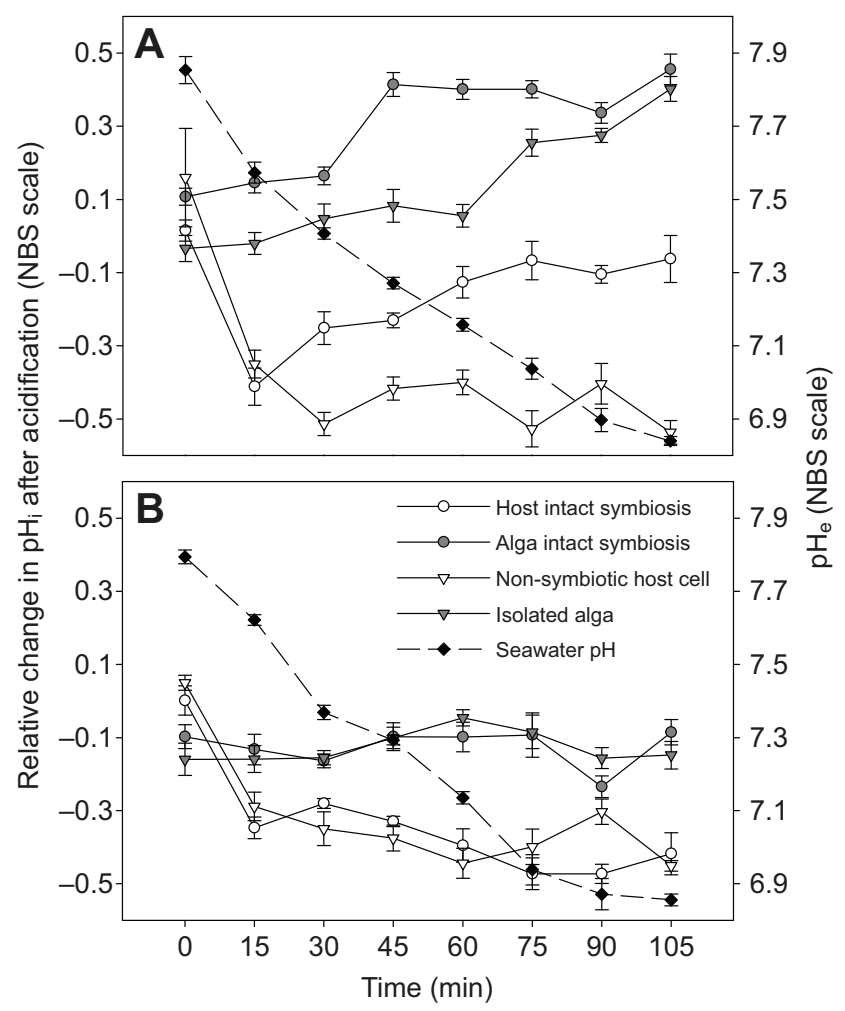

Fig. 2. The impact of $\mathrm{CO}_{2}$ addition on $\mathrm{pH}_{\mathrm{i}}$ in $P$. damicornis cells and Symbiodinium cells. The figure shows the relative change in $\mathrm{pH}_{\mathrm{i}}$ after acidification (the $\mathrm{pH}_{\mathrm{i}}$ value after acidification minus the mean $\mathrm{pH}_{\mathrm{i}}$ of the control at each time point, means \pm s.e.m., $N=5$ ) under two treatments: (A) saturating white $400 \mu \mathrm{mol}$ photons $\mathrm{m}^{-2} \mathrm{~s}^{-1} \mathrm{PAR}$; (B) saturating white $400 \mu \mathrm{mol}$ photons $\mathrm{m}^{-2} \mathrm{~s}^{-1}$ PAR in the presence of the photosynthetic inhibitor DCMU Data are shown for Symbiodinium freshly isolated from the host coral cell; the isolated non-symbiotic host coral cell; and the isolated host coral cell and its symbiotic algae. The dashed line plotted on the secondary $y$-axis represents the $\mathrm{pH}$ of the surrounding medium (external $\mathrm{pH}, \mathrm{pH}_{\mathrm{e}}$ ) at each time point $(N=5)$.

cells to a wide range of $\mathrm{pH}_{e}$, at levels of $\mathrm{CO}_{2}$ much greater than those predicted to arise from ocean acidification. These treatments were not designed to replicate climate change scenarios but rather to provide a means of determining how the symbiotic state influences the recovery of its coral host cell under induced cellular acidosis. Our results reveal that the photosynthetic activity of the symbiont increases the ability of the host cell to recover from cellular acidosis after exposure to high $\mathrm{CO}_{2} /$ low $\mathrm{pH}$. The responses seen in the various symbiotic states are summarised in Fig. 3 and are discussed in more detail here.

$\mathrm{CO}_{2}$ and $\mathrm{H}_{2} \mathrm{O}$ exist in equilibrium with carbonic acid $\left(\mathrm{H}_{2} \mathrm{CO}_{3}\right)$, so when $\mathrm{CO}_{2}$ is removed for photosynthesis it causes an increase in the conversion of bicarbonate $\left(\mathrm{HCO}_{3}^{-}\right)$to $\mathrm{H}_{2} \mathrm{CO}_{3}$, a process that consumes protons $\left(\mathrm{H}^{+}\right)$(Allemand et al., 1998). Conversely, an increase in $\mathrm{CO}_{2}$ will reverse the process, resulting in the production of $\mathrm{H}^{+}$and leading to cellular acidosis. The $\mathrm{pH}_{\mathrm{i}}$ of freshly isolated Symbiodinium cells is therefore strongly influenced by the availability of $\mathrm{CO}_{2}$ in the surrounding seawater (Nimer et al., 1999) (Fig. 3A). Our results clearly show that, upon $\mathrm{CO}_{2}$ addition, Symbiodinium cells are able to increase their $\mathrm{pH}_{\mathrm{i}}$ relative to the control, by up to $0.5 \mathrm{pH}$ units. This alkalinisation demonstrates the capacity of Symbiodinium cells to strongly buffer the external environmental $\mathrm{pH}$ signal, probably due to a fertilising effect on photosynthesis in these normally $\mathrm{CO}_{2}$-limited algae (Nimer et al., 1999). An increase in photosynthetic productivity after $\mathrm{CO}_{2}$ addition has also been observed in other symbiotic associations, most notably in the temperate sea anemones Anemonia viridis (Suggett et al., 2012) and Anthopleura elegantissima (Towanda and Thuesen, 2012), and the benthic foraminiferan Marginopora vertebralis (Uthicke and Fabricius, 2012). The application of DCMU (a photosynthetic inhibitor) reversed the increase in $\mathrm{pH}_{\mathrm{i}}$, confirming that the change was a direct consequence of photosynthesis, as the inhibited photosynthetic machinery of the symbionts is not able to ameliorate the increasing $\mathrm{H}^{+}$concentration (Fig. 3A).

$\mathrm{CO}_{2}$ supplementation initiated a markedly different response in the host coral cells compared with the symbiont. In the host cells, acidosis of the cytoplasm was observed within $15 \mathrm{~min}$ of $\mathrm{CO}_{2}$ addition, with a decline in $\mathrm{pH}_{\mathrm{e}}$ of $0.2 \mathrm{pH}$ units causing the $\mathrm{pH}_{\mathrm{i}}$ to fall $0.3-0.4 \mathrm{pH}$ units below the usual $\mathrm{pH}$ of the cell, irrespective of the presence or absence of DCMU and the symbiotic state of the cell (Fig. 3B). This strongly suggests that the host's intrinsic buffering capacity is, initially at least, overwhelmed by the accumulation of protons resulting from the passive diffusion of $\mathrm{CO}_{2}$, and active transport of $\mathrm{HCO}_{3}{ }^{-}$into the cell (Furla et al., 2000), which drives the

Table 1. Post hoc results of paired $t$-tests following rmANOVA, showing the effect of symbiotic state $\times$ external $\mathrm{pH}_{\text {on }} \mathrm{pH}$ point

\begin{tabular}{|c|c|c|c|c|c|c|c|c|c|}
\hline \multirow[b]{2}{*}{ Treatment } & \multirow[b]{2}{*}{ Pair } & \multicolumn{8}{|c|}{$P$-value } \\
\hline & & $0 \min$ & $15 \min$ & $30 \mathrm{~min}$ & $45 \mathrm{~min}$ & $60 \mathrm{~min}$ & $75 \mathrm{~min}$ & $90 \mathrm{~min}$ & $105 \mathrm{~min}$ \\
\hline \multirow[t]{4}{*}{ Light (-DCMU) } & 1 & - & - & - & - & * & * & * & * \\
\hline & 4 & - & * & * & * & - & * & * & * \\
\hline & 5 & - & * & * & * & * & * & * & * \\
\hline & 6 & - & - & - & * & * & - & - & - \\
\hline & 3 & - & - & - & * & * & - & - & * \\
\hline & 4 & - & - & - & * & * & * & * & - \\
\hline & 5 & - & - & - & * & * & * & * & * \\
\hline & 6 & - & - & - & - & - & - & - & - \\
\hline
\end{tabular}

Asterisks indicate a significant interaction between the paired cell types $(P<0.001)$. Pairs are as follows: 1 , non-symbiotic coral cell versus symbiotic coral cell; 2 , non-symbiotic coral cell versus isolated algal cell; 3 , non-symbiotic coral cell versus symbiotic algal cell; 4 , symbiotic coral cell versus isolated algal cell; 5 , symbiotic coral cell versus symbiotic algal cell; and 6 , symbiotic algal cell versus isolated algal cell. Only Bonferroni-corrected significant interactions ( $\alpha=0.001)$ are included. 


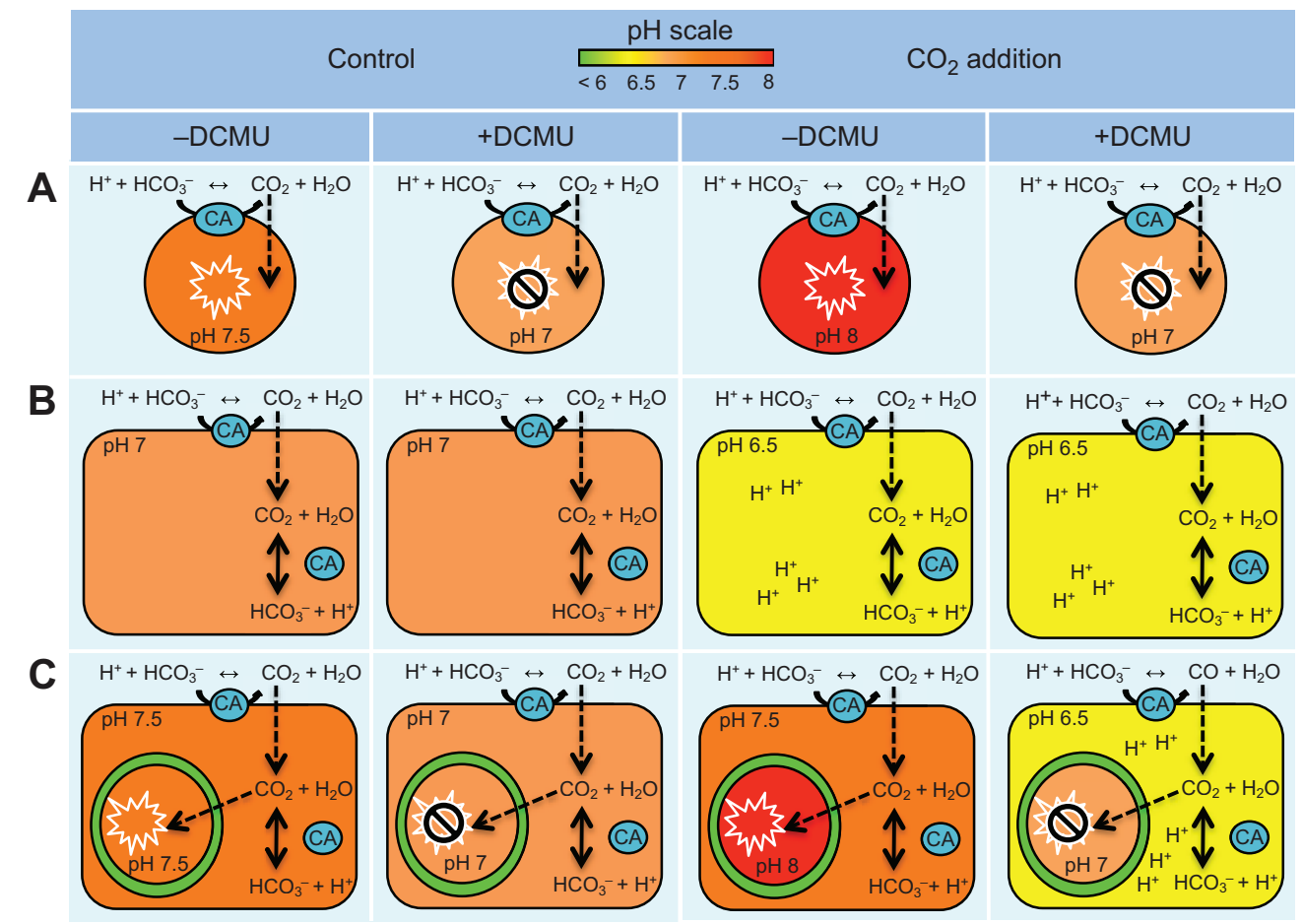

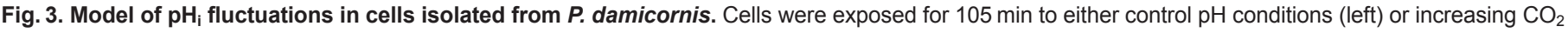
(right) according to the state of the equilibrium reaction that exists between $\mathrm{CO}_{2}+\mathrm{H}_{2} \mathrm{O} \leftrightarrow \mathrm{H}_{2} \mathrm{CO}_{3} \leftrightarrow \mathrm{HCO}_{3}{ }^{-}+\mathrm{H}^{+}$. (A-C) Symbiotic state of the cell: (A)

Symbiodinium freshly isolated from host coral cell; $(B)$ isolated non-symbiotic host coral cell; and (C) host coral cell containing symbiotic algae. The columns show the different treatments (from left to right): control conditions ( $\mathrm{pH} 7.8$ ) in the absence of the photosynthetic inhibitor DCMU (-DCMU); control conditions $(\mathrm{pH} 7.8)$ in the presence of DCMU (+DCMU); increasing $\mathrm{CO}_{2}(\mathrm{pH} 6.8)$ in the absence of DCMU (-DCMU); and increasing CO 2 (pH 6.8) in the presence of $\mathrm{DCMU}(+\mathrm{DCMU})$. All experiments were conducted under saturating $\left(400 \mu \mathrm{mol}\right.$ photons $\left.\mathrm{m}^{-2} \mathrm{~s}^{-1}\right) \mathrm{PAR}$. Dashed arrows show passive $\mathrm{CO}_{2}$ diffusion. Sunburst symbol represents photosynthetic processes and CA represents carbonic anhydrase. Colours indicate $\mathrm{pH}$ as identified in the colour gradient above. With increasing seawater $\mathrm{CO}_{2}$ there is a shift in carbonate chemistry equilibrium, leading to an accumulation of internal $\mathrm{H}^{+}$in the absence of photosynthesis. Note that for simplicity not all active inorganic carbon uptake pathways are shown.

aforementioned equilibrium reaction. The decline in $\mathrm{pH}_{\mathrm{i}}$, however, was halted after $15 \mathrm{~min}$ in both the symbiotic and non-symbiotic host cells. It is likely that this represents a time lag between the onset of acidosis and the activation of the regulatory membrane transporters. Indeed, such activity could explain the subsequent stability ( $\sim \mathrm{pH} 6.6)$ of $\mathrm{pH}_{\mathrm{i}}$ in non-symbiotic host cells, which was achieved irrespective of the surrounding seawater being subject to further acidification. Nevertheless, the $\mathrm{pH}_{\mathrm{i}}$ of these non-symbiotic host cells never recovered to pre-acidosis levels. In contrast, the $\mathrm{pH}_{\mathrm{i}}$ of symbiotic host cells showed a full recovery to control $\mathrm{pH}$ levels within 105 min of $\mathrm{CO}_{2}$-addition (Fig. 3C). Again, this recovery was negated in the presence of DCMU, confirming that the photosynthetic removal of $\mathrm{CO}_{2}$ by the symbiont (and hence the consumption of protons) was responsible for the increase in the host's $\mathrm{pH}_{\mathrm{i}}$.

These results confirm that the symbiont is able to exert a significant level of control over its host's cellular $\mathrm{pH}$, corroborating the findings of previous research on reef corals (Laurent et al., 2013). Furthermore, they demonstrate that the photosynthetic activity of the symbionts plays a key role, at least in the short term, in regulating the cellular response of their host to external $\mathrm{CO}_{2}$ driven acidification. Perhaps more importantly, however, the inability of non-symbiotic or photosynthetically compromised symbiotic host cells to recover from cellular acidosis in the short term (at least under the experimental conditions used here) suggests that they may be more susceptible than are host cells that contain fully functional Symbiodinium cells. However, whether the cells have the potential for recovery in the longer term, especially under constant $\mathrm{pH}$, warrants further investigation. While some caution needs to be exercised when interpreting the results for the nonsymbiotic coral cells, as we cannot be sure of their precise origin (i.e. ectodermal or endodermal), it is notable that the symbiotic endodermal host cells responded in the same manner when photosynthesis was inhibited. This limited capacity to withstand acidosis in the absence of a functional symbiont could therefore be a general response. If this is the case, it raises the possibility that the number of Symbiodinium cells that a coral host cell contains may also influence the cellular response to acidification. In Stylophora pistillata, for example, the majority of host cells $(\sim 60 \%)$ typically contain one algal cell, while fewer contain two $(\sim 35 \%)$ or more $(<5 \%)$ (Houlbrèque et al., 2004). Given that we focused on host cells that harboured two algal symbionts only, there is a need for future studies that clarify the influence of symbiont number on $\mathrm{pH}_{\mathrm{i}}$, and the overall response at the organismal level.

The regulation of $\mathrm{pH}_{\mathrm{i}}$ in corals is an important area for future research as cellular acidosis has serious physiological repercussions for the fitness of the individual. At a biochemical level, acidosis disrupts ion transport, nutrient trafficking and carbon acquisition (Fabry et al., 2008), causing metabolic suppression (Pörtner et al., 2004) and inevitably leading to shortfalls in the energy available for other cellular processes (Reipschläger and Pörtner, 1996). In addition to these fundamental cellular attributes, regulating $\mathrm{pH}_{\mathrm{i}}$ is particularly important in reef-building corals for calcification. In the recently proposed 'proton flux hypothesis', Jokiel presented the first 
organism-scale model of acid-base balance in corals (Jokiel, 2011). The hydroxide ions $\left(\mathrm{OH}^{-}\right)$produced as an indirect by-product of $\mathrm{CO}_{2}$ removal (Furla et al., 2000) are proposed to play a critical role in calcification, neutralising protons released by $\mathrm{H}^{+} / \mathrm{Ca}^{2+}$ ion exchangers in the gastrovascular cavity, and thus facilitating a $\mathrm{pH}$ gradient high enough for the precipitation of $\mathrm{CaCO}_{3}$ (Jokiel, 2011; Comeau et al., 2013). Acidosis of the host coral cells could therefore place further chemical and energetic constraints on corals by affecting their ability to calcify (Jokiel, 2011; Venn et al., 2013). It remains to be seen whether a non-symbiotic host cell can reverse the changes in $\mathrm{pH}_{\mathrm{i}}$ over a longer time frame, though this might depend, in part, on its ability to upregulate the expression of membrane transporters (Kaniewska et al., 2012), as this will afford greater control over $\mathrm{pH}_{\mathrm{i}}$. Indeed, several organisms are able to reverse initial decreases in $\mathrm{pH}_{\mathrm{i}}$ (Michaelidis et al., 2005; Stumpp et al., 2012).

The ability of corals to respond to external $\mathrm{pH}$ change is likely to depend on the response of both the symbionts and coral host (McCulloch et al., 2012). There is considerable diversity within the genus Symbiodinium (Pochon and Gates, 2010), which translates into substantial genotypic differences in physiology (Tchernov et al., 2004; Hennige et al., 2009; Brading et al., 2011; Gibbin and Davy, 2013). Our experiment used genetically identical fragments from a single colony. This had two advantages: firstly, it minimised the baseline variation in host cellular activity; and secondly, it reduced the chances of sampling corals that contained very different Symbiodinium clades. However, future research should aim to determine whether the host and symbiont responses, and their relative abilities to buffer the effects of $\mathrm{CO}_{2}$-driven acidification, vary according to host and symbiont genotype. In addition, it will be important to determine whether the patterns we observed in isolated coral cells are replicated in intact coral tissues, and whether longer-term incubations at more moderate levels of acidification (i.e. predicted climate change scenarios) induce similar responses to those reported here. Nevertheless, our model system elucidates the interrelationship between symbiont photosynthesis and the capacity of host coral cells to withstand $\mathrm{CO}_{2}$-driven acidification. Moreover, our findings highlight the possibility that bleached corals may be more sensitive to cellular acidosis than are their non-bleached counterparts; this is an especially interesting topic for future research.

\section{MATERIALS AND METHODS}

\section{Coral collection and maintenance}

One large normally pigmented adult $P$. damicornis colony was collected 3 weeks prior to experimentation (in February 2013) from a shallow fringing reef $(<3 \mathrm{~m})$ in Kaneohe Bay, Hawaii. This single colony was cut into 50 genetically identical fragments $(4 \times 2 \mathrm{~cm})$ that were secured to $3 \times 3 \mathrm{~cm}$ plastic tiles with underwater expoxy (Z-spar, Splash Zone compound) and placed in a 501 holding tank supplied with flowing seawater from Kaneohe Bay. Seawater chemistry was monitored frequently according to the recommended best practices for ocean acidification research and reporting (Riebesell et al., 2010), with daily measurements of salinity (psu) as well as $\mathrm{pH}$ (NBS scale), taken via the $m$-Cresol dye method stipulated in SOP 6B (Dickson et al., 2007); total alkalinity (TA) was measured on a weekly basis (Dickson et al., 2007). These characteristics were stable for the duration of the experiment, with an average salinity of $35.5 \pm 0.1 \mathrm{ppt}$, $\mathrm{pH}$ of $7.8 \pm 0.1$ and a TA of $2166 \pm 25$ (means \pm s.e.m., $N=5$ ). It is important to note that the $P_{\mathrm{CO}_{2}}$ of seawater in Kaneohe Bay is markedly higher than average oceanic conditions (Drupp et al., 2011), resulting in a lower ambient $\mathrm{pH}$. An ambient seasonal temperature of $22.6 \pm 0.3^{\circ} \mathrm{C}$ was maintained by a dual-stage temperature controller (Aqualogic, TR115DN), while tanks were illuminated on a $12 \mathrm{~h}: 12 \mathrm{~h}$ light/dark cycle by metal halide lights (Ice CapMetal Halide lights, $250 \mathrm{~W}$ DE $14 \mathrm{~K}$ bulbs, $250 \mathrm{~W}$ double-ended pendants), which were mounted on motorised light rails and provided irradiances ranging between 3.85 and $328.85 \mu \mathrm{mol}$ photons $\mathrm{m}^{-2} \mathrm{~s}^{-1}$, corresponding to a mean irradiance of $125 \pm 10 \mu \mathrm{mol}$ photons $\mathrm{m}^{-2} \mathrm{~s}^{-1}$ over each coral fragment.

\section{Experimental design}

Four experimental treatments were designed to investigate how $\mathrm{CO}_{2}$ addition influenced $\mathrm{pH}_{\mathrm{i}}$ (NBS scale) in cells isolated from the coral $P$. damicornis. Three symbiotic states were tested: (1) isolated Symbiodinium cells; (2) isolated non-symbiotic host coral cells; and (3) isolated host coral cells containing their symbiotic algae (Fig. 1). Visual inspection (by both light and confocal microscopy) failed to establish conclusively whether isolated Symbiodinium cells were surrounded by an intact symbiosome membrane. Non-symbiotic host coral cells were classified as intact host cells not containing an algal symbiont. Typically $10 \mu \mathrm{m}$ in diameter and spherical, it is not known whether these cells were ectodermal or endodermal in origin (see Discussion). Finally, only symbiotic cells containing two algal cells were used for calculating the $\mathrm{pH}_{\mathrm{i}}$ change in symbiotic host coral cells. These were deemed the most suitable choice for two major reasons: (1) the host cell region of interest (ROI) is much larger in doublet cells than in host cells containing a single alga, making $\mathrm{pH}_{\mathrm{i}}$ measurements much easier (Venn et al., 2009); and (2) this cell type is found in much greater abundance than triplet cells (Houlbrèque et al., 2004). Furthermore, standardisation of symbiont number allowed for the possibility that this parameter influences host $\mathrm{pH}_{\mathrm{i}}$ (see Discussion).

The cell and dye loading procedure was repeated five times for each treatment $(N=5)$ to achieve independent replicate cell preparations. Individual cells were then imaged every 15 min for 105 min, with $\mathrm{pH}_{\mathrm{i}}$ calculated from the images taken. At each experimental time point, $1.5 \mathrm{ml}$ of seawater was carefully removed by pipette so as not to disrupt the cells and analysed for $\mathrm{pH}_{\mathrm{e}}(\mathrm{NBS}$ scale, $N=5)$ via the $m$-Cresol dye method described in SOP 6B (Dickson et al., 2007). The treatments were carried out under an external white light source, provided by a variable-irradiance fibre optic cable (Halogen Reflector lamp, 150 W GX5.3 21V 1CT bulb, Philips, Somerset, NJ, USA) that produced a saturating irradiance of $\sim 400 \mu \mathrm{mol}$ photons $\mathrm{m}^{-2} \mathrm{~s}^{-1}$ photosynthetically active radiation. Previous studies have shown that photosynthetic activity in the symbiont modifies the $\mathrm{pH}_{\mathrm{i}}$ of the host under normal $\mathrm{CO}_{2}$ conditions (Venn et al., 2009), so a preliminary measurement was performed with no additional $\mathrm{CO}_{2}$ added, in order to establish the control or baseline change in $\mathrm{pH}_{\mathrm{i}}$ caused by photosynthesis. This experimental run was then repeated with $\mathrm{CO}_{2}$ addition $(5.0 \%$ setting on the incubation unit of the LSM 710 confocal microscope, Carl Zeiss, Oberkochen, Germany), resulting in a decreasing gradient of $\mathrm{pH}_{\mathrm{e}}$ over time. The negative controls were run in the light, as before, under zero and high $\mathrm{CO}_{2}$ conditions, but in the presence of $100 \mu \mathrm{mol} \mathrm{l}^{-1}$ 3-(3-4-dichlorophenyl)1,1 -dimethylurea (DCMU) in $0.1 \%$ acetone, a photosynthetic inhibitor that blocks the plastiquinone binding site of photosystem II and thus prevents the transfer of electrons and formation of ATP. DCMU has been used extensively to study photosynthesis in Symbiodinium, as it effectively blocks photosynthesis without impairing cellular functioning (Iglesias-Prieto et al., 1992).

\section{Isolation of cells and dye-loading procedure}

Coral fragments were selected randomly from the acclimation tank before the start of each experimental run. Cells were isolated immediately by gently brushing the tip of a partially submerged fragment in $50 \mathrm{ml}$ of $0.22 \mu \mathrm{m}$ filtered seawater (FSW) using a soft bristle toothbrush. The resulting slurry was centrifuged for $5 \mathrm{~min}$ at $1700 \mathrm{~g}$. The supernatant was discarded and the pellet re-suspended in a further $50 \mathrm{ml} \mathrm{FSW}$. An additional centrifugation step was introduced to wash the pellet and remove any residual host-generated mucus. This time, when the supernatant was discarded, the pellet was resuspended in $1 \mathrm{ml} \mathrm{FSW}$ containing $10 \mu \mathrm{mol}^{-1}$ BCECF-AM ester and $0.01 \%$ Pluronic F-127 with/without $100 \mu \mathrm{mol}^{-1}$ DCMU and $0.1 \%$ acetone depending on the treatment in question, to give a final concentration of $\sim 1 \times 10^{6}$ cells ml $^{-1}$. The dye-loaded cell suspension was then transferred to a $35 \mathrm{~mm}$ poly-D-lysine-coated Petri dish (MatTek Corporation, Ashland, MA, USA) and placed on the stage of a confocal microscope (LSM 710), where the cells were left to settle for $30 \mathrm{~min}$ in the dark at $22^{\circ} \mathrm{C}$. After dye loading, 
the cells were carefully washed twice in $1 \mathrm{ml} \mathrm{FSW}$ to remove any residual dye without dislodging cells from the surface of the dish. Finally, $6 \mathrm{ml} \mathrm{FSW}$ was added and the dish was placed in a closed-exchange live-cell chamber (PeCon, Erbach, Germany) before experimental treatments were carried out. All dyes used for microscopy were purchased from Invitrogen (Grand Island, NY, USA)

\section{Measurement of $\mathrm{pH}_{\mathrm{i}}$ by confocal microscopy}

The fluorescent dye BCECF-AM, in conjunction with confocal microscopy, has been widely used to study $\mathrm{pH}_{\mathrm{i}}$ in marine algae (Hervé et al., 2012) as its dual-excitation spectral properties allow fluorescence measurements to be taken that are not compounded by chlorophyll autofluorescence $(>640 \mathrm{~nm})$. In this study, confocal microscopy was conducted on a LSM 710 confocal microscope equipped with UV and visible laser lines. Cells loaded with BCECF-AM were sequentially excited, first at $458 \mathrm{~nm}$ then at $488 \mathrm{~nm}$, both with laser strength set at $10 \%$ and pinhole set at 1.51 units using an X63fold oil-immersion lens. Under both excitations, fluorescence emission was captured at $525 \pm 10 \mathrm{~nm}$ by imaging the $z$-stack profile of each cell 10 times in the $x / y$ plane. BCECF-AM is able to enter both the host and the symbiont, and can therefore be used for imaging of both compartments of an intact symbiosis. However, the signal is much stronger in the host cell than in the symbiont, probably due to the thick cell wall that surrounds the symbiont. Therefore, prior optimisation of laser settings was essential to maximise the signal strength in the algae, without overexposing the host cell. In vivo calibration was carried out on each partner in the intact symbiosis to yield two separate calibration curves, one for the symbiont and one for the host (supplementary material Fig. S2). The calibration series is dependent on the calculation of the fluorescence intensity ratio $\left(R ; F_{488} / \mathrm{F}_{458}\right)$ after cells are suspended in buffers of a known $\mathrm{pH}(\mathrm{pH} 6-8.5)$ in the presence of $5 \mu \mathrm{mol} 1^{-1}$ nigericin (Venn et al., 2009). This $R$ value can then be linked to $\mathrm{pH}_{\mathrm{i}}$ by the logarithmic equation $\mathrm{pH}=\mathrm{p} K_{\mathrm{a}}+\log \left\{\left[\left(R-R_{\mathrm{A}}\right) /\left(R_{\mathrm{B}}-R\right)\right] \times\left(F_{\mathrm{A}, 458} / F_{\mathrm{B}, 458}\right)\right\}$, where $\mathrm{p} K_{\mathrm{a}}$ represents the acid dissociation constant and A and B represent the acidic and basic end points of the titration. To check the level of background fluorescence in the sample, cells were loaded separately with $10 \mu \mathrm{mol} \mathrm{l}^{-1}$ BCECF-free acid (in the presence of $0.1 \%$ DMSO and $0.01 \%$ Pluronic F127), a membrane-impermeant form of the dye. Background fluorescence was negligible, with no accumulation in either the symbiont or host cells.

\section{Manipulation of $\mathbf{p H}_{\mathbf{e}}$}

$\mathrm{pH}_{\mathrm{e}}$ was manipulated via in vitro addition of $99 \% \mathrm{CO}_{2}$ in a fully adjustable $\mathrm{CO}_{2}$ /temperature-controlled live-cell chamber attached to an Axiovert 200 microscope. The amount of $\mathrm{CO}_{2}$ that was added was controlled using Zen 2011 software (Carl Zeiss), with the pre-defined volume mixed in a $\mathrm{CO}_{2}$ module and directly injected into the chamber. The final $\mathrm{pH}_{\mathrm{e}}$ and the time taken for the $\mathrm{pH}_{\mathrm{e}}$ to stabilise were dependent on the amount of $\mathrm{CO}_{2}$ added (supplementary material Fig. S3). We selected the $\mathrm{CO}_{2}$ injection setting that produced a gradient of $\mathrm{pH}_{\mathrm{e}}$ that spanned one $\mathrm{pH}$ unit and stabilised below $\mathrm{pH}$ 7. This also provided an optimal time frame for monitoring $\mathrm{pH}$, as experiments lasting longer than $2 \mathrm{~h}$ are often impacted by photo-bleaching or dye-leakage from the cells (Musgrove et al., 1986). The temperature of the microscope stage was maintained at a constant $22^{\circ} \mathrm{C}$ by a custom-made Plexiglas incubator encasing the entire system.

\section{Statistics}

Data were analysed as the relative change in $\mathrm{pH}_{\mathrm{i}}$ (the $\mathrm{pH}_{\mathrm{i}}$ value after acidification minus the mean $\mathrm{pH}_{\mathrm{i}}$ of the control at each time point). Actual $\mathrm{pH}$ values are provided in supplementary material Fig. S1. The effect of the symbiotic state (between-subject factor), external $\mathrm{pH}$ and external $\mathrm{pH} \times$ symbiotic state (both within-subject factors) were analysed using rmANOVA. Initial analysis of the dataset confirmed that there was a significant interaction between external $\mathrm{pH} \times$ symbiotic state $\times$ DCMU treatment (rmANOVA, $F_{15.03,160.34}=4.60, P<0.001$ ), so subsequent analyses were carried out on the two separate treatments (no DCMU and DCMU added). Likewise, post hoc analysis was carried out at the treatment level using Bonferroni-corrected paired $t$-test comparisons $(\alpha=0.001)$. The assumptions of normality were confirmed using the Kolgomorov-Smirnov test. The sphericity of the data was tested using Mauchly's sphericity test.
Epsilon-adjusted univariate $F$-test (Greenhouse-Geisser) values are reported. All data were analysed using JMP 10.0.0 (SAS Institute Inc., USA).

Acknowledgements

We thank Shaun Wilkinson and Nyssa Silbiger for statistical advice.

\section{Competing interests}

The authors declare no competing financial interests.

\section{Author contributions}

E.M.G., H.M.P., S.K.D. and R.D.G. designed the research; E.M.G. performed the research; E.M.G. and H.M.P. analysed the data; and E.M.G., H.M.P., S.K.D. and R.D.G. wrote the paper.

\section{Funding}

This research was funded by a Commonwealth PhD Scholarship and a Kathleen Stewart Postgraduate Scholarship, both awarded to E.M.G. This manuscript is Hawaii Institute of Marine Biology (HIMB) contribution number 1587.

\section{Supplementary material}

Supplementary material available online at

http://jeb.biologists.org/lookup/suppl/doi:10.1242/jeb.099549/-/DC1

\section{References}

Allemand, D., Furla, P. and Tambutté, S. B. (1998). Mechanisms of carbon acquisition for endosymbiont photosynthesis in Anthozoa. Botany 76, 925-941.

Allemand, D., Ferrier-Pagès, C., Furla, P., Houlbrèque, F., Puverel, S., Reynaud, S., Tambutte, E., Tambutte, S. and Zoccola, D. (2004). Biomineralisation in reefbuilding corals: from molecular mechanisms to environmental control. Comptes Rendus Palevol 3, 453-467.

Boron, W. F. (2004). Regulation of intracellular pH. Adv. Physiol. Educ. 28, 160-179. Brading, P., Warner, M. E., Davey, P., Smith, D. J., Achterberg, E. P. and Suggett, D. J. (2011). Differential effects of ocean acidification on growth and photosynthesis among phylotypes of Symbiodinium (Dinophyceae). Limnol. Oceanogr. 56, 927938.

Casey, J. R., Grinstein, S. and Orlowski, J. (2010). Sensors and regulators of intracellular pH. Nat. Rev. Mol. Cell Biol. 11, 50-61.

Comeau, S., Carpenter, R. C. and Edmunds, P. J. (2013). Coral reef calcifiers buffer their response to ocean acidification using both bicarbonate and carbonate. Proc. Biol. Sci. 280, 20122374-20122374.

Davy, S. K., Allemand, D. and Weis, V. M. (2012). Cell biology of cnidariandinoflagellate symbiosis. Microbiol. Mol. Biol. Rev. 76, 229-261.

Dickson, A. G., Sabine, C. L. and Christian, J. R. (2007). Guide to best practices for ocean $\mathrm{CO}_{2}$ measurements. PICES Special Publication 3.

Drupp, P., De Carlo, E. H., Mackenzie, F. T., Bienfang, P. and Sabine, C. L. (2011). Nutrient inputs, phytoplankton response, and $\mathrm{CO}_{2}$ variations in a semi-enclosed subtropical embayment, Kaneohe Bay, Hawaii. Aquat. Geochem. 17, 473-498.

Fabry, V. J., Seibel, B. A., Feely, R. A. and Orr, J. C. (2008). Impacts of ocean acidification on marine fauna and ecosystem processes. ICES J. Mar. Sci. 65, 414432

Furla, P., Allemand, D. and Orsenigo, M. N. (2000). Involvement of $\mathrm{H}^{+}$-ATPase and carbonic anhydrase in inorganic carbon uptake for endosymbiont photosynthesis. Am. J. Physiol. 278, R870-R881.

Gibbin, E. M. and Davy, S. K. (2013). Intracellular pH of symbiotic dinoflagellates. Coral Reefs 32, 859-863.

Hennige, S., Suggett, D., Warner, M., McDougall, K. and Smith, D. (2009). Photobiology of Symbiodinium revisited: bio-physical and bio-optical signatures. Coral Reefs 28, 179-195.

Hervé, V., Derr, J., Douady, S., Quinet, M., Moisan, L. and Lopez, P. J. (2012). Multiparametric analyses reveal the $\mathrm{pH}$-dependence of silicon biomineralization in diatoms. PLoS ONE 7, e46722.

Hoegh-Guldberg, O. (1999). Climate change, coral bleaching and the future of the world's coral reefs. Mar. Freshw. Res. 50, 839-866.

Hoegh-Guldberg, O., Mumby, P. J., Hooten, A. J., Steneck, R. S., Greenfield, P., Gomez, E., Harvell, C. D., Sale, P. F., Edwards, A. J., Caldeira, K. et al. (2007). Coral reefs under rapid climate change and ocean acidification. Science 318, 17371742.

Hofmann, G. E., Smith, J. E., Johnson, K. S., Send, U., Levin, L. A., Micheli, F., Paytan, A., Price, N. N., Peterson, B., Takeshita, Y. et al. (2011). High-frequency dynamics of ocean $\mathrm{pH}$ : a multi-ecosystem comparison. PLOS ONE 6, e28983.

Hofmann, L. C., Straub, S. and Bischof, K. (2013). Elevated $\mathrm{CO}_{2}$ levels affect the activity of nitrate reductase and carbonic anhydrase in the calcifying rhodophyte Corallina officinalis. J. Exp. Bot. 64, 899-908.

Houlbrèque, F., Tambutté, E., Allemand, D. and Ferrier-Pagès, C. (2004). Interactions between zooplankton feeding, photosynthesis and skeletal growth in the scleractinian coral Stylophora pistillata. J. Exp. Biol. 207, 1461-1469.

Iglesias-Prieto, R., Matta, J. L., Robins, W. A. and Trench, R. K. (1992). Photosynthetic response to elevated temperature in the symbiotic dinoflagellate Symbiodinium microadriaticum in culture. Proc. Natl. Acad. Sci. USA 89, $10302-$ 10305. 
Jokiel, P. L. (2011). Ocean acidification and control of reef coral calcification by boundary layer limitation of proton flux. Bulletin of Marine Science 87, 639-657.

Jones, R. J., Hoegh-Guldberg, O., Larkum, A. W. D. and Schreiber, U. (1998) Temperature-induced bleaching of corals begins with impairment of the $\mathrm{CO}_{2}$ fixation mechanism in zooxanthellae. Plant Cell Environ. 21, 1219-1230.

Kaniewska, P., Campbell, P. R., Kline, D. I., Rodriguez-Lanetty, M., Miller, D. J. Dove, S. and Hoegh-Guldberg, O. (2012). Major cellular and physiological impacts of ocean acidification on a reef building coral. PLoS ONE 7, e34659.

Laurent, J., Tambutté, S., Tambutté, É., Allemand, D. and Venn, A. (2013). The influence of photosynthesis on host intracellular $\mathrm{pH}$ in scleractinian corals. J. Exp. Biol. 216, 1398-1404

Madshus, I. H. (1988). Regulation of intracellular pH in eukaryotic cells. Biochem. J. 250, 1-8.

McCulloch, M., Falter, J., Trotter, J. and Montagna, P. (2012). Coral resilience to ocean acidification and global warming through $\mathrm{pH}$ up-regulation. Nature Climate Change 2, 623-627.

Michaelidis, B., Ouzounis, C., Paleras, A. and Pörtner, H. O. (2005). Effects of longterm moderate hypercapnia on acid-base balance and growth rate in marine mussels Mytilus galloprovincialis. Mar. Ecol. Prog. Ser. 293, 109-118.

Muscatine, L., Goiran, C., Land, L., Jaubert, J., Cuif, J. P. and Allemand, D. (2005) Stable isotopes $(\delta 13 \mathrm{C}$ and $\delta 15 \mathrm{~N})$ of organic matrix from coral skeleton. Proc. Natl. Acad. Sci. USA 102, 1525-1530.

Musgrove, E., Rugg, C. and Hedley, D. (1986). Flow cytometric measurement of cytoplasmic pH: a critical evaluation of available fluorochromes. Cytometry 7, 347355.

Nimer, N. A., Brownlee, C. and Merrett, M. J. (1999). Extracellular carbonic anhydrase facilitates carbon dioxide availability for photosynthesis in the marine dinoflagellate prorocentrum micans. Plant Physiol. 120, 105-112.

Ohki, S., Irie, T., Inoue, M., Shinmen, K., Kawahata, H., Nakamura, T., Kato, A., Nojiri, Y., Suzuki, A. and Sakai, K. (2013). Symbiosis increases coral tolerance to ocean acidification. Biogeosciences Discuss. 10, 7013-7030.

Orr, J. C., Fabry, V. J., Aumont, O., Bopp, L., Doney, S. C., Feely, R. A., Gnanadesikan, A., Gruber, N., Ishida, A., Joos, F. et al. (2005). Anthropogenic ocean acidification over the twenty-first century and its impact on calcifying organisms. Nature 437, 681-686.

Pandolfi, J. M., Connolly, S. R., Marshall, D. J. and Cohen, A. L. (2011). Projecting coral reef futures under global warming and ocean acidification. Science 333, 418422

Pochon, X. and Gates, R. D. (2010). A new Symbiodinium clade (Dinophyceae) from soritid foraminifera in Hawai'i. Mol. Phylogenet. Evol. 56, 492-497.

Pörtner, H. O., Langenbuch, M. and Reipschläger, A. (2004). Biological impact of elevated ocean $\mathrm{CO}_{2}$ concentrations: lessons from animal physiology and earth history. J. Oceanography 60, 705-718.
Price, N. N., Martz, T. R., Brainard, R. E. and Smith, J. E. (2012). Diel variability in seawater $\mathrm{pH}$ relates to calcification and benthic community structure on coral reefs. PLOS ONE 7, e43843.

Putnam, H. M. (2012). Resilience and Acclimatization Potential of Reef Corals Under Predicted Climate Change Stressors. University of Hawai'i at Manoa, HI: ProQuest, UMI Dissertations Publishing, 3569106.

Reipschläger, A. and Pörtner, H. O. (1996). Metabolic depression during environmental stress: the role of extracellular versus intracellular $\mathrm{pH}$ in Sipunculus nudus. J. Exp. Biol. 199, 1801-1807.

Riebesell, U., Fabry, V. J., Hansson, L. and Gattuso, J.-P. (2010). Guide to Best Practices for Ocean Acidification Research and Data Reporting. Luxembourg: Publications Office of the European Union.

Silverman, J., Lazar, B., Cao, L., Caldeira, K. and Erez, J. (2009). Coral reefs may start dissolving when atmospheric $\mathrm{CO}_{2}$ doubles. Geophys. Res. Lett. 5, L05606

Smith, F. A. and Raven, J. A. (1979). Intracellular pH and its regulation. Annu. Rev. Plant Physiol. Plant Mol. Biol. 30, 289-311.

Stumpp, M., Hu, M. Y., Melzner, F., Gutowska, M. A., Dorey, N., Himmerkus, N., Holtmann, W. C., Dupont, S. T., Thorndyke, M. C. and Bleich, M. (2012). Acidified seawater impacts sea urchin larvae $\mathrm{pH}$ regulatory systems relevant for calcification. Proc. Natl. Acad. Sci. USA 109, 18192-18197.

Suggett, D. J., Hall-Spencer, J. M., Rodolfo-Metalpa, R., Boatman, T. G., Payton, R., Tye Pettay, D., Johnson, V. R., Warner, M. E. and Lawson, T. (2012). Sea anemones may thrive in a high $\mathrm{CO}_{2}$ world. Glob. Change Biol. 18, 3015-3025.

Tchernov, D., Gorbunov, M. Y., de Vargas, C., Narayan Yadav, S., Milligan, A. J., Häggblom, M. and Falkowski, P. G. (2004). Membrane lipids of symbiotic algae are diagnostic of sensitivity to thermal bleaching in corals. Proc. Natl. Acad. Sci. USA 101, 13531-13535.

Towanda, T. and Thuesen, E. V. (2012). Prolonged exposure to elevated $\mathrm{CO}_{2}$ promotes growth of the algal symbiont Symbiodinium muscatinei in the intertidal sea anemone Anthopleura elegantissima. Biol. Open 1, 615-621.

Uthicke, S. and Fabricius, K. E. (2012). Productivity gains do not compensate for reduced calcification under near-future ocean acidification in the photosynthetic benthic foraminifer species Marginopora vertebralis. Glob. Change Biol. 18, 2781 2791.

Venn, A. A., Tambutté, E., Lotto, S., Zoccola, D., Allemand, D. and Tambutté, S. (2009). Imaging intracellular $\mathrm{pH}$ in a reef coral and symbiotic anemone. Proc. Natl. Acad. Sci. USA 106, 16574-16579.

Venn, A. A., Tambutté, E., Holcomb, M., Laurent, J., Allemand, D. and Tambutté, S. (2013). Impact of seawater acidification on $\mathrm{pH}$ at the tissue-skeleton interface and calcification in reef corals. Proc. Natl. Acad. Sci. USA 110, 1634-1639.

Weis, V. M., Davy, S. K., Hoegh-Guldberg, O., Rodriguez-Lanetty, M. and Pringle, J. R. (2008). Cell biology in model systems as the key to understanding corals. Trends Ecol. Evol. 23, 369-376. 



\title{
The photo-physiological response of a model cnidarian-dinoflagellate symbiosis to $\mathrm{CO}_{2}$-induced acidification at the cellular level
}

\author{
Emma M. Gibbin, Simon K. Davy * \\ School of Biological Sciences, Victoria University of Wellington, PO Box 600, Wellington 6140, New Zealand
}

\section{A R T I C L E I N F O}

\section{Article history:}

Received 28 February 2014

Received in revised form 20 March 2014

Accepted 22 March 2014

Available online $\mathrm{xxxx}$

\section{Keywords:}

Aiptasia

Ocean acidification

Climate change

Intracellular $\mathrm{pH}$

Symbiodinium

Symbiosis

\begin{abstract}
A B S T R A C T
We measured the relationship between $\mathrm{CO}_{2}$-induced seawater acidification, photo-physiological performance and intracellular $\mathrm{pH}\left(\mathrm{pH}_{\mathrm{i}}\right)$ in a model cnidarian-dinoflagellate symbiosis - the sea anemone Aiptasia sp. - under ambient $(289.94 \pm 12.54 \mu \mathrm{atm})$, intermediate $(687.40 \pm 25.10 \mu \mathrm{tm})$ and high $(1459.92 \pm 65.51 \mu \mathrm{atm}) \mathrm{CO}_{2}$ conditions. These treatments represented current $\mathrm{CO}_{2}$ levels, in addition to $\mathrm{CO}_{2}$ stabilisation scenarios IV and VI provided by the Intergovernmental Panel on Climate Change (IPCC). Anemones were exposed to each treatment for two months and sampled at regular intervals. At each time-point we measured a series of physiological responses: maximum dark-adapted fluorescent yield of PSII $\left(\mathrm{F}_{\mathrm{v}} / \mathrm{F}_{\mathrm{m}}\right)$, gross photosynthetic rate, respiration rate, symbiont population density, and light-adapted $\mathrm{pH}_{\mathrm{i}}$ of both the dinoflagellate symbiont and isolated host anemone cell. We observed increases in all but one photo-physiological parameter $\left(\mathrm{P}_{\text {gross }}: \mathrm{R}\right.$ ratio). At the cellular level, increases in light-adapted symbiont $\mathrm{pH}_{\mathrm{i}}$ were observed under both intermediate and high $\mathrm{CO}_{2}$ treatments, relative to control conditions $\left(\mathrm{pH}_{\mathrm{i}} 7.35\right.$ and 7.46 versus $\mathrm{pH}_{\mathrm{i}}$ 7.25, respectively). The response of light-adapted host $\mathrm{pH}_{\mathrm{i}}$ was more complex, however, with no change observed under the intermediate $\mathrm{CO}_{2}$ treatment, but a $0.3 \mathrm{pH}$-unit increase under the high $\mathrm{CO}_{2}$ treatment $\left(\mathrm{pH}_{\mathrm{i}} 7.19\right.$ and 7.48 , respectively). This difference is likely a result of a disproportionate increase in photosynthesis relative to respiration at the higher $\mathrm{CO}_{2}$ concentration. Our results suggest that, rather than causing cellular acidosis, the addition of $\mathrm{CO}_{2}$ will enhance photosynthetic performance, enabling both the symbiont and host cell to withstand predicted ocean acidification scenarios.
\end{abstract}

(c) 2014 Elsevier B.V. All rights reserved.

\section{Introduction}

At 380 ppm, present-day atmospheric $\mathrm{CO}_{2}$ concentrations are higher than at any point in the past 740,000 years (Hoegh-Guldberg et al., 2007), and are predicted to reach 500-1000 ppm by 2100 (Vuuren et al., 2011). It is estimated that approximately one third of all anthropogenic $\mathrm{CO}_{2}$ is sequestered by the oceans (Sabine et al., 2004). This continuous dissolution of $\mathrm{CO}_{2}$ lowers the $\mathrm{pH}$ of seawater and alters the speciation of dissolved inorganic carbon (DIC), in a process known as ocean acidification. Such changes are of great concern for marine ecosystems, but are particularly pertinent for those in which calcifying

Abbreviations: BCECF-AM ester, 2',7'-bis-(2-carboxyethyl)-5-(and-6)-carboxyfluorescein, acetoxymethyl ester; BSA, bovine serum albumin; CaFSW, calcium-free seawater; CCM, carbon-concentrating mechanism; DCMU, 3-(3,4-dichlorophenyl)-1,1dimethylurea; DIC, dissolved inorganic carbon; DMSO, dimethyl sulfoxide; $\mathrm{F}_{\mathrm{v}} / \mathrm{F}_{\mathrm{m}}$, maximum dark-adapted yield of photosystem II; IPCC, intergovernmental panel on climate change; $\mathrm{PAR}$, photosynthetically active radiation; $\mathrm{P}_{\text {gross }}$, gross photosynthesis rate; $\mathrm{pH}_{\mathrm{i}}$, intracellular $\mathrm{pH}$; $\mathrm{P}_{\text {net }}$, net photosynthesis rate; PSII, photosystem II; R, respiration rate; ROI, region of interest; SNARF-4F, 5-(and-6)-carboxylic acid, acetoxymethyl ester acetate.

* Corresponding author. Tel.: +64 4 4635573; fax: +64 44635331.

E-mail address: simon.davy@vuw.ac.nz (S.K. Davy). organisms play a major role (Fabry et al., 2008). Coral reefs, therefore, which are recognised for their high diversity and productivity (Bellwood and Hughes, 2001), have received considerable attention (Crook et al., 2012; Fabricius et al., 2011; Hall-Spencer et al., 2008).

Predicting the response of reef-building corals to ocean acidification is complicated by the presence of the single-celled photosynthetic dinoflagellates (Symbiodinium spp.) that they harbour within their gastrodermal tissue layer. The photosynthetic products that are supplied by these dinoflagellate symbionts are of great metabolic importance to their host, facilitating growth, reproduction and, ultimately, survival (Muscatine, 1990). Therefore, the adaptive capacity of corals is not only determined by the responses of the host but also those of the symbionts it contains (McCulloch et al., 2012). Understanding the cellular mechanisms that underpin the complex interrelationship between the symbiont and host is a vital step towards understanding why the physiological response to $\mathrm{CO}_{2}$-addition differs so substantially between species (Anthony et al., 2008; Kroeker et al., 2010; Pandolfi et al., 2011; Ries et al., 2009). Of specific interest in this context is characterising intracellular $\mathrm{pH}\left(\mathrm{pH}_{\mathrm{i}}\right)$ under normal conditions and determining its response to ocean acidification (Brownlee, 2009; Schneider and Erez, 2006).

Acid-base regulation is an essential facet of cellular metabolism in all organisms (Busa and Nuccitelli, 1984), but is particularly important 
for symbiotic anthozoan cells that are subjected to significant fluctuations in $\mathrm{pH}_{\mathrm{i}}$ through the photosynthetic and respiratory activity of their symbionts (Gibbin and Davy, 2013; Laurent et al., 2013a; Venn et al., 2009). Deviation from the optimal $\mathrm{pH}_{\mathrm{i}}$, a process known as acidosis, often leads to cellular dysfunction (Pörtner et al., 2004), and while short-term acidosis can typically be recovered from (Fabry et al., 2008), longer periods of exposure can result in metabolic depression (Reipschläger and Pörtner, 1996) and reduced rates of protein synthesis (Hand, 1991), which are detrimental to fitness. We currently know little about how the cnidarian-dinoflagellate symbiosis might respond to $\mathrm{CO}_{2}$-induced acidification at the cellular level. Indeed, there have been just two studies to focus on this, in which short-term experimental perfusions $(<2 \mathrm{~h}$ ) of isolated, symbiotic gastrodermal cells from the sea anemone Anemonia viridis in $\mathrm{HCl}$-acidified seawater (Laurent et al., 2013b) and the coral Pocillopora damicornis in $\mathrm{CO}_{2}$-acidified seawater (Gibbin et al., 2014) revealed no detrimental effects on the $\mathrm{pH}_{\mathrm{i}}$ of the host cell, and host and symbiont cells, respectively. On the contrary, there is growing evidence that increased $\mathrm{CO}_{2}$ availability associated with ocean acidification could enhance primary productivity in Symbiodinium cells (Brading et al., 2011; Jarrold et al., 2013; Marubini et al., 2008; Suggett et al., 2012; Towanda and Thuesen, 2012), and thus may limit the potential for host cell acidosis (Gibbin et al., 2014). This photosynthetically driven up-regulation of $\mathrm{pH}_{\mathrm{i}}$ under high $\mathrm{CO}_{2}$ has been postulated as one potential mechanism for countering the negative impacts of acidification on coral calcification (Ries et al., 2009). Yet, to date, no study has examined the longer-term impacts of $\mathrm{CO}_{2}$-addition on both host and symbiont $\mathrm{pH}_{\mathrm{i}}$ in the cnidariandinoflagellate symbiosis. This is an essential step if we are to fully appreciate the impacts that ocean acidification might have on this ecologically important association.

Here, we investigated the relationship between photo-physiology and $\mathrm{pH}_{\mathrm{i}}$ under long-term $\mathrm{CO}_{2}$ addition. To achieve this, we exposed the sea anemone Aiptasia sp., a model system for the study of cnidarian-dinoflagellate symbiosis (Weis et al., 2008), to conditions representative of the intermediate (IV; 520-700 ppm) and high-end (VI; 1000-1300 ppm) $\mathrm{CO}_{2}$ stabilisation scenarios provided by the Intergovernmental Panel on Climate Change (IPCC, 2007). Over a twomonth period we measured a suite of physiological responses: maximum dark-adapted fluorescent yield of PSI $\left(\mathrm{F}_{\mathrm{v}} / \mathrm{F}_{\mathrm{m}}\right)$, gross photosynthetic rate, respiration rate, symbiont population density, and $\mathrm{pH}_{\mathrm{i}}$ of both the dinoflagellate symbiont and host anemone. We tested the prediction that, rather than causing cellular acidosis, the addition of $\mathrm{CO}_{2}$ would enhance photosynthetic performance, enabling both the symbiont and host cell to withstand the predicted ocean acidification scenarios.

\section{Materials and methods}

\subsection{Experimental organisms}

A long-term aquarium stock of the sea anemone Aiptasia sp., originating from an unknown location in the Pacific, was grown at $25{ }^{\circ} \mathrm{C}$ under a $12 \mathrm{~h}$ light: $12 \mathrm{~h}$ dark cycle, with $80-100 \mu \mathrm{mol}$ photons $\mathrm{m}^{-2} \mathrm{~s}^{-1}$ provided by cool white fluorescent lamps (Osram Dulux $36 \mathrm{~W} / 890$ fluorescent bulbs), and fed freshly-hatched Artemia sp. nauplii every 3 days. These anemones contain Symbiodinium ITS2 type B1 (Gibbin and Davy, 2013). One month prior to experimentation, 300 anemones (oral disc $\sim 1 \mathrm{~cm}$ diameter) were randomly selected and transferred to 2-L glass beakers ( 20 individuals per beaker) containing $1 \mu \mathrm{m}$-filtered seawater (FSW). The beakers were then split evenly between three water baths (i.e. $\mathrm{n}=5$ independent beakers per water bath), under the same light and temperature conditions described above. During this acclimation period, water was changed daily to ensure that $\mathrm{pH}(8.1 \pm 0.1)$ and salinity $(35.5 \pm 0.1 \mathrm{ppt})$ were kept constant. Nutrient concentrations were not monitored during the experiment, but levels are typically low (DIN $\sim 2 \mu \mathrm{M}, \mathrm{NH}_{3}$ and $\mathrm{NO}_{3}^{-}$ $\sim 1 \mu \mathrm{M}, \mathrm{NO}_{2}^{-}$and $\left.\mathrm{PO}_{4}^{3-}<1 \mu \mathrm{M}\right)$, and relatively stable in the coastal waters around Wellington, New Zealand, from where the seawater was collected (Dudley and Shima, 2010). Tanks were cleaned weekly and water temperature was monitored using HOBO data loggers (Onset Corporation, Bourne, MA, USA).

\subsection{Experimental design}

Anemones were exposed to three $\mathrm{pH}$ treatments over a two-month period: $8.14 \pm 0.01,7.83 \pm 0.01$ and $7.54 \pm 0.02$ [Table 1]. These values correspond to $\mathrm{pCO}_{2}$ concentrations of $289.94 \pm 12.54 \mu \mathrm{atm}, 687.40 \pm$ $25.10 \mu \mathrm{atm}$ and $1459.92 \pm 65.51 \mu \mathrm{atm}$, respectively. The treatments were chosen to represent current $\mathrm{CO}_{2}$ levels, plus $\mathrm{CO}_{2}$ stabilisation scenarios IV and VI provided by the IPCC. Photosynthesis caused the seawater $\mathrm{pH}$ to fluctuate by $\sim 0.1 \mathrm{pH}$ unit over $24 \mathrm{~h}$, so water changes were performed daily. Addition of gaseous $\mathrm{CO}_{2}$ to seawater was performed in a 50-L black plastic reservoir, via a $\mathrm{CO}_{2}$ solenoid valve connected to a PINPOINT $\mathrm{pH}$ controller (American Marine Inc., Ridgefield, CT, USA). The final pH of the seawater was checked with an independent $\mathrm{pH}$ probe, adjusted accordingly if needed, and recorded before being added to the beakers. In addition to this, $\mathrm{pH}$ readings were taken daily before the water change, to provide a full record of the $\mathrm{pH}$ experienced in each beaker [Supplementary information, Fig. S1]. Anemones were haphazardly selected for sampling at 0, 1, 2, 4, 6 and 8 weeks. Not all of the anemones placed in each beaker were sampled during the experiment. At each time-point, two anemones were removed from each beaker. One was used to quantify symbiont $\mathrm{pH}_{\mathrm{i}}$, in addition to a suite of photo-physiological parameters (described below), and the other was used to determine the host cell $\mathrm{pH}_{\mathrm{i}}$.

\subsection{Photo-physiological responses}

Maximum dark-adapted yield of PSII $\left(\mathrm{F}_{\mathrm{v}} / \mathrm{F}_{\mathrm{m}}\right)$ of each anemone was measured $30 \mathrm{~min}$ before the lights were switched on, using pulse amplitude modulated fluorometry (Diving-PAM, Walz, Effeltrich, Germany; settings: measuring light $=8$, saturation intensity $=8$, saturation width $=0.8 \mathrm{~s}$, gain $=5$ and damping $=2$ ). Triplicate measurements were performed for each anemone, with readings taken $1 \mathrm{~cm}$ immediately above the oral disc, and $45^{\circ}$ either side of this point. Anemones were then placed singly with FSW into a 10 -mL glass chamber, and left to settle for an hour; this was sufficient time for attachment to a thin nylon mesh grid that overlaid a magnetic spinbar. A glass lid, held in place by a rubber O-ring, sealed the chamber, into which a temperature probe and an oxygen electrode (FIBOX 3 fibre-optic oxygen meter, PreSens, GmbH, Germany) were inserted such that both probes were positioned $\sim 1 \mathrm{~cm}$ above the anemone's oral disc. The chamber was then wrapped in aluminium foil to ensure that no light could enter and placed on top of a submersible magnetic stirrer, itself placed in a transparent water bath set to $25^{\circ} \mathrm{C}$. Respiratory oxygen consumption ( $\mathrm{R} ; \mathrm{mL} \mathrm{O}_{2} \mathrm{~h}^{-1}$ ) was measured every $10 \mathrm{~s}$ in darkness until a constant rate was observed (normally after $\sim 30 \mathrm{~min}$ ). The foil was then removed and the chamber illuminated at $400 \mu \mathrm{mol}$ photons $\mathrm{m}^{-2} \mathrm{~s}^{-1}$ by a $150 \mathrm{~W}$ sealed beam PAR38 lamp (Thorn Lighting Ltd., Durham, UK). This light level was chosen because it is well above the photosynthesis-saturating irradiance for Aiptasia sp., which is typically between 200 and $250 \mu \mathrm{mol}$ photons $\mathrm{m}^{-2} \mathrm{~s}^{-1}$ (Muller-Parker, 1984) but is not high enough to cause photoinhibition, which usually begins at irradiances greater than $600 \mu \mathrm{mol}$ photons $\mathrm{m}^{-2}$ $\mathrm{s}^{-1}$ in this anemone (Lesser and Shick, 1989). Net photosynthetic oxygen evolution $\left(P_{\text {net }}\right)$ was then measured until a constant rate was observed. Gross photosynthesis $\left(\mathrm{P}_{\text {gross }}\right)$ was calculated by adding $\mathrm{P}_{\text {net }}$ to $R$, and the resulting values were used to determine the $P_{\text {gross }}: R$ ratio for each anemone on an idealized day (assuming $12 \mathrm{~h}$ light and $12 \mathrm{~h}$ dark), a proxy for autotrophic potential. It was assumed that $\mathrm{R}$ in the light was the same as in the dark (i.e. total respiration per day $=\mathrm{R} \times 24 \mathrm{~h}$ ). 
Table 1

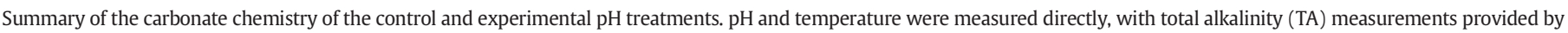

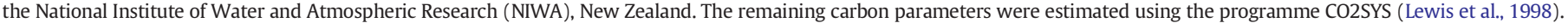
Values represent daily mean $\pm S E(n=60)$.

\begin{tabular}{|c|c|c|c|c|c|}
\hline $\begin{array}{l}\mathrm{pH} \\
\text { (NBS-scale) }\end{array}$ & $\begin{array}{l}\text { Temperature } \\
\left({ }^{\circ} \mathrm{C}\right)\end{array}$ & $\begin{array}{l}\text { TA } \\
\left(\mu \mathrm{mol} \mathrm{kg}{ }^{-1}\right)\end{array}$ & $\mathrm{pCO}_{2}(\mu \mathrm{atm})$ & $\begin{array}{l}\mathrm{HCO}_{3} \\
\left(\mu \mathrm{mol} \mathrm{kg}{ }^{-1}\right)\end{array}$ & $\begin{array}{l}\mathrm{CO}_{3} \\
\left(\mu \mathrm{mol} \mathrm{kg}{ }^{-1}\right)\end{array}$ \\
\hline $8.143 \pm 0.015$ & $25.461 \pm 0.070$ & $2258.810 \pm 4.056$ & $289.939 \pm 1.773$ & $1648.396 \pm 2.521$ & $247.661 \pm 1.017$ \\
\hline $7.843 \pm 0.019$ & $25.783 \pm 0.062$ & $2258.810 \pm 4.056$ & $687.404 \pm 3.550$ & $1909.885 \pm 1.578$ & $141.979 \pm 0.642$ \\
\hline $7.570 \pm 0.023$ & $25.843 \pm 0.056$ & $2258.810 \pm 4.056$ & $1459.916 \pm 9.265$ & $2066.220 \pm 1.181$ & $78.485 \pm 0.481$ \\
\hline
\end{tabular}

After the $\mathrm{O}_{2}$-flux measurements were complete, each anemone was then placed in a $1.5-\mathrm{mL}$ microcentrifuge tube and homogenised in $1.1 \mathrm{~mL}$ FSW using a plastic tissue grinder. From the resulting slurry, a $100 \mu \mathrm{L}$ aliquot was removed, and frozen at $-20^{\circ} \mathrm{C}$. This was later used to determine symbiont density ( $\mathrm{n}=6$ counts per sample) using an Improved Neubauer haemocytometer (Boeco, Hamburg, Germany). The remaining $1 \mathrm{~mL}$ was centrifuged for $5 \mathrm{~min}$ at $1000 \times g$ to separate the algal fraction from host tissue. Once isolated, the host supernatant was decanted and stored at $-20^{\circ} \mathrm{C}$ prior to analysis of the host protein content, using the Bradford assay (Bradford, 1976) and bovine serum albumin (BSA) as the standard. These values were subsequently used to normalise $P_{\text {gross }}, \mathrm{R}$ and symbiont density values. The remaining algal pellet was re-suspended in FSW at a final density of $1 \times 10^{6}$ cells $\mathrm{mL}^{-1}$, for analysis of symbiont $\mathrm{pH}_{\mathrm{i}}$ (see below).

\subsection{Measuring $\mathrm{pH}_{i}$ of the symbiont and host}

Light-adapted symbiont $\mathrm{pH}_{\mathrm{i}}$ was measured according to the protocol described in Gibbin and Davy (2013). Briefly, cells were incubated with FSW containing $10 \mu \mathrm{M}$ BCECF-AM ester, 0.1\% DMSO and 0.01\% Pluronic $\mathrm{F}-127$ for $20 \mathrm{~min}$ on an orbital shaker set to $250 \mathrm{rpm}$. The samples were then transferred to a flow cytometer (FACScan, Becton-Dickinson, Franklin Lakes, NJ, USA), where they were illuminated by $400 \mu \mathrm{mol}$ photons $\mathrm{m}^{-2} \mathrm{~s}^{-1}$ of white light, provided by an external variable-irradiance fibre optic cable (Halogen Reflector lamp, 150W GX5.3 21V 1CT bulb, Philips, Somerset, New Jersey, USA), for 20 min. Samples were excited with a $488 \mathrm{~nm}$ argon laser, and BCECF-AM fluorescence was measured in linear mode in the 515-545 nm (FL1) and 564-606 nm (FL2) filter channels, with 5000 individual cells recorded per sample. The average ratio of fluorescence, $\mathrm{R}$ (FL1/FL2), was calculated per sample and converted to $\mathrm{pH}_{\mathrm{i}}$ using a calibration curve [Supplementary information, Fig. 2A].

The light-adapted $\mathrm{pH}_{\mathrm{i}}$ of host cells was calculated from viable symbiotic endodermal cells (i.e. the host cell with its enclosed dinoflagellate symbiont) isolated using a protocol adapted from Gates and Muscatine (1992). Briefly, tentacles were excised and sliced into 1-2 mm lengths. These were transferred between a series of glass slides containing $10 \mu \mathrm{L}$ of calcium-free filtered seawater (CaFSW) to remove mucus. The tentacles were then placed in a watch glass and the excess seawater removed, before being subjected to tryptic maceration $(0.1 \%$ $\mathrm{w} / \mathrm{v}$ in CaFSW). The watch glass was covered with parafilm to avoid evaporation, placed on an orbital mixer and agitated at $180 \mathrm{rpm}$ for $30 \mathrm{~min}$. The cells were transferred to a poly-L-lysine coated dish (MatTek Corporation, Ashland, MA, USA) and left to settle for $15 \mathrm{~min}$. After this time, any excess trypsin-CaFSW solution was carefully pipetted off, and $1 \mathrm{~mL}$ FSW containing $10 \mu \mathrm{M}$ SNARF-4F AM-ester, 0.1\% DMSO and $0.01 \%$ Pluronic F-127 was added. The samples were left for a further 20 min before the stain was washed off with FSW. The cells were then transferred to a confocal microscope (Fluoview 1000, Olympus, Pennsylvania, USA), excited with a $559 \mathrm{~nm}$ laser, and imaged with the pinhole set at 1.51 Airy units, using a $\times 63$ oil immersion lens. Only doublet cells (i.e. host cells containing two symbiont cells) were selected for analysis, since they were more numerous than triplet cells, and have a larger region of interest (ROI) than singlet symbiotic cells (Venn et al., 2009). This should be kept in mind when extrapolating results to the organismal level, because symbiont number could influence host cell $\mathrm{pH}_{\mathrm{i}}$. Individual cells were imaged 10 times in the z-plane, with fluorescence emission captured at $585 \pm 10 \mathrm{~nm}$ and $635 \mathrm{~nm} \pm 10 \mathrm{~nm}$. Three cells were imaged per replicate anemone to account for any variability, and subsequent image analysis and estimation of $\mathrm{pH}_{\mathrm{i}}$ were carried out as described by Venn et al. (2009), using a calibration curve [Supplementary information, Fig. 2B].

\subsection{Data analysis}

Repeated measures analysis of variance (rmANOVA) was used to test the response of each variable to $\mathrm{pH}$ over time. Post hoc analyses represent Bonferroni-corrected pair-wise comparisons of estimated marginal means between each of the two enhanced- $\mathrm{CO}_{2}$ treatments and the ambient $\mathrm{CO}_{2}$ control at a particular time-point. Epsilonadjusted Greenhouse-Geisser (G-G) values are reported whenever Mauchly's Sphericity Test returned a significant result. Linear regression analyses were performed to evaluate the relationship between symbiont and host $\mathrm{pH}_{\mathrm{i}}$. Data were examined for normality prior to parametric analysis using the Shapiro-Wilk Test, and were transformed where necessary to satisfy these requirements. All data were analysed using the PASW Statistics 20.0 package (IBM, Armonk, NY, USA).

\section{Results}

In general, the addition of $\mathrm{CO}_{2}$ caused a significant increase in all but one of the photo-physiological parameters measured ( $\mathrm{P}_{\text {gross }}: \mathrm{R}$ ratio) [Table 2]. Typically these increases were detected within 2-3 weeks of $\mathrm{CO}_{2}$ addition, and in most cases the increased response appeared to be proportional to the amount of $\mathrm{CO}_{2}$ added [Fig. 1]. However, in some cases, the full treatment effect was not fully apparent until the end of the experiment.

\subsection{Photo-physiological responses to $\mathrm{CO}_{2}$ addition}

Over the course of the experiment, anemones exposed to high and intermediate levels of $\mathrm{CO}_{2}$ exhibited increased symbiont densities relative to the control group [Fig. 1A; Table 2]. Moderate increases were observed from week 2 onwards in the intermediate treatment and densities were $32 \%$ higher than in the control by the end of the experiment [Fig. 1A]. High $\mathrm{CO}_{2}$ addition induced a greater response, with a $54 \%$ increase evident by week 2 , increasing to $81 \%$ by the end of the experiment.

Table 2

Statistical analysis of the response variables in Aiptasia sp. when exposed to different $\mathrm{pH}$ treatments. The F-statistic represents the overall rmANOVA interaction (time $\times \mathrm{pH}$ treatment) for each parameter and asterisks denote statistical significance at ${ }^{*} \mathrm{p}<0.05$ or ${ }^{* *} \mathrm{p}<0.001$.

\begin{tabular}{lll}
\hline Response variable & F-statistic & p-Value \\
\hline Symbiont density $\left(\times 10^{6}\right.$ cells $\mathrm{mg}^{-1}$ protein $)$ & $\mathrm{F}_{10,60}=5.006$ & $<0.001^{* *}$ \\
Max. quantum yield $\left(\mathrm{F}_{\mathrm{v}} / \mathrm{F}_{\mathrm{m}}\right)$ & $\mathrm{F}_{10,60}=2.088$ & $0.039^{*}$ \\
$\mathrm{P}_{\text {gross }}\left(\mu \mathrm{g} \mathrm{O}_{2} \mathrm{mg}^{-1} \mathrm{protein}^{-1}\right)$ & $\mathrm{F}_{3.90,23.403}=11.181$ & $<0.001^{* *}$ \\
$\mathrm{P}_{\text {gross }}\left(\mathrm{pg} \mathrm{O}_{2} \mathrm{cell}^{-1} \mathrm{~h}^{-1}\right)$ & $\mathrm{F}_{10,60}=2.204$ & $0.030^{*}$ \\
$\mathrm{R}\left(\mu \mathrm{g} \mathrm{O} \mathrm{mg}^{-1}\right.$ protein h$\left.^{-1}\right)$ & $\mathrm{F}_{10,60}=2.191$ & $0.031^{*}$ \\
$\mathrm{P}_{\text {gross }}: \mathrm{R}$ & $\mathrm{F}_{4.957,29.745}=0.597$ & 0.701 \\
Symbiont $\mathrm{pH}_{\mathrm{i}}$ & $\mathrm{F}_{10,60}=3.403$ & $0.001^{*}$ \\
Host cell $\mathrm{pH}_{\mathrm{i}}$ & $\mathrm{F}_{10,60}=3.436$ & $0.001^{*}$ \\
\hline
\end{tabular}



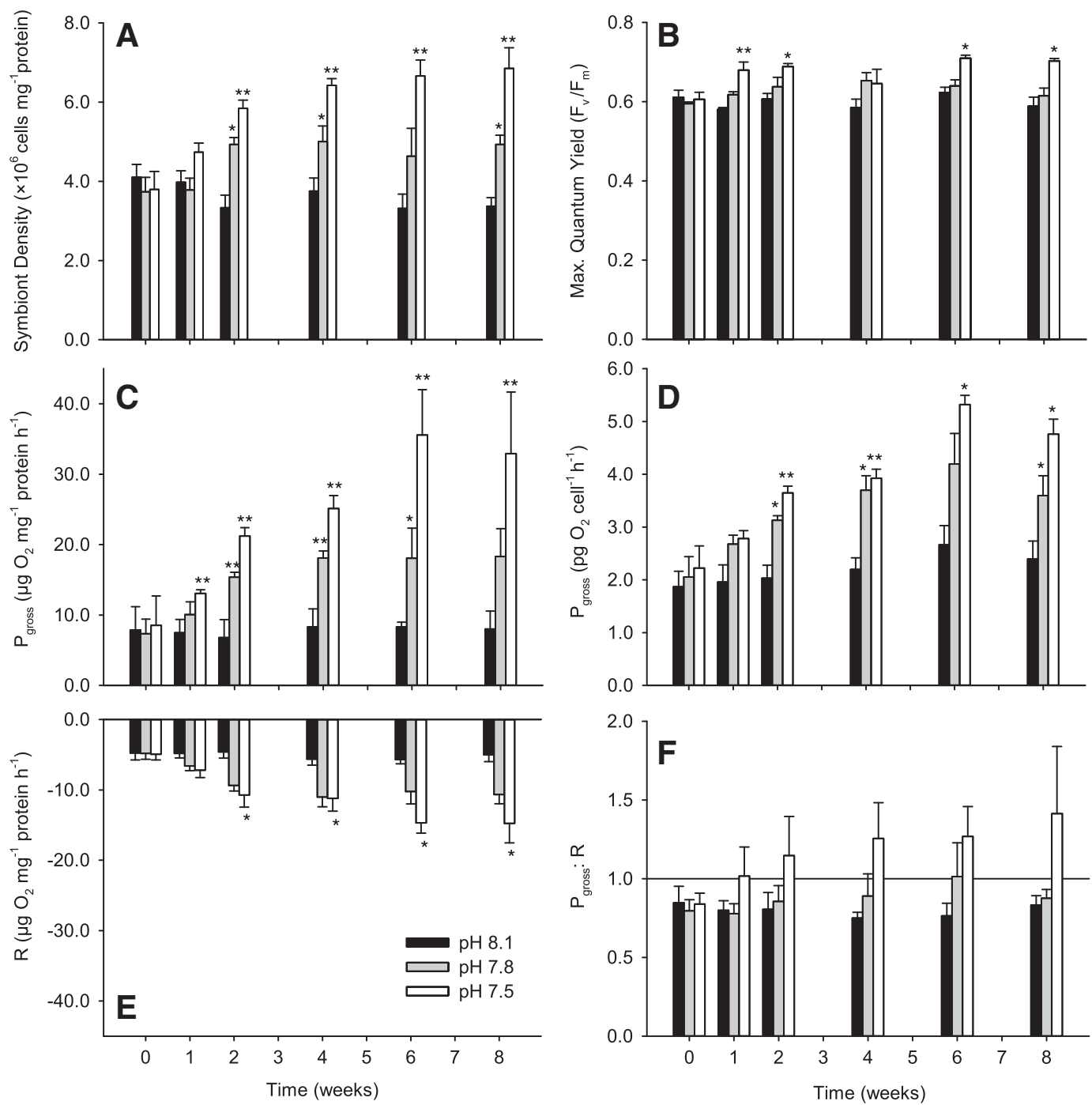

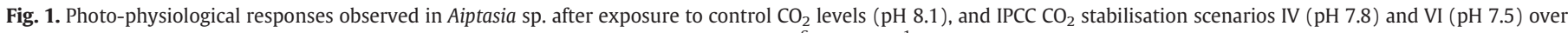

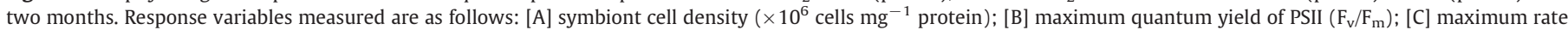

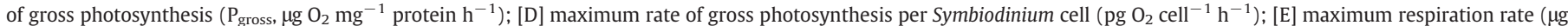

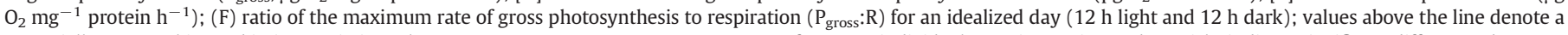

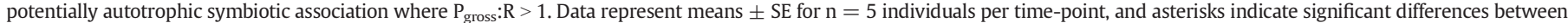
elevated $\mathrm{CO}_{2}$ treatments relative to the control at each time point (rmANOVA, pairwise post hoc with Bonferroni correction, ${ }^{*} \mathrm{p}<0.05,{ }^{* *} \mathrm{p}<0.001$ ).

Maximum dark-adapted yield $\left(\mathrm{F}_{\mathrm{v}} / \mathrm{F}_{\mathrm{m}}\right)$ showed no response to the intermediate $\mathrm{CO}_{2}$ treatment but under high $\mathrm{CO}_{2}$ there was a significant increase in $\mathrm{F}_{\mathrm{v}} / \mathrm{F}_{\mathrm{m}}$ relative to both the control and the intermediate treatment at weeks 1, 6 and 8 [Fig. 1B].

The response of total maximum gross photosynthetic rate $\left(\mathrm{P}_{\text {gross }}\right)$ to $\mathrm{CO}_{2}$ addition was pronounced [Fig. 1C; Table 2]. Under intermediate $\mathrm{CO}_{2}$ addition, a two-fold increase in $P_{\text {gross }}$ was evident by week 2 , which remained more or less constant thereafter. In comparison, exposure to high $\mathrm{CO}_{2}$ induced a 2.5-fold increase in $\mathrm{P}_{\text {gross }}$ after two weeks, and an almost 4 -fold increase from week 6 onwards. These patterns were similar when $P_{\text {gross }}$ was expressed on a cell-specific basis [Fig. 1D]. Over the duration of the experiment, cell-specific photosynthetic rate increased by $81.6 \%$ and $114 \%$ in the intermediate and high $\mathrm{CO}_{2}$ treatments, respectively.

Total respiration $(\mathrm{R})$ also responded to the addition of $\mathrm{CO}_{2}$ [Fig. 1E; Table 2]. $\mathrm{R}$ tended to increase in the intermediate $\mathrm{CO}_{2}$ treatment from at least week 2 onwards, but this increase was not significant. In contrast, there was a significant, two-fold increase in $\mathrm{R}$ from week 2 onwards in the high $\mathrm{CO}_{2}$ treatment. Given the more marked influence of $\mathrm{CO}_{2}$ addition on total photosynthesis than respiration, the ratio of
$\mathrm{P}_{\text {gross }}$ to $\mathrm{R}$ increased, though variability in this parameter masked any statistical significance [Fig. 1F; Table 2].

\subsection{Cellular $\mathrm{pH}_{i}$ response to $\mathrm{CO}_{2}$ addition}

The light-adapted intracellular $\mathrm{pH}\left(\mathrm{pH}_{\mathrm{i}}\right)$ of both the symbiont [Fig. 2A] and host [Fig. 2B] was significantly modified via the addition of $\mathrm{CO}_{2}$ [Table 2]. Symbiont cells isolated from anemones exposed to the highest $\mathrm{CO}_{2}$ treatment showed the most rapid response, with $\mathrm{pH}_{\mathrm{i}}$ increasing $\sim 0.2 \mathrm{pH}$ units, from $7.25 \pm 0.05$ to $7.46 \pm 0.06$, within a week, and stabilising at this level for the remainder of the experiment. The $\mathrm{pH}_{\mathrm{i}}$ of symbiont cells exposed to intermediate $\mathrm{CO}_{2}$ levels showed the largest increase between weeks 1 and 4, when it reached $7.37 \pm$ 0.09; the $\mathrm{pH}_{\mathrm{i}}$ remained at a similar level for the remainder of the experiment.

There were discernible differences between the response of host $\mathrm{pH}_{\mathrm{i}}$ and symbiont $\mathrm{pH}_{\mathrm{i}}$ under acidification [Fig. 2]. Interestingly, exposure to intermediate $\mathrm{CO}_{2}$ had no effect on host cell $\mathrm{pH}_{\mathrm{i}}$ [Fig. 2B], with mean values comparable to those observed in the control anemones $(7.19 \pm 0.01$ versus $7.17 \pm 0.01)$ throughout the experiment. In stark 

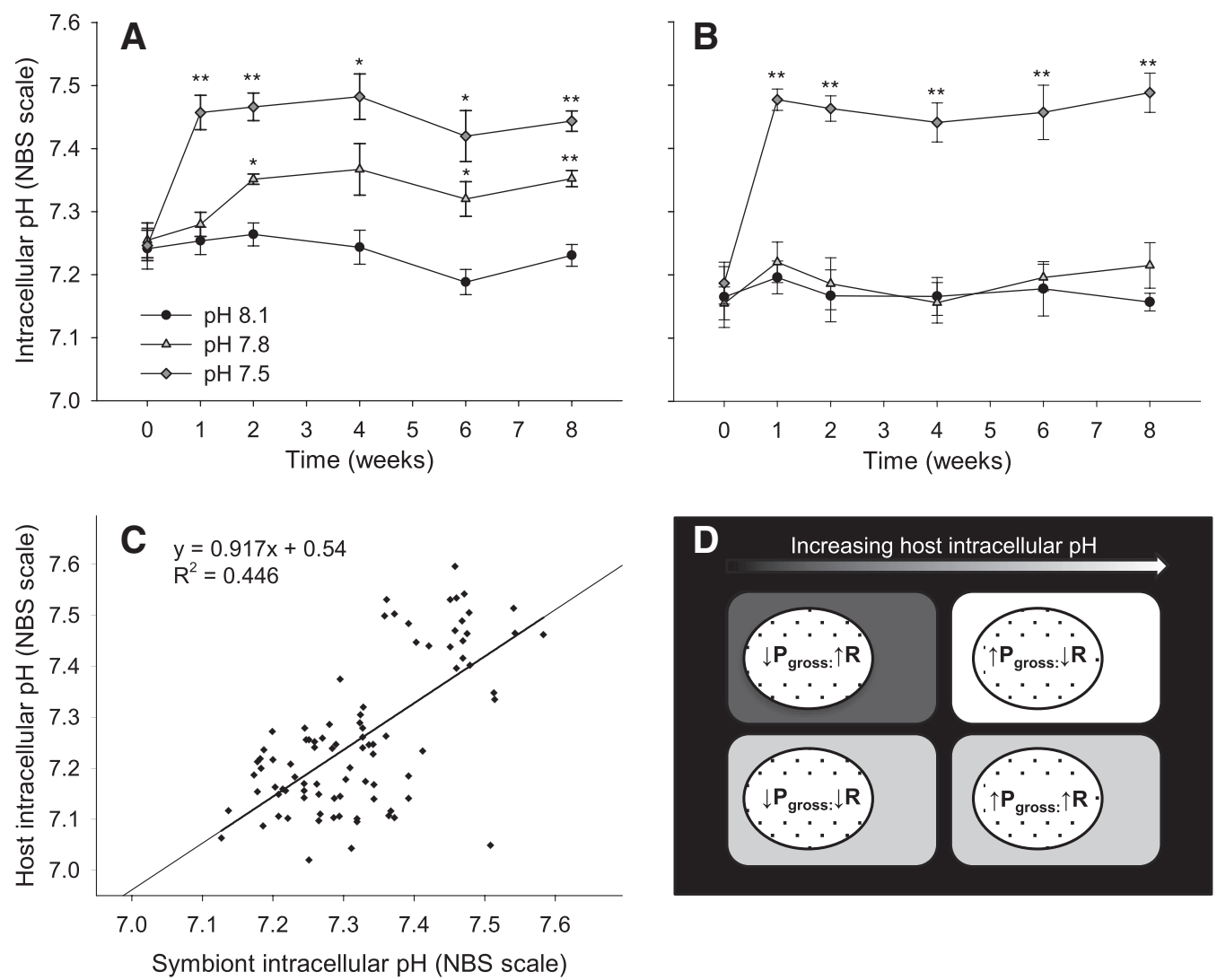

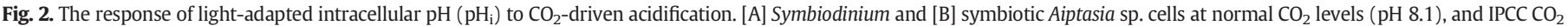

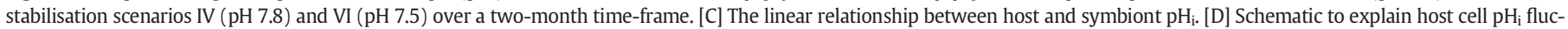

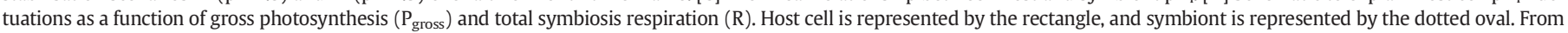

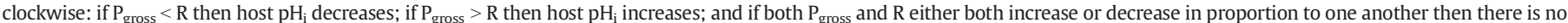

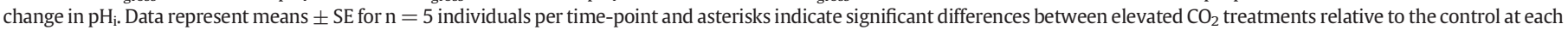
time point (RMANOVA, pairwise post hoc with Bonferroni correction, ${ }^{*} \mathrm{p}<0.05,{ }^{* *} \mathrm{p}<0.001$ ).

contrast, the $\mathrm{pH}_{\mathrm{i}}$ of host cells exposed to high $\mathrm{CO}_{2}$ increased by almost $0.3 \mathrm{pH}$ units within a week, rising from $7.19 \pm 0.03$ to $7.48 \pm$ 0.02 , and remained relatively constant thereafter. Linear regression showed a strong predictive relationship between symbiont and host $\mathrm{pH}_{\mathrm{i}}(\mathrm{p}<0.001)$, and suggests that a $0.1 \mathrm{pH}$ unit increase in symbiont $\mathrm{pH}_{\mathrm{i}}$ is associated with a $0.63 \mathrm{pH}$ unit increase in host $\mathrm{pH}_{\mathrm{i}}$ [Fig. 2C].

\section{Discussion}

Ocean acidification $(\mathrm{OA})$ - once referred to as "the other $\mathrm{CO}_{2}$ problem" (Doney et al., 2009) - is now recognised as a major selective force in determining ecosystem structure and function (Christen et al., 2013; Godbold and Calosi, 2013; Hall-Spencer et al., 2008). Marine organisms exhibit high variability in their physiological and cellular tolerance to $\mathrm{CO}_{2}$ addition (Fabry et al., 2008). While considered detrimental on the whole for calcifying organisms (Hoegh-Guldberg et al., 2007; Kroeker et al., 2010; Marubini et al., 2008), there is growing evidence that enhanced $\mathrm{CO}_{2}$ levels may benefit soft-bodied photosynthetic anthozoans (Inoue et al., 2013; Suggett et al., 2012; Towanda and Thuesen, 2012) through the alleviation of carbon limitation, that is thought typical of the symbiont population (Davy and Cook, 2001; Weis, 1993). The increased photosynthetic production that arises as a consequence of this likely has two major advantages for the host: (1) increased translocation of photosynthate for growth and reproduction (Brownlee, 2009); and (2) the prevention of cellular acidosis that arises from increased concentrations of $\mathrm{CO}_{2}$ and hence protons (Gibbin et al., 2014). Our study lends support to the potential success of noncalcifying symbiotic cnidarians in a $\mathrm{CO}_{2}$-enriched world, and confirms the positive relationship between $\mathrm{CO}_{2}$ supply, photosynthesis and the prevention of cellular acidosis in the model symbiotic cnidarian, Aiptasia sp.

Increases in symbiont density, photosynthetic health $\left(\mathrm{F}_{\mathrm{v}} / \mathrm{F}_{\mathrm{m}}\right)$, overall and cell-specific gross photosynthetic rate $\left(\mathrm{P}_{\text {gross }}\right)$, and respiration rate $(\mathrm{R})$ were commensurate with the $\mathrm{CO}_{2}$ concentration, signifying enhanced primary productivity and hence symbiont growth in response to the increased availability of dissolved inorganic carbon (DIC). Similar findings were reported for two temperate sea anemone species exposed to elevated $\mathrm{CO}_{2}$. A. viridis sampled from high $\mathrm{CO}_{2}$ sites (corresponding to $1428 \mu \mathrm{atm}$ ) along a naturally occurring $\mathrm{CO}_{2}$ vent, contained up to fourtimes more Symbiodinium cells than when at control sites (300 $\mu \mathrm{atm}$ ), resulting in enhanced rates of both $\mathrm{P}_{\text {gross }}$ and $\mathrm{R}$; though, as in the current study, $\mathrm{P}_{\text {gross }}$ increased more than $\mathrm{R}$ (Suggett et al., 2012). These patterns were mirrored in Anthopleura elegantissima after six weeks of incubation at $\mathrm{pH} 7.3$, although there was no accompanying change in symbiont density (Towanda and Thuesen, 2012). The increased primary productivity seen here in Aiptasia sp. is unsurprising given that seawater $(\mathrm{pH}$ 8.2) contains less than half of the DIC $\left(2.2 \mathrm{mM} \mathrm{HCO}_{3}^{-}, 30 \mu \mathrm{M} \mathrm{CO}_{2}\right)$ required to saturate photosynthesis in this species under normal circumstances (5 mM DIC; Weis, 1993). Nevertheless, Aiptasia sp. can still achieve its autotrophic potential (i.e. $\mathrm{P}_{\text {gross }}: \mathrm{R}>1$ ) with respect to carbon (Starzak et al., 2014), in part because of the activity of carbonconcentrating mechanisms (CCM's) that concentrate $\mathrm{CO}_{2}$ at the site of photosynthesis (Leggat et al., 1999; Weis et al., 1989). $\mathrm{CO}_{2}$ enrichment may therefore provide a further benefit through reducing the metabolic costs of maintaining CCM activity (Raven et al., 2012).

However, not all studies report increases in anemone productivity after $\mathrm{CO}_{2}$ addition. Six weeks of exposure to $\mathrm{pH} 7.6$ had no effect on symbiont density or physiological performance in the temperate 
anemone Anthopleura aureoradiata (Doherty, 2009). Similarly, two weeks of exposure to $\mathrm{pH} 7.4$ caused declines in symbiont density, but did not affect either $\mathrm{P}_{\text {gross }}$ or $\mathrm{R}$ in laboratory-maintained $A$. viridis (Jarrold et al., 2013); though our results suggest that a two-week time period may not always be long enough to observe significant changes in physiology. Differences in the organismal response to $\mathrm{CO}_{2}$ addition are potentially attributable to the type of Symbiodinium present. Indeed, there is growing evidence that the response to $\mathrm{CO}_{2}$-addition may be type-specific (Brading et al., 2011; Buxton et al., 2009). For example, when a range of cultured Symbiodinium types were exposed to a twofold increase in $\mathrm{CO}_{2}$ concentration (corresponding to $\mathrm{pH} 7.79$ - the intermediate treatment in our study), there was an increase of $~ 60 \%$ in the growth rate and photosynthetic capacity of types A13 and A2, respectively, while types $\mathrm{A} 1$ and $\mathrm{B} 1$ did not respond at all (Brading et al., 2011). Of note, this lack of response by Symbiodinium B1 in culture is different to our observations here, when this same type was in hospite. Future studies should consider how $\mathrm{CO}_{2}$ concentration may influence different host-symbiont combinations.

One of the key objectives of this study was to establish the response of intracellular $\mathrm{pH}\left(\mathrm{pH}_{\mathrm{i}}\right)$ to $\mathrm{CO}_{2}$-addition, simultaneously in the host and symbiont. To achieve this, we measured the light-adapted $\mathrm{pH}_{\mathrm{i}}$ of both partners. The values measured in the control anemones were similar to those measured previously in a range of cultured Symbiodinium types ( $\mathrm{pH}$ 7.21-7.39), and both the host and symbiont cells of Aiptasia sp. (pH $7.02 \pm 0.06$ and $7.25 \pm 0.01$, respectively; Gibbin and Davy, 2013). Light-adapted host $\mathrm{pH}_{\mathrm{i}}$ in this anemone species was, however, slightly lower than that measured in the cnidarians A. viridis ( $\mathrm{pH} 7.41$ \pm 0.22 ) and Stylophora pistillata (7.29 \pm 0.15$)$ (Venn et al., 2009). Under normal conditions, photosynthesis in the symbiont results in an alkalinisation of the host cell (Venn et al., 2009), the magnitude of which is proportional to the irradiance (Laurent et al., 2013a). As such, we predicted that $\mathrm{CO}_{2}$ addition would increase the photosynthetic rate and hence symbiont $\mathrm{pH}_{\mathrm{i}}$, and trigger a similar increase in the host cell $\mathrm{pH}_{\mathrm{i}}$. Our results were consistent with this prediction, with symbiont $\mathrm{pH}_{\mathrm{i}}$ increasing in proportion to the $\mathrm{CO}_{2}$ concentration. The response in the host cell was not quite so marked, however, with there being no change in the $\mathrm{pH}_{\mathrm{i}}$ of the host cell under the intermediate $\mathrm{CO}_{2}$ treatment ( $\mathrm{pH} 7.8)$, but a substantial increase in alkalinity ( $\sim 0.3 \mathrm{pH}$ units) under the high $\mathrm{CO}_{2}$ treatment ( $\mathrm{pH} 7.5$ ). While the high buffering capacity of the cnidarian cell likely plays a role (Laurent et al., 2013b), our results suggest a strong link between the relative rates of photosynthesis and respiration in dictating the $\mathrm{pH}_{\mathrm{i}}$ of the host in response to external, $\mathrm{CO}_{2}$-induced $\mathrm{pH}$ change. In particular, the increase in alkalinity reported for the high $\mathrm{CO}_{2}$ treatment is potentially attributable to the elevated $\mathrm{P}_{\text {gross }}: \mathrm{R}$ ratio seen under these conditions (in contrast to the intermediate $\mathrm{CO}_{2}$ treatment). This could indicate a partial decoupling of the rates of photosynthesis and respiration, which typically facilitate one another through the evolution of $\mathrm{O}_{2}$ and $\mathrm{CO}_{2}$ respectively (Harland and Davies, 1995), and a concomitant decrease in the intracellular $\mathrm{CO}_{2}$ concentration. The mechanism by which the $\mathrm{pH}_{\mathrm{i}}$ of the host cell may be pushed upwards by $\mathrm{CO}_{2}$ enrichment is summarized in Fig. 2D.

In summary, these findings demonstrate that the photo-physiological response to predicted ocean acidification scenarios has the potential to alter the $\mathrm{pH}_{\mathrm{i}}$ of both host and symbiont simultaneously, and therefore affect the functioning of the cnidarian-dinoflagellate symbiosis. Of particular importance, our data suggest improved photosynthetic performance and an absence of cellular acidosis in the light in response to $\mathrm{CO}_{2}$-driven acidification. We did not measure $\mathrm{pH}_{\mathrm{i}}$ in the dark and it would be interesting to know what impact these different conditions have on night-time $\mathrm{pH}_{\mathrm{i}}$, though we have previously shown that isolated host cells of the reef coral P. damicornis are more susceptible to acidification when the photosynthetic activity of their symbionts is inhibited by DCMU (Gibbin et al., 2014). The enhanced performance in the light, however, raises important questions about the future of non-calcareous symbiotic anthozoans in a high- $\mathrm{CO}_{2}$ ocean. In particular, several studies have reported that ocean acidification initiates a shift in ecosystem structure from a calcareous to a non-calcareous, algal-dominated community (Hall-Spencer et al., 2008; Inoue et al., 2013; Suggett et al., 2012) that has the potential to act as a significant carbon sink (Anthony et al., 2011; Russell et al., 2013). Similarly, our results, along with those of Suggett et al. (2012), suggest that symbiotic sea anemones could not only survive ocean acidification, but also thrive under future conditions. However, it is important to bear in mind that ocean acidification is only one aspect of climate change, with the effects of global warming likely to influence the physiological response to elevated $\mathrm{CO}_{2}$ levels. In particular, thermal stress and the resulting photosynthetic dysfunction may increase the likelihood for cellular acidosis in $\mathrm{CO}_{2}$-enriched waters. The model system we describe here provides a basis for future study of this topic in the intact cnidarian-dinoflagellate symbiosis.

\section{Acknowledgments}

EMG was supported by a Commonwealth PhD Scholarship. We thank Drs. Cliff Law and Kim Currie, of the National Institute of Water and Atmospheric Research (NIWA, New Zealand) for providing the total alkalinity readings, Oliver Bone for laboratory assistance and Dr. Tom Hawkins for providing constructive comments on the manuscript.[SS]

\section{Appendix A. Supplementary data}

Supplementary data to this article can be found online at http://dx. doi.org/10.1016/j.jembe.2014.03.015.

\section{References}

Anthony, K.R.N., Kline, D.I., Diaz-Pulido, G., Dove, S., Hoegh-Guldberg, O., 2008. Ocean acidification causes bleaching and productivity loss in coral reef builders. Proc. Natl. Acad. Sci. U. S. A. 105, 17442-17446.

Anthony, K.R.N., Kleypas, J.A., Gattuso, J.P., 2011. Coral reefs modify their seawater carbon chemistry - implications for impacts of ocean acidification. Global Change Biol. 17, 3655-3666.

Bellwood, D.R., Hughes, T.P., 2001. Regional-scale assembly rules and biodiversity of coral reefs. Science 292, 1532-1535.

Bradford, M.M., 1976. A rapid and sensitive method for the quantitation of microgram quantities of protein utilizing the principle of protein-dye binding. Anal. Biochem. $72,248-254$.

Brading, P., Warner, M.E., Davey, P., Smith, D.J., Achterberg, E.P., Suggett, D.J., 2011. Differential effects of ocean acidification on growth and photosynthesis among phylotypes of Symbiodinium (Dinophyceae). Limnol. Oceanogr. 56, 927-938.

Brownlee, C., 2009. pH regulation in symbiotic anemones and corals: a delicate balancing act. Proc. Natl. Acad. Sci. U. S. A. 106, 16541-16542.

Busa, W.B., Nuccitelli, R., 1984. Metabolic regulation via intracellular pH. Am. J. Physiol. Reg. 246, 409-438.

Buxton, L., Badger, M., Ralph, P., 2009. Effects of moderate heat stress and dissolved inorganic carbon concentration on photosynthesis and respiration of Symbiodinium sp (Dinophyceae) in culture and in symbiosis. J. Phycol. 45, 357-365.

Christen, N., Calosi, P., McNeill, C.L., Widdicombe, S., 2013. Structural and functional vulnerability to elevated $p \mathrm{CO}_{2}$ in marine benthic communities. Mar. Biol. 160, 2113-2128.

Crook, E.D., Potts, D., Rebolledo-Vieyra, M., Hernandez, L., Paytan, A., 2012. Calcifying coral abundance near low-pH springs: implications for future ocean acidification. Coral Reefs 31, 239-245.

Davy, S.K., Cook, C.B., 2001. The relationship between nutritional status and carbon flux in the zooxanthellate sea anemone Aiptasia pallida. Mar. Biol. 139, 999-1005.

Doherty, M.J.W., 2009. Ocean acidification: Comparative impacts on the photophysiology of a temperate symbiotic sea anemone and a tropical coral. Unpublished MSc Thesis, Victoria University, Wellington, New Zealand.

Doney, S.C., Fabry, V.J., Feely, R.A., Kleypas, J.A., 2009. Ocean acidification: the other $\mathrm{CO}_{2}$ problem. Annu. Rev. Mar. Sci. 1, 169-192.

Dudley, B.D., Shima, J.S., 2010. Algal and invertebrate bioindicators detect sewage effluent along the coast of Titahi Bay, Wellington, New Zealand. N. Z. J. Mar. Freshw. Res. 44 39-51.

Fabricius, K.E., Langdon, C., Uthicke, S., Humphrey, C., Noonan, S., De'ath, G., Okazaki, R. Muehllehner, N., Glas, M.S., Lough, J.M., 2011. Losers and winners in coral reefs acclimatized to elevated carbon dioxide concentrations. Nat. Clim. Change 1, 165-169.

Fabry, V.J., Seibel, B.A., Feely, R.A., Orr, J.C., 2008. Impacts of ocean acidification on marine fauna and ecosystem processes. ICES J. Mar. Sci. 65, 414-432.

Gates, R.D., Muscatine, L., 1992. Three methods for isolating viable anthozoan endoderm cells with their intracellular symbiotic dinoflagellates. Coral Reefs 11, 143-145.

Gibbin, E.M., Putnam, H.M., Davy, S.K., Gates, R.D., 2014. J. Exp. Biol. http://dx.doi.org/10. $1242 /$ jeb.099549 (in press). 
Gibbin, E.M., Davy, S.K., 2013. Intracellular pH of symbiotic dinoflagellates. Coral Reefs 32 , 859-863.

Godbold, J.A., Calosi, P., 2013. Ocean acidification and climate change: advances in ecology and evolution. Philos. Trans. R. Soc. B 368, 20120448.

Hall-Spencer, J.M., Rodolfo-Metalpa, R., Martin, S., Ransome, E., Fine, M., Turner, S.M. Rowley, S.J., Tedesco, D., Buia, M.-C., 2008. Volcanic carbon dioxide vents show ecosystem effects of ocean acidification. Nature 454, 96-99.

Hand, S.C., 1991. Metabolic dormancy in aquatic invertebrates. In: Giles, R. (Ed.), Advances in Comparative and Environmental Physiology. Springer-Verlag, Heidelberg, pp. $1-50$.

Harland, A.D., Davies, P.S., 1995. Symbiont photosynthesis increases both respiration and photosynthesis in the symbiotic sea anemone Anemonia viridis. Mar. Biol. 123, 715-722.

Hoegh-Guldberg, O., Mumby, P.J., Hooten, A.J., Steneck, R.S., Greenfield, P., Gomez, E., Harvell, C.D., Sale, P.F., Edwards, A.J., Caldeira, K., Knowlton, N., Eakin, C.M., IglesiasPrieto, R., Muthiga, N., Bradbury, R.H., Dubi, A., Hatziolos, M.E., 2007. Coral reefs under rapid climate change and ocean acidification. Science 318, 1737-1742.

Inoue, S., Kayanne, H., Yamamoto, S., Kurihara, H., 2013. Spatial community shift from hard to soft corals in acidified water. Nat. Clim. Change 3, 683-687.

Intergovernmental Panel on Climate Change, 2007. Climate Change 2007: Synthesis Report. pp. 26-73.

Jarrold, M.D., Calosi, P., Verberk, W.C., Rastrick, S.P., Atfield, A., Spicer, J.I., 2013. Physiological plasticity preserves the metabolic relationship of the intertidal non-calcifying anthozoan-Symbiodinium symbiosis under ocean acidification. J. Exp. Mar. Biol. Ecol. 449, 200-206.

Kroeker, K.J., Kordas, R.L., Crim, R.N., Singh, G.G., 2010. Meta-analysis reveals negative yet variable effects of ocean acidification on marine organisms. Ecol. Lett. 13, 1419-1434.

Laurent, J., Tambutté, S., Tambutté, É., Allemand, D., Venn, A., 2013a. The influence of photosynthesis on host intracellular pH in scleractinian corals. J. Exp. Biol. 216 1398-1404.

Laurent, J., Venn, A., Tambutté, É., Ganot, P., Allemand, D., Tambutté, S., 2013b. Regulation of intracellular pH in cnidarians: response to acidosis in Anemonia viridis. FEBS J. 281, 683-695.

Leggat, W., Badger, M.R., Yellowlees, D., 1999. Evidence for an inorganic carbonconcentrating mechanism in the symbiotic dinoflagellate Symbiodinium sp. Plant Physiol. 121, 1247-1255.

Lesser, M.P., Shick, J.M., 1989. Effects of irradiance and ultraviolet radiation on photoadaptation in the zooxanthellae of Aiptasia pallida: primary production, photoinhibition, and enzymic defenses against oxygen toxicity. Mar. Biol. 102, 243-255.

Lewis, E., Wallace, D., Allison, L.J., 1998. Program Developed for CO2 System Calculations. ORNL/CDIAC-105. (Carbon Dioxide Information Analysis Center, Oak Ridge National Laboratory, U.S. Department of Energy, Oak Ridge, TN).

Marubini, F., Ferrier-Pagès, C., Furla, P., Allemand, D., 2008. Coral calcification responds to seawater acidification: a working hypothesis towards a physiological mechanism. Coral Reefs 27, 491-499.

McCulloch, M., Falter, J., Trotter, J., Montagna, P., 2012. Coral resilience to ocean acidification and global warming through $\mathrm{pH}$ up-regulation. Nat. Clim. Change 2, 623-633.

Muller-Parker, G., 1984. Photosynthesis-irradiance responses and photosynthetic periodicity in the sea anemone Aiptasia pulchella and its zooxanthellae. Mar. Biol. 82, 225-232.
Muscatine, L., 1990. The role of symbiotic algae in carbon and energy flux in reef corals. In: Dubinsky, Z. (Ed.), Coral Reefs. Elsevier, Amsterdam, pp. 75-87.

Pandolfi, J.M., Connolly, S.R., Marshall, D.J., Cohen, A.L., 2011. Projecting coral reef futures under global warming and ocean acidification. Science 333, 418-422.

Pörtner, H.O., Langenbuch, M., Reipschläger, A., 2004. Biological impact of elevated ocean $\mathrm{CO}_{2}$ concentrations: lessons from animal physiology and earth history. J. Oceanogr. $60,705-718$

Raven, J.A., Giordano, M., Beardall, J., Maberly, S.C., 2012. Algal evolution in relation to atmospheric $\mathrm{CO}_{2}$ : carboxylases, carbon-concentrating mechanisms and carbon oxidation cycles. Philos. Trans. R. Soc. B 367, 493-507.

Reipschläger, A., Pörtner, H., 1996. Metabolic depression during environmental stress: the role of extracellular versus intracellular pH in Sipunculus nudus. J. Exp. Biol. 199, $1801-1807$

Ries, J.B., Cohen, A.L., McCorkle, D.C., 2009. Marine calcifiers exhibit mixed responses to $\mathrm{CO}_{2}$-induced ocean acidification. Geology 37, 1131-1134.

Russell, B.D., Connell, S.D., Uthicke, S., Muehllehner, N., Fabricius, K.E., Hall-Spencer, J.M., 2013. Future seagrass beds: can increased productivity lead to increased carbon storage? Mar. Pollut. Bull. 73, 463-469.

Sabine, C.L., Feely, R.A., Gruber, N., Key, R.M., Lee, K., Bullister, J.L., Wanninkhof, R., Wong, C.S., Wallace, D.W.R., Tilbrook, B., Millero, F.J., Peng, T.-H., Kozyr, A., Ono, T., Rios, A.F., 2004. The oceanic sink for anthropogenic $\mathrm{CO}_{2}$. Science 305, 367-371.

Schneider, K., Erez, J., 2006. The effect of carbonate chemistry on calcification and photosynthesis in the hermatypic coral Acropora eurystoma. Limnol. Oceanogr. 51, 1284-1293.

Starzak, D.E., Quinnell, R.G., Nitschke, M.R., Davy, S.K., 2014. The influence of symbiont type on photosynthetic carbon flux in a model cnidarian-dinoflagellate symbiosis. Mar. Biol. http://dx.doi.org/10.1007/s00227-013-2372-8.

Suggett, D.J., Hall-Spencer, J.M., Rodolfo-Metalpa, R., Boatman, T.G., Payton, R., Tye Pettay, D., Johnson, V.R., Warner, M.E., Lawson, T., 2012. Sea anemones may thrive in a high $\mathrm{CO}_{2}$ world. Global Change Biol. 18, 3015-3025.

Towanda, T., Thuesen, E.V., 2012. Prolonged exposure to elevated $\mathrm{CO}_{2}$ promotes growth of the algal symbiont Symbiodinium muscatinei in the intertidal sea anemone Anthopleura elegantissima. Biol. Open 1, 615-621.

Venn, A.A., Tambutté, E., Lotto, S., Zoccola, D., Allemand, D., Tambutté, S., 2009. Imaging intracellular pH in a reef coral and symbiotic anemone. Proc. Natl. Acad. Sci. U. S. A. 106, 16574-16579.

Vuuren, D., Edmonds, J., Kainuma, M., Riahi, K., Thomson, A., Hibbard, K., Hurtt, G., Kram, T., Krey, V., Lamarque, J.-F., Masui, T., Meinshausen, M., Nakicenovic, N., Smith, S., Rose, S., 2011. The representative concentration pathways: an overview. Clim. Change 109, 5-31.

Weis, V.M., 1993. Effect of dissolved inorganic carbon concentration on the photosynthesis of the symbiotic sea anemone Aiptasia pulchella Carlgren: role of carbonic anhydrase. J. Exp. Mar. Biol. Ecol. 174, 209-225.

Weis, V.M., Smith, G.J., Muscatine, L., 1989. A "CO 2 supply" mechanism in zooxanthellate cnidarians: role of carbonic anhydrase. Mar. Biol. 100, 195-202.

Weis, V.M., Davy, S.K., Hoegh-Guldberg, O., Rodriguez-Lanetty, M., Pringle, J.R., 2008. Cell biology in model systems as the key to understanding corals. TREE 23, 369-376. 